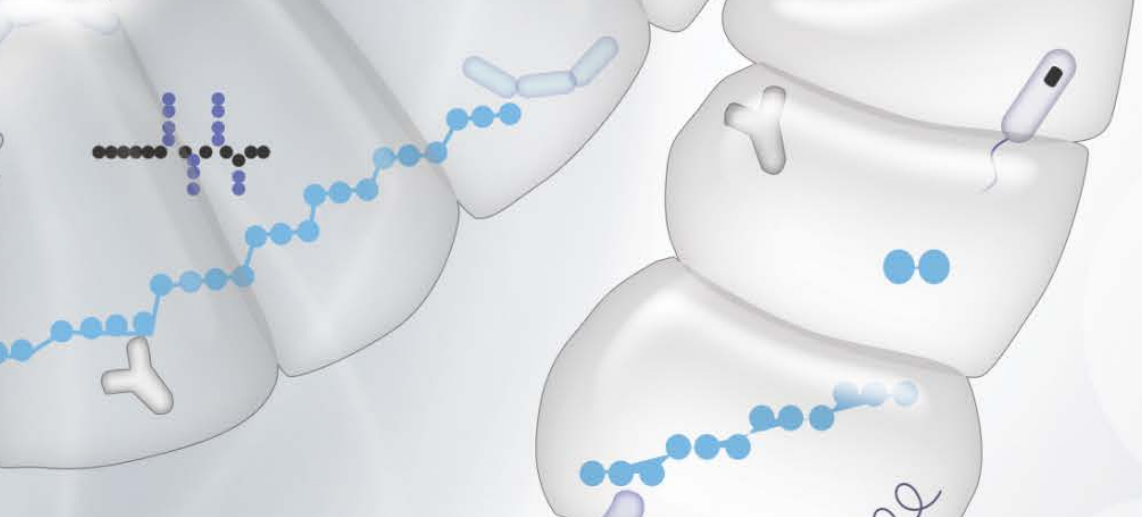




\section{In vitro fermentation and immunomodulating characteristics of dietary fibres}

Christiane Rösch 


\section{Thesis committee}

\section{Promotors}

Prof. Dr H. Gruppen

Professor of Food Chemistry

Wageningen University

Prof. Dr H.A. Schols

Personal chair at the Laboratory of Food Chemistry

Wageningen University

\section{Other members}

Prof. Dr E.J.M. Feskens, Wageningen University

Prof. Dr P. de Vos, University of Groningen

Dr S.H. Knutsen, Institute of Food, Fisheries and Aquaculture Research, Ås, Norway

Prof. Dr M. Kleerebezem, Wageningen University

This research was conducted under the auspices of the Graduate School VLAG (Advanced studies in Food Technology, Agrobiotechnology, Nutrition and Health Sciences). 


\title{
In vitro fermentation and immunomodulating characteristics of dietary fibres
}

\section{Christiane Rösch}

\author{
Thesis \\ submitted in fulfilment of the requirements for the degree of doctor \\ at Wageningen University \\ by the authority of the Rector Magnificus \\ Prof. Dr A.P.J. Mol, \\ in the presence of the \\ Thesis Committee appointed by the Academic Board \\ to be defended in public \\ on Thursday 16 June 2016 \\ at 11 a.m. in the Aula.
}




\section{Christiane Rösch}

In vitro fermentation and immunomodulating characteristics of dietary fibres 140 pages.

PhD thesis, Wageningen University, Wageningen, NL (2016)

With references, with summary in English

ISBN: 978-94-6257-795-4 


\begin{abstract}
Dietary fibres are a diverse group of substances, indigestible by human digestive enzymes, but (partially) fermentable in the human large intestine by the resident microbiota. Many health beneficial effects of fibres such as lowering blood cholesterol levels or increasing stool bulk have been reported. For some fibres, immunomodulating properties have been shown. Other studies investigate the degradation fate of fibres by the bacteria. In this $\mathrm{PhD}$ thesis BMDCs from TLR2/4 knock out mice were validated to be unresponsive to naturally present contaminants like LPS and proved to be a good tool to analyse the immune response of dietary fibres. A variety of 44 fibres, was tested on these immune cells and all fibres were found to modulated the immune system differently. Also, different immunomodulating properties of an oat and barley $\beta$-glucan having rather similar chemical structures, were found. The insoluble fraction of the $\beta$ glucans induced highest amounts of cytokines. As a consequence, sample preparation such as drying, dispersing and heating were shown to affect the immunomodulatory properties. The in vitro fermentation characteristics of barley $\beta$-glucan and sugar beet pectin and the immunomodulatory properties of their degradation products on BMDCs were compared and shown to be substrate and degradation product specific. This study showed, that glycosidic degradation products of both fibres induced higher amounts of cytokines than their intact polysaccharide. An in vitro batch fermentation of soluble, indigestible maltodextrins by human faecal inocula was monitored and the activity of carbohydrate degrading enzymes, produced by the microbiota, was analysed. Results revealed that the maltodextrin was only slowly and incompletely fermented, despite the high potential of microbial enzymes present to degrade typical starch linkages.

Overall, this thesis showed that dietary fibres interact and influence the immune system dependent on their individual chemical fine structure. Additionally, an evaluation of the health impact of dietary fibres can only be complete when also glycosidic fermentation products are considered.
\end{abstract}





\section{Table of contents}

Chapter $1 \quad$ General Introduction

Chapter 2 Structure related immunomodulation by sugar beet arabinans is induced via Syk tyrosine kinase-dependent pathway

Chapter 3 Immunomodulatory properties of oat and barley $\beta$ glucans on bone marrow derived dendritic cells

Chapter 4 Effects of in vitro fermentation of barley $\beta$-glucan and sugar beet pectin using human faecal inocula on cytokine expression by dendritic cells

Chapter 5 Characterization and in vitro fermentation of resistant maltodextrins using human faecal inoculum and analysis of bacterial enzymes present

Chapter 6 General Discussion

Summary 

Chapter 1

General Introduction 


\section{THE PROJECT}

Dietary fibres are a diverse group of indigestible substances, which are (partially) fermentable in the large intestine by the resident microbiota. They are known to beneficially influence human health, for example by lowering blood cholesterol levels or increasing stool bulk, but the mechanisms are not yet fully elucidated. Additionally, the fermentation degradation products produced by the microbiota are not much investigated. Dietary fibres are known to interact with gastrointestinal immune cells, for example dendritic cells, thereby inducing anti- or pro-inflammatory cytokine responses. However, research on the fermentation of dietary fibres and their immunomodulatory properties is still in its infancy and the relationship between their structure and biological activities on host cells are either unknown or contradictory.

The multidisciplinary project "Molecular interactions of mucosal tissue, bacteria and fibres" within the "Gastrointestinal Health" theme of the Top Institute Food and Nutrition (TIFN) aimed to unravel the complex host-fibre-microbe relationships in the human large intestine.

As part of this project, this thesis research focused on the characterisation of selected dietary fibres and their in vitro fermentation characteristics by human faecal microbiota. In addition, the immunomodulatory properties of a diverse range of dietary fibres were investigated in relation to their physico-chemical characteristics.

\section{DIETARY FIBRES}

The definition of dietary fibres has been discussed over many years from a biological, chemical, nutritional, physiological or analytical perspective [1]. The current, version adopted in the European Union describes dietary fibres to mean:

"carbohydrate polymers with three or more monomeric units, which are neither digested nor absorbed in the human small intestine and belong to the following categories:

- Edible carbohydrate polymer [also to the polysaccharide closely associated lignin and other non-carbohydrate compounds e.g. phenolic compounds when fibre is derived from plant origin] naturally occurring in the food as consumed;

- Edible carbohydrate polymers, which have been obtained from food raw material by physical, enzymatic or chemical means and which have a beneficial physiological effect demonstrated by generally accepted scientific evidence;

- Edible synthetic carbohydrate polymers which have a beneficial physiological effects demonstrated by generally accepted scientific evidence." [2].

\section{Classification of dietary fibres}

Dietary fibres are a diverse group of substances. Hence, it would be useful to define them into subgroups within the given definition above. An approach of this, based on several fibre characteristics, is given in Figure 1. However, this is difficult due to their diversity in structure and properties. 


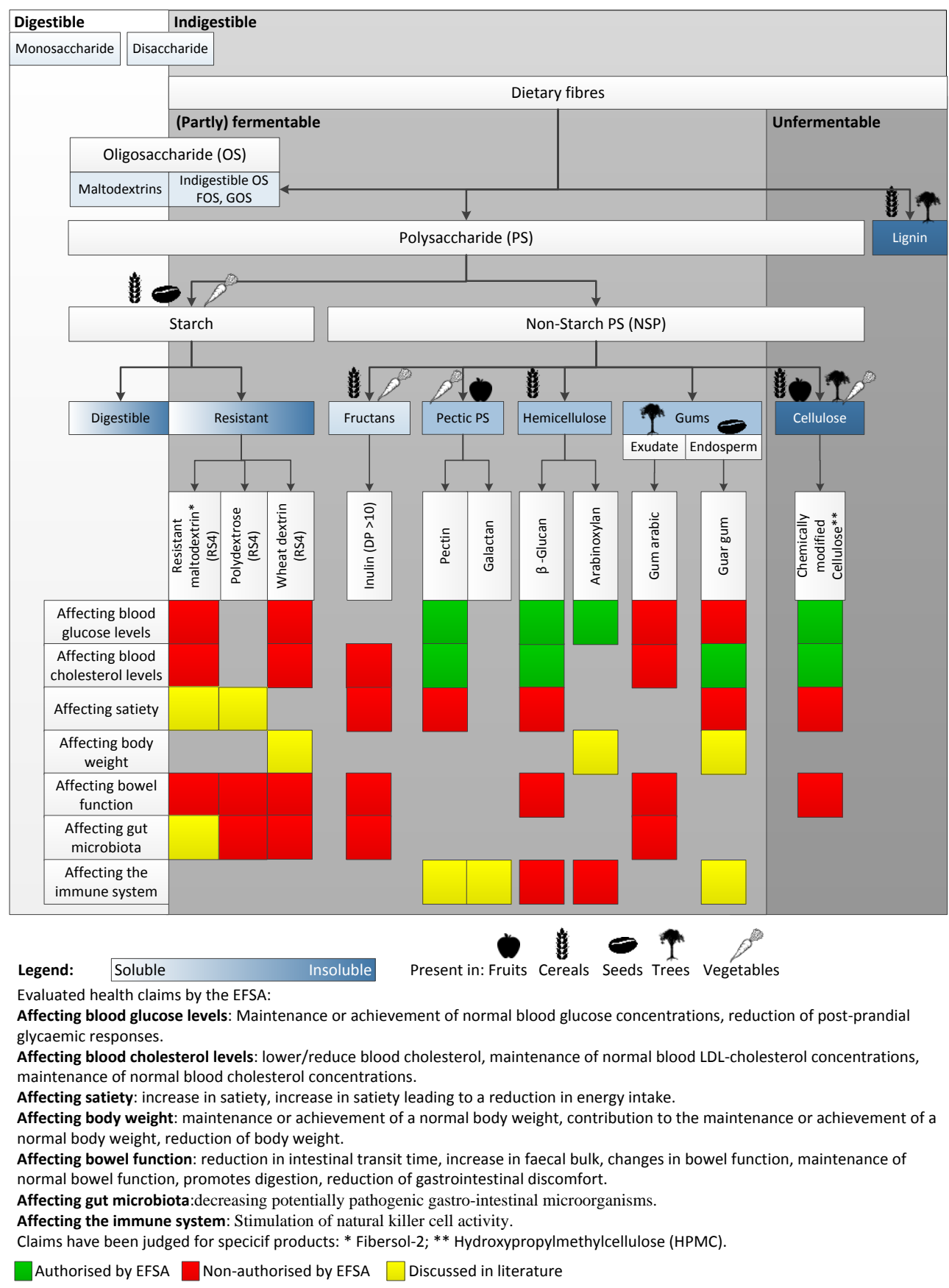

Figure 1: Overview of carbohydrates (and lignin) and categorisation based on their chemical, physical and physiological characteristics. The classification is adapted from [3-11]. If an authorised or nonauthorised claim is indicated in the graph, at least one of the below categorized claims is applicable for the fibre. 
As given by the definition above, fibres are indigestible carbohydrates, while most of them are (partly) fermentable by resident bacteria of the human gut. Cellulose and lignin are fibres unfermentable by human gut microbes. Fibres can be classified based on their degree of polymerisation (DP). This divides fibres into oligosaccharides (OS) (DP 3-9) and polysaccharides (PS) (DP $\geq 10$ ). PS can be subdivided into starch and non-starch polysaccharides (NSP). Opposite to digestible starch, resistant starch (RS) is considered dietary fibre, because of its indigestibility. RS are classified into four different types, based on the reason for their resistance and will be explained below [3]. A further sub classification of the NSP based on the monosaccharide constitution, leads to sub classes as: fructans, pectic PS, hemicelluloses, gums and cellulose. These sub classes vary in physical properties, such as solubility, viscosity and water holding capacity, and are present in a variety of fruits, cereals, seeds, vegetables and exudate from trees, as indicated in Figure 1. For each of these sub classes, specific examples for fibre structures, for example pectins, to which all substances with a backbone consisting of $\alpha(1,4)$ linked galacturonic acid units belong, are given and further discussed below [3]. Furthermore, the health effects of these fibres, as evaluated by the European Food and Safety Authority (EFSA) or discussed in literature are given and also discussed below. Overall, this is an incomplete selection of fibres, which is based on the relevance for this thesis and the evaluation of health claims by the EFSA.

\section{Dietary fibres examples}

As indicated in Figure 1, dietary fibres are i.a. naturally present in plants, where they form a complex network and have several functions, for example giving the plant rigidity and shape. Depending on the plant species and part of the plant, the composition of dietary fibres varies [12]. This section will give an impression of the diversity and complexity of dietary fibres structures. Two fibres, pectin and $\beta$-glucan are discussed in more detail, as they are most relevant for this thesis.

\section{Glucans}

Glucans are polysaccharides consisting only of glycosidic linked glucose moieties. The linkages can be either in $\alpha$ or $\beta$ configuration and at different O-positions of the glucose. Cellulose, $\beta$-glucans and resistant starch are glucan fibres, while digestible starch is not.

\section{Cellulose}

Cellulose is the most common fibre and is present in the primary cell wall of all plants. It is composed of $\beta(1,4)$ glycosidic linked glucose units, which create a long unbranched homopolymeric chain. These chains align with each other via hydrogen bonds, forming insoluble, crystalline microfibrils $[13,14]$.

\section{B-Glucan}

Cereal mixed $\beta$-glucans consist of $\beta(1,3)(1,4)$ glycosidic linked glucose units and vary in their linear cello-triosyl and cello-tetraosyl blocks. Mixed $\beta$-glucans consist mostly of cello-triosyl and cello-tetraosyl blocks, which are linked to each other through an $\beta(1,3)$ linkage (Figure 2 ) and is depending on the cereal type. In contrast to cellulose, cereal $\beta$-glucans are non-linear, which leads to a higher solubility of the molecules [12, 14]. They belong to hemicelluloses and are present in plants only in cell walls of 
Poaceae, for example, wheat (Triticum spp.), barley (Hordeum spp.) and oat (Avena spp.).

Furthermore, $\beta$-glucans of $\beta(1,3)$ linked glucose units with substitution in the O-6 position are present in fungal and yeast cell walls [12]. The individual structural characteristics of the $\beta$-glucans assign them differences in health and technological functionality, as discussed below.

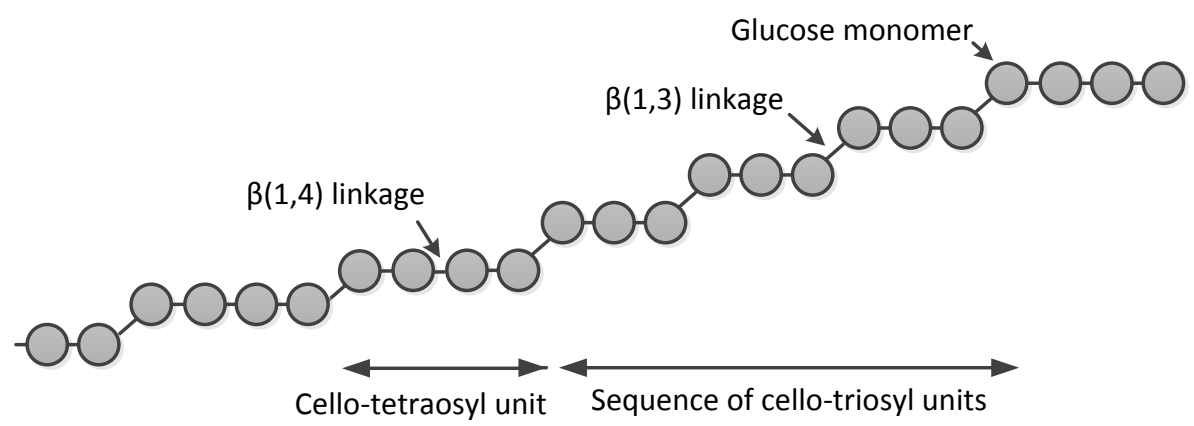

Figure 2: Schematic diagram of a cereal $\beta(1,3)(1,4)$ glucan molecule. Adapted from [15].

\section{Resistant starch}

Resistant starch is an $\alpha$-glucan made from starch, which is present in the endosperm of i.a. grains and consists mainly of $\alpha(1,4)$ or $\alpha(1,6)$ linked glucose units. RS can be classified into one of four types, based on the reason for their resistance. RS type 1 is physically inaccessible starch and for example present in whole grains. Type 2 are resistant starch granules, type 3 is retrograded starch and type 4 is modified starch [3, 16]. RS type 4 can consist of glycosidic linkages not present in the original starch, for example in resistant maltodextrins (RMD) (e.g. Fibersol-2, polydextrose and wheat dextrin), which are made from starch by chemical treatments. In addition, RMD also includes starches having non glycosidic substituents to modify starch functions [17].

\section{Pectins}

Pectins are heterogeneous polysaccharides, which are present in plants in the primary cell wall and are the main compound of the middle lamella. They are industrially extracted from citrus peel and apple pomace. The pectin structure can be divided into the main structural elements: homogalacturonan $(\mathrm{HG})$ and rhamnogalacturonan I (RG I) and two minor elements rhamnogalacturonan II (RG II) and xylogalacturonan (XGA) (Figure 3). The HG backbone is composed of $\alpha(1,4)$ glycosidic linked galacturonic acids, which can be decorated to different extents with methyl esters via the carboxyl group of the galacturonic acid or with acetyl groups at position O-2 and/or O-3 of the galacturonic acid, depending on the source of the pectin. RG I consists of a backbone of alternating galacturonic acid and rhamnose, to which arabinan and galactan side chains are attached. The RG II consists of a short homogalacturonan segment (DP 8), to which different neutral sugars are linked in a defined way [18]. Figure 3 illustrates a possible model of pectin. 


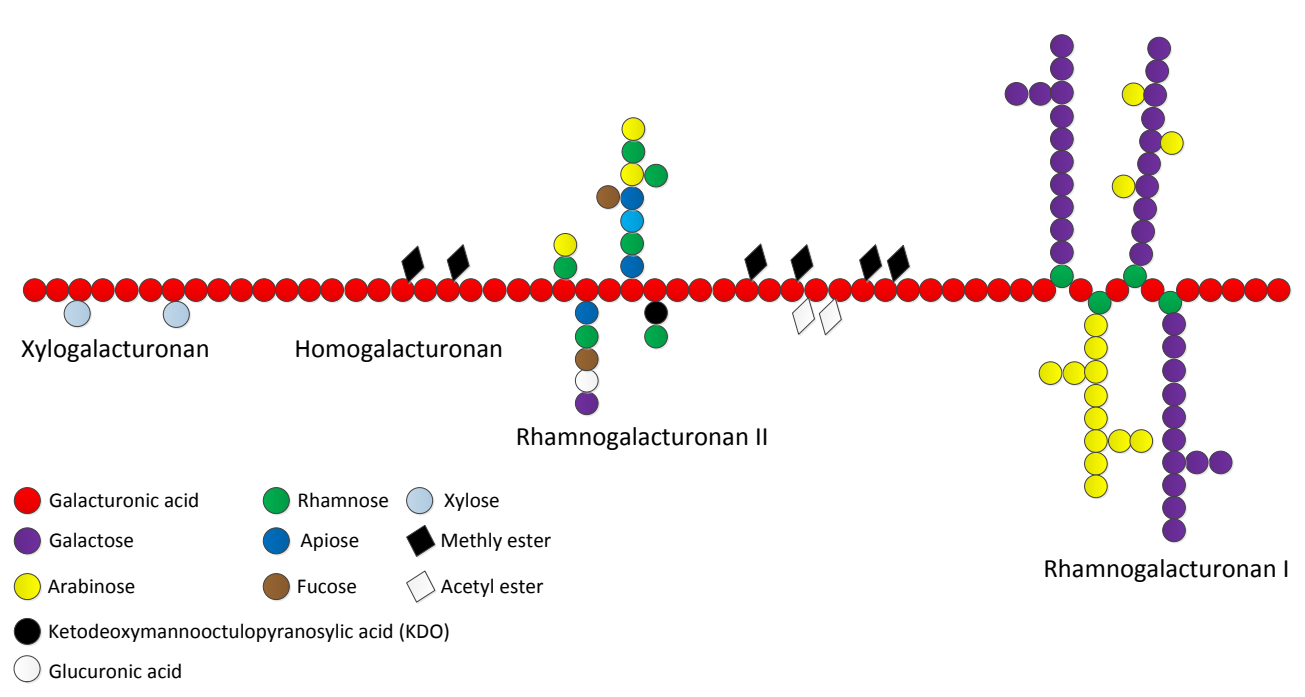

Figure 3: Schematic representation of pectin. Adapted from [19].

\section{Gums}

Gums are either plant exudates (e.g. gum arabic) or extracted from the leguminous seeds (e.g. guar gum, locust bean gum). Gum Arabic consists of a $\beta(1,3)$ linked galactose backbone, with side chains of arabinose, rhamnose and glucuronic acid. Guar gum and locust bean gum, are galactomannans consisting of $\beta(1,4)$ glycosidically linked mannose units, which are substituted with galactose residues in different ratios [18].

\section{Fructans}

Fructans are $\beta(2,1)$ linked fructose units with a terminal glucose $(\mathrm{GFn})$ or fructose (FFn) at the non-reducing end. They are present in many plant species, but are for industrial purpose mainly extracted from chicory (Cichorium intybus). Native chicory inulin has an average DP of 10-60 and can be enzymatically processed to oligofructose of DP 2-10 [20, 21].

\section{Arabinoxylan}

Arabinoxylans belong to hemicelluloses and consists of linear $\beta(1,4)$ linked xylan backbone to which non, mono- or di $\alpha$-L-arabinofuranose units are attached. Depending on the origin and variety, the arabinoxylans differ in the substitution pattern, which can be in O-position 2 or 3 of the xylose moiety. Arabinoxylans are present in cereal cell walls of the bran and endosperm [22]. The xylan backbone may also be substituted with $\alpha-D$-glucopyranosyl uronic acids, its methyl derivative and/or with acetyl groups [23].

\section{Lignin}

Lignin is a phenolic polymer cementing the cellulose fibres in plants. Lignin is built up by the combination of three basic monomer units (p-coumaryl alcohol, coniferyl alcohol, sinapyl alcohol), which differ in the substitution to the aromatic ring [24, 25]. 
Even though lignin is not a saccharide, it is considered as dietary fibre if it is closely associated to saccharides [2].

\section{Cereal brans}

The term "bran" describes usually the non-endospermic milling fraction of cereals, containing the outer bran layers and aleurone layer. Brans are a mixture of many different above mentioned dietary fibres such as cellulose, $\beta(1,3)(1,4)$ linked glucans, $\beta(1,4)$ linked arabinoxylans, fructans (only in rye and wheat) and lignin. The ratio an structure of these fibres may vary significantly, depending on the cereal species. Brans are an example of mostly insoluble fibres [26, 27].

\section{Properties and physiological functions}

The technological functions, such as solubility, water holding capacity and viscosity/gelling of dietary fibres are strongly connected with their physiological effects. Table 1 gives a view on how these properties are related among fibres. However, the level of these properties reported depends on the analytical method and can be only cautiously interpreted and compared.

Solubility has profound effects on fibre functionality. Polysaccharides with irregularities, like side chains and branches, such as pectins and $\beta$-glucans, are rather soluble, while linear fibres are usually insoluble polysaccharides, such as cellulose [28].

Soluble fibres, have a high water holding capacity and viscosity, which is considered in literature to be the responsible property to reduce the blood glucose and cholesterol levels $[29,30]$. Pectins are also known and used for their gelling properties. Low methyl esterified pectins gel via ionic linkages between $\mathrm{Ca}^{2+}$ and carboxyl groups, while high methyl esterified pectins gel via hydrogen bonds and hydrophobic interactions between pectin molecules. The charge, molecular size, side chains and the degree of methylation influence the gelling behaviour of pectins [31].

Insoluble fibres are able to hold water in their porous structure, which increases faecal bulk and reduces the intestinal transit time. This is a major functionality of cellulose and oat- and wheat bran [29, 30, 32]. Furthermore, particle size of fibres play also a role in terms of transit time, fermentation and faecal excretion [28].

Table 1: Properties of dietary fibres. Adapted from [33], if not otherwise indicated.

\begin{tabular}{lccc}
\hline Fibre & Solubility & Water holding capacity & Viscosity/gelling \\
\hline Lignin & - & - & - \\
Cellulose & - & + & - \\
Resistant starch & - & + & + \\
Hemicellulose & + ++ & ++ & + \\
$\beta$-Glucans & + & +++ & +++ \\
Pectin & ++ & +++ & +++ \\
Inulin & + +++ [34] & + & $++/-/+[34,35]$ \\
\hline- , absent; $(+)$, minor; + , low;,++ medium;,+++ good;,++++ very good.
\end{tabular}




\section{Health effects}

Health effects attributed to dietary fibres are extensively discussed in literature, but mechanisms explaining the effects are mostly lacking. As described above, dietary fibre are very diverse in their compositional characteristics. Nevertheless, dietary fibres used in health studies are often compared, but not well-characterised, which is a reason for many contradictions in literature.

Figure 1 summarizes the authorised or non-authorised health claims of dietary fibres, as judged by the European Commission [36]. The specific health effects are combined in groups as described in the legend of the Figure. Only health effects affecting the blood glucose or cholesterol levels for a few fibres are authorised by the EFSA. Most health claims are non-authorised by the EFSA.

The EFSA does not mention details of dietary fibre characteristics, such as the viscosity or structure of e.g. $\beta$-glucans, in their scientific opinion on health claims. One hypothesis in literature, explaining the mechanism of the lipid-lowering effect of dietary fibres, is related to the viscosity of dietary fibres. It was shown in studies, that a gelling fibre of high-viscosity causes the lipid lowering effect more strongly than one of low-viscosity [37].

Neither does the EFSA differentiate claims for different pectins, for example concerning plant origin or molecular weight, which are related to different properties of the pectins and thus to their health effects [38]. An in vivo study, comparing three different pectins (i.a. which differ in molecular mass and gelling/viscosity), showed that the most gelling pectin reduced appetite the most [39].

Oat-, wheat-, barley- and rye bran were given several approved health claims by EFSA (not indicated in table 1), which affect the bowel function. Other claims for brans, those which are affecting the body weight and blood glucose levels were nonauthorised by the EFSA. No purity of brans or ratios of polysaccharides are described, such as minimum necessary amount of cellulose, arabinoxylans or $\beta$-glucans or type of arabinoxylan [32].

Figure 1 also shows that three resistant starches of type 4 have been evaluated as nonauthorised for some health claims by the EFSA, while RS 2 was authorised to be claimed as reducing post-prandial glycaemic responses, but not to be claimed to promote a healthy digestive system [40]. Other RS types have not been further judged by the EFSA.

In general, the health claims are related to necessary daily serving amounts, but no detailed comments on the physico-chemical characteristics of the fibre in relation to the health effects are given. Furthermore, modification of the dietary fibres due to processing methods are not considered concerning the validity of the claims. Dietary fibres have beneficial health effects, for example lowering the blood cholesterol level or lowering blood glucose levels $[41,42]$ and health effects, which can be achieved by fermentation end products in form of short chain fatty acids (SCFA) as produced in the gut [43].

\section{Immunomodulation}

Many in vivo and in vitro studies on immune-stimulatory effects of dietary fibre have been performed [11]. As the immune system is very complex, most studies are difficult to compare due to the use of different immunoassays or readouts. A huge variety of 
different plant extracts have been studied for their bioactivity. So far, no health claims in relation to effects on the immune system have been approved by EFSA [36], even though many studies proved e.g. that yeast $\beta$-glucans are immunomodulating [44]. In terms of immunomodulation, the most studied plant derived polysaccharides are glucans, mannans, pectic polysaccharides. Their molecular structure and physicochemical properties differ enormously, as described above. Most of the immunological studies on these dietary fibres, focus on the molecular mass or functional groups, such as acetyl groups on pectins, as active component of the fibre. Furthermore, the polysaccharide structure and degree of branching are often tested for their key function in terms of immunomodulatory activity [10]. However, systematic studies investigating the structure-function relationships of immunomodulating dietary fibres are lacking, impure substances are investigated or the chemical characterisation of the dietary fibre is insufficient $[10,11]$. Currently, no generic or distinct structure-function relationships have been established for the immunomodulatory activity of fibres.

\section{FERMENTATION}

In the human large intestine indigestible food constituents, e.g. dietary fibres, encounter a huge diversity of microbes. The anaerobic breakdown of dietary fibres, or proteins by microbes is called fermentation. The major end products of fermentation are short chain fatty acids, gases as $\mathrm{H}_{2}$ and $\mathrm{CO}_{2}$, ammonia and energy. These end products can be absorbed from the gut and influence the human and microbial metabolism [45].

\section{Fermentation of dietary fibres}

Dietary fibres have an important role in the maintenance of gut health and are the main energy source for the intestinal microbiota $[46,47]$. SCFA are related to some of the health beneficial effects of dietary fibres [48]. Studies on fermentation of dietary fibres focus mostly on the SCFA produced and changes on the gut microbiota [49]. Only a few studies monitor the degradation of dietary fibres and the formation of metabolites other than SCFA [4, 50-53]. Dietary fibres are differently fermented, depending on their monosaccharide constitution, linkage compositions, degree of polymerisation, lignification, molecular conformation and ratio of soluble and insoluble fibres $[4,47$, 50]. These fibre characteristics influence the extent of fermentation, rate of fermentation, sites of fermentation, type and level of fermentation products like SCFA [28]. Soluble fibres are generally more rapidly and completely fermented than insoluble fibres, which fermentation is mainly determined by the porosity and particle size of fibres [28], but also depends on specific structures [50]. The more complex an insoluble fibre is, the longer it takes to be degraded and fermented by the microbiota, resulting in a fermentation along the full length of the gut [47, 54]. Furthermore, it was found that fibres in the diet influence each other's fermentation. This results, in a preferred fermentation of the one fibre in the more proximal part of the colon and a shift of fermentation of the other fibre to the more distal part of the colon [4].

The fermentation characteristics of dietary fibres and thus their effects on the host's metabolism depend on many factors as mentioned above. Investigation on the formation of carbohydrate metabolites is necessary in order to understand, influence and improve gut health. 


\section{In vivo fermentation models}

In vivo experiments in humans are one option to study the interaction of host-microbediet in the gastrointestinal tract. However, human trials are always highly restricted due to ethical concerns and they are expensive and time-consuming. Furthermore, limitations on the type of foods exist and access to gut content and tissue is difficult in practice [55]. Hence, animal models are used to study food fermentation in vivo. The pig and rat are the most common species of choice for digestion studies of dietary components. The closest model to the human in terms of physiological and anatomical similarities of the digestive tract is the pig [56]. In order to control the difference in gut microbiome between human and animals, germ-free rodents are suitable and can be inoculated with human faeces [57].

\section{In vitro fermentation models}

Several in vitro models exist to mimic the fermentation of dietary fibres in the gut. They can be divided into static (batch fermentation model) or dynamic (i.a. TIM-2, SHIME, SIMGI) fermentation models. All models are operated under anaerobic conditions, they are temperature and $\mathrm{pH}$ controlled and have individual advantages and limitations. An overall advantage in comparison to in vivo studies is that no ethical concerns need to be considered. Also, they are comparably inexpensive to operate and toxic substances can be tested $[55,58]$. A limitation is that all these models lack feedback mechanisms by the host and are usually inoculated with microbiota from faecal samples, thus not exactly representing the microbiota composition in the proximal colon. Furthermore, the systems are not provided with epithelial cells and immune cells, which are a key feature of the interactions in the gut $[59,60]$.

Fermentation models are applied in order to study, for example the effect of food components on the microbiota and composition, the potential of functional foods, studies with the isotope ${ }^{13} \mathrm{C}$, toxic compounds, drugs, proteins and dietary fibres [59]. In in vitro fermentation, faecal inocula from donors are used. These faecal inocula are usually pooled from several individuals. The use of pooled microbiota for fermentations are claimed not to result in deviated microbiota compositions and is more stochastic than the use of microbiota from a single individual [61]. Mixing of inocula from different donors does not affect the functionality of the microbiota, since the bacteria have similar metabolisms [62].

\section{Batch fermentation model}

The batch fermentation model is a static, closed one-compartment model, mostly a sealed bottle or controlled reactor, containing a medium with nutrients, faecal inocula and the fermentation substrate. It is operated under anaerobic conditions and a temperature of $37^{\circ} \mathrm{C}$. This model is a comparatively simple model and useful to study the effect of a substrate on the intestinal microorganisms and vice versa [63].

The advantages of this model are its simplicity in operating the system and sampling, reproducible sampling and the anaerobic conditions can easily be maintained. Furthermore, the batch fermentation is very suitable for experiments explaining the chemical bioconversion of dietary fibres, it is inexpensive and allows a highthroughput of samples. The limitations of the system are that it is not possible to mimic $\mathrm{pH}$ changes and absorption of metabolites and end products, which might accumulate 
and inhibit further microbial activity. To avoid this accumulation, the microbiota must be diluted, which extends the fermentation periods up to 24 or more hours $[59,63,64]$.

\section{Continuous fermentation models}

Continuous fermentation models are more complex and exist as either single or multi compartment systems. The latter can simulate the fermentation process in the proximal, transverse and distal colon region by connecting three fermentation units (e.g. SHIME) [63]. As an example of a continuous single compartment fermentation model, the TIM2 model (TNO intestinal model-2) is discussed (Figure 4). This model is dynamic and computer-controlled, simulating the large intestine. It is a rather complex system and closer to the physiological conditions in humans than the batch fermentation model. Its advantages are that it is $\mathrm{pH}$ controlled, mimics peristaltic movements via a flexible membrane and no phase separation of the digesta occurs. Furthermore, it consists of an absorption mimicking dialysis system, which allows the production of physiological concentrations of metabolites and the use of normal dense microbiota. The limitations of the model are that it does not have epithelial and immune cells and that it is rather labour intense in comparison to the simple batch fermentation [62, 65].

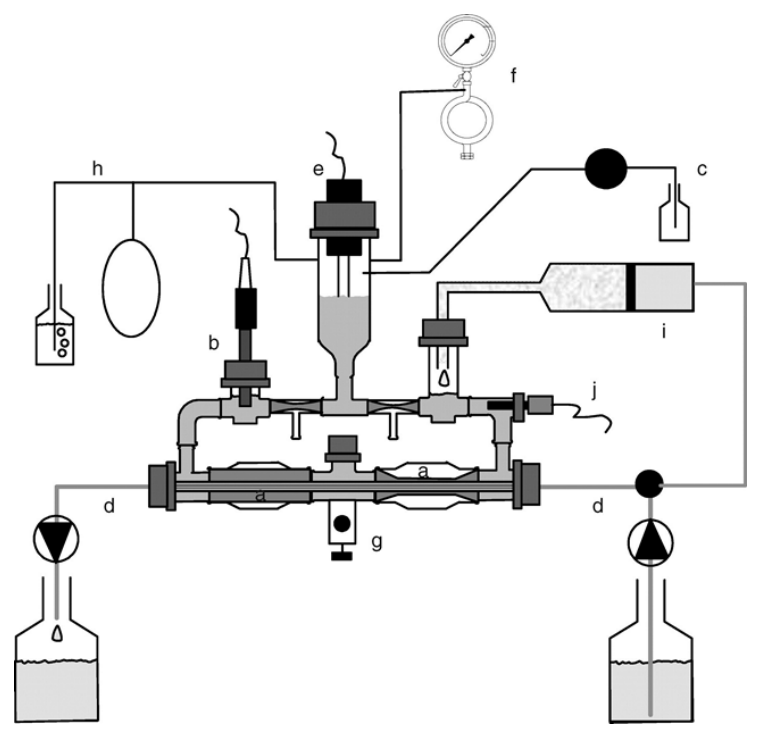

Figure 4: Schematic representation of the large intestinal model TIM-2. a = Peristaltic compartments containing faecal matter, $b=\mathrm{pH}$ electrode, $c=$ alkali pump, $d=$ dialysis liquid circuit with hollow fibre membrane, $e=$ level sensor, $f=\mathrm{N}_{2}$ gas, [66].

\section{Role of microbiota in the gastro intestinal tract}

The human gastro intestinal tract (GIT) comprises the stomach, small intestine (duodenum, jejunum, ileum) and large intestine (ascending colon, transverse colon, descending colon, sigmoid colon, rectum) and contains a complex microbial ecosystem. The microbial density increases along these compartments, starting with $10^{1}$ in the stomach to $10^{12}$ cells/gram in the large intestine (Figure 5). The diversity and composition varies along the GIT [67] and in the human large intestine mainly members of the phyla Firmicutes and Bacteroidetes are present [68]. 


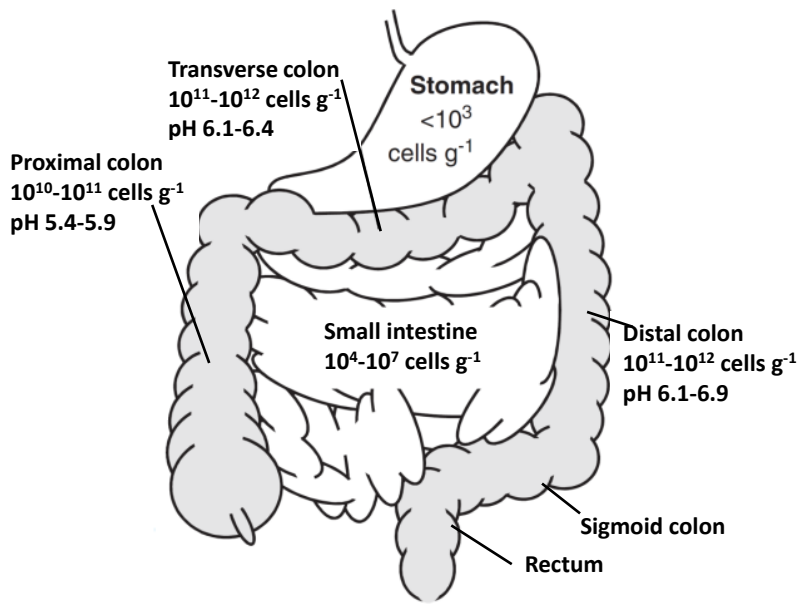

Figure 5: Schematic representation of the human gut and amount of bacteria per gram of intestinal content. Adapted from [63].

The functions of the intestinal microbiota in the GIT are protective (i.a. colonisation resistance against pathogens), structural (i.a. enhancement of gut barrier functions) and metabolic (i.a. fermentation of dietary fibres) [69]. Bacterial fermentation of dietary fibres mainly takes place in the ascending colon and results in the formation of SCFA. The ratio and amount of acetic, propionic and butyric acid depends on type and source of dietary fibre. SCFA decrease the $\mathrm{pH}$ in the colon and inhibit the growth of pathogenic bacteria. Furthermore, SCFA have different functions, e.g. butyric acid is the main energy source for colonic epithelial cells and prevents colon cancer [70].

Although the intestinal microbiota is in long term relatively stable throughout adult life, changes during aging occur [71, 72]. The microbiota composition is mainly influenced by the diet, specifically by the type and amount of dietary fibres [70]. Dietary fibres, ending up in the large intestine, are used by bacteria as energy source. Bacteroides of the phyla Bacteroidetes are capable of metabolizing a variety of dietary fibres [73]. A study of the faecal microbiota of African children following a diet high in fibre compared to European children with a western diet showed significant differences in the microbiota composition. The African children had a microbiota composition high in Bacteroidetes and low in Firmicutes, with a high abundance of bacteria from the genus Prevotella and Xylanibacter, which were absent in the European children. These latter species are able to produce enzymes necessary for the hydrolysis of fibres as cellulose and xylans as present in e.g. cereals [74]. Different diseases, for example, autoimmune and allergic diseases, obesity, inflammatory bowel diseases (IBD: Crohn's diseases and ulcerative colitis) and diabetes are associated with dysbiosis of the microbiota. These are all diseases, which have increased in incidence in developed countries [72] and the diet may be linked to this phenomenon, due to the influence on gut host-microbiota interactions.

\section{IMMUNE SYSTEM}

The primary function of the immune system is to protect the body from pathogens. Therefore, a complex set of mechanisms is used, which rely on the detection of the 
pathogen in order to prevent damage to the host's cells. The immune response can be divided into innate and adaptive function, which complement each other (Figure 6). The innate function acts rapidly in an unspecific way to recognise and kill pathogens and is constitutively present. The adaptive immune response is antigen-specific, needs several days for initiation, involves production of antigen specific immunoglobulins and cytotoxic T-cells and exhibits immunological memory [75].

The innate and adaptive immune system have both cellular and humoral elements. The cellular innate immunity encompasses the activity of e.g. natural killer cells (NK), macrophages, neutrophils, dendritic cells (DCs), while the humoral innate immune system encompasses e.g. complement proteins, mannose-binding lectin and antimicrobial peptides. The cellular adaptive immunity includes the activity of T- and B-cells and the adaptive humoral active compounds are immunoglobulins secreted by B-cells [76].

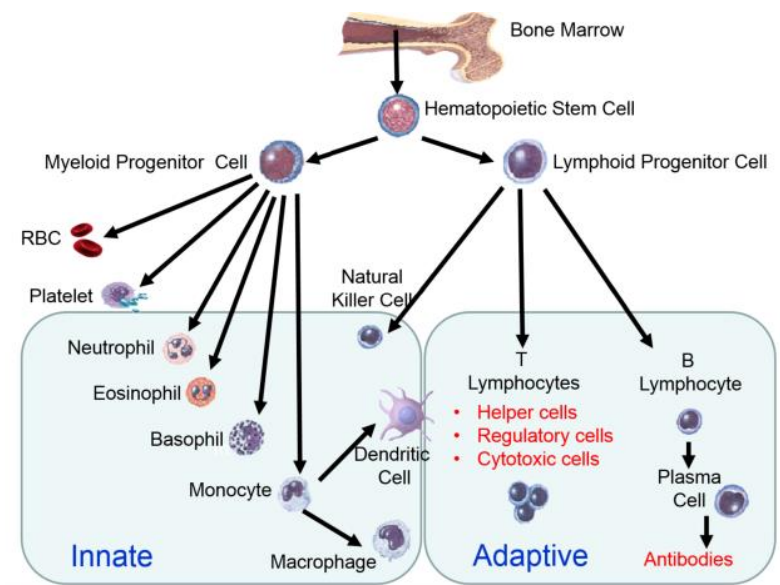

Figure 6: Cells of the innate and adaptive immune system. Adapted from [77].

\section{Gastrointestinal immune system}

A monolayer of intestinal epithelial cells (IECs) provides a physical barrier between the lumen, which contains microorganisms, undigested food and nutrients, and the intestinal lamina propria (LP), which contains many different immune cells (Figure 7). The IECs constitute a first line of defence against pathogens and adjacent IECs are sealed by tight junctions. Goblet cells in the epithelium secrete a layer of protective mucus and enterocytes and Paneth cells in the small intestine produce antimicrobial factors to prevent invasion by microbes [78].

Intestinal DCs are located in Peyer's patches and the LP. Epithelial associated DCs and macrophages can sample antigens in the lumen by extending dendrites between the IEC tight junctions. DCs located in the Peyer's patches sample luminal antigens transported via the microfold cells (M-cells) [79]. M-cells are specialised epithelial cells that transport antigens from the lumen to lymphoid tissues [80].

\section{Immune cells}

As mentioned above, the innate and adaptive immune system can be assigned to different immune cells (Figure 6). All of these cells secrete a wide array of effector cytokines and chemokines within complex signalling pathways. 


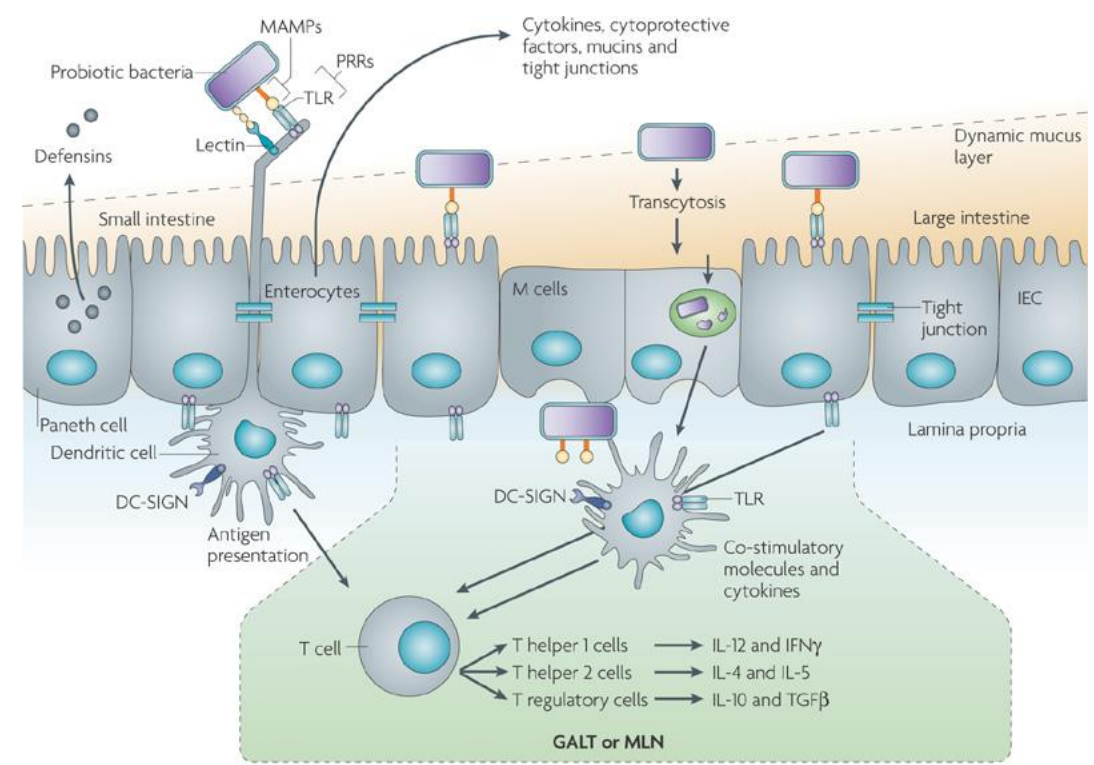

Figure 7: Interaction of bacteria with intestinal epithelial cells and DCs from the GALT, adapted from [81]. GALT, gut-associated lymphoid tissue; DC, dendritic cell; IEC, intestinal epithelial cells; MAMPs, microbe-associated molecular pattern; MLN, mesenteric lymph nodes; PRRs, pathogen recognition receptor; TLR, toll-like receptor; DC-SIGN, dendritic cell-specific intercellular adhesion molecule-3grabbing non-integrin.

Lymphocytes belong to the adaptive immune system and can differentiate into B-cells and T-cells (T-helper-cells and cytotoxic T-cell) or natural killer cells. Granulocytes belong to the innate immune system and differentiate into eosinophils, basophils, neutrophils or monocytes. The monocytes, can further differentiate into macrophages or DCs. All cells can be cultivated in vitro as primary cells or transformed cell lines [82]. As DCs were mainly used for immunoassays in this thesis, they are described in more detail below.

\section{Dendritic cells}

Dendritic cells are the most important antigen-presenting cells (APCs) and activate cells of the innate and adaptive immune systems (T-and B-cells) (Figure 6) [83].

They are derived from monocytes in the bone marrow, which circulate in the blood. DCs are present in peripheral tissue, such as the lamina propria in the gut (Figure 7). Immature DCs capture antigens in several pathways, for example, receptor-mediated endocytosis via C-type lectin receptors or phagocytosis of particulate antigens from their surroundings. They phagocytise and process the pathogens and present the antigen via a peptide called major histocompatibility complex (MHC) on their cell surface. The mature DCs migrate to secondary lymphoid organs, where they activate immune cells. The main function of DCs is to present antigens, to prime and to activate the differentiation of naïve T-cells into T-helper cell 1 (Th1) or 2 (Th2) (Figure 7) [83, 84]. Besides the activation of naïve T-helper cells, the DCs can produce a large variety of cytokines. Depending on the antigen presented by the DCs, co-stimulatory 
molecules and cytokines affect T-cells to differentiate into different T-cell subsets such as Th1, Th2 or T regulatory cells $[85,86]$.

DCs exist in different subpopulations, which have varying properties depending on their location (e.g. Peyers's patches, small or colonic lamina propria). They can be further classified based on their cell-surface receptors [80].

For immunoassays, DCs can be derived from cell lines, in vitro-generated or isolated from bone marrow cells, monocytes or blood. However, the amount of primary DCs in blood is low, difficult to obtain and different subsets of DCs are present in the blood. DC cell lines are commonly derived from leukemia-derived cells, for example THP-1 or MUTZ-3. They have a large number of synchronised cells and a long life span. However, they need the addition of specific growth and differentiation factors. DCs can be generated in vitro from monocytes isolated from peripheral blood mononuclear cells (PBMCs) or bone marrow stem cells and differentiated by culture in the presence of specific factors. These cells are relatively easy to obtain and culture and are very well studied [86].

\section{Pattern recognition receptors}

Cells of the immune system and tissues express various pattern recognition receptors (PRRs) in order to respond to pathogenic and commensal bacteria or dietary compounds present in the lumen (Figure 7). IECs and DCs recognise via their PRRs microbe-associated molecular patterns (MAMPs) or pathogen-associated molecular patterns (PAMPs). PRRs are for example Toll-like receptors (TLRs), nucleotidebinding oligomerization domain receptor (NLRs) and C-type lectin receptors (CLRs) $[87,88]$. Their principal functions are opsonisation and promotion of phagocytosis as well as the induction of signalling cascades and expression of effector molecules (e.g. cytokines, chemokines) [89].

DCs express TLRs and at least 10 types of TLRs have been identified in humans, with each having a distinct function [89]. DCs express also C-type lectin receptors (CLRs), for example DC-SIGN (dendritic-cell-specific ICAM-3 grabbing non-integrin) MMR (macrophage mannose receptor) or Dectin-1 (dendritic-cell C-type lectin 1). Carbohydrates interact with these type of receptors, partially depending on calcium binding. Table 2 gives an overview of identified ligand-receptor interactions present on DCs.

Table 2: Receptors expressed by i.a. DCs and their ligands present in bacteria or food compounds.

\begin{tabular}{ll}
\hline Ligand & Receptor \\
\hline $\begin{array}{l}\text { Lipopeptides (Gram-positive and Gram-negative } \\
\text { bacteria) }\end{array}$ & TLR 2 and 1/6 [90] \\
$\begin{array}{l}\text { Lipopolysaccharide (outer membrane of Gram- } \\
\text { negative bacteria) }\end{array}$ & TLR 4 [90] \\
Flagellin and RNA & TLR 5 and TLR3 [90] \\
Mannose, glucomannan & DC-SIGN, CR3, MR and TLRs [91, 92] \\
$\begin{array}{l}\beta(1,3) \text { glucans } \\
\text { Fucose }\end{array}$ & Dectin-1 [93] \\
\hline CR3, complement receptor 3; MR, mannose receptor; DC-SIGN, dendritic-cell-specific ICAM-3 grabbing non- \\
integrin; Dectin-1, dendritic-cell C-type lectin 1; TLR, Toll-like receptor.
\end{tabular}


TLRs and CLRs bind MAMPs or carbohydrates, which affect the conformation of the receptors, resulting in a cascade of signals [90]. All receptors have different signalling

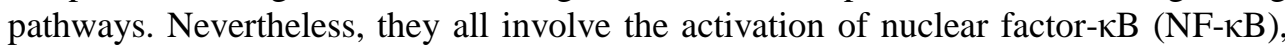
which is a protein controlling the expression of genes and cytokine production $[89,94$, 95]. However, the ligands for these type of receptors are still mostly undiscovered and most studies focus rather on carbohydrates present in pathogens than in food compounds.

\section{Cytokines}

Interactions of PRRs on DCs up-regulate the production of specific cytokines and chemokines as well as surface receptors e.g. involved in antigen presentation. Cytokines are proteins, causing subsequent cascades of intracellular signalling, regulating immune response [96]. Cytokines encompass interferons, interleukins (IL), lymphokines, tumor necrosis factor (TNF) and the chemokine monocyte chemoattractant protein-1 (MCP-1). Specific cytokines are involved in cytotoxic, humoral, cell-mediated or allergic reactions [97]. Inflammatory cytokines are involved in either acute (i.a. IL-16, IL-8) or chronic inflammation (i.a. IL-2-5, IL-7, IL-9, IL-10, IL-12-15, IFNs, TGF- $\alpha$, TNF- $\beta$ ), or both (i.a. IL-1, IL-6, IL-11, IL-17, TNF- $\alpha$ ). Most cytokines are multifunctional and involved in extensive networks of synergistic and antagonistic interactions [98]. They can act on the cells that secret them, on nearby cells or on distant cells. Cytokines are mainly produced by T-cells and myeloid cells $[96,99]$. The type of cytokines influences the activation of different T-cell responses [83].

More than 300 cytokines with their varying functions on the immune system and organs in the body have been described. Table 3 lists the cytokines, as they were measured in this thesis, and some of their biological functions. However, the diverse functions and interactions of many cytokines are poorly understood [96].

Table 3: Cytokines, selected based on importance in this thesis and some of their biological activities.

\begin{tabular}{|c|c|}
\hline Cytokine & Selected biological activities \\
\hline IL-6 & $\begin{array}{l}\text { anti- and pro-inflammatory, thyroiditis, diabetes, arthritis, leukaemia [98], } \\
\text { stimulates B-cell differentiation, T-cell activation, fever [96] }\end{array}$ \\
\hline IL-10 & $\begin{array}{l}\text { anti-inflammatory [99], Inhibits Th1 function, mitigation of allergic } \\
\text { inflammation [100], cytotoxic [97] }\end{array}$ \\
\hline IL-12 & $\begin{array}{l}\text { pro-inflammatory, stimulates Th1 development, regulation of } \\
\text { immunoglobulin production [98], cytotoxic [97] }\end{array}$ \\
\hline TNF- $\alpha$ & $\begin{array}{l}\text { induces fever, pro-inflammatory, arthritis, induced by LPS [98], cytotoxic } \\
\text { effects on cancerous cells, activates neutrophils, causes cachexia in } \\
\text { infections and cancer [96] }\end{array}$ \\
\hline IFN- $\gamma$ & $\begin{array}{l}\text { diabetes, arthritis [98], mitigation of allergic inflammation, responsible for } \\
\text { cell-mediated immunity (stimulation of macrophages, NK and neutrophils) } \\
\text { [96] }\end{array}$ \\
\hline MCP-1 & pro-inflammatory, chemotactic for innate immune cells [96] \\
\hline
\end{tabular}




\section{THESIS OUTLINE}

Only a limited number of fermentation studies monitor the degradation of dietary fibres and the formation of oligosaccharides. Furthermore, structure-function interactions of many dietary fibres or fermentation metabolites with gastrointestinal immune cells are unexplored or contradictory. Hence, the aim of this thesis was to investigate the fermentation characteristics and immunomodulation by dietary fibres in relation to their chemical properties.

Chapter 2 describes a new approach to analyse the immunomodulation properties of 44 different dietary fibres. The fibres are incubated on dendritic cells derived from bone marrow from TLR2/4 knock out mice. The use of these cells was first validated and then three fibres were selected in order to further investigate structure related immunologic effects. Chapter 3 focusses on oat and barley $\beta$-glucans and aims to explain their different immunomodulation capacity. Immunomodulation by different $\beta$ glucan fractions, as well as influences of sample processing are considered.

In Chapter 4, the fermentation characteristics of barley $\beta$-glucan and sugar beet pectin and the immunomodulating properties of their fermentation digesta is compared. Direct incubation of complex fermentation digesta on immune cells could be a new approach to measure the immunological effects of fermentation metabolites. In Chapter $\mathbf{5}$ a batch fermentation of a commercially available, soluble resistant starch (Fibersol-2) with human faecal inocula is described, as well as the microbial enzymes present. The results gained from several in vitro batch fermentation studies of dietary fibre using human faecal inocula and the immunomodulating properties of dietary fibres are discussed in Chapter 6.

\section{REFERENCES}

[1] Champ, M., Langkilde, A.-M., Brouns, F., Kettlitz, B., Collet, Y. L. B., Advances in dietary fibre characterisation. 1. Definition of dietary fibre, physiological relevance, health benefits and analytical aspects. Nutrition Research Reviews 2003, 16, 71-82.

[2] European-Commission, Commission Directive 2008/100/EC of 28 October 2008 amending Council Directive 90/496/EEC on nutrition labelling for foodstuffs as regards recommended daily allowances, energy conversion factors and definitions. Official Journal of the European Union 2008, L 285, 9-12.

[3] Cummings, J., Stephen, A., Carbohydrate terminology and classification. European Journal of Clinical Nutrition 2007, 61, S5-S18.

[4] Jonathan, M. C., Monitoring the degradation of individual dietary fibres in pig models. Ph.D. Thesis, University of Wagenignen, Wageningen, The Netherlands. 2013.

[5] Slavin, J., Green, H., Dietary fibre and satiety. Nutrition Bulletin 2007, 32, 32-42.

[6] Wanders, A. J., van den Borne, J. J. G. C., de Graaf, C., Hulshof, T., et al., Effects of dietary fibre on subjective appetite, energy intake and body weight: a systematic review of randomized controlled trials. Obesity Reviews 2011, 12, 724-739.

[7] Gibson, G. R., Dietary modulation of the human gut microflora using the prebiotics oligofructose and inulin. The Journal of Nutrition 1999, 129, 1438S-1441s.

[8] Hashizume, C., Okuma, K., Fibersol ${ }^{\circledR}-2$ resistant Maltodextrin: Functional Dietary Fiber Ingredient. Fiber Ingredients-Foods Applications and Health Benefits. CRC Press, Boca Raton, FL, USA 2009, 61-78.

[9] Ye, Z., Arumugam, V., Haugabrooks, E., Williamson, P., Hendrich, S., Soluble dietary fiber (Fibersol-2) decreased hunger and increased satiety hormones in humans when ingested with a meal. Nutrition Research 2015, 35, 393-400.

[10] Ferreira, S. S., Passos, C. P., Madureira, P., Vilanova, M., Coimbra, M. A., Structure-function relationships of immunostimulatory polysaccharides: A review. Carbohydrate Polymers 2015, 132, 378-396.

[11] Ramberg, J. E., Nelson, E. D., Sinnott, R. A., Immunomodulatory dietary polysaccharides: a systematic review of the literature. Nutrition Journal 2010, 9, 1-22. 


\section{CHAPTER 1}

[12] Scheller, H. V., Ulvskov, P., Hemicelluloses. Plant Biology 2010, 61, 263-289.

[13] O'Sullivan, A., Cellulose: the structure slowly unravels. Cellulose 1997, 4, 173-207.

[14] Cosgrove, D. J., Growth of the plant cell wall. Nature Review Molecular Cell Biology 2005, 6, 850-861.

[15] Tosh, S. M., Brummer, Y., Wood, P. J., Wang, Q., Weisz, J., Evaluation of structure in the formation of gels by structurally diverse $(1 \rightarrow 3)(1 \rightarrow 4)$ - $\beta$-d-glucans from four cereal and one lichen species. Carbohydrate Polymers $2004,57,249-259$.

[16] Leszczyñski, W. a., Resistant starch-classification, structure, production. Polish Journal of Food and Nutrition Sciences 2004, 13, 37-50.

[17] Fuentes-Zaragoza, E., Riquelme-Navarrete, M. J., Sánchez-Zapata, E., Pérez-Álvarez, J. A., Resistant starch as functional ingredient: A review. Food Research International 2010, 43, 931-942.

[18] Daniel, J., Whistler, R., Voragen, A., Pilnik, W., in: Elvers B., Hawkins S., Russey W. (Eds.), Ullmann's Encyclopedia of Industrial Chemistry, VCH Verlagsgesellschaft, Weinheim, Germany 1994.

[19] Pedrolli, D. B., Monteiro, A. C., Gomes, E., Carmona, E. C., Pectin and pectinases: production, characterization and industrial application of microbial pectinolytic enzymes. Open Biotechnology Journal 2009, 9-18.

[20] Roberfroid, M. B., Delzenne, N. M., Dietary Fructans. Annual Review of Nutrition 1998, 18, 117-143.

[21] Flamm, G., Glinsmann, W., Kritchevsky, D., Prosky, L., Roberfroid, M., Inulin and oligofructose as dietary fiber: a review of the evidence. Critical Reviews in Food Science and Nutrition 2001, 41, 353-362.

[22] Izydorczyk, M. S., Biliaderis, C. G., Cereal arabinoxylans: advances in structure and physicochemical properties. Carbohydrate Polymers 1995, 28, 33-48.

[23] Sørensen, H. R., Pedersen, S., Meyer, A. S., Characterization of solubilized arabinoxylo-oligosaccharides by MALDI-TOF MS analysis to unravel and direct enzyme catalyzed hydrolysis of insoluble wheat arabinoxylan. Enzyme and Microbial Technology 2007, 41, 103-110.

[24] Dimmel, D., Lignin and lignans: advances in chemistry, CRC Press, Boca Raton, FL, USA 2010.

[25] Suhas, Carrott, P. J. M., Ribeiro Carrott, M. M. L., Lignin - from natural adsorbent to activated carbon: A review. Bioresource Technology 2007, 98, 2301-2312.

[26] Collins, H. M., Burton, R. A., Topping, D. L., Liao, M.-L., et al., REVIEW: Variability in Fine Structures of Noncellulosic Cell Wall Polysaccharides from cereal grains: potential importance in human health and nutrition. Cereal Chemistry 2010, 87, 272-282.

[27] Selvendran, R. R., The plant cell wall as a source of dietary fiber: chemistry and structure. The American Journal of Clinical Nutrition 1984, 39, 320-337.

[28] Guillon, F., Champ, M., Structural and physical properties of dietary fibres, and consequences of processing on human physiology. Food Research International 2000, 33, 233-245.

[29] Cui, S. W., Wu, Y., Ding, H., Fibre-Rich and Wholegrain Foods, Woodhead Publishing 2013, pp. 96-119.

[30] Elleuch, M., Bedigian, D., Roiseux, O., Besbes, S., et al., Dietary fibre and fibre-rich by-products of food processing: Characterisation, technological functionality and commercial applications: A review. Food Chemistry 2011, 124, 411-421.

[31] Thakur, B. R., Singh, R. K., Handa, A. K., Rao, M., Chemistry and uses of pectin-a review. Critical Reviews in Food Science \& Nutrition 1997, 37, 47-73.

[32] EFSA Panel on Dietetic Products Nutrition and Allergies (NDA), Scientific Opinion on the substantiation of health claims related to wheat bran fibre and increase in faecal bulk (ID 3066), reduction in intestinal transit time (ID 828, 839, 3067, 4699) and contribution to the maintenance or achievement of a normal body weight (ID 829) pursuant to Article 13(1) of Regulation (EC) No 1924/2006. EFSA Journal 2010; , 8(10) 1817-1835.

[33] Trepel, F., [Dietary fibre: more than a matter of dietetics. I. Compounds, properties, physiological effects]. Wiener Klinische Wochenschrift 2004, 116, 465-476.

[34] Franck, A., Technological functionality of inulin and oligofructose. British Journal of Nutrition 2002, 87, S287S291.

[35] Schneeman, B. O., Fiber, inulin and oligofructose: similarities and differences. The Journal of nutrition 1999, 129, 1424-1427.

[36] European-Commission, http://ec.europa.eu/nuhclaims/?event=search 2016.

[37] Vuksan, V., Jenkins, A. L., Rogovik, A. L., Fairgrieve, C. D., et al., Viscosity rather than quantity of dietary fibre predicts cholesterol-lowering effect in healthy individuals. British Journal of Nutrition 2011, 106, 1349-1352.

[38] EFSA Panel on Dietetic Products Nutrition and Allergies (NDA), Scientific Opinion on the substantiation of health claims related to pectins and reduction of post-prandial glycaemic responses (ID 786), maintenance of normal blood cholesterol concentrations (ID 818) and increase in satiety leading to a reduction in energy intake (ID 4692) pursuant to Article 13(1) of Regulation (EC) No 1924/2006. EFSA Journal 2010, 8, 1747-1764. 
[39] Wanders, A. J., Feskens, E. J. M., Jonathan, M. C., Schols, H. A., et al., Pectin is not pectin: A randomized trial on the effect of different physicochemical properties of dietary fiber on appetite and energy intake. Physiology \& Behavior 2014, 128, 212-219.

[40] EFSA Panel on Dietetic Products Nutrition and Allergies (NDA), Scientific Opinion on the substantiation of health claims related to resistant starch and reduction of post-prandial glycaemic responses (ID 681), "digestive health benefits" (ID 682) and "favours a normal colon metabolism" (ID 783) pursuant to Article 13(1) of Regulation (EC) No 1924/20061. EFSA Journal 2011; , 9, 2024-2040.

[41] Brown, L., Rosner, B., Willett, W. W., Sacks, F. M., Cholesterol-lowering effects of dietary fiber: a metaanalysis. The American Journal of Clinical Nutrition 1999, 69, 30-42.

[42] Stephen, A. M., Cummings, J. H., Water-holding by dietary fibre in vitro and its relationship to faecal output in man. Gut 1979, 20, 722-729.

[43] Wong, J. M. W., de Souza, R., Kendall, C. W. C., Emam, A., Jenkins, D. J. A., Colonic Health: Fermentation and Short Chain Fatty Acids. Journal of Clinical Gastroenterology 2006, 40, 235-243.

[44] Volman, J. J., Ramakers, J. D., Plat, J., Dietary modulation of immune function by $\beta$-glucans. Physiology $\&$ Behavior 2008, 94, 276-284.

[45] Cummings, J., Macfarlane, G., The control and consequences of bacterial fermentation in the human colon Journal of Applied Bacteriology 1991, 70, 443-459.

[46] Brownlee, I. A., The physiological roles of dietary fibre. Food Hydrocolloids 2011, 25, 238-250.

[47] Montagne, L., Pluske, J., Hampson, D., A review of interactions between dietary fibre and the intestinal mucosa, and their consequences on digestive health in young non-ruminant animals. Animal feed science and technology 2003, 108, 95-117.

[48] Scharlau, D., Borowicki, A., Habermann, N., Hofmann, T., et al., Mechanisms of primary cancer prevention by butyrate and other products formed during gut flora-mediated fermentation of dietary fibre. Mutation Research/Reviews in Mutation Research 2009, 682, 39-53.

[49] Montagne, L., Pluske, J. R., Hampson, D. J., A review of interactions between dietary fibre and the intestinal mucosa, and their consequences on digestive health in young non-ruminant animals. Animal Feed Science and Technology 2003, 108, 95-117.

[50] Ramasamy, U. S., The role of soluble and insoluble fibers during fermentation of Chicory root pulp. Ph.D. Thesis, Wageningen University, Wageningen, The Netherlands. 2014.

[51] Ramasamy, U. S., Venema, K., Schols, H. A., Gruppen, H., Effect of soluble and insoluble fibers within the in vitro fermentation of chicory root pulp by human gut bacteria. Journal of agricultural and food chemistry 2014, $62,6794-6802$.

[52] Karppinen, S., Liukkonen, K., Aura, A. M., Forssell, P., Poutanen, K., In vitro fermentation of polysaccharides of rye, wheat and oat brans and inulin by human faecal bacteria. Journal of the Science of Food and Agriculture 2000, 80, 1469-1476.

[53] Leijdekkers, A. G., Aguirre, M., Venema, K., Bosch, G., et al., In vitro fermentability of sugar beet pulp derived oligosaccharides using human and pig fecal inocula. Journal of agricultural and food chemistry 2014, 62, 10791087.

[54] Govers, M., Gannon, N., Dunshea, F., Gibson, P., Muir, J., Wheat bran affects the site of fermentation of resistant starch and luminal indexes related to colon cancer risk: a study in pigs. Gut 1999, 45, 840-847.

[55] Macfarlane, G. T., Macfarlane, S., Models for intestinal fermentation: association between food components, delivery systems, bioavailability and functional interactions in the gut. Current Opinion in Biotechnology 2007, 18, 156-162.

[56] Miller, E., Ullrey, D., The pig as a model for human nutrition. Annual review of nutrition 1987, 7, $361-382$.

[57] Rumney, C. J., Rowland, I. R., In vivo and in vitro models of the human colonic flora. Critical Reviews in Food Science and Nutrition 1992, 31, 299-331.

[58] Verhoeckx K, in: Verhoeckx K, Cotter P, López-Expósito I, Kleiveland C, et al. (Eds.), The impact of Food Boactives on Health, Springer, Cham, Heidelberg, New York, Dordrecht, London 2015, pp. 275-279.

[59] Venema, K., van den Abbeele, P., Experimental models of the gut microbiome. Best Practice \& Research Clinical Gastroenterology 2013, 27, 115-126.

[60] Williams, C., Walton, G., Jiang, L., Plummer, S., et al., Comparative Analysis of Intestinal Tract Models. Annual Review of Food Science and Technology 2015, 6, 329-350.

[61] Aguirre, M., Ramiro-Garcia, J., Koenen, M. E., Venema, K., To pool or not to pool? Impact of the use of individual and pooled fecal samples for in vitro fermentation studies. Journal of Microbiological Methods 2014 107, 1-7.

[62] Verhoeckx, K., Cotter, P., López-Expósito, I., Kleiveland, C., et al., The Impact of Food Bioactives on Health, Springer International Publishing, Heidelberg, Germany 2015, pp. 293-304. 


\section{CHAPTER 1}

[63] Payne, A. N., Zihler, A., Chassard, C., Lacroix, C., Advances and perspectives in in vitro human gut fermentation modeling. Trends in Biotechnology 2012, 30, 17-25.

[64] Aura, A.-M., Maukonen, J., in: Verhoeckx, K., Cotter, P., López-Expósito, I., Kleiveland, C., et al. (Eds.), The Impact of Food Bioactives on Health, Springer International Publishing 2015, pp. 281-292.

[65] Minekus, M., Smeets-Peeters, M., Bernalier, A., Marol-Bonnin, S., et al., A computer-controlled system to simulate conditions of the large intestine with peristaltic mixing, water absorption and absorption of fermentation products. Applied Microbiology and Biotechnology 1999, 53, 108-114.

[66] Maathuis, A., Hoffman, A., Evans, A., Sanders, L., Venema, K., The effect of the undigested fraction of maize products on the activity and aomposition of the microbiota determined in a dynamic in vitro model of the human proximal large intestine. Journal of the American College of Nutrition 2009, 28, 657-666.

[67] Sekirov, I., Russell, S. L., Antunes, L. C. M., Finlay, B. B., Gut Microbiota in Health and Disease. Physiological Reviews 2010, 90, 859-904.

[68] Eckburg, P. B., Bik, E. M., Bernstein, C. N., Purdom, E., et al., Diversity of the human intestinal microbial flora. Science 2005, 308, 1635-1638.

[69] O'Hara, A. M., Shanahan, F., The gut flora as a forgotten organ. EMBO reports 2006, 7, 688-693.

[70] Scott, K., Duncan, S., Flint, H., Dietary fibre and the gut microbiota. Nutrition Bulletin 2008, 33, 201-211.

[71] Woodmansey, E., Intestinal bacteria and ageing. Journal of Applied Microbiology 2007, 102, 1178-1186.

[72] Clemente, Jose C., Ursell, Luke K., Parfrey, Laura W., Knight, R., The impact of the gut microbiota on human health: $n$ integrative view. Cell 2012, 148, 1258-1270.

[73] Salyers, A., Vercellotti, J., West, S., Wilkins, T., Fermentation of mucin and plant polysaccharides by strains of Bacteroides from the human colon. Applied and Environmental Microbiology 1977, 33, 319-322.

[74] De Filippo, C., Cavalieri, D., Di Paola, M., Ramazzotti, M., et al., Impact of diet in shaping gut microbiota revealed by a comparative study in children from Europe and rural Africa. Proceedings of the National Academy of Sciences of the United States of America 2010, 107, 14691-14696.

[75] Chaplin, D. D., 1. Overview of the human immune response. Journal of Allergy and Clinical Immunology 2006, 117, S430-S435.

[76] Turvey, S. E., Broide, D. H., Innate immunity. Journal of Allergy and Clinical Immunology 2010, 125, S24-S32.

[77]LaMorte, W., http://sphweb.bumc.bu.edu/otlt/MPH-Modules/PH/Ph709_Defenses/PH709_Defenses23.html 2014.

[78] Schenk, M., Mueller, C., The mucosal immune system at the gastrointestinal barrier. Best Practice \& Research Clinical Gastroenterology 2008, 22, 391-409.

[79] Chieppa, M., Rescigno, M., Huang, A. Y., Germain, R. N., Dynamic imaging of dendritic cell extension into the small bowel lumen in response to epithelial cell TLR engagement. The Journal of experimental medicine 2006, 203, 2841-2852.

[80] Coombes, J. L., Powrie, F., Dendritic cells in intestinal immune regulation. 2008, 8, 435-446.

[81] Lebeer, S., Vanderleyden, J., De Keersmaecker, S. C. J., Host interactions of probiotic bacterial surface molecules: comparison with commensals and pathogens. 2010, 8, 171-184.

[82] Aura, A.-M., Maukonen, J., in: Verhoeckx, K., Cotter, P., López-Expósito, I., Kleiveland, C., et al. (Eds.), The Impact of Food Bioactives on Health, Springer International Publishing, Heidelberg, Germany 2015, pp. 84-140.

[83] Banchereau, J., Briere, F., Caux, C., Davoust, J., et al., Immunobiology of dendritic cells. Annual review of immunology 2000, 18, 767-811.

[84] Steinman, R. M., The dendritic cell system and its role in immunogenicity. Annual review of immunology 1991, 9, 271-296.

[85] Castillo, L., MacCallum, D. M., Host-Fungus Interactions, Springer 2012, pp. 425-434.

[86] Plantinga, M., de Haar, C., Nierkens, S., The Impact of Food Bioactives on Health, Springer 2015, pp. 181-196.

[87] Artis, D., Epithelial-cell recognition of commensal bacteria and maintenance of immune homeostasis in the gut. Nature Reviews Immunology 2008, 8, 411-420.

[88] Geijtenbeek, T. B. H., Gringhuis, S. I., Signalling through C-type lectin receptors: shaping immune responses. 2009, 9, 465-479.

[89] Medzhitov, R., Toll-like receptors and innate immunity. 2001, 1, 135-145.

[90] Moresco, E. M. Y., LaVine, D., Beutler, B., Toll-like receptors. Current Biology 2011, 21, R488-R493.

[91] Figdor, C. G., van Kooyk, Y., Adema, G. J., C-type lectin receptors on dendritic cells and langerhans cells. 2002, 2, 77-84.

[92] Chlubnová, I., Sylla, B., Nugier-Chauvin, C., Daniellou, R., et al., Natural glycans and glycoconjugates as immunomodulating agents. Natural product reports 2011, 28, 937-952.

[93] Brown, G. D., Herre, J., Williams, D. L., Willment, J. A., et al., Dectin-1 mediates the biological effects of $\beta$ glucans. The Journal of Experimental Medicine 2003, 197, 1119-1124. 


\section{General Introduction}

[94] Li, Q., Verma, I. M., NF-kB regulation in the immune system. 2002, 2, 725-734.

[95] van Kooyk, Y., Rabinovich, G. A., Protein-glycan interactions in the control of innate and adaptive immune responses. Nature immunology 2008, 9, 593-601.

[96] Commins, S. P., Borish, L., Steinke, J. W., Immunologic messenger molecules: cytokines, interferons, and chemokines. Journal of Allergy and Clinical Immunology 2010, 125, S53-S72.

[97] Borish, L. C., Steinke, J. W., 2. Cytokines and chemokines. Journal of Allergy and Clinical Immunology 2003, 111, S460-S475.

[98] Feghali, C. A., Wright, T. M., Cytokines in acute and chronic inflammation. Front Bioscience 1997, 2, d12-d26.

[99] Zhang, J.-M., An, J., Cytokines, inflammation and pain. International anesthesiology clinics 2007, 45, 27.

[100] Borish, L., IL-10: Evolving concepts. Journal of Allergy and Clinical Immunology 1998, 101, 293-297. 


\section{ChAPTER 1}




\title{
Chapter 2
}

\section{Structure related immunomodulation by sugar beet arabinans is induced via Syk tyrosine kinase-dependent pathway}

\begin{abstract}
The immunomodulatory activity of dietary fibres may be influenced by contamination with microbial-associated molecular patterns (MAMPs), such as lipopolysaccharide (LPS) and lipoteichoic acids, which are difficult to remove completely from biological samples. Our new approach, using BMDCs from TLR2/4 KO mice, enabled the determination of the immunomodulatory properties of 44 different dietary fibres without interference from mentioned impurities.

The 44 screened dietary fibres induced different amounts of cytokines in BMDCs. A linear arabinan (LA) induced higher amounts of cytokines than a branched arabinan (BA). Hence, these samples were used to demonstrate structure related immune functionality. Both are derived from sugar beet pulp and are structurally rather similar. The most stimulatory part of the substrates was the particulate fraction. Enzymatic linearization of BA increased the immune activity. Additionally, mechanistic studies indicated the existence of a novel Syk-dependent carbohydrate-receptor interaction for linear and branched arabinans, eliciting immune responses.
\end{abstract}

This chapter is part of a publication to be submitted:

Meijerink, M., Rösch, C., Taverne, N., Venema, K., Gruppen, H., Schols, H. A. \& Wells J.M. (2016). Structure related immunomodulation by sugar beet arabinans is induced via Syk tyrosine kinase-dependent pathway. 


\section{INTRODUCTION}

Dietary fibres are defined as the edible part of plants that are resistant to digestion and absorption in the human small intestine with at least partial fermentation in the large intestine. They have beneficial health effects [1, 2]. Dietary fibres include polysaccharides, oligosaccharides and lignin [2, 3]. Poly- and oligosaccharide based fibres have been categorized based on their chemical properties, such as monosaccharide composition or physical properties, such as solubility and particle size [3].

The dietary $\beta(1,3)$ linked glucans found in cell walls of mushrooms and other fungi have been shown to have direct immunostimulatory effects on immune cells. The $\beta$ glucans trigger a variety of cellular responses, including maturation of myeloid cells, the respiratory burst in innate phagocytes and production of cytokines, such as TNF- $\alpha$, IL-6, IL-10 and IL-23[4]. These responses are mediated through binding of the $\beta(1,3)$ linked glucans to Dectin-1, a member of the C-type lectin family of receptors (CLR) [5]. Dectin-1 utilises a tyrosine kinase (Syk) as a primary signal transduction molecule to induce inflammatory responses [6]. Recruitment of Syk is considered to be dependent on the bridging of two phosphorylated immunoreceptor tyrosine-based activation (ITAM) by the dimerization of Dectin-1 [6]. Dectin-1 and other CLRs are expressed on dendritic cells and macrophages, subsets of which are associated with intestinal epithelial cells and can sample antigens directly through the epithelium. Recently, Dectin -1 was also shown to be expressed in primary colonic enterocytes and to induce chemokine secretion upon ligand binding to $\beta(1,3)$ linked glucans [5]. It is not known if other CLRs, such as Dectin-2 and macrophage inducible $\mathrm{Ca}^{2+}$-dependent (C-type) lectin (Mincle), are expressed in intestinal epithelial cells. Further evidence that Dectin-1 is important in the gut derives from the finding that a loss of function polymorphism in Dectin-1 is associated with severe, intractable forms of ulcerative colitis resulting from fungal microorganisms in the intestine [7].

The possibility that dietary fibres modulate immune responses through C-type lectin receptors or other pattern recognition receptors (PRRs) recognising carbohydrate structures has been proposed in previous studies [8, 9], but there is little knowledge about the physio-chemical requirements of such signalling interactions. One difficulty in the field is the presence of contaminating microbial-associated molecular patterns (MAMPs), such as lipopolysaccharide (LPS) and lipoteichoic acids, which are difficult to remove completely from biological samples.

The aim of the present study was to screen 44 dietary fibres based on their cytokine responses in bone marrow derived dendritic cells (BMDCs) from mice lacking TLR2/4. We chose from this set two structurally related dietary fibres, linear and branched arabinan (LA, BA), and sugar beet pectin (SBP), all derived from sugar beet pulp and having different immunostimulatory activities. In order to investigate structure related immunomodulatory activity, these fibres were chemically and 
Immunomodulation by dietary fibres

enzymatically modified. Mechanistic studies on LA and BA were performed to determine whether Dectin-1 and the Syk dependent carbohydrate receptors were involved in the immunostimulation by LA and BA.

\section{MATERIALS AND MethodS}

\section{Substrates}

A collection of 44 fibres substrates, representing a diverse range of plant derived dietary fibres, was used. They were categorized, based on their constituent monosaccharide composition, into 7 categories. The manufacturers information of all substrates are given in table 1. A description of the fibres is given in the results section.

\section{TLR assays}

TLR signalling capacities of the fibres were determined using a reporter assay with Human Embryonic Kidney (HEK) 293 cells (Invivogen, Toulouse, France). These cells express: human TLR2 and TLR6 heterodimers, which recognize lipoteichoic acid (LTA) and lipoprotein lipid anchors of Gram-positive bacteria [10]; human TLR2; human TLR1/2; human TLR4, which recognise LPS (from Escherichia coli (SigmaAldrich, St Louis, USA)) and TLR5, which recognises flagellin. The TLR signalling assays were performed essentially as previously described [11]. Briefly, HEK293 cells were transformed with one of the above mentioned human TLR(s) and pNIFTY, a NF$\kappa \mathrm{B}$ luciferase reporter construct (Invivogen). Additionally, HEK293 cells were transformed with only the pNIFTY [11]. The cells were plated at a concentration of $6 \times 10^{4}$ cells per well in DMEM medium (Invitrogen, Breda, The Netherlands) and put overnight in the incubator at $37^{\circ} \mathrm{C}$. Cells were then stimulated with the different fibres $(400 \mu \mathrm{g} / \mathrm{mL})$ or positive controls in different doses: LPS (1-750 ng/ml), LTA (0.312 $20 \mu \mathrm{g} / \mathrm{mL})$, flagellin $(1.3-1000 \mathrm{ng} / \mathrm{mL})$, PAM3 (64-1000 ng/mL) and PAM2 (40 $\mathrm{ng} / \mathrm{mL}$ ) (all Invivogen) or with medium alone (negative control). The assays were incubated at $37^{\circ} \mathrm{C}$ for 6 hours under a $5(\mathrm{v} / \mathrm{v}) \% \mathrm{CO}_{2}$ atmosphere. Subsequently, the medium was replaced with Bright glow (Promega, Leiden, The Netherlands), and the plates shaken for 5 minutes before measuring the luminescence in a Spectramax M5 (Molecular Devices, Sunnyvale, CA, USA).

\section{Generation of mouse bone-marrow derived dendritic cells (BMDCs)}

To obtain BMDC cells, 6-10 week old TLR2/4 KO C57bl/6 mice were euthanized, femurs were isolated, washed and gently crushed in $10 \mathrm{~mL}$ of RPMI-1640 medium (without HEPES) supplemented with 100 units/mL penicillin G (Invitrogen) and 100 $\mu \mathrm{g} / \mathrm{mL}$ streptomycin (Invitrogen). Cells were filtered using a Steriflip ${ }^{\circledR}$ Filter Unit (Millipore, Billerica, MA, USA) and around 2-4 x $10^{4}$ cells per well were seeded in a 96-well flat bottom plate in complete media (RPMI-1640 medium, containing: $10 \%$ heat-inactivated Fetal Calf Serum (Sigma-Aldrich, St. Louis, MO, USA), 100 units/mL penicillin $\mathrm{G}, 100 \mu \mathrm{g} / \mathrm{mL}$ streptomycin, $20 \mathrm{ng} / \mathrm{mL}$ of recombinant mouse granulocyte- 
macrophage colony-stimulating-factor (GM-CSF) (R\&D Systems, Minneapolis, MN, USA) and $0.05 \mathrm{mM}$ of $\beta$-mercaptoethanol (Invitrogen)). Cells were incubated at $37^{\circ} \mathrm{C}$ in $5 \%(\mathrm{v} / \mathrm{v}) \mathrm{CO}_{2}$ atmosphere and medium was changed every three days. At day six BMDCs were stimulated with $400 \mu \mathrm{g} / \mathrm{mL}$ fibre or different doses for the dose-response assays, TLR ligands as mentioned above and depleted zymosan $(20 \mu \mathrm{g} / \mathrm{mL})$ (Invivogen).

\section{Dectin-1 and Syk tyrosine-kinase pathway}

In order to determine whether Dectin-1 and the Syk dependent carbohydrate receptors were involved in the immunostimulation by LA and BA, BMDC from TLR2/4 KO mice were pre-incubated for one hour with a Dectin inhibitor antibody $(10 \mu \mathrm{g} / \mathrm{mL})$, corresponding isotype $(10 \mu \mathrm{g} / \mathrm{mL})$ or piceattanol $(10 \mu \mathrm{M})$ (all Sigma-Aldrich). Subsequently, LA and BA ( $400 \mu \mathrm{g} / \mathrm{mL})$ were added to the assay. Additionally, cells were stimulated with different doses of fibres $(25,50,200$ and $400 \mu \mathrm{g} / \mathrm{mL})$ and positive control depleted zymosan $(20 \mu \mathrm{g} / \mathrm{mL})$.

\section{Cytokine assays}

Supernatants from the BMDC stimulation assays were collected after stimulation for 24 hours. A cytometric bead-based BD Mouse inflammation kit was used to measure the cytokines IL-6, IL-10, IL-12p70 (henceforth referred to as IL-12), interferon- $\gamma$ (IFN $\gamma$ ) (henceforth referred to as IFN), TNF and the chemokine MCP-1. This kit was used for multiplex measurements of cytokines in cell supernatants by flow cytometry according to the manufacturer's protocol (BD Biosciences, Breda, The Netherlands) [12]. The limits of detection, as indicated by the supplier, were 5.0, 17.5, 10.7, 2.5, 52.7 and $7.3 \mathrm{pg} / \mathrm{mL}$ for IL-6, IL-10, IL-12, IFN, MCP-I and TNF, respectively. IFN $\gamma$ levels were all below detection limit and are, therefore, not shown. The flow cytometry data were analysed using the BD FCAP software.

\section{Characterisation of dietary fibres}

\section{Constituent monosaccharide composition}

The constituent monosaccharide composition was determined using a pre-hydrolysis step with $72 \%(\mathrm{w} / \mathrm{w})$ sulphuric acid at $30^{\circ} \mathrm{C}$ for 1 hour, followed by hydrolysis with 1 $\mathrm{M}$ sulphuric acid at $100{ }^{\circ} \mathrm{C}$ for 3 hours. The monosaccharides released, were derivatized to alditol acetates and analysed by gas chromatography using inositol as an internal standard [13]. Uronic acid (UA) in the samples was substantiated by using the colorimetric m-hydroxydiphenyl assay [14] automated on an autoanalyser [15] (Skalar, Breda, The Netherlands).

\section{Protein content}

Total nitrogen content ( $\mathrm{N}$ x 6.25) of the 44 fibres was determined in triplicate with the Dumas method using a Flash EA $1112 \mathrm{~N}$ analyser (Thermo Fisher Scientific, Waltham, MA, USA) and D-methionine for calibration. 
Immunomodulation by dietary fibres

High performance size exclusion chromatography (HPSEC)

The arabinan solutions ( $5 \mathrm{mg} / \mathrm{mL}$ water, RT) were centrifuged (10 min, RT, $18000 \mathrm{x} \mathrm{g}$ ) and the supernatant was analysed for molecular weight distribution by high performance size exclusion chromatography (HPSEC) on an Ultimate 3000 HPLC (Dionex, Sunnyvale, CA, USA) equipped with a Shodex RI-101 refractive index detector (Showa Denko, Tokyo, Japan). Three TSK-Gel columns connected in series (4000-3000-2500 SuperAW; $150 \times 6 \mathrm{~mm}$ ) were used for the analysis. These columns were preceded by a TSK Super AW-L guard column ( 35 x 4.6mm). All columns were from Tosoh Bioscience (Tokyo, Japan) and covered a molecular mass range from 0$250 \mathrm{kDa}$. Twenty $\mu \mathrm{L}$ sample were injected and eluted with $0.2 \mathrm{M} \mathrm{NaNO}_{3}$, at $40{ }^{\circ} \mathrm{C}$ with a flow rate of $0.6 \mathrm{~mL} / \mathrm{min}$. Pullulan molecular-mass standards (Polymer Laboratories, Palo Alto, CA, USA) were used for calibration.

\section{Particle size distribution}

The particle size of LA, BA and SBP was determined using laser light diffraction (Mastersizer 2000, Malvern Instruments, Malvern, UK) equipped with a Hydro SM sample dispersion unit. The aqueous suspensions were analysed in triplicate and averaged. To derive the particle size distribution and average median diameter the Fraunhofer model with an absorption of 0.1 for the particles and a refractive index of 1.33 for water was used.

\section{Chemical and physical treatments of fibres}

Several methods were used to modify or separate the fibres into different fractions. Next, the capacity of these fractions to activate BMDCs and to induce cytokine production was investigated. The unmodified substrates of LA, BA and SBP will be referred to as 'parental' fraction.

\section{Separation by water extraction}

LA, BA and SBP were suspended in millipore water $(10 \mathrm{mg} / \mathrm{mL})$, incubated for 2 hours, then centrifuged (10 min, RT, $18000 \mathrm{x}$ g) and both supernatant and particulate fraction were freeze-dried. The fractions were analysed for their constituent monosaccharide composition and immune-activity on BMDCs as described above. The supernatant fraction will be referred to as 'soluble' and the particulate fraction as 'particulate'.

\section{Ethanol extraction}

In order to remove a-polar components present in the substrate, possibly capable of inducing cytokines in BMDCs, the substrates were suspended in $70 \%(w / w)$ ethanol in a concentration of $10 \mathrm{mg} / \mathrm{mL}$ at RT, then centrifuged (10 min, RT, $18000 \mathrm{x}$ g,) and separated by decanting. After evaporating the ethanol, the soluble fraction and the pellet were freeze dried. The fractions were analysed for their immune-activity and the constituent monosaccharide composition was determined. 


\section{Size separation by sieving}

LA, BA and SBP were separated by sieving (106 $\mu \mathrm{m}$ sieve (Retsch, Haan, Germany)) into a fraction smaller and larger than $106 \mu \mathrm{m}$. The sieve shaker type AS200 digit (Retsch) was set to an amplitude of 50 for $1 \mathrm{~min}$. These samples will be referred to with the prefix `small`or `large`.

\section{Enzyme treatment}

Arabinofuranosidase (Chrysosporium lucknowense [16], $0.95 \mathrm{U} / \mathrm{mg}$ ) was used to remove arabinose-side chains from the (highly) BA to linearize it and make it structurally similar to LA.

BA $(5 \mathrm{mg} / \mathrm{mL})$ in $50 \mathrm{mM}$ sodiumacetate buffer $\mathrm{pH} 5.0$ was incubated with $30 \mu \mathrm{L}$ arabinofuranosidase at $40{ }^{\circ} \mathrm{C}$ at $600 \mathrm{rpm}$ for $0.5,1,2,4,7,24$ and 48 hours. The reaction was stopped by heating the samples for $10 \mathrm{~min}$ at $100{ }^{\circ} \mathrm{C}$ in a water bath. Blanks prepared in buffer, only containing enzyme or arabinans, were incubated similarly as the samples. The incubations were performed in duplicate and the enzyme digesta were analysed for their apparent molecular masses with HPSEC. The immuneactivity was analysed after freeze-drying of the sample.

\section{Statistics}

All statistical tests were performed using GraphPad Prism 5.0 software (GraphPad, San Diego, CA, USA). Data shown are the means and the standard errors of the means (SEM). Data were tested for normality with the D'Agostino and Pearson normality test. Statistical analysis of normally distributed data was performed with the 2 tailed unpaired $\mathrm{T}$ test. Data that did not show normal distribution were analysed with the Welch's correction to determine equal variances between the groups. When the variances were unequal between the groups, the data was analysed using the unpaired $\mathrm{T}$ test with Welch's correction. Differences were considered statistically significant when the $P$ value was $\leq 0.05$.

\section{RESULTS AND DISCUSSION}

\section{Categories of fibres included in the screen}

The collection of 44 dietary fibres were categorized, based on their constituent monosaccharide composition, into 7 classes: 'starchy material', 'cellulosic fibres', 'pectic fibres', 'crude fibres', 'hemicelluloses', 'gums' and 'prebiotics' (Table 1). The fibres of each category have all a common structural characteristic, but many substrate specific, individual variations (monosaccharide and glycosidic linkage composition, solubility and particle size) within each category are possible. These differences in physico-chemical characteristics might lead to differences in immune responses and will be discussed further below.

The fibres in the group of 'starchy materials' are resistant starches (RS) of RS types 2, 3 and 4 . The RS 3 samples consist of quite high portions of digestible starch and are 
partly insoluble (results not shown). All starchy materials are mainly $\alpha(1,4)(1,6)$ linked glucose units, but through different glycosidic linkages, which results in different conformations. RS 4 samples are soluble and consist of chemically modified starches containing all possible glycosyl linkages $[17,18]$.

The fibres of the category 'cellulosic fibres' consist of $\beta(1,4)$ linked glucose moieties [19]. The 'cellulosic fibre' substrates investigated, are commercial products with cellulose as the main component (Table 1). However, depending on the manufacturing process, they still contain some hemicelluloses (e.g. arabinoxylan).

Table 1: Monosaccharide composition of the analysed dietary fibres. RS, resistant starch; Rha rhamnose; Fuc, fucose; Ara, arabinose; Xyl, xylose; Man, mannose; Gal, galactose; Glc, glucose; F:G fructose:glucose.

\begin{tabular}{|c|c|c|c|c|c|c|c|c|c|c|c|}
\hline \multirow{2}{*}{\multicolumn{2}{|c|}{$\begin{array}{c}\text { Sample name } \\
\text { (according to supplier) }\end{array}$}} & \multirow[b]{2}{*}{ Supplier } & \multicolumn{7}{|c|}{$\mathrm{mol} \%$} & \multirow[b]{2}{*}{$\begin{array}{l}\text { Total } \\
\mathrm{w} / \mathrm{w} \%\end{array}$} & \multirow[b]{2}{*}{$\begin{array}{l}\text { Protein } \\
w / w \%\end{array}$} \\
\hline & & & Rha & Ara & Xyl & Man & Gal & $\mathrm{Glc}$ & $\begin{array}{c}\text { Uronic } \\
\text { acid }\end{array}$ & & \\
\hline \multirow{9}{*}{ 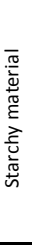 } & Nutriose FM 06, RS 4 & Ingredion (Westchester, IL, USA) & 0 & 0 & 0 & 0 & 0 & 99 & 1 & 86 & 0 \\
\hline & Nutriose FB 06, RS 4 & Ingredion (Westchester, IL, USA) & 0 & 0 & 0 & 0 & 0 & 99 & 1 & 83 & 0 \\
\hline & Soluble corn fiber, RS 4 & Tate \& Lyle (London, United Kingdom) & 0 & 0 & 0 & 0 & 0 & 99 & 1 & 90 & 0 \\
\hline & Sta-Lite Polydextrose, RS 4 & Tate \& Lyle (London, United Kingdom) & 0 & 0 & 0 & 0 & 0 & 97 & 1 & 90 & 0 \\
\hline & Fibersol-2, RS 4 & ADM/Matsutani LLC (Hyogo, Japan) & 0 & 0 & 0 & 0 & 0 & 99 & 1 & 85 & 1 \\
\hline & Resistant wheat dextrin, RS 4 & Roquette (Lestrem, France) & 0 & 0 & 0 & 0 & 0 & 99 & 1 & 87 & 0 \\
\hline & Maize, RS 3 & Nutricia Research (Utrecht, The Netherlands) & 0 & 0 & 0 & 0 & 0 & 99 & 1 & 87 & 3 \\
\hline & Novelose 330, RS 3 & Ingredion (Westchester, IL, USA) & 0 & 0 & 0 & 0 & 0 & 99 & 1 & 82 & 2 \\
\hline & High maiz 260, RS 2 & Ingredion (Westchester, LL, USA) & 0 & 0 & 0 & 0 & 0 & 99 & 1 & 85 & 2 \\
\hline \multirow{5}{*}{ 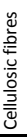 } & Cellulose & Nutricia Research (Utrecht, The Netherlands) & 0 & 0 & 19 & 0 & 0 & 80 & 1 & 66 & 0 \\
\hline & Wheat cellulose & J. Rettenmaier \& Söhne (Rosenberg, Germany) & 0 & 2 & 27 & 0 & 0 & 70 & 2 & 81 & 0 \\
\hline & Oat bran & Megro GmbH \& Co KG (Eppelborn, Germany) & 0 & 2 & 3 & 0 & 0 & 91 & 3 & 59 & 19 \\
\hline & Carboxymethyl cellulose & Sigma-Aldrich (St. Louis, MO, USA) & 0 & 0 & 3 & 0 & 0 & 94 & 3 & n.a. & 0 \\
\hline & Microcrystalline cellulose & Brunschwig Chemie (Amsterdam, The Netherlands) & 0 & 0 & 2 & 2 & 0 & 95 & 1 & 53 & 0 \\
\hline \multirow{10}{*}{ 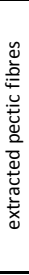 } & Lemon pectin DM67 & CP Kelco (Copenhagen, Denmark) & 1 & 2 & 0 & 0 & 4 & 1 & 92 & 86 & 2 \\
\hline & Lemon pectin DM30 & CP Kelco (Copenhagen, Denmark) & 0 & 0 & 0 & 0 & 3 & 0 & 96 & 82 & 3 \\
\hline & Apple pectin DM63 & Herbstreith \& Fox KG (Neuenbürg, Germany) & 1 & 3 & 2 & 0 & 6 & 2 & 87 & 72 & 13 \\
\hline & Apple pectin DM41 & Herbstreith \& Fox KG (Neuenbürg, Germany) & 1 & 1 & 1 & 0 & 4 & 2 & 92 & 83 & 2 \\
\hline & Sugar beet pectin (SBP) & DuPont (Brabrand, Denmark) & 2 & 6 & 0 & 0 & 12 & 2 & 78 & 73 & 5 \\
\hline & Linear arabinan (LA) & British sugar (Peterborough, United Kingdom) & 3 & 60 & 0 & 0 & 17 & 6 & 13 & 69 & 3 \\
\hline & Branched arabinan (BA) & British sugar (Peterborough, United Kingdom) & 1 & 74 & 0 & 1 & 13 & 3 & 9 & 67 & 2 \\
\hline & Soy pectin & Fuji Oil Co. Ltd (Osaka, Japan) & 2 & 27 & 7 & 0 & 42 & 3 & 20 & 68 & 5 \\
\hline & Pectin hydrolysed & Nutricia Research (Utrecht, The Netherlands) & 1 & 2 & 0 & 0 & 4 & 1 & 92 & 93 & 3 \\
\hline & Potato galactan & Megazyme (Bray, Ireland). & 2 & 4 & 0 & 0 & 73 & 1 & 20 & 66 & 2 \\
\hline \multirow{8}{*}{ 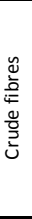 } & Wheat bran & The King Milling Company (Lowell, MA, USA) & 0 & 18 & 32 & 1 & 2 & 42 & 4 & 48 & 14 \\
\hline & Barley bran & Cargill (Vilvoorde, Belgium) & 0 & 7 & 11 & 1 & 0 & 79 & 2 & 58 & 18 \\
\hline & Rye bran & CSM (Bremen, Germany) & 0 & 12 & 33 & 2 & 2 & 47 & 4 & 55 & 16 \\
\hline & Oat cellulose & White Star GmbH (Thannhausen, Germany) & 0 & 4 & 44 & 0 & 0 & 50 & 3 & 75 & 0 \\
\hline & Soy bran & Caj. Strobl-Naturmühle GesmbH (Linz-Ebelsberg, Austria) & 1 & 9 & 11 & 9 & 6 & 43 & 21 & 48 & 7 \\
\hline & Soy fibre & Fuji Oil Co. (Osaka, Japan) & 1 & 20 & 8 & 2 & 36 & 18 & 16 & 68 & 10 \\
\hline & Apple fibre & GoodMills Innovation GmbH (Hamburg, Germany) & 1 & 11 & 5 & 8 & 6 & 45 & 24 & 55 & 7 \\
\hline & Sugar beet cellulose & Nordic sugar A/S (Copenhagen, Denmark) & 2 & 28 & 3 & 2 & 7 & 26 & 33 & 63 & 9 \\
\hline \multirow{5}{*}{ 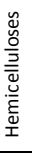 } & Wheat arabinoxylan & Megazyme (Bray, Ireland). & 0 & 35 & 67 & 0 & 0 & 0 & 0 & 82 & 1 \\
\hline & Rye arabinoxylan & Megazyme (Bray, Ireland). & 0 & 31 & 67 & 0 & 1 & 0 & 1 & 74 & 1 \\
\hline & Arabinoxylan & Kelloggs (Battle Creek, MI, USA) & 0 & 14 & 69 & 0 & 0 & 15 & 1 & 85 & 0 \\
\hline & Oat $\beta$-glucan & Megazyme (Bray, Ireland). & 0 & 0 & 0 & 0 & 0 & 99 & 1 & 100 & 1 \\
\hline & Barley $\beta$-glucan & Megazyme (Bray, Ireland). & 0 & 0 & 0 & 0 & 0 & 99 & 1 & 99 & 0 \\
\hline \multirow{3}{*}{$\sum_{5}^{n}$} & Gum guar & C.E. Roeper GmbH (Hamburg, Germany) & 0 & 3 & 1 & 57 & 34 & 4 & 2 & 73 & 6 \\
\hline & Locust bean gum & CP Kelco (Copenhagen, Denmark) & 0 & 0 & 0 & 64 & 16 & 17 & 2 & 80 & 0 \\
\hline & Gum arabic & Nutricia Research (Utrecht, The Netherlands) & 4 & 43 & 0 & 0 & 39 & 0 & 14 & 73 & 1 \\
\hline \multirow{4}{*}{ 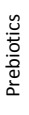 } & GOS Vivinal & Friesland Campina (Wageningen, The Netherlands) & 0 & 0 & 0 & 0 & 48 & 51 & 1 & 51 & 1 \\
\hline & FOS Chicory & Nutricia Research (Utrecht, The Netherlands) & \multicolumn{7}{|c|}{$F: G=22$} & 91 & 0 \\
\hline & Inulin chicory & Nutricia Research (Utrecht, The Netherlands) & \multicolumn{7}{|c|}{$F: G=13$} & 95 & 0 \\
\hline & Inulin chicory high DP & Nutricia Research (Utrecht, The Netherlands) & \multicolumn{7}{|c|}{$F: G=45$} & 88 & 1 \\
\hline
\end{tabular}


The extracted 'pectic fibres', is a heterogeneous class of dietary fibres, that all have in common to consist of a homogalacturonan backbone. Depending on the origin (lemon, apple, sugar beet), these homogalacturonan sequences are differently decorated with methyl esters and acetyl groups and/or interspersed with stretches of rhamnogalacturonan I backbone having arabinan and galactan sidechains. These decorations and interspersing influence their solubility [20, 21].

Hemicelluloses are represented by $\beta(1,3)(1,4)$ glucans and arabinoxylans from wheat, rye and oat. Arabinoxylans consist of different ratios of arabinose and xylose. $\beta(1,4)$ Linked xyloses form a backbone, which can be mono- or di-substituted by arabinose at positions O-2 or O-3 [22]. The $\beta(1,3)(1,4)$ linked glucans of different origins vary in their DP3/DP4 ratio [23, 24].

The substrates presented in the 'prebiotic' category are oligosaccharides consisting of glucose linked with different amounts of fructose or galactose, for fructooligosaccharides (FOS) or galactooligosaccharides (GOS) [25, 26], respectively. The sample inulin chicory consists mainly of DP 2-15, while the inulin chicory high DP consists of fructans with DP 10-30 [27]. All three fructans consist of different fructose/glucose ratios as indicated in table 1 and was analysed by quantification of enzymatically released glucose and fructose by HPAEC [27].

The 'crude fibres' are by-products from the agro industry and include brans from the flour production, soy bean flour from the oil production and remaining apple pomace from juice production. 'Crude fibres' are typically characterized as a complex mixture of different fibres, such as cellulose, $\beta$-glucan, arabinoxylan and/or pectins, present in different ratios and of different structures, depending on the source [28, 29]. Additionally, the 'crude fibres' (except oat cellulose) and soy- and apple fibre samples contained relatively high amounts of proteins (6-19 w/w\%) in comparison to the rest of the fibre samples, which contained $<6 \mathrm{w} / \mathrm{w} \%$ protein, except apple pectin DM63 and oat bran (Table 1).

Overall, it can be concluded that a given product name for a fibre sample is not always indicative for its content. Within each category every fibre has a unique chemical structure, as indicated by the monosaccharide composition, which might lead to unique substrate properties.

\section{TLR signalling by fibre samples}

In a preliminary screening, several of the 44 fibres described above activated human peripheral blood mononuclear cells (PBMCs), thereby suggesting that they might have immunostimulatory activities (data not shown). To be able to distinguish between such an immunostimulatory activity and possible contamination with MAMPs, such as LPS, we screened each fibre for its capacity to induce TLR signalling, as this would indicate potential contamination with MAMPs. Embryonic HEK293 reporter cells expressing different human TLR receptors and carrying the reporter plasmid pNifty, which expresses luciferase in response to activation of NF- $\mathrm{KB}$ were used. Luciferase 30 
Immunomodulation by dietary fibres

expression was induced in all TLR reporter cell lines by TNF- $\alpha$ and only the specific TLR agonists induced significant expression of luciferase in the TLR reporter cell line (Supplementary Figure 1). The induced NF-kB activation and luciferase activity was in a dose-dependent fashion. None of the TLR2 agonists tested (i.e. Pam2CSK4, lipoteichoic acid and Pam3CSK4) activated NF- $\mathrm{KB}$ in the TLR4 reporter cell line, thereby showing its specificity for LPS. In contrast LPS, a TLR4 agonist, induced NF$\kappa \mathrm{B}$ activation in the TLR2 reporter cell line possibly due to cross-recognition via the TLR2 lipid-binding pocket. In the TLR5 reporter cell line only flagellin activated NF$\kappa B$, whereas flagellin weakly activated NF- $\kappa B$ in the TLR2 and TLR4 reporter cells at the highest concentrations (Supplementary Figure 1), possibly due to contamination with small amounts of other bacterial MAMPs.

Some of the immunostimulatory fibres, notably arabinoxylans, most 'crude fibres', linear arabinan and some other members of the 'pectic fibres' category strongly activated NF- $\mathrm{KB}$ in both the TLR2 and TLR4 reporter cells, suggesting they were contaminated with bacterial MAMPs (Figure 1). Indeed, measurements of LPS revealed that it was present in the above mentioned fibre substrates (data not shown). None of the fibres significantly activated NF- $\mathrm{KB}$ in HEK293 cells carrying only pNifty and not expressing pattern-recognition receptors (PRRs) (e.g. C-type lectin receptors, such as Dectin-1).

\section{CLR but not TLR agonists induce cytokine secretion in BMDCs from TLR2/4 knockout mice}

Although some of the fibres induced cytokine responses in PBMCs, they also induced TLR2 and TLR4 signalling suggesting contamination with MAMPs. Hence, we decided to use bone marrow derived dendritic cells (BMDCs) from TLR2/4 knockout mice (KO) to test the immunomodulatory properties of the fibres. Dendritic cells (DCs) were chosen because they are known to express several receptors of the C-type lectin family that might bind to carbohydrate structures in fibres [30]. To validate the suitability of these cells, BMDCs from TLR2/4 KO mice were stimulated with a wide range of concentrations of different purified agonists (LPS, LTA, flagellin, $\mathrm{Pam}_{3} \mathrm{CSK} 4$ ) (Supplementary Figure 2). None of the TLR2 and 4 agonists tested elicited significant amounts of cytokines, while they induced strong immune responses in BMDCs from wild-type mice (data not shown). Flagellin did not elicit cytokine responses in BMDCs from knockout or wild type mice, and a similar finding has been described previously [31]. Zymosan, depleted of TLR activity, was included as a positive control and showed that the activation of DCs via Dectin-1 receptor could be used (Supplementary Figure 2). These results showed that BMDCs from TLR2/4 KO mice do not respond via TLR2 and 4, but do respond via C-type lectin receptors e.g. Dectin-1. 

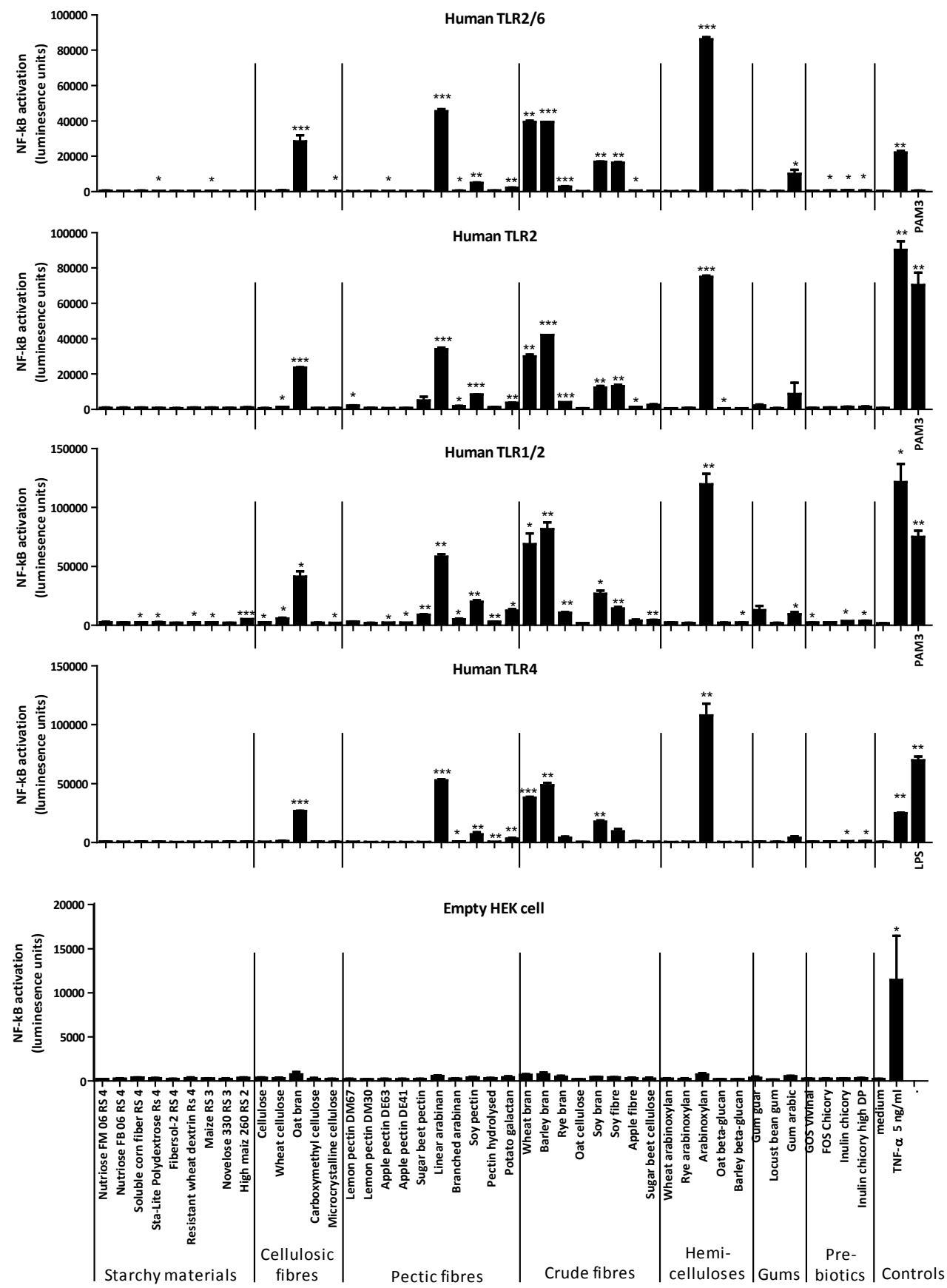

Figure 1: TLR signalling response to different fibres. HEK293 cells were incubated with different fibres $(400 \mu \mathrm{g} / \mathrm{mL})$ and positive controls (TNF $(5 \mathrm{ng} / \mathrm{mL})$, PAM3 $(200 \mathrm{ng} / \mathrm{mL})$, and LPS $(250 \mathrm{ng} / \mathrm{mL})$. Stars represent classes of statistically significant different responses compared to the medium control (* $\mathrm{P}<0.05,{ }^{* *} \mathrm{P}<0.01$ and $\left.{ }^{* * *} \mathrm{P}<0.0001\right)$. 
Immunomodulation by dietary fibres

In conclusion, BMDCs from TLR2/4 knockout mice are a reliable approach to analyze the immunomodulatory properties of a diverse range of dietary fibres, by avoiding immune cell activation due to contaminating microbial TLR agonists. The latter has to date been a major problem in the field.

\section{Several fibres induce cytokine secretion in BMDCs from TLR2/4 KO mice}

Several fibres, including many of the category 'crude fibres', 'cellulosic-' and 'pectic fibres' (SBP, LA, and BA) and some resistant starches (RS types 2 \& 3) induced significant secretion of cytokines in BMDCs from TLR2/4 KO mice compared to nonstimulated control cells (Figure 2). As these BMDCs did not respond to high doses of bacterial MAMPs, we concluded that the fibres were inducing cytokine secretion through interactions with different receptors, for example CLRs. Further evidence for this hypothesis comes from the finding that some fibres, such as cellulosic fibres, did not possess any TLR signalling activity in TLR reporter cell lines, but were signalling in the BMDC assays (Figures 1 and 2). The responses to fibres were not due to cell toxicity as we determined the proportion of live cells using an Annexin V/ propidium iodide staining in BMDCs stimulated with different fibres, depleted zymosan and in unstimulated cells (data not shown). Some dietary fibres induced amounts of cytokines (Figure 2) strikingly different from those produced by members of the same class e.g. brans and some pectic fibres. This suggests that their immunomodulatory properties are influenced by the different physico-chemical properties of the individual fibre.

To rule out immune stimulation from other than carbohydrate compounds, fibres were washed with $70(\mathrm{v} / \mathrm{v}) \%$ ethanol to remove a-polar compounds that might have an immune-stimulating activity. In this solvent, almost all polysaccharides are insoluble. The suspension in ethanol was separated in soluble and particulate fractions, dried and tested at the same concentration $(400 \mu \mathrm{g} / \mathrm{mL})$ for their capacity to stimulate cytokine secretion by BMDCs from TLR2/4 KO mice. The ethanol soluble fraction in general represented less than ca. $6 \mathrm{w} / \mathrm{w} \%$ of the starting material. Most of these fractions did not induce cytokine secretion, ethanol soluble fractions that induced cytokines consisted of either small oligosaccharides or other (polar) compounds, which had been solubilized in $\mathrm{EtOH}$. Compounds as present in the dried $\mathrm{EtOH}$ fraction were tested at much higher doses (data not shown) than they occur in the parental fibre, we concluded that the strongest immunostimulatory activity was associated with the ethanol insoluble fibres.

Thus, the immunomodulatory properties are specific for each fibre and a general conclusion about the immunomodulatory properties cannot be based simply on the fibre category. 

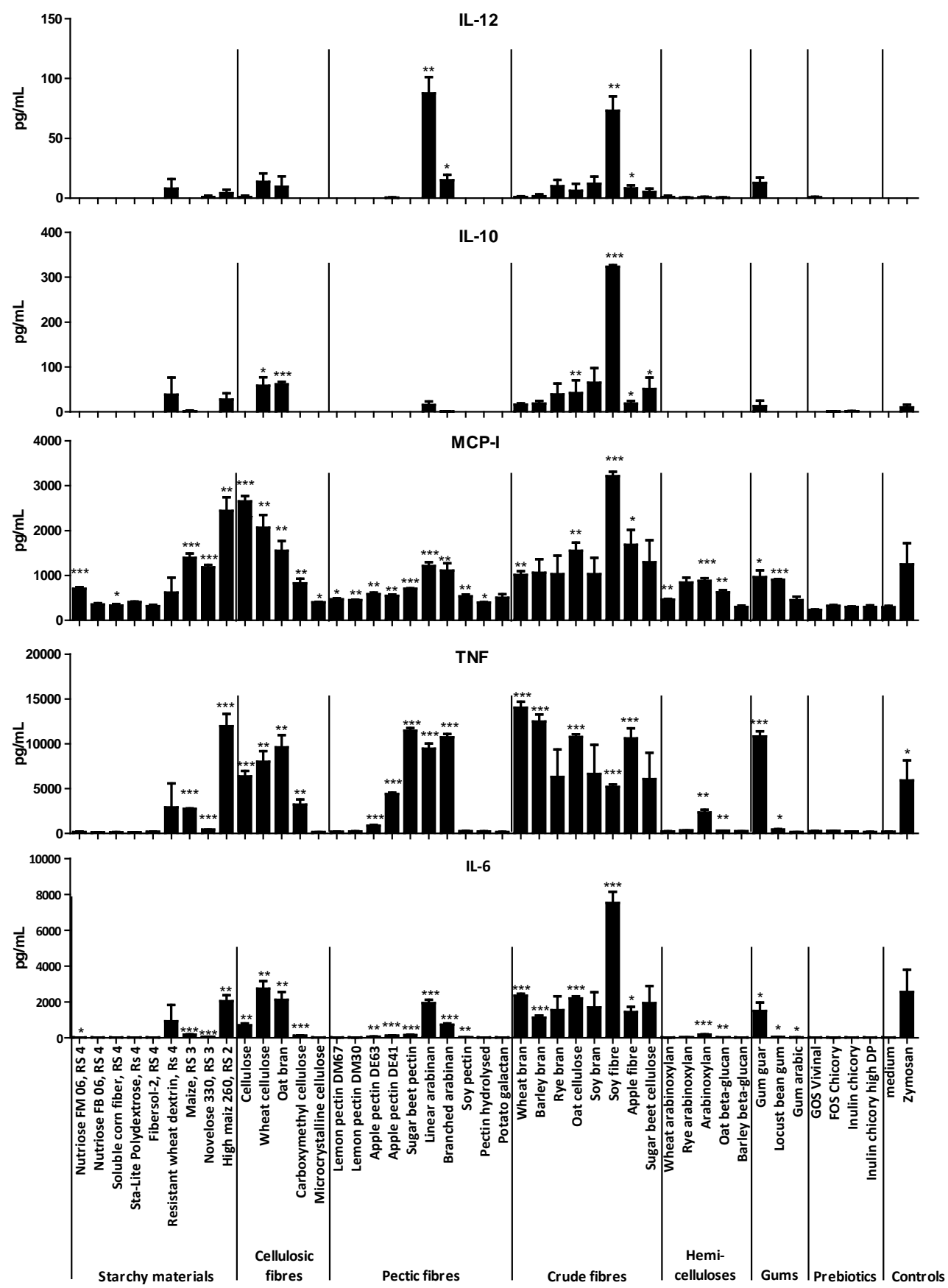

Figure 2: BMDC from TLR2/4 KO mice cytokine response to different fibres. Cells were incubated with different fibres $(400 \mu \mathrm{g} / \mathrm{mL})$ and positive control depleted zymosan $(20 \mu \mathrm{g} / \mathrm{mL})$. Stars represent classes of statistically significant different responses compared to the medium control $(* \mathrm{P}<0.05, * *$ $\mathrm{P}<0.01$ and $* * * \mathrm{P}<0.0001)$. 
Immunomodulation by dietary fibres

\section{Sugar beet pectin, linear arabinan and branched arabinan differentially induce cytokine secretion in BMDCs}

We decided to focus further studies on the LA and BA as well as SBP, as these extracted pectic polymers originated all from sugar beet pulp [32, 33], had the same monosaccharide composition, but different immunomodulatory properties (Table 1, Figure 3). SBP is an acidic extract from sugar beet pulp and besides the galacturonic acid backbone, only short galactan and arabinan side chains are present [34]. BA is an alkali extract from sugar beet pulp and consists of pectin backbone remnants with branches from the arabinan side chains. LA is derived from BA by enzymatically removal of the arabinan side chains. LA, BA and SBP consist of 19, 2 and $63 \mathrm{w} / \mathrm{w} \%$ particulate material, respectively.

In order to identify the bioactive compound, the parental, soluble and particulate fractions of LA, BA and SBP were incubated with BMDCs from TLR2/4 KO mice in an independent experiment. This resulted in different amounts of induced cytokines for LA, BA and SBP than in the screen of all fibres. However, the results shown in Figure 3 are representative for multiple immunoassays. These three fibres differentially induced cytokines in the BMDCs in their 'parental-suspended' form, 'soluble' or 'particulate' fraction (Figure 3). The 'particulate' LA and BA fractions induced significant higher amounts of TNF, IL-6 and IL-10 compared to the 'parentalsuspended' and 'soluble' samples (Figure 3). In contrast, the MCP-1, IL-10 and IL-6 responses to 'particulate' BA were lower than those to 'particulate' LA at the same concentration. The obvious importance of the particulate fractions to activate BMDCs via Dectin-1 has been observed previously for particulate yeast $\beta$-glucans, which clusters Dectin-1, allowing Syk to be recruited intracellularly and trigger activation of NF- $\mathrm{kB}$ through a signalling cascade [35].

SBP samples tested induced significant amounts TNF and MCP-1, but not IL-6 or IL10 (Figure 3). When the soluble and particulate LA fractions were incubated with BMDCs at the concentration as present in the parental material 81 (w/w\%) and 19 (w/w\%), respectively, it seems that the soluble LA molecules behave as an antagonist for the particulate LA material. This can be concluded based on the fact that the particulate LA makes up only 19 (w/w\%) of the parental material, but induces larger amounts of cytokines in BMDCs than the suspended parental LA. Particulate BA, which makes up only $2 \mathrm{w} / \mathrm{w} \%$ of the parental material induces ca. $50 \%$ of TNF induced by the suspended parental BA at equally dosed concentrations (Figure 3). Hence, this shows that the particulate BA has most immune stimulatory activity. To further explore the reasons for the immune-modulating differences between these three fibres, we investigated their chemical and physical characteristics. 


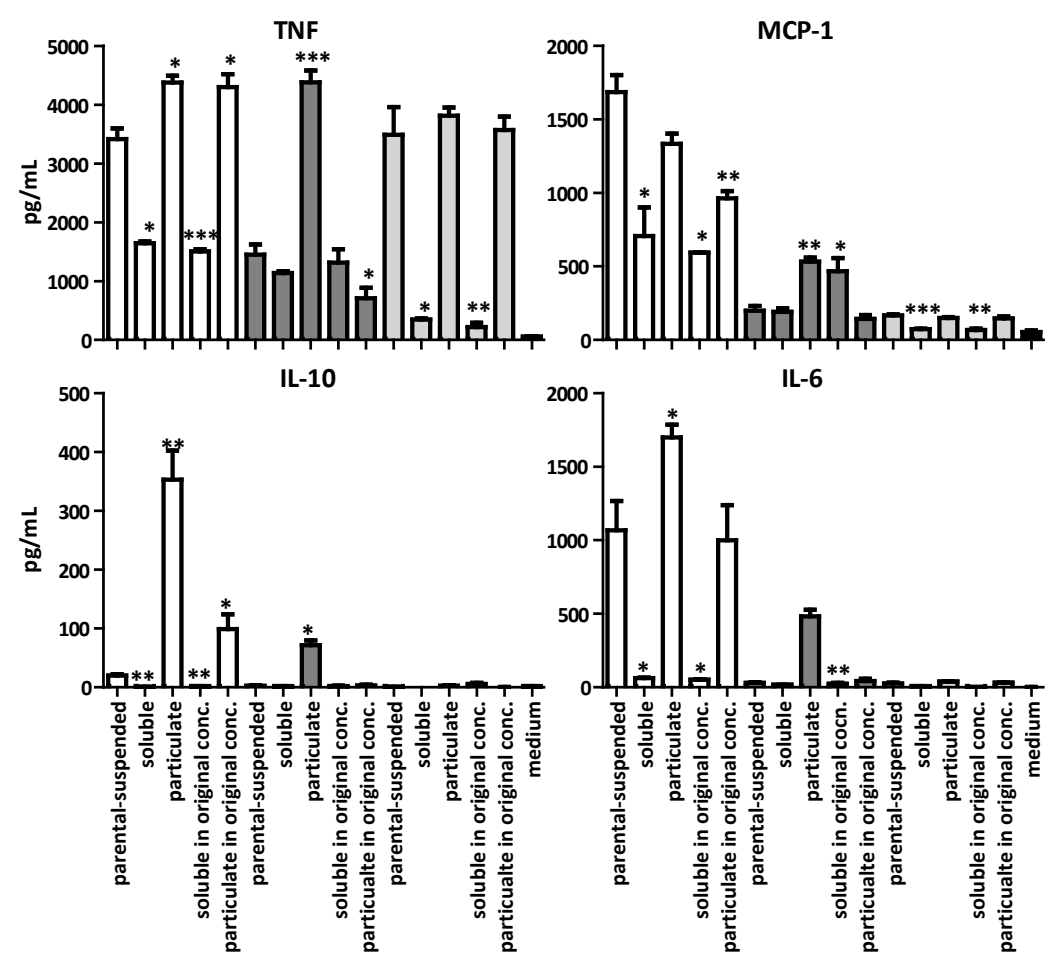

Figure 3: Cytokine response to LA (white), BA (dark grey) and SBP (light grey) fractions. Stars represent classes of statistically significant different responses compared to the parental-suspended fibre $\left(* \mathrm{P}<0.05,{ }^{* *} \mathrm{P}<0.01\right.$ and $\left.{ }^{* * *} \mathrm{P}<0.0001\right)$.

\section{Particle size distribution of the arabinans}

The particle size distributions of the three fibres were significantly different in terms of average median particle size and distribution pattern (Figure 4). The particulate LA fraction is normally distributed with the size of 80 volume \% fraction in the range of 13-227 $\mu \mathrm{m}$. The average median LA particle size is $59 \mu \mathrm{m}$.

The particle size distribution of BA consists of one main, normally distributed population and two small populations. The size of 80 volume $\%$ fraction ranges from 0.8-6.3 $\mu \mathrm{m}$ with an average median of $2.1 \mu \mathrm{m}$. The two other small populations, which make up only a small part, have an average size of 24.7 and $106.9 \mu \mathrm{m}$.

Despite the difference in particulate size between the BA and LA substrates, sieving both dry materials into two fractions of small and large particles did not lead to different cytokine responses when incubating the individual fractions with BMDCs (data not shown). In contrast to BA and LA, the sieved large fraction of SBP, induced significantly lower amounts of cytokines than the small sized fraction (data not shown). This might be due to a lower solubility and higher inhomogeneity of the large SBP fraction as previously found for cereal $\beta$-glucans [36]. Overall, the results indicate that 
different particle size distributions do not account for the different immunomodulatory activities of LA and BA.

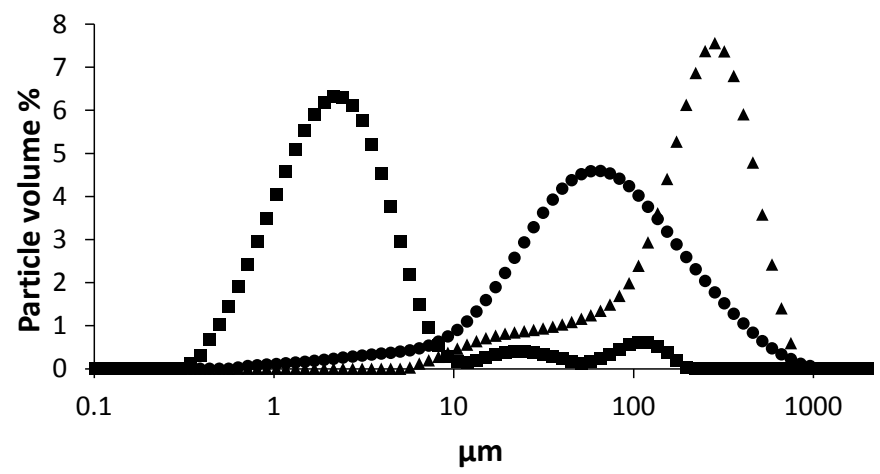

Figure 4: Particle size distribution of suspended BA $(\boldsymbol{\bullet})$, LA $(\bullet)$ and SBP $(\boldsymbol{\Delta})$ analysed with mastersizer.

\section{Hydrodynamic volume of the arabinans}

There are many studies stating that the molecular mass of dietary fibres as glucans, mannans, galactans and fructans influences their immunostimulatory activity, as reviewed in [8]. Although the soluble fractions were less immunomodulatory than the particulate fibre fraction (Figure 3), the molecular mass of the three substrates was analysed for differences with HPSEC (elution patterns not shown). BA and LA have rather similar average molecular masses of 78 and $72 \mathrm{kDa}$, respectively. Soluble SBP consists of molecules of average molecular mass of $213 \mathrm{kDa}$. The higher molecular mass of SBP in comparison to LA and BA was expected, as BA and LA represent mainly side chain remnants of the native SBP. As the molecular masses distributions of BA and LA were rather similar, it is unlikely that this is the reason for their different immunomodulatory activities.

\section{Constituent monosaccharide composition of the soluble and particulate arabinans}

In order to zoom in on differences of soluble and particulate fractions, their monosaccharide composition (Table 2) were determined. The parental BA consists of $74 \mathrm{~mol} \%$ arabinose, $13 \mathrm{~mol} \%$ galactose and $9 \mathrm{~mol} \%$ uronic acid with a total monosaccharide content of $67 \mathrm{w} / \mathrm{w} \%$. The parental LA consists of $60 \mathrm{~mol} \%$ arabinose, $17 \mathrm{~mol} \%$ galactose and $13 \mathrm{~mol} \%$ uronic acid with a total monosaccharide content of 69 w/w\%. SBP consists mainly of $\alpha(1,4)$ linked galacturonic acid $(78$ mol\%) present in the backbone, while $53 \%$ of all galacturonic acid residues are methyl esterified and 17 $\%$ carry an acetyl group [34]. Side chains of galactose (12 mol\%) and arabinose (6 mol\%) with an average length of ca. 9 residues are attached to the rhamnose within the rhamnogalacturonan backbone. The yields of the particulate BA and LA fractions are 2 and $19 \mathrm{w} / \mathrm{w} \%$, of the parental substrates, respectively (Table 2). Both being immune 
stimulating. The carbohydrate content of particulate BA and LA fractions are 32 and $79 \mathrm{w} / \mathrm{w} \%$, respectively, which leads to only 0.6 and $15 \mathrm{w} / \mathrm{w} \%$ particulate carbohydrates present in the parental BA. As particulate BA and LA were the active fractions of the fibres (Figure 3), their monosaccharide composition was analysed and found to be similar to each other. This could suggest that soluble BA precipitated because it became more linear than the soluble BA and resembled the particulate LA structures, explaining its increased immune activity.

Table 2: Constituent monosaccharide composition of LA, BA, SBP fibres, their particulate and their soluble fractions.

\begin{tabular}{|c|c|c|c|c|c|c|c|c|c|}
\hline \multirow[b]{2}{*}{ Sample } & \multicolumn{7}{|c|}{ (mol\%) } & \multirow[b]{2}{*}{$\begin{array}{c}\text { Total } \\
\text { (w/w\%) }\end{array}$} & \multirow[b]{2}{*}{$\begin{array}{c}\text { Yield } \\
\text { (w/w\%) }\end{array}$} \\
\hline & Rha & Ara & Xyl & Man & Gal & Glc & $\begin{array}{c}\text { Uronic } \\
\text { acid }\end{array}$ & & \\
\hline SBP & 2 & 6 & 0 & 0 & 12 & 2 & 78 & 73 & n.a. \\
\hline $\mathrm{BA}$ & 1 & 74 & 0 & 1 & 13 & 3 & 9 & 67 & n.a. \\
\hline LA & 3 & 60 & 0 & 0 & 17 & 6 & 13 & 69 & n.a. \\
\hline particulate SBP & 3 & 6 & 0 & 0 & 18 & 1 & 71 & 72 & 63 \\
\hline soluble SBP & 1 & 7 & 0 & 0 & 9 & 2 & 81 & 75 & 37 \\
\hline particulate BA & 2 & 69 & 0 & 1 & 12 & 4 & 11 & 32 & 2 \\
\hline soluble BA & 2 & 74 & 0 & 0 & 12 & 3 & 8 & 74 & 98 \\
\hline particulate LA & 1 & 73 & 0 & 0 & 12 & 5 & 9 & 79 & 19 \\
\hline soluble LA & 3 & 53 & 0 & 0 & 22 & 6 & 16 & 63 & 68 \\
\hline
\end{tabular}

\section{Enzymatic linearized BA is more immunostimulatory}

As the LA was more immunostimulatory than BA or SBP, we investigated whether enzymatically linearization of BA could increase its immunomodulation. It was shown for synthetic $\beta$-glucans that the presence of one single glucose side chain linked in $\beta(1,3)$ O-position increased the affinity for Dectin-1 [37]. Indeed, incubation of BA with arabinofuranosidase, which removes the arabinose side chains connected to the arabinose backbone [16], affected the amounts of induced TNF over time (Figure 5). The amount of TNF elicited by the enzyme treated BA samples decreased significantly by $4 \mathrm{~h}$ of enzyme action. Next, it increased more than 3-fold up to 48 hours of enzyme incubation. The other cytokines measured were secreted in low amounts and no effect of enzyme treatment was apparent.

It is likely that a precipitation of particulate substrate due to molecule alignment after linearization took place [38] and that the increased amount of particulate material is responsible for the increased amounts of induced TNF.

Monitoring the molecular mass of the incubated samples indicated that there was no significant shift of the BA molecular masses (data not shown). This was expected, as the molecular mass is determined by the hydrodynamic volume of the backbone chain and the exo enzyme used is known to cleave off only the side chains [39]. This finding provides further support that the linearity is, while the molecular mass is not, influencing induced amounts of TNF by arabinans. 

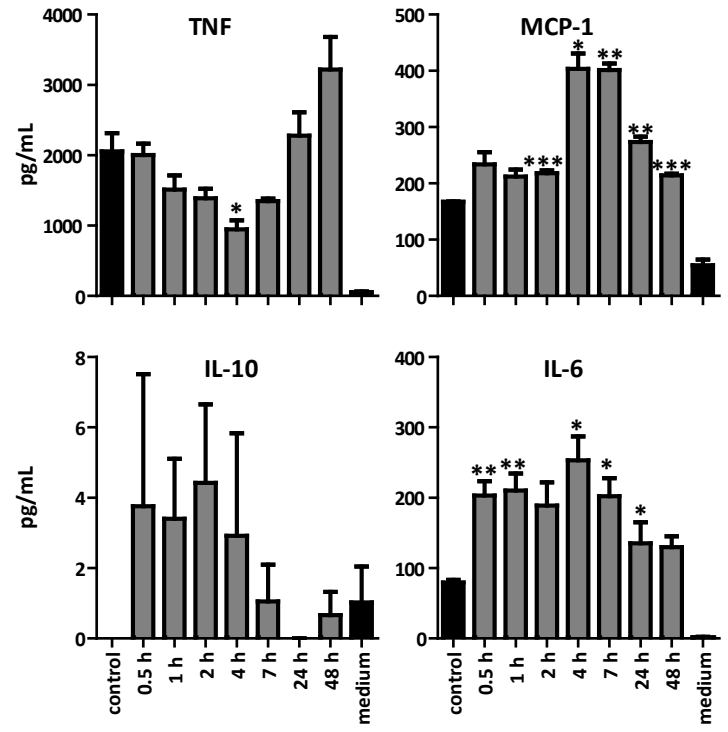

Figure 5: Cytokine response to suspended enzymatically linearized BA incubated for $0.5,1,2,4,7$, 24, $48 \mathrm{~h}$. Stars represent classes of statistically significant different responses compared to the control (BA and enzyme, not incubated) ( ${ }^{*} \mathrm{P}<0.05,{ }^{*} \mathrm{P}<0.01$ and $\left.{ }^{* * *} \mathrm{P}<0.0001\right)$.

\section{The role of Syk kinase in cytokine response to BA and LA}

Dectin-1 is one of several C-type lectin receptors possessing a single cytoplasmic hemiITAM motif that can recruit Syk kinase upon clustering of the receptor signalling complex. Even in MyD88 TRIF knockout mice, that lack TLR-dependent pathways of NF- $\kappa B$ activation, Dectin-1 binding to particulate $\beta(1,3)$ linked glucans can induce Syk-dependent activation of DCs and production of IL-2, IL-6, IL-10, IL-23 and TNF$\alpha$, but little IL-12 [40]. To investigate whether the induction of IL-6, IL-10, IL-12 and TNF were Syk-dependent, we initially determined the dose-dependency of the cytokine response to SBP, BA and LA and the effect of piceatannol, a pharmacological inhibitor of Syk kinase, on cytokine secretion in BMDCs from TLR2/4 KO mice.

As shown above (Figure 3) LA induced significant amounts of IL-6, IL-10, IL-12 and TNF in BMDCs, whereas at the same concentration BA and SBP only induced TNF and MCP-1. Furthermore, LA induced secretion of larger quantities of cytokines than BA and SBP in a dose-dependent fashion (Figure 6). In BMDCs stimulated with LA at the highest dose $(400 \mu \mathrm{g} / \mathrm{mL})$, piceatannol significantly reduced the amounts of secreted IL-6, IL-10, IL-12 and TNF (Figure 6) suggesting that the fibre is inducing cytokines in a Syk-dependent manner. This was not due to an effect of the inhibitor on cell viability as shown by quantification of Annexin $\mathrm{V}$ and propidium iodide stained cells by flow cytometry (data not shown). A significant inhibitory effect of piceatannol on induction of cytokine secretion was also observed for BMDCs stimulated with BA and SBP. To investigate whether SBP, LA and BA interacted with Dectin-1 receptor, we added a blocking antibody (anti-dectin) to Dectin-1 prior to the incubation of the 
fibres with BMDCs and included an isotype control antibody in the assay to rule out non-specific effects of antibody binding (Figure $6 \mathrm{~A}$ and $\mathrm{B}$ ). The anti-dectin antibody significantly reduced the IL-10 induction by LA, but had no significant effect on all other cytokines induced by LA or BA. To control for the ability of the anti-dectin antibody to block the Dectin-1 receptor we added it to BMDCs incubated with depleted zymosan, a known agonist of the Dectin-1 receptor. As expected, anti-dectin strongly reduced the induction of IL-10 and IL-6 by depleted zymosan (Figure 6C). Taken together, these results suggest that LA and BA activate BMDCs and induce cytokine secretion via a Syk-dependent pathway, and through a CLR other than Dectin-1.
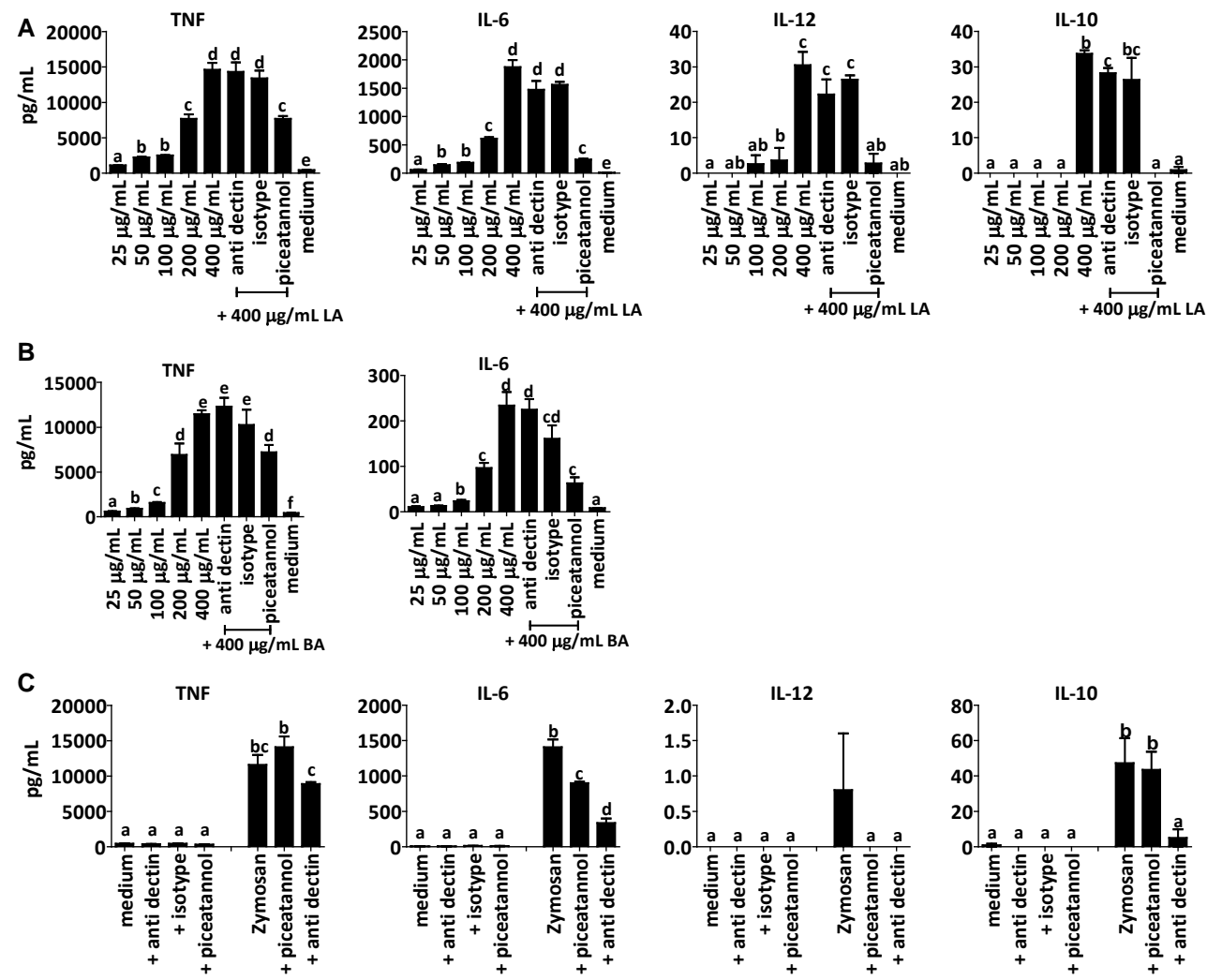

Figure 6: BMDC from TLR2/4 KO mice cytokine response to LA (A) and BA (B) with Syk pathway inhibitor $(10 \mu \mathrm{M})$ and Dectin inhibitor antibody (anti dectin) $(10 \mu \mathrm{g} / \mathrm{mL})$. Cells were incubated with different doses of fibres $(25,50,200$ and $400 \mu \mathrm{g} / \mathrm{mL}$ ) and positive control depleted zymosan (C) (20 $\mu \mathrm{g} / \mathrm{mL}$ ). Different letters represent classes of statistically significant different responses compared to each stimulation.

\section{CONCLUSIONS}

The use of BMDCs from TLR2/4 KO mice was validated as a suitable approach to measure cytokine responses to dietary fibres, while not responding to endotoxin contamination. The 44 screened dietary fibres induced different amounts of cytokines in BMDCs. Fibres being mostly insoluble (crude fibres) and separated particulate 
fractions of SBP, BA and LA were shown to be most immunostimulatory. For arabinans the branching pattern is a crucial immunomodulating structural feature, which is most probably related to formation of precipitates. Furthermore, for LA and BA a new Syk tyrosine-kinase dependent pathway inducing immune response was identified.

\section{ABbreViations}

BA, branched arabinan; LA, linear arabinan; SBP, sugar beet pectin; Ara, arabinose; Gal, galactose; Glc, glucose; Xyl, xylose; Man, mannose; NF-кB, nuclear factor kappalight-chain-enhancer of activated B cells; LPS, Lipopolysaccharides; TNF Tumor necrosis factor; MCP-1 Monocyte chemoattractant protein-1, IL-, interleukin; BMDC, bone marrow derived dendritic cell; TLR, Toll like receptor; HEK cells, Human Embryonic Kidney 293 cells; Mincle, macrophage inducible $\mathrm{Ca}^{2+}$-dependent (C-type) lectin; MAMP, microbial-associated molecular patterns.

\section{ACKNOWLEDGEMENTS}

This work has been funded by TIFN (Top Institute Food and Nutrition) project GH004.2.

\section{REFERENCES}

[1] DeVries, J. W., On defining dietary fibre. Proceedings of the Nutrition Society 2003, 62, 37-43.

[2] European-Commission, Commission Directive 2008/100/EC of 28 October 2008 amending Council Directive 90/496/EEC on nutrition labelling for foodstuffs as regards recommended daily allowances, energy conversion factors and definitions. Official Journal of the European Union 2008, L 285, 9-12.

[3] Cummings, J., Stephen, A., Carbohydrate terminology and classification. European Journal of Clinical Nutrition 2007, 61, S5-S18.

[4] Brown, G. D., Innate antifungal immunity: the key role of phagocytes. Annual Review of Immunology 2011, 29,

[5] Kimberg, M., Brown, G. D., Dectin-1 and its role in antifungal immunity. Medical Mycology 2008, 46, 631-636. [6] Kerrigan, A. M., Brown, G. D., Syk-coupled C-type lectins in immunity. Trends in Immunology 2011, 32, 151156.

[7] Iliev, I. D., Funari, V. A., Taylor, K. D., Nguyen, Q., et al., Interactions between commensal fungi and the C-type lectin receptor Dectin-1 influence colitis. Science 2012, 336, 1314-1317.

[8] Ferreira, S. S., Passos, C. P., Madureira, P., Vilanova, M., Coimbra, M. A., Structure-function relationships of immunostimulatory polysaccharides: A review. Carbohydrate Polymers 2015, 132, 378-396.

[9] Ramberg, J. E., Nelson, E. D., Sinnott, R. A., Immunomodulatory dietary polysaccharides: a systematic review of the literature. Nutrition Journal 2010, 9, 1-22.

[10] Akira, S., Takeda, K., Kaisho, T., Toll-like receptors: critical proteins linking innate and acquired immunity. Nature Immunology 2001, 2, 675-680.

[11] Karczewski, J., Troost, F. J., Konings, I., Dekker, J., et al., Regulation of human epithelial tight junction proteins by Lactobacillus plantarum in vivo and protective effects on the epithelial barrier. American Journal of Physiology-Gastrointestinal and Liver Physiology 2010, 298, G851-G859.

[12] Morgan, E., Varro, R., Sepulveda, H., Ember, J. A., et al., Cytometric bead array: a multiplexed assay platform with applications in various areas of biology. Clinical Immunology 2004, 110, 252-266.

[13] Englyst, H. N., Cummings, J. H., Simplified method for the measurement of total non-starch polysaccharides by gas - liquid chromatography of constituent sugars as alditol acetates. The Analyst 1984, 109, 937-942.

[14] Ahmed, A. E. R., Labavitch, J. M., A simplified method for accurate determination of cell wall uronide content. Journal of Food Biochemistry 1978, 1, 361-365.

[15] Thibault, J., Automatisation du dosage des substances pectiques par la méthode au méta-hydroxydiphenyl. Lebensmittel-Wissenschaft undTechnologie. 1979, 12, 247-251. 


\section{CHAPTER 2}

[16] Kühnel, S., Hinz, S., Pouvreau, L., Wery, J., et al., Chrysosporium lucknowense arabinohydrolases effectively degrade sugar beet arabinan. Bioresource Technology 2010, 101, 8300-8307.

[17] Rösch, C., Venema, K., Gruppen, H., Schols, H. A., Characterisation and in vitro fermentation of resistant maltodextrins using human faecal inoculum and analysis of bacterial enzymes present. Bioactive Carbohydrates and Dietary Fibre 2015, 6, 46-53.

[18] Sajilata, M. G., Singhal, R. S., Kulkarni, P. R., Resistant starch-a review. Comprehensive Reviews in Food Science and Food Safety 2006, 5, 1-17.

[19] O'Sullivan, A., Cellulose: the structure slowly unravels. Cellulose 1997, 4, 173-207.

[20] Voragen, A. G., Coenen, G.-J., Verhoef, R. P., Schols, H. A., Pectin, a versatile polysaccharide present in plant cell walls. Structural Chemistry 2009, 20, 263-275.

[21] Daniel, J., Whistler, R., Voragen, A., Pilnik, W., in: Elvers B., Hawkins S., Russey W. (Eds.), Ullmann's Encyclopedia of Industrial Chemistry, VCH Verlagsgesellschaft, Weinheim, Germany 1994.

[22] Izydorczyk, M. S., Biliaderis, C. G., Cereal arabinoxylans: advances in structure and physicochemical properties. Carbohydrate Polymers 1995, 28, 33-48.

[23] Tosh, S. M., Brummer, Y., Wood, P. J., Wang, Q., Weisz, J., Evaluation of structure in the formation of gels by structurally diverse $(1 \rightarrow 3)(1 \rightarrow 4)-\beta$-D-glucans from four cereal and one lichen species. Carbohydrate Polymers $2004,57,249-259$.

[24] Johansson, L., Structural analyses of (1-> 3),(1-> 4)-B-D-glucan of oats and barley. Ph.D thesis 2006, University of Helsinki, Helsinki, Finland.

[25] Roberfroid, M., Gibson, G. R., Hoyles, L., McCartney, A. L., et al., Prebiotic effects: metabolic and health benefits. British Journal of Nutrition 2010, 104, 1-63.

[26] Ladirat, S., Schols, H., Nauta, A., Schoterman, M., et al., In vitro fermentation of galacto-oligosaccharides and its specific size-fractions using non-treated and amoxicillin-treated human inoculum. Bioactive Carbohydrates and Dietary Fibre 2014, 3, 59-70.

[27] Vogt, L., Ramasamy, U., Meyer, D., Pullens, G., et al., Immune modulation by different types of $\beta 2 \rightarrow 1$ fructans is toll-like receptor dependent. PLoS One 2013, 8, e68367.

[28] Collins, H. M., Burton, R. A., Topping, D. L., Liao, M.-L., et al., Review: Variability in fine structures of noncellulosic cell wall polysaccharides from cereal grains: potential importance in human health and nutrition. Cereal Chemistry 2010, 87, 272-282.

[29] Huisman, M., Schols, H., Voragen, A., Cell wall polysaccharides from soybean (Glycine max.) meal. Isolation and characterisation. Carbohydrate Polymers 1998, 37, 87-95.

[30] Geijtenbeek, T. B., Gringhuis, S. I., Signalling through C-type lectin receptors: shaping immune responses. Nature Reviews Immunology 2009, 9, 465-479.

[31] Dearman, R. J., Cumberbatch, M., Maxwell, G., Basketter, D. A., Kimber, I., Toll-like receptor ligand activation of murine bone marrow-derived dendritic cells. Immunology 2009, 126, 475-484.

[32] McCleary, B. V., Cooper, J. M., Williams, E. L., Debranched araban and its use as af at substitute. Patent US5250306A, USA 1993.

[33] Oosterveld, A., Beldman, G., Schols, H. A., Voragen, A. G., Arabinose and ferulic acid rich pectic polysaccharides extracted from sugar beet pulp. Carbohydrate Research 1996, 288, 143-153.

[34] Remoroza, C., Cord-Landwehr, S., Leijdekkers, A., Moerschbacher, B., et al., Combined HILIC-ELSD/ESI-MS n enables the separation, identification and quantification of sugar beet pectin derived oligomers. Carbohydrate Polymers 2012, 90, 41-48.

[35] Goodridge, H. S., Underhill, D. M., Touret, N., Mechanisms of Fc receptor and Dectin-1 activation for phagocytosis. Traffic 2012, 13, 1062-1071.

[36] Rösch, C., Meijerink, M., Delahaije, R. J., Taverne, N., et al., Immunomodulatory effects of oat and barley $\beta$ glucans on bone marrow derived dendritic cells. This thesis, chapter 3.

[37] Adams, E. L., Rice, P. J., Graves, B., Ensley, H. E., et al., Differential high-affinity interaction of Dectin-1 with natural or synthetic glucans is dependent upon primary structure and is influenced by polymer chain length and side-chain branching. Journal of Pharmacology and Experimental Therapeutics 2008, 325, 115-123.

[38] Beldman, G., Schols, H., Pitson, S., Searle-van Leeuwen, M., Voragen, A., in: Sturgeon, R. (Ed.), Advanced Macromolecular Carbohydrate Research, JAI Press., Greenwich, UK, 1997, pp. 1-64.

[39] Schols, H. A., Posthumus, M. A., Voragen, A. G., Structural features of hairy regions of pectins isolated from apple juice produced by the liquefaction process. Carbohydrate Research 1990, 206, 117-129.

[40] LeibundGut-Landmann, S., Groß, O., Robinson, M. J., Osorio, F., et al., Syk-and CARD9-dependent coupling of innate immunity to the induction of Thelper cells that produce interleukin 17. Nature Immunology 2007, 8, 630638. 


\section{SUPPLEMENTARY DATA:}
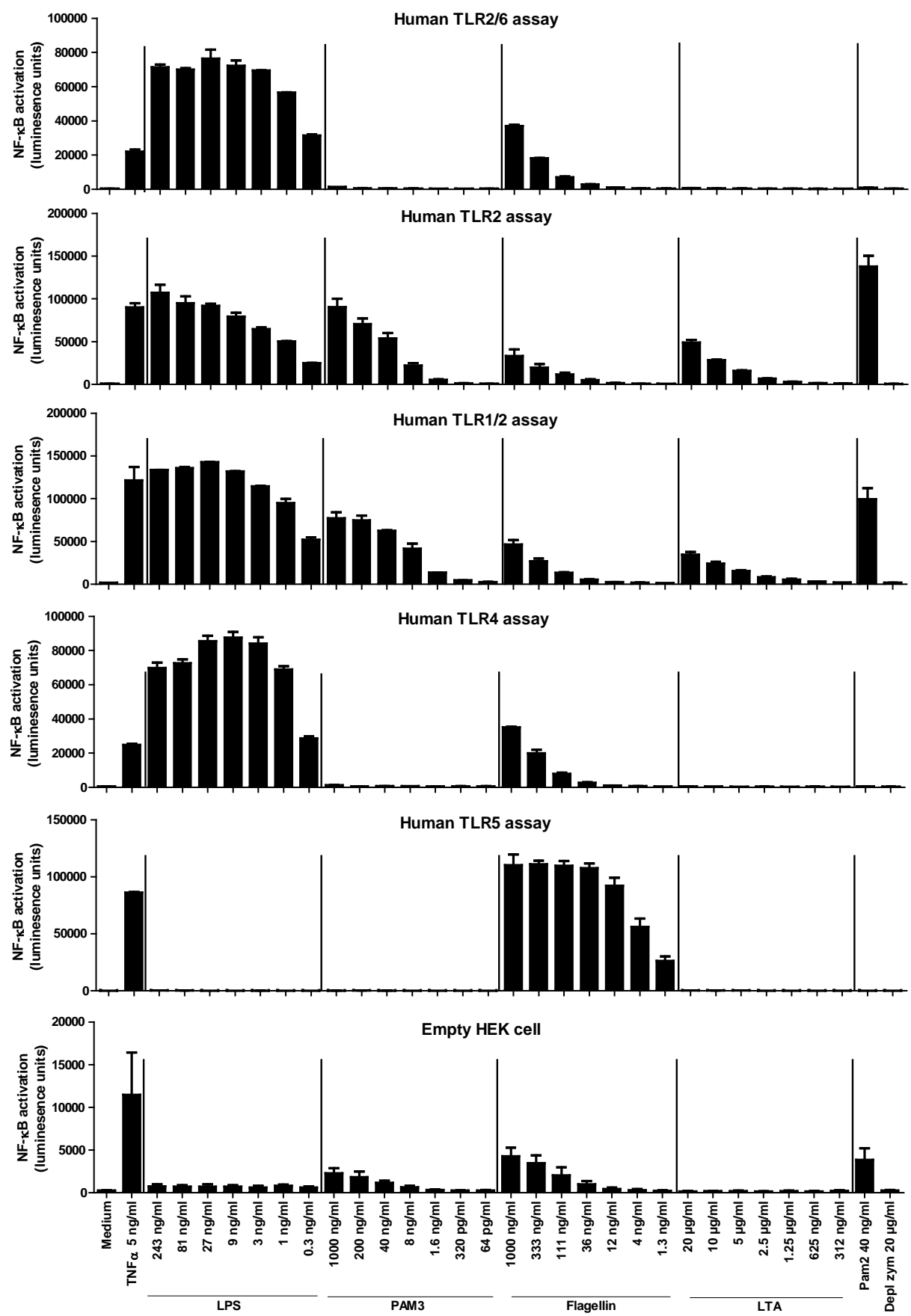

Supplementary Figure 1: TLR signalling response to different ligands. HEK293 cells were incubated with LPS (1 ng/mL-750ng/mL), PAM3 (64 ng/mL-1 $\mu \mathrm{g} / \mathrm{mL})$, flagellin $(1.3 \mathrm{ng} / \mathrm{mL}-1 \mu \mathrm{g} / \mathrm{mL}), \mathrm{LTA}(312$ $\mathrm{ng} / \mathrm{mL}-20 \mu \mathrm{g} / \mathrm{mL})$, PAM2 $(40 \mathrm{ng} / \mathrm{mL})$ and depleted zymosan $(20 \mu \mathrm{g} / \mathrm{mL})$. 


\section{CHAPTER 2}
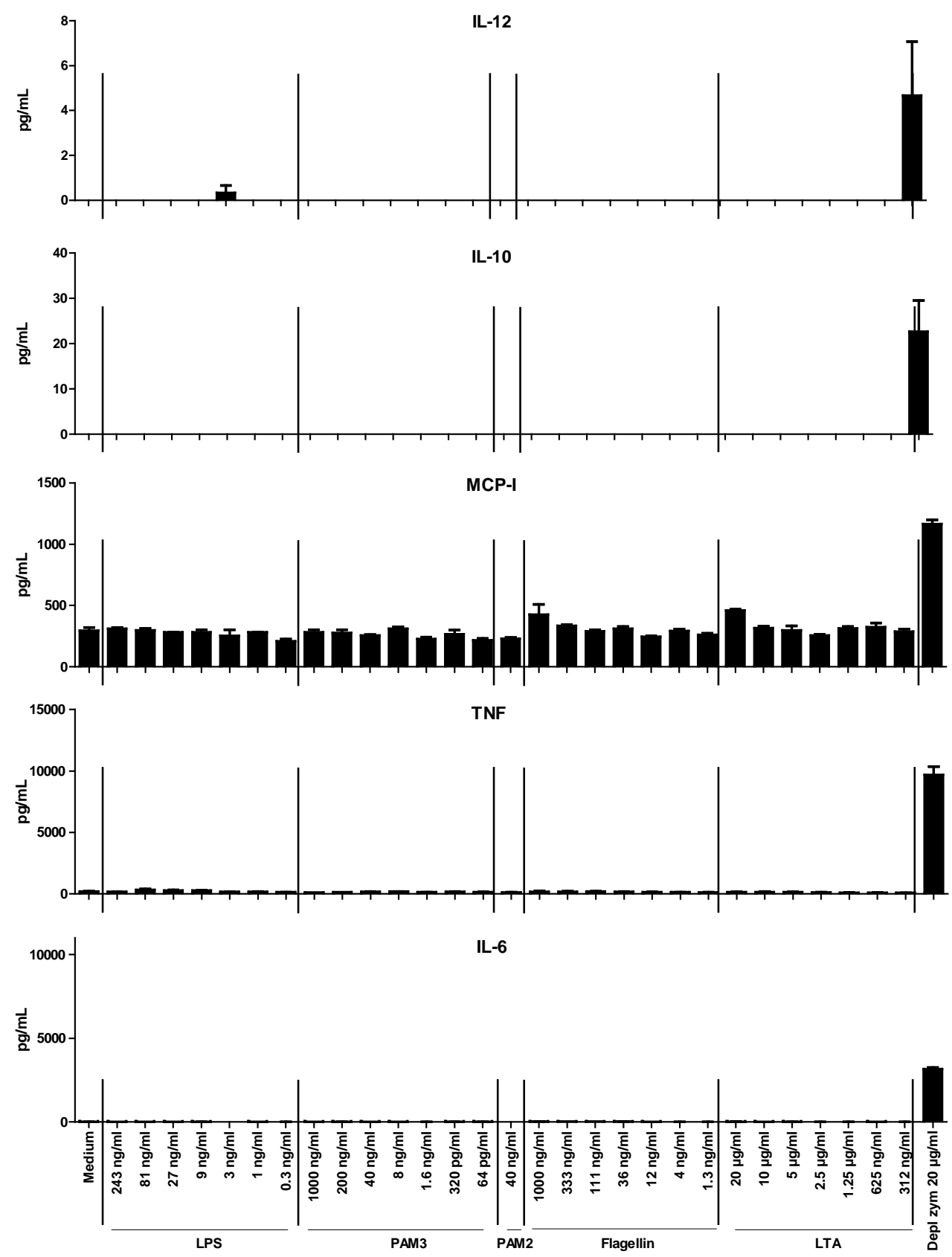

Supplementary Figure 2: BMDC from TLR2/4 KO mice response to different ligands. Cells were incubated with LPS (1 ng/mL-243ng/mL), PAM3 $(64 \mathrm{ng} / \mathrm{mL}-1 \mu \mathrm{g} / \mathrm{mL})$, PAM2 $(40 \mathrm{ng} / \mathrm{mL})$, Flagellin (1.3 $\mathrm{ng} / \mathrm{mL}-1 \mu \mathrm{g} / \mathrm{mL})$, LTA (312 ng/mL-20 $\mu \mathrm{g} / \mathrm{mL})$, and depleted zymosan $(20 \mu \mathrm{g} / \mathrm{mL})$. 


\title{
Chapter 3
}

\section{Immunomodulatory properties of oat and barley $\beta$-glucans on bone marrow derived dendritic cells}

\begin{abstract}
The chemical structural differences between cereal $\beta(1,3)(1,4)$ glucans are well described. Still, it needs to be revealed which $\beta$-glucan characteristics are responsible for in vitro immunomodulatory properties.

Oat and barley $\beta$-glucan powders were separated by water extraction or sieving and heated, homogenised or modified by incubation with enzymes. Subsequently, all fractions were tested for their immunomodulatory capacity on bone marrow derived dendritic cells (BMDC) from mice.

In general, barley $\beta$-glucan fractions induced larger amounts of cytokines in BMDCs than their oat equivalents, which indicates that molecular specificity matters for immunomodulatory activity. The particulate fractions of both glucans induced high amounts of cytokines, when the fraction was homogenised. The higher immunestimulation of small compared to large particulate $\beta$-glucans is suggested to be caused by their naturally higher homogeneity. The soluble fraction and heated suspension behaved similar in immunoassays, inducing only low amounts of cytokines. Nevertheless, immune responses of the soluble $\beta$-glucans differed, which indicates that also molecular specificity matters for immunomodulation.

The key feature influencing the immunomodulatory activity is the insolubility of $\beta$ glucans, to which other characteristics as particle size, granule conformation and particulate homogeneity are related. These findings illustrate the consequences of sample preparation and its influence on the immunomodulatory activity of $\beta$-glucans.
\end{abstract}

Submitted for publication as:

Rösch, C., Meijerink, M., Delahaije, R.J.B.M., Taverne, N., Gruppen, H., Wells, J.M. \& Schols, H. A. (2016). Immunomodulatory properties of oat and barley $\beta$-glucans on bone marrow derived dendritic cells. 


\section{INTRODUCTION}

The immunomodulatory properties of yeast, fungal or bacterial $\beta$-glucans have been studied extensively. In contrast, only few studies have been carried out on the immunomodulatory activity of non-cellulosic $\beta$-glucans derived from cereals (further denoted as $\beta$-glucans).

$\beta$-Glucans from cereals, consisting of $\beta(1,3)(1,4)$ linked glucose moieties, are known to vary in their structure depending on the cereal origin. For example, the ratio of cellotriosyl/cello-tetraosyl (DP3/DP4) repeats is reported to be higher for barley than for oat $\beta$-glucans. The trimers and tetramers are linked to each other via $\beta(1,3)$ glycosidic linkages, while their internal glucoses are linked via $\beta(1,4)$ linkages. It is suggested that the higher the DP3/DP4 ratio of $\beta$-glucans the lower their solubility $[1,2]$.

Solubility, sample preparation, aggregation and molecular structure (DP3/DP4) have been discussed in immunomodulatory studies on cereal $\beta$-glucans as being relevant for their function [3]. Some studies on yeast $\beta$-glucans, which consist of a $\beta(1,3)$ linked backbone with glucose substitution via $\beta(1,6)$ linkage, suggest that the native triple helix conformation, branching pattern of $\beta(1,6)$ linked glucoses, the microstructure achieved during the drying process and the molecular mass are key factors in respect of immunomodulating properties [4-6]. However, the outcomes of previous studies are contradictory, stating, for example, that the molecular mass was either not important at all or that a specific molecular mass range of the $\beta$-glucans accounted for the immunomodulatory effect [5-9]. A study on cereal $\beta$-glucans claims intermediate molecular masses of a rather broad range of $25-215 \mathrm{kDa}$ as being the most immunomodulatory [9], while a study on microbial $\beta$-glucan showed that a molecular mass of $550 \mathrm{kDa}$ was most immune stimulating [6].

The origin and characteristics of the $\beta$-glucan as well as the experimental set up of the immunoassays (cell line, types of cytokines measured and lipopolysaccharide (LPS) contamination levels) vary enormously between studies, making it impossible to conclude which $\beta$-glucan characteristics are responsible for their immunomodulatory effects.

Soluble and particulate $\beta$-glucans of various sources are found to signal via Dectin-1 receptors [10-12]. Dectin-1 is a C-type lectin receptor expressed predominantly on myeloid cells (monocytes/macrophage, dendritic cells and neutrophils) and $\beta(1,3)$ linked glucans have higher affinities to the receptor than $\beta(1,3)(1,4)$ linked glucans [13]. This recognition via Dectin-1 triggers the production of a variety of responses depending on the cell type and co-stimulation through other pattern recognition receptors, such as Toll-like receptors (TLRs). It has been found that Dectin-1 signalling in dendritic cells (DCs) induces maturation and cytokine responses driving adaptive 
immune responses [13]. Although both soluble and particulate $\beta$-glucan polymers can bind to Dectin-1, the receptor differentially recognises glucans based on structural factors as polymer length and side chain branching [14] and signalling seems to be mainly activated by multivalent binding of particulate $\beta$-glucans, causing clustering of the receptor $[10,15]$.

The aim of this study was to investigate the physico-chemical properties responsible for the different immunomodulatory activities of oat and barley $\beta$-glucans on bone marrow derived dendritic cells (BMDCs).

\section{Materials AND MethodS}

\section{Chemicals}

Barley $\beta$-glucans (low viscosity) and oat (medium viscosity) $\beta$-glucans were purchased from Megazyme (Bray, Ireland). Lichenase (1000 U/mL, Lot No MLI82001) was obtained from Megazyme and endoglucanase I was purified from a commercial cellulose preparation derived from Trichoderma viride $(0.64 \mathrm{U} / \mathrm{mL})$, as described elsewhere [16].

LPS from Escherichia coli (Sigma-Aldrich, St Louis, USA), was used as a control to show unresponsiveness of the BMDCs from TLR2/4 knockout mice to this common microbe-associated molecular pattern (MAMP). Depleted (alkali treated) zymosan, a particulate $\beta(1,3)$ glucan cell wall compound from Saccharomyces cerevisiae (Invivogen, Toulouse, France), was used as positive control in the immunoassays.

\section{Chemical, physical and enzymatic analyses}

\section{Constituent monosaccharide composition}

The constituent monosaccharide composition for oat and barley $\beta$-glucans was determined using a pre-hydrolysis step with $72 \%(\mathrm{w} / \mathrm{w})$ sulphuric acid at $30{ }^{\circ} \mathrm{C}$ for 1 hour, followed by hydrolysis with $1 \mathrm{M}$ sulphuric acid at $100{ }^{\circ} \mathrm{C}$ for 3 hours. The monosaccharides released were derivatized to alditol acetates and analysed by gas chromatography using inositol as an internal standard [17]. The absence of uronic acid (UA) in the samples was substantiated by using the colorimetric m-hydroxydiphenyl assay [18] automated on a Skalar autoanalyser (Breda, The Netherlands) as described before [19].

\section{Structural modification and fractionation of $\beta$-glucans}

Several methods were used to modify or separate the parental $\beta$-glucan powders (referred to as 'parental') into different fractions (Figure 1), which were then analysed for induced amounts of cytokines in BMDCs; 
1. 'Parental' $\beta$-glucans were suspended ( $400 \mu \mathrm{g} / \mathrm{mL})$ in RPMI medium and will be referred to as 'suspended' $\beta$-glucans.

2. The 'parental' $\beta$-glucans were suspended in water $(10 \mathrm{mg} / \mathrm{mL})$ for $30 \mathrm{~min}$, then centrifuged (RT, $10 \mathrm{~min}, 18000 \times \mathrm{g}$ ) to separate them into soluble and particulate fractions, followed by freeze-drying. These samples will be referred to as 'soluble' and 'particulate' $\beta$-glucans.

3. 'Parental' $\beta$-glucan suspensions $(10 \mathrm{mg} / \mathrm{mL})$ were heated at $80^{\circ} \mathrm{C}$ for 2 hours to obtain a complete solubilisation. These samples will be referred to as 'heated-soluble' $\beta$-glucans.

4. The solution obtained after heating the suspension was freeze-dried and suspended in RPMI medium. This sample will be referred to as 'hs-fd suspended' (hs, heated-soluble; fd, freeze-dried).

5. The dry $\beta$-glucan powders were separated by sieving (106 $\mu \mathrm{m}$ sieve (Retsch, Haan, Germany)) into fractions smaller and larger than $106 \mu \mathrm{m}$. The sieve shaker type AS200 digit (Retsch) was set to an amplitude of 50 for 1 min. These samples will be referred to with the prefix 'small' or 'large' $\beta$-glucans. These samples are further separated into particulate and soluble fractions as described above.

6. The 'particulate', 'small particulate' and 'large particulate' $\beta$-glucan fractions were suspended in RPMI medium and dispersed using an Ultra-Turrax T 25 (IKA-Werke, Staufen, Germany) with a shear rate of $24000 \mathrm{rpm}$ for $1 \mathrm{~min}$. These samples will be referred to as 'particulate homogenised', 'small particulate homogenised' and 'large particulate homogenised' $\beta$-glucans, respectively.

7. Different weight ratios $(0 / 100,10 / 90,25 / 75,50 / 50,75 / 25,90 / 10$ (particulate/soluble)) of 'particulate' and 'soluble' $\beta$-glucans were either suspended or suspended and homogenised. These samples will be referred to as 'suspended' and 'homogenised' oat and barley.

\section{Enzyme treatment of $\beta$-glucans}

The two parental $\beta$-glucans were suspended at a concentration of $25 \mathrm{mg} / \mathrm{mL}$ in $0.2 \mathrm{M}$ $\mathrm{NaOAc}$ buffer $\mathrm{pH}$ 5.0. Subsequently, $1 \mathrm{~mL}$ was incubated $\left(37^{\circ} \mathrm{C}, 1000 \mathrm{rpm}\right)$ with 20 $\mu \mathrm{L}$ of 100 times diluted lichenase solution for $0.5,3,5$ and 7 hours or with $10 \mu \mathrm{L}$ endoglucanase I for $0.5,3,5,7$ and 24 hours. Blanks of solely substrate or enzyme were incubated for 0 and 7 hours (lichenase) and 0 and 24 hours (endoglucanase I). In one set of experiments all incubations were stopped by heating at $100{ }^{\circ} \mathrm{C}$ for $10 \mathrm{~min}$ and in another experiment by increasing the $\mathrm{pH}$ to 9-10 by addition of $1 \mathrm{M} \mathrm{NaOH}$ for $10 \mathrm{~min}$ and then readjusting to $\mathrm{pH} 5.8$ with glacial acetic acid. Subsequently, the 
samples were freeze-dried and used for the immunoassay and high performance size exclusion chromatography (HPSEC) analysis.

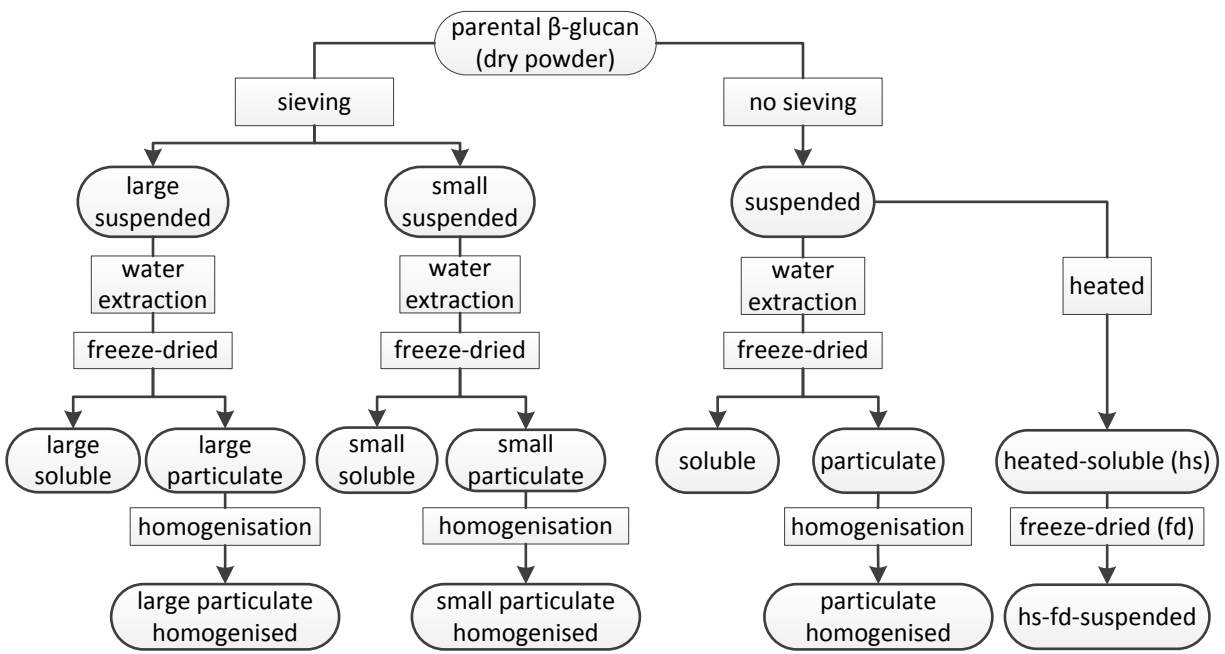

Figure 1: Oat and barley $\beta$-glucan sample preparation scheme. Arrows indicate tested fractions used in immunoassays. hs, heated-soluble; fd, freeze-dried.

\section{High performance size exclusion chromatography (HPSEC)}

The oat and barley $\beta$-glucan digests and parental substrates were suspended $(4 \mathrm{mg} / \mathrm{mL})$ and centrifuged (10 min, RT, $18000 \mathrm{x} g$ ). The supernatant was analysed by HPSEC on an Ultimate 3000 HPLC (Dionex, Sunnyvale, CA, USA) equipped with a Shodex RI101 refractive index detector (Showa Denko, Tokyo, Japan). Three TSK-Gel columns (Tosoh Bioscience, Tokyo, Japan) connected in series (4000-3000-2500 SuperAW; 150 x $6 \mathrm{~mm}$ ) were used for separation. The columns were preceded by a TSK Super AW-L guard column ( $35 \times 4.6 \mathrm{~mm})$. The three columns covered a molecular mass range from 0-250 kDa. Twenty $\mu \mathrm{L}$ of the sample was injected and eluted with $0.2 \mathrm{M} \mathrm{NaNO}_{3}$ at 40 ${ }^{\circ} \mathrm{C}$ at a flow rate of $0.6 \mathrm{~mL} / \mathrm{min}$. Pullulan molecular-mass standards from 0.18 to 212 kDa (Polymer Laboratories, Palo Alto, CA, USA) were used for calibration.

\section{Particle size distribution determination}

The particle size distribution of the $\beta$-glucans and their fractions was determined using laser light diffraction (Mastersizer 2000, Malvern Instruments, Malvern, UK) equipped with a Hydro SM sample dispersion unit. The maximum size of detection was 2000 $\mu \mathrm{m}$. The aqueous suspensions were analysed in triplicate and data were averaged. To derive the particle size distribution, the Fraunhofer model with an absorption of 0.1 for the particles and a refractive index of 1.33 for water were used. 


\section{Asymmetric flow field flow fractionation (AF4)}

AF4 was used to determine the radius and molecular mass of soluble and heatedsoluble $\beta$-glucans by means of in-line multi-angle static light scattering (MALS) combined with RI detection to determine the concentration. An Ultimate 3000 HPLC unit (Dionex) was connected with an Eclipse Dual Tech (Wyatt Technology, Santa Barbara, CA, USA), which contained the flow control valves, MALS (Dawn Heleos-II, $\lambda=658 \mathrm{~nm}, 130 \mathrm{~mW}$ Laser, vertically polarised), RI detector (Optilab T-rEX), flow cell and its various parts (spacer, membrane, porous support plate etc.). The system parameters were controlled by Chromeleon software (Dionex) and for data collection and analysis ASTRA-6 (Wyatt Technology) was used. The flow cell comprised a channel of $145 \mathrm{~mm}$ length, fitted with a spacer of $350 \mu \mathrm{m}$ gap (350 W) and a $10 \mathrm{kDa}$ regenerated cellulose membrane. The carrier liquid was a $10 \mathrm{mM} \mathrm{NaNO}$ solution, filtered through a $0.1 \mu \mathrm{m}$ pore-size cellulose filter.

Oat- and barley $\beta$-glucan suspensions of $4 \mathrm{mg} / \mathrm{mL}$ were prepared and either centrifuged (10 min, $5000 \times \mathrm{g}$, RT) or heated $\left(80^{\circ} \mathrm{C}, 30 \mathrm{~min}\right)$. The method for separation was adapted from [20] and the sample ( $25 \mu \mathrm{L})$ was injected at a rate of $0.2 \mathrm{~mL} / \mathrm{min}$ during $3 \mathrm{~min}$. The sample injected was focused for $4 \mathrm{~min}$ and elution started at an initial crossflow of $0.6 \mathrm{~mL} / \mathrm{min}$ for $7 \mathrm{~min}$, which was subsequently decreased linearly with $0.06 \mathrm{~mL} / \mathrm{min}$ to $0.0 \mathrm{ml} / \mathrm{min}$ after $19 \mathrm{~min}$. After elution, the channel was rinsed without crossflow for $15 \mathrm{~min}$. Light scattering signals from angles between $53.3^{\circ}$ to $139.6^{\circ}$ were used for the extrapolation using $2^{\text {nd }}$ order fits with Berry formalism and a dn/dc of 0.146 to obtain $\mathrm{M}_{\mathrm{w}}$ and $\mathrm{R}_{\mathrm{g}}$ [20].

\section{Scanning electron microscopy}

The 'parental', 'soluble' and 'particulate' $\beta$-glucan fractions were attached on a scanning electron microscopy sample holder using carbon adhesive tabs (EMS, Washington DC, USA), sputter coated with tungsten (EM SCD 500, Leica, Vienna, Austria) and subsequently analyzed with a field emission scanning electron microscope (Magellan 400, FEI, Eindhoven, The Netherlands) with SE detection at $2 \mathrm{kV}$.

\section{Generation and stimulation of bone marrow derived dendritic cells}

In a previous study we showed that BMDCs from TLR2/4 KO mice were not responding to LPS, lipoteichoic acid (LTA) and synthetic diacylated lipoprotein agonists of TLR2 (Pam2CSK4 and Pam3CSK4) [21]. As the $\beta$-glucan substrates might have been contaminated with LPS, we also chose to generate BMDCs from TLR2/4 knockout mice for this study. To obtain BMDCs, 6-10 week old C57bl/6 mice lacking both TLR2 and TLR4 were euthanized and the femurs were isolated, washed and gently crushed in $10 \mathrm{ml}$ of RPMI-1640 medium (without HEPES) supplemented with 100 units/ml penicillin G (Invitrogen, Breda, The Netherlands) and $100 \mu \mathrm{g} / \mathrm{ml}$ 
streptomycin (Invitrogen). Bone marrow cells were filtered using a Steriflip ${ }^{\circledR}$ Filter Unit (Millipore, Merck, Darmstadt, Germany) and around 2- $4 \times 10^{4}$-cells per well were seeded in a 96-well flat bottom plate in complete media (RPMI-1640 medium containing $10 \%$ heat-inactivated Fetal Calf Serum (FCS, Sigma-Aldrich), 100 units/ml penicillin G (Invitrogen), $100 \mu \mathrm{g} / \mathrm{ml}$ streptomycin (Invitrogen), $20 \mathrm{ng} / \mathrm{ml}$ of recombinant mouse granulocyte-macrophage colony-stimulating-factor (GM-CSF) (R\&D Systems, Minneapolis, MN, USA) and $0.05 \mathrm{mM} \beta$-mercaptoethanol. Cells were incubated at $37^{\circ} \mathrm{C}$ in $5 \%(\mathrm{v} / \mathrm{v}) \mathrm{CO}_{2}$ atmosphere and the medium was changed every three days. On day six BMDCs were stimulated with $400 \mu \mathrm{g} / \mathrm{mL}$ (or 600, 400, 200, $100,50,25 \mu \mathrm{g} / \mathrm{mL}$ for the dose response assay) fiber or the controls LPS $(1 \mu \mathrm{g} / \mathrm{mL})$, depleted zymosan $(20 \mu \mathrm{g} / \mathrm{mL})$ or medium (unstimulated).

\section{Cytokine quantification in culture supernatants}

Supernatants from the BMDC stimulation assays were collected after stimulation for 24 hours and analysed for the presence of cytokines (IL-6, IL-10, MCP-I and TNF). A cytometric bead-based BD mouse inflammation kit (BD Biosciences, Breda, The Netherlands), that enables multiplex measurements of soluble cytokines in the same sample, was used [22]. The sensitivity-limits of detection were as follows: 5.0, 17.5, 52.7 and 7.3 and $\mathrm{pg} / \mathrm{mL}$ for IL-6, IL-10, MCP-1 and TNF, respectively. The flow cytometry data were analysed using the BD FCAP software (BD Biosciences).

This study discusses results of two independent immunoassays on BMDCs, which gave different total amounts of cytokines. Trends and significant differences between the samples and controls were similar.

\section{Statistics}

All statistical tests were performed using GraphPad Prism 5.0 software (GraphPad, San Diego, CA, USA). Data shown are the means and the standard errors of the means (SEM). Data were tested for normality with the D'Agostino and Pearson normality test. Statistical analysis of normally distributed data were performed with the 2 tailed unpaired $\mathrm{T}$ test. Data that did not show normal distribution were analysed with the Welch's correction to determine equal variances between the groups. When the variances were unequal between the groups, the data were analysed using the unpaired $\mathrm{T}$ test with Welch's correction. Differences were considered statistically significant, highly significant and extremely significant when the $\mathrm{P}$ value was $<0.05,<0.001$ or $<0.0001$. 


\section{RESULTS AND DISCUSSION}

\section{Characteristics of oat and barley $\beta$-glucan}

Both cereal $\beta$-glucans and their sub-fractions induced different amounts of TNF, MCP1, IL-6 and IL-10 when added to BMDCs (Figure 2).

'Suspended' barley $\beta$-glucan induced significantly higher amounts of TNF (10408 $\mathrm{pg} / \mathrm{mL}$ ) than 'suspended' oat $\beta$-glucan (6202 $\mathrm{pg} / \mathrm{mL}$ ), confirming previous results [9]. The same was observed for MCP-1, IL-6 and IL-10. The differences were either highly or extremely significant $(\mathrm{P}<0.001$ or $\mathrm{P}<0.0001)$, respectively. In the following section the focus will be on the induced amounts of TNF.

The cytokine response positively correlated within the concentration range 25-400 $\mu \mathrm{g} / \mathrm{mL}$ of 'suspended' oat and barley $\beta$-glucan (Supplementary Figure 1 ). For both $\beta$ glucans a concentration of $600 \mu \mathrm{g} / \mathrm{mL}$ resulted in a lower cytokine response than 400 $\mu \mathrm{g} / \mathrm{mL}$ and no assured explanation for this phenomenon can be given.

Stimulation of BMDCs with either the 'soluble' and 'particulate' $\beta$-glucan fractions at the same concentration as that of the 'suspended' $\beta$-glucans $(400 \mu \mathrm{g} / \mathrm{mL})$ showed that the induced immune responses of the 'soluble' and 'particulate' fractions were lower than that of the 'suspended' $\beta$-glucans (Figure 2). This gives a hint, that the 'particulate' fraction was affected by sample preparation or synergistic effects between soluble and particulate $\beta$-glucans exist.

In addition, the particulate depleted zymosan control $(20 \mu \mathrm{g} / \mathrm{mL})$ induced much higher amounts of TNF $(21551 \mathrm{pg} / \mathrm{mL})$ than a comparable concentration $(25 \mu \mathrm{g} / \mathrm{mL})$ of 'suspended' oat $(805 \mathrm{pg} / \mathrm{mL})$ and barley $\beta$-glucans $(2248 \mathrm{pg} / \mathrm{mL}$ ) (Supplementary Figure 1). This confirms that non-cereal $\beta(1,3)$ glucans are much more immunostimulating than 'suspended' cereal $\beta$-glucans [9].

'Heat-soluble' $\beta$-glucans induced much lower amounts of cytokines than 'suspended' and 'particulate' fractions. Only the barley 'hs-fd suspended' $\beta$-glucans induced again higher amounts of cytokines, but the corresponding oat fraction did not. Hence, the immunostimulatory activity of oat $\beta$-glucan is more affected by freeze-drying than barley $\beta$-glucan (Figure 2).

Besides the investigation of the immunological characteristics of the $\beta$-glucans, which will be further discussed below, also physico-chemical properties were investigated in order to explain and predict the immunological activities. A slight difference between the average molecular masses for the soluble part of oat $(373 \mathrm{kDa})$ and barley $\beta$-glucan (277 kDa) was observed, as determined by HPSEC (Supplementary Figure 2). The solubilities of oat and barley $\beta$-glucans at RT were 30 and $25 \mathrm{w} / \mathrm{w} \%$, respectively. The monosaccharide composition analysis showed that both $\beta$-glucans consist of $99 \mathrm{~mol} \%$ 
glucose. The DP3/DP4 ratios of the oat and barley $\beta$-glucan as used in this study were previously determined to be 2.5 and 4.0 , respectively [3].

Scanning electron microscopy of the 'parental' $\beta$-glucan powders showed that oat $\beta$ glucan consisted of more, but smaller, particles than barley $\beta$-glucan (Supplementary Figure 3). The barley $\beta$-glucan granules were more porous than the oat $\beta$-glucans. This characteristic is even more pronounced in the 'particulate' fractions. The 'particulate' oat $\beta$-glucans became denser after freeze-drying than the 'particulate' barley $\beta$-glucans. The two 'soluble' $\beta$-glucan fractions build an open network and looked similar (Supplementary Figure 3). In conclusion, the two $\beta$-glucan sources and their fractions are different with respect to their size and porosity, which may influence the solubility of the fractions. The physico-chemical properties (DP3/DP4 ratio, molecular mass, granular conformation) as well as the immunomodulating properties of the two $\beta$ glucans are different.
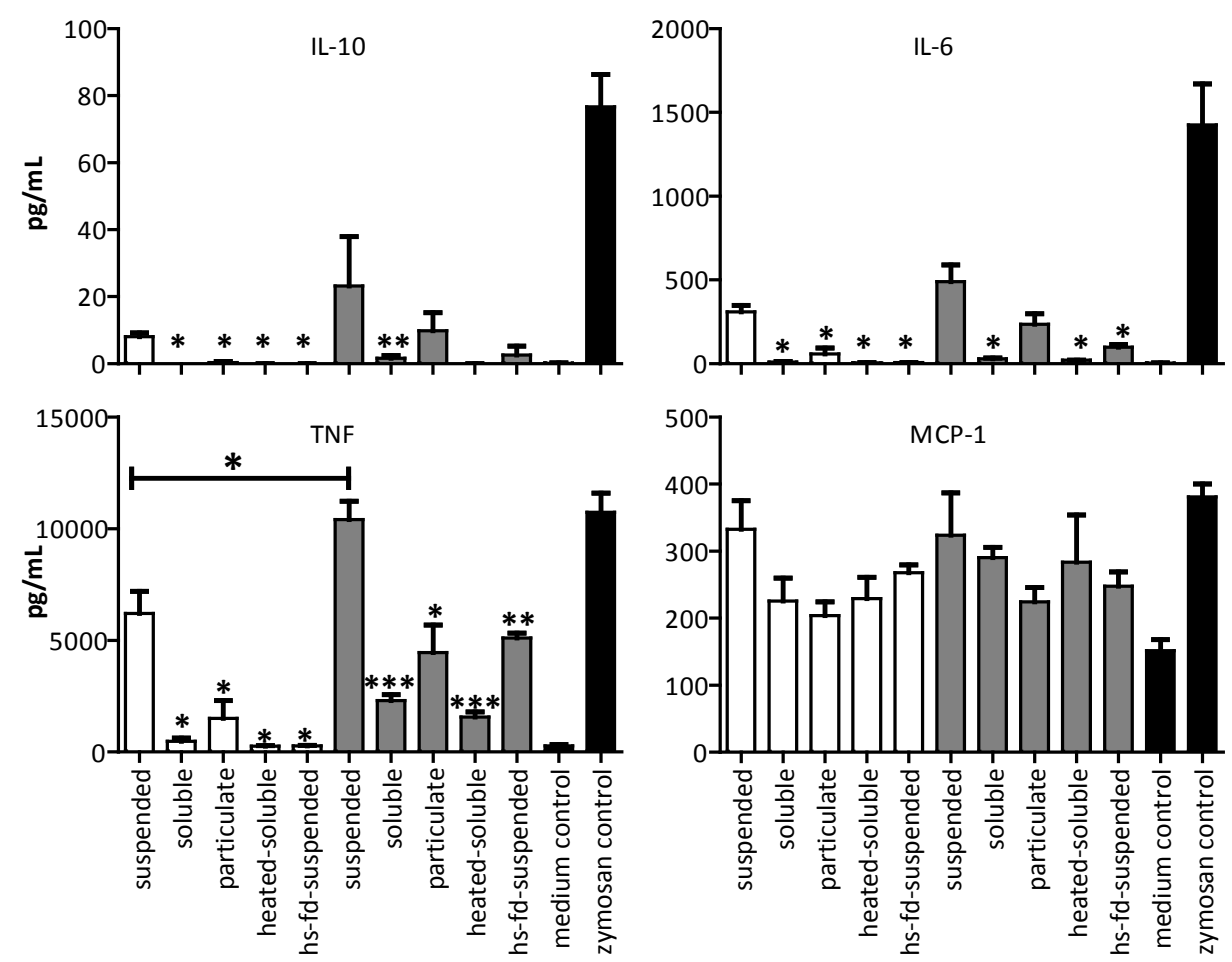

Figure 2: Cytokine induction to oat (white)-, barley (grey) $\beta$-glucan fractions $(400 \mu \mathrm{g} / \mathrm{mL}$ ) and controls (black). Data are means of triplicates \pm SEM. hs, heated-soluble; fd, freeze-dried. Stars represent classes of statistically significant different responses compared to the suspended fibre (* $\mathrm{P}<0.05, * * \mathrm{P}<0.01$ and $* * * \mathrm{P}<0.0001)$. 


\section{Effects of molecular mass on immunomodulatory properties}

In order to investigate the immunomodulatory effects of different molecular masses of oat- and barley $\beta$-glucans, lichenase and endoglucanase I were used to enzymatically degrade the $\beta$-glucans.

\section{Solubility of oat and barley $\beta$-glucan enzyme digesta}

Heat and $\mathrm{pH}$ inactivation after enzyme incubation, as described in the material and method section, affected the solubility of the $\beta$-glucans, as calculated from the area under the curve in the HPSEC chromatograms (Supplementary Figure 2). Figure 3 shows the effect on the solubility of the $\beta$-glucans for the $\mathrm{pH}$-inactivation. It has been shown that the conformation of $\beta$-glucans is reorganised to the original status, when the $\mathrm{pH}$ is neutralized again after a $\mathrm{pH}$ increase and change of the triple-helix conformation [23]. The solubility of the $\beta$-glucans increased starting from 0.5 and 3 hours of incubation, for barley and oat, respectively. At the end of the incubations the solubility was $45-58 \%$ (lichenase) and 45-53\% (endoglucanase I) (Figure 3). The molecular mass of the soluble $\beta$-glucans decreased steadily and at the end of the incubation with lichenase and endoglucanase I the molecular mass of both soluble $\beta$-glucans decreased to $<9 \mathrm{kDa}(7 \mathrm{~h})$ and $<2 \mathrm{kDa}(24 \mathrm{~h})$, respectively (Figure 3$)$. The HPSEC chromatograms indicate the broad range of $\beta$-glucan molecular masses for the digesta (Supplementary Figure 2). The increase in amounts of molecules of smaller molecular mass led to a higher solubility.

\section{Immunomodulation of barley $\beta$-glucan digesta}

For the pH-inactivated barley $\beta$-glucan degradation products, the increased TNF response (Figure 4) correlated with an increase in solubility to $45-53 \%$ of the total material (Figure 3) and with a decrease in molecular mass. The immune response is attributed to the decrease of the molecular mass, as the 'soluble' $\beta$-glucans were shown to induce lower amounts of cytokines (Figure 2). Additionally, still small $\beta$-glucan particles might have been present, adding up to the higher immune response.

The cytokine amounts induced by the heat-inactivated barley $\beta$-glucan degradation products mostly reached $80 \%$ of the amounts of the control (data not shown). This was independent of the incubation time point and no clear correlation between molecular mass and immunomodulating properties could be observed (data not shown).

\section{Immunomodulation of oat $\beta$-glucan digesta}

Unlike the barley $\beta$-glucan, all heat (data not shown) and $\mathrm{pH}$ inactivated oat $\beta$-glucan digesta induced low amounts of cytokines compared with the oat controls (Figure 4). This could have been caused by the freeze-drying step, as described previously in 3.1 and elsewhere [24]. Freeze-drying resulted in inhomogeneous, dense, gelled 
particulates (no further data shown). This may have influenced the immunomodulating properties, as indicated in Figure 2. Exceptions were the oat $\beta$-glucans incubated with endoglucanase I for 7 and $24 \mathrm{~h}$, exposed to $\mathrm{pH}$ inactivation (Figure 4). These samples induced relatively high amounts of cytokines, which is maybe attributed to an increase in the formation of specific soluble oat $\beta$-glucan oligosaccharides [12].

Overall, these findings suggest that besides the effect of the inactivation method $(\mathrm{pH}$ or heat) and drying process on the solubility, also the decrease in molecular mass of the $\beta$ glucans and thereby the immunomodulating properties of the substrates changed. This is in line with previous observations, which described that $\beta$-glucans are affected by processing, such as freeze-thaw cycles and drying, which resulted in a conformational change of the $\beta$-glucans $[24,25]$. This effect is substrate specific and affects barley $\beta$ glucans much less than oat.
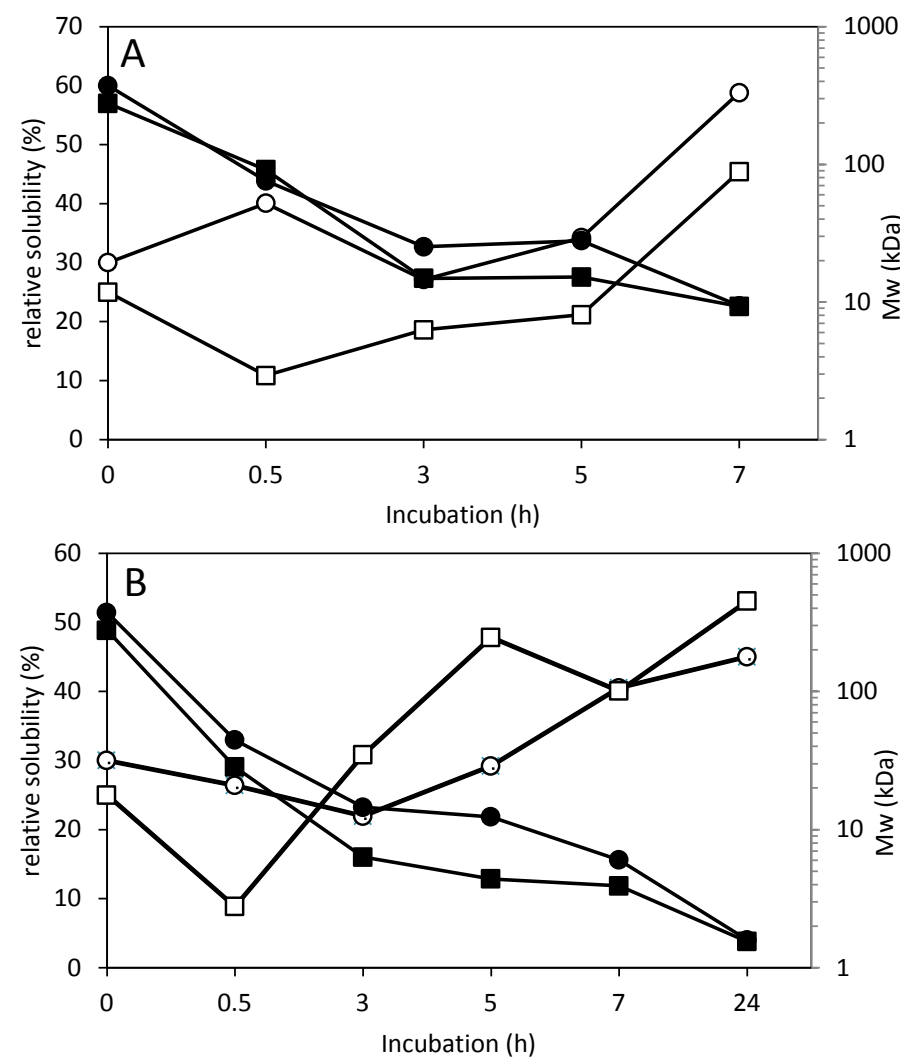

Figure 3: Effect of incubation with lichenase (A) and endoglucanase I (B) after $\mathrm{pH}$ inactivation on the solubility of oat $(O)$ and barley $(\square)$ and molecular mass of oat $(\bullet)$ and barley $(\square) \beta$-glucan over time. 


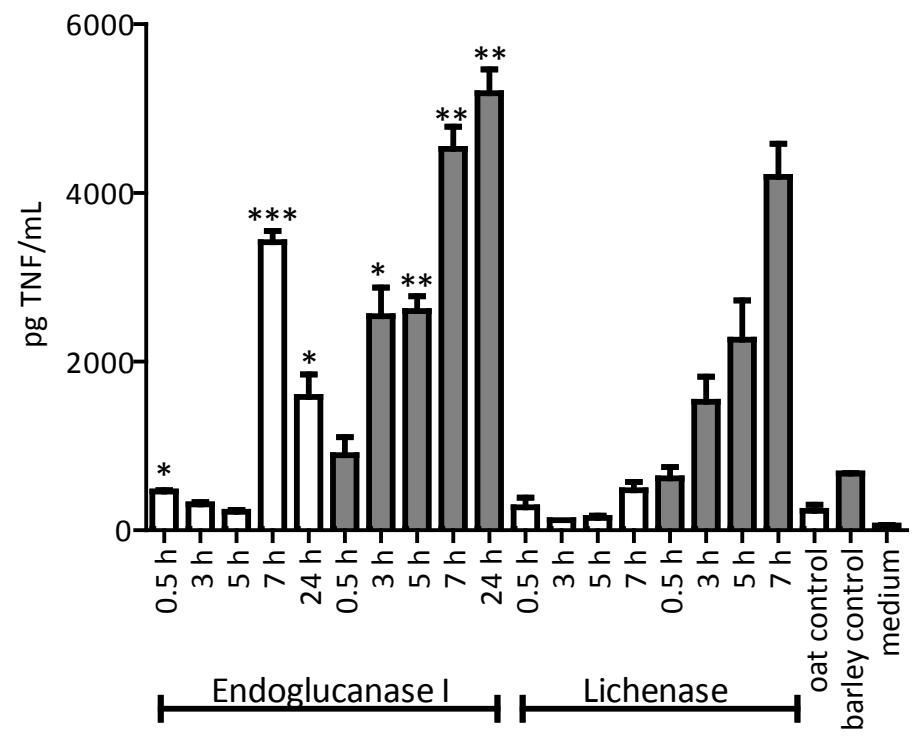

Figure 4: TNF induction to enzymatically degraded oat (white) and barley (grey) $\beta$-glucan with either endoglucanase I (E) or lichenase (L) over 24 or $7 \mathrm{~h}$ with $\mathrm{pH}$ inactivation. Medium blank is shown in black. Data are means of triplicates \pm SEM. Stars represent classes of statistically significant different responses compared to the oat or barley control ( $* P<0.05,{ }^{* *} P<0.01$ and $\left.* * * P<0.0001\right)$.

\section{Soluble $\boldsymbol{\beta}$-glucans decreased immunomodulating properties}

The 'soluble' oat and barley $\beta$-glucans, representing 30 and $25 \mathrm{w} / \mathrm{w} \%$ of the parental material, respectively, induced less cytokine secretion by BMDCs than the 'particulate' $\beta$-glucans (Figure 2). Especially, the amounts of IL-6 and IL-10 were very low for both substrates. In a slightly different experimental set up, this finding was observed previously [3]. In addition, complete solubilisation of the $\beta$-glucan by heating the suspension also reduced its capacity to induce the cytokine secretion in BMDCs (Figure 2).

AF4 was used to determine the molecular mass and radius of the 'soluble' and 'heatedsoluble' $\beta$-glucans. The separation by AF4 is based on the hydrodynamic volume of the molecules [26]. The soluble oat and barley $\beta$-glucans eluted in the same time window (Figures $5 \mathrm{~A}$ and $\mathrm{B}$ ). This means that their hydrodynamic radii were similar. Furthermore, their elution over a time window of ca. 8 minutes showed that the samples are polydisperse. The soluble barley $\beta$-glucans have a different distribution pattern than soluble oat $\beta$-glucans, as they consist of relatively less molecules of larger hydrodynamic radii (eluting after $5 \mathrm{~min}$ ) compared to soluble oat $\beta$-glucans. The average molecular mass $\left(\mathrm{M}_{w}\right)$ of the soluble $\beta$-glucans is similar, being 300 and 285 $\mathrm{kDa}$ for oat and barley $\beta$-glucans, respectively. The radii of gyration $\left(\mathrm{R}_{g}\right)$, which is the root mean square distribution accounting the mass distribution around the centre of the molecule, of the soluble oat and barley $\beta$-glucan were $143 \mathrm{~nm}$. 

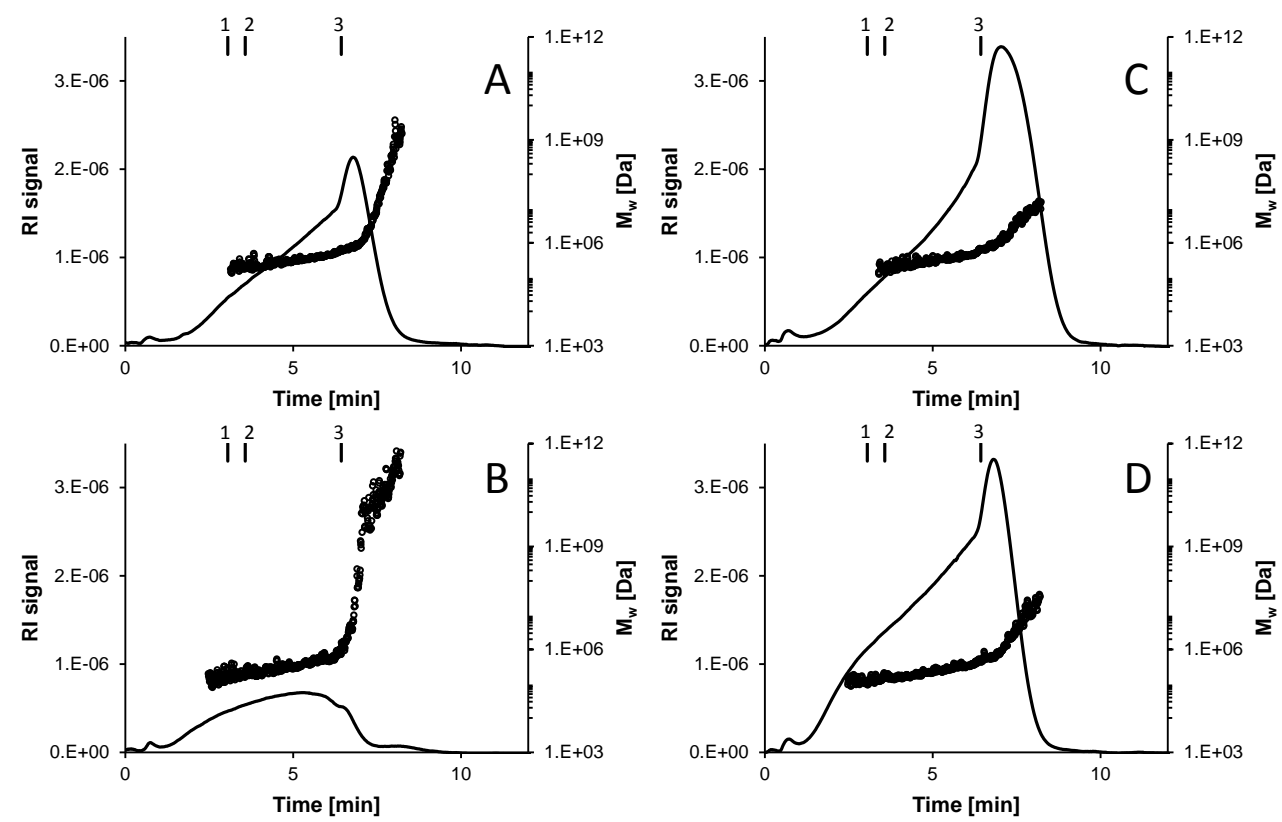

Figure 5: AF4 fractograms of soluble (A and B) and heated ( $C$ and $D)$ oat ( $A$ and $C$ ) and barley ( $B$ and D) $\beta$-glucans. Lines with numbers 1-3 represent pullulan standards of 112,212 and $404 \mathrm{kDa}$, respectively.

The distribution pattern and solubility of barley $\beta$-glucan changed due to heating. This resulted in a more similar distribution pattern for the heated $\beta$-glucans (Figures $5 \mathrm{C}$ and $D$ ) than for the soluble $\beta$-glucans (Figures $5 \mathrm{~A}$ and B). Nevertheless, the heated barley $\beta$-glucan consists of slightly more smaller and less larger molecules than the heated oat $\beta$-glucan. This explains that the average molecular mass for the heated barley $\beta$-glucan (195 kDa) was lower than that of heated oat $\beta$-glucan ( $294 \mathrm{kDa})$. Heating did not affect the $\mathrm{R}_{\mathrm{g}}(143 \mathrm{~nm})$. This is in line with observations in previous studies [27]. This means that the 'soluble' and 'heated-soluble' $\beta$-glucans consist of quite similar molecules, explaining their similar behaviour in immunoassays in comparison to 'particulate' $\beta$ glucans (Figure 2). The similarity of the soluble molecules is confirmed by the conformation plot of $\mathrm{R}_{g}$ versus $\mathrm{M}_{w}$, which showed a similar slope for all four samples (data not shown). This indicates that the heat treatment does not affect the structural characteristics of the molecules, such as $\mathrm{M}_{w}$ or radius. Structural differences, not measurable with AF4, such as differences in DP3/DP4 ratio, exist between the two soluble $\beta$-glucans, causing a different receptor binding affinity and thereby small differences in immune effects (Figure 2). Overall, these results showed that commonly applied sample preparation methods, such as heating after an enzyme incubation, affect the solubility and thereby the immunomodulating properties of $\beta$-glucans. 


\section{Particulate size dependent immunomodulatory properties}

It has been suggested that the particle size of polysaccharides, for example of microbial $\beta$-glucans and resistant starches, influence their immunomodulating capacity $[4,28]$. This was of interest, as our study showed that the 'particulate' part of the $\beta$-glucans induced the strongest immune-responses. Enhanced immunomodulation due to aggregate formation in comparison to individual triple helices structures has been also observed for fungal $\beta(1,3)$ glucan [29].

In order to determine whether the difference in particle size caused different immunomodulatory responses, the $\beta$-glucans were separated by sieving the 'parental' $\beta$-glucans into fractions smaller and larger than $106 \mu \mathrm{m}$. For both cereals, the 'small suspended' $\beta$-glucan fractions induced a stronger cytokine response in BMDCs than the 'large suspended' $\beta$-glucan fractions (Figure 6), with barley $\beta$-glucan being more stimulating than oat $\beta$-glucan for both size fractions.

In addition to AF4 analysis (nm scale) of the soluble $\beta$-glucans, static light scattering using a mastersizer ( $\mu \mathrm{m}$ scale) was performed to determine particle size distributions of the 'parental' $\beta$-glucan. If the average median and particle size of those fractions are compared (Figures 6A and B), the two 'small suspended' fractions show a very similar distribution and volume-surface diameter of 89 and $94 \mu \mathrm{m}$ for oat and barley respectively. Nevertheless, their induced TNF responses were different: $16943 \mathrm{pg} / \mathrm{mL}$ and $22191 \mathrm{pg} / \mathrm{mL}$ for oat and barley $\beta$-glucan, respectively. This indicates that particle size did not correlate with immunomodulating properties.

In another set of experiments, the fractions of the 'small suspended' and 'large suspended' substrates were additionally separated into 'soluble' and 'particulate' fractions.
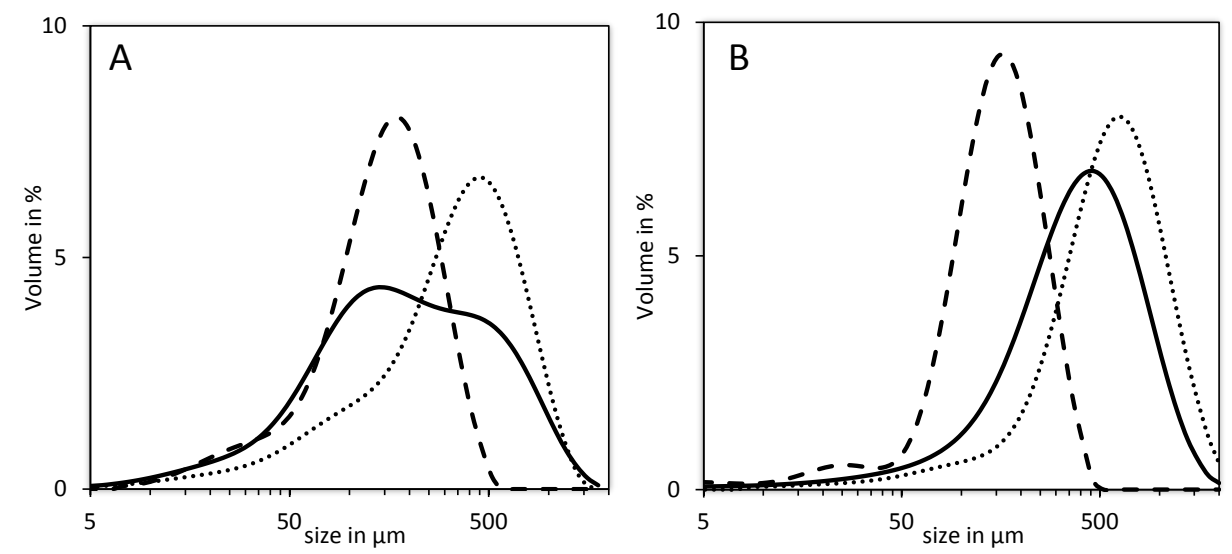

Figure 6: Particle size distribution of the 'suspended' (solid line), 'small suspended' (dashed line) and 'large suspended' (dotted line) oat (A) and barley (B) $\beta$-glucan. 
All oat $\beta$-glucan fractions (i.e. 'small' or 'large', 'soluble' or 'particulate') induced very low amounts of TNF (193-1833 pg/mL). Again, freeze-drying most probably affected the solubility behaviour of oat $\beta$-glucans [24]. The 'small particulate' oat still induced the highest levels $(1833 \mathrm{pg} / \mathrm{mL}$ ) of all four oat fractions (Figure 7).

For barley $\beta$-glucan, the 'small particulates' clearly elicited the highest amount of TNF (20798 pg/mL), followed by the 'small soluble' (3048 pg/mL), 'large soluble' (1908 $\mathrm{pg} / \mathrm{mL}$ ) and 'large particulate' (918 pg/mL) fractions (Figure 7).

These two experiments show that the 'small particulate' fractions of oat and barley $\beta$ glucans induced the largest immune-response. In addition, the 'small particulate' barley $\beta$-glucans induced significantly more cytokines than the 'small particulate' oat $\beta$-glucans. This indicates that there must be more features influencing the immunomodulatory properties of these two substrates than only the particle size.
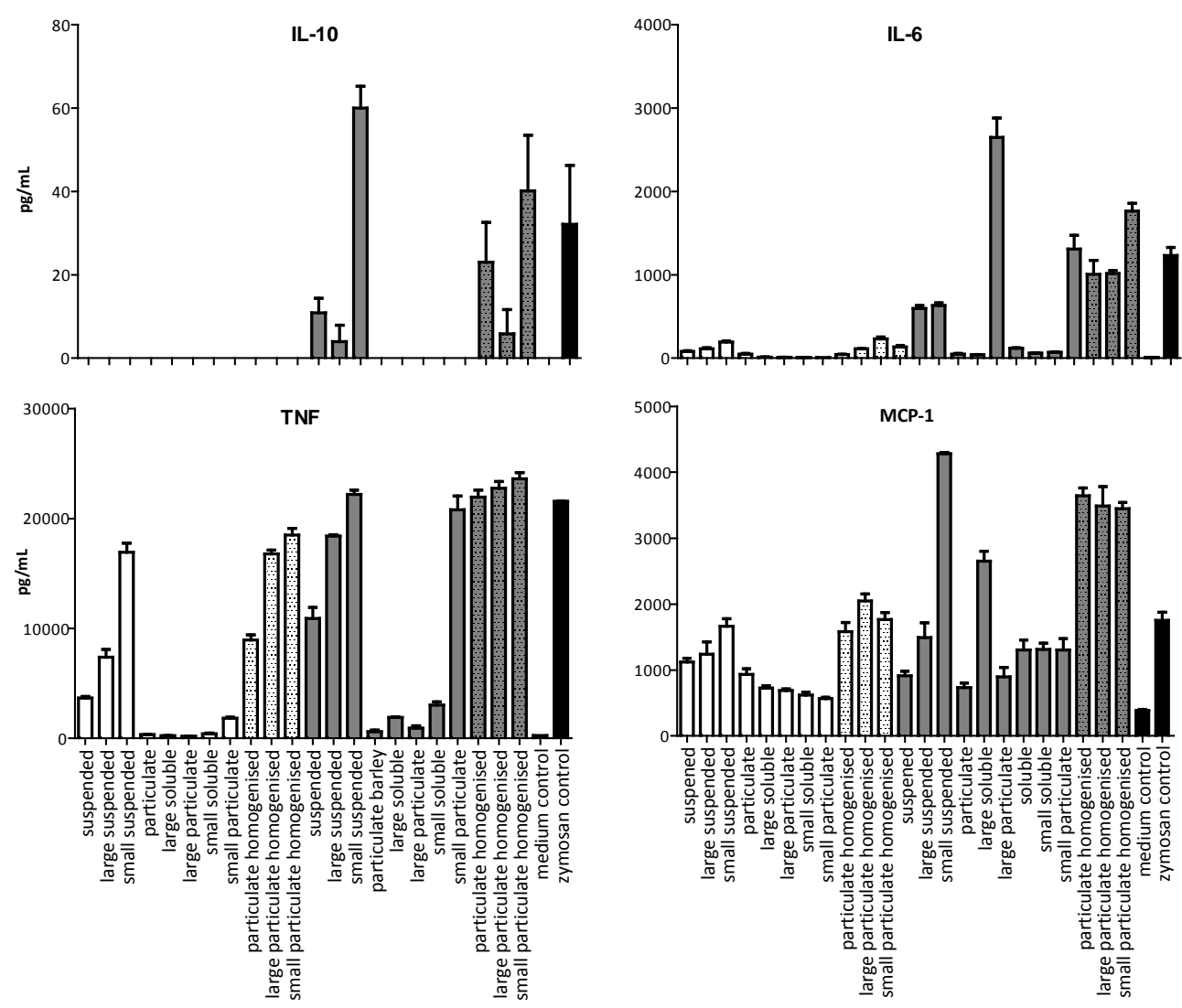

Figure 7: Cytokine induction to oat (white)- and barley (grey) $\beta$-glucan fractions and controls (black) Data are means of triplicates \pm SEM. Dotted filling pattern indicates homogenised samples. 


\section{Homogeneity of particulate $\beta$-glucans increases immunomodulating activity}

The 'particulate' $\beta$-glucan fraction of oat and barley induced higher cytokine response in immunoassays than the 'soluble' fractions, but did not reach the cytokine amounts of the 'suspended' oat and barley $\beta$-glucans (Figure 2).

The difficulty with the 'particulate' fraction was to prepare homogenous samples in such a way that all assays were incubated with the same material. This inaccuracy can be seen when the ratio of amounts of cytokines for the 'particulate' and 'suspended' $\beta$ glucan samples of two independent immunoassays are compared (Figures 2 and 7).

In order to prepare more homogeneous 'particulate' samples, mechanical disruption by shear force was used. Homogenisation resulted in higher immune stimulatory activity for both 'particulate-homogenised' $\beta$-glucans (TNF oat: 8968 pg/mL, barley: 21956 $\mathrm{pg} / \mathrm{mL}$ ) compared to the non-homogenised 'particulate' $\beta$-glucan fractions (TNF oat: $343 \mathrm{pg} / \mathrm{mL}$, barley: $606 \mathrm{pg} / \mathrm{mL}$ ) (Figure 7). Additionally, also the 'small particulate homogenised' and 'large particulate homogenised' fractions of oat and barley $\beta$-glucan increased in cytokine induction compared to their non-homogenised fractions. This was the case although, the 'small particulate' barely fraction induced already without homogenisation high amounts of cytokines, as discussed above (Figure 7).

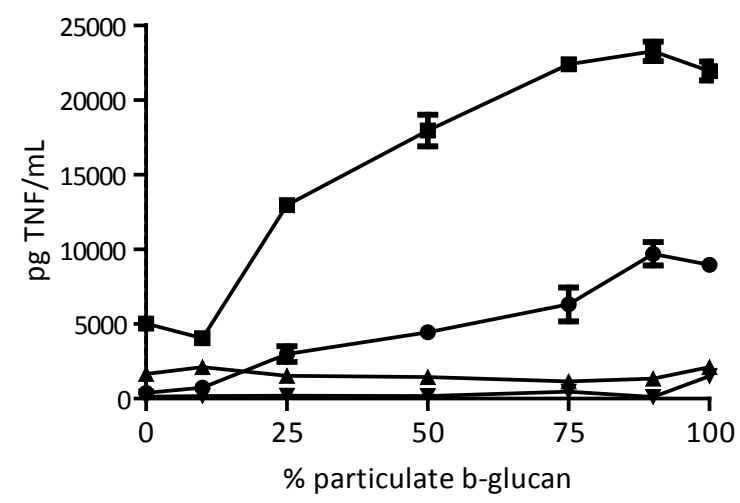

Figure 8: TNF induction to different ratios of 'soluble' and 'particulate' $\beta$-glucans. $(\bullet)$ 'homogenised' oat $\beta$-glucan, $(\boldsymbol{\square})$ 'homogenised' barley $\beta$-glucan, $\boldsymbol{\nabla}$ 'suspended' oat $\beta$-glucan and ( $\boldsymbol{\Delta}$ ) 'suspended' barley $\beta$-glucan. Depleted zymosan control $>21600 \mathrm{pg} / \mathrm{mL}$, medium control $=261 \mathrm{pg} / \mathrm{mL}$.

Another approach to indicate the necessity to homogenise $\beta$-glucan samples is given by the cytokine response of assays with different ratios of 'soluble' and 'particulate' $\beta$ glucan fractions (Figure 8). The homogenised samples showed a positive correlation between the concentration of 'particulate' $\beta$-glucans and amounts of induced TNF, while in the experiment without homogenisation no clear correlation was observed (Figure 8). Again, this highlights that the 'particulate' cereal $\beta$-glucan fraction is more immunostimulatory than the 'soluble' fraction when it is homogenised. As 'particulate' 
$\beta$-glucans induced much stronger cytokine responses than 'soluble' $\beta$-glucans, the effect of homogenisation of a sample is of high importance. This is in line with previous observations on yeast $\beta-(1,3)$ glucans, which showed that micro-particulates $(1-2 \mu \mathrm{m})$ are more homogenous and more easily phagocytosed in vivo in mouse experiments, than equivalent $\beta(1,3)$ glucan aggregates [4].

\section{CONCLUSIONS}

The key feature influencing the immunomodulating properties of $\beta$-glucans is their insolubility, to which characteristics as particle size, granule conformation and particulate homogeneity are related. Besides the importance of particulate $\beta$-glucans, differences in immunomodulation were observed between the two soluble $\beta$-glucans, which indicates that substrate specific molecular characteristics are important regarding the immune response.

Sample preparations, such as drying, dispersing and heating, strongly affect the physico-chemical characteristics of the substrate and thereby the immunomodulatory properties. These processes and preparation methods should, therefore, be considered when identifying structure related immunomodulatory activity of $\beta$-glucans.

\section{AbBreviations}

BMDC, bone marrow derived dendritic cell; DC, dendritic cell; LPS, lipopolysaccharide; LTA, lipoteichoic acid; MAMP, microbe-associated molecular pattern; SEM, standard error of the means; TLR, toll-like receptor.

\section{ACKNOWLEDGEMENTS}

This work has been funded by TIFN (Top Institute Food and Nutrition) project GH004.2. We thank the Wageningen Electron Microscopy Centre for the scanning electron micrograph analysis.

\section{REFERENCES}

[1] Johansson, L., Structural analyses of (1-> 3),(1-> 4)- $\beta$-D-glucan of oats and barley. Ph.D thesis 2006, University of Helsinki, Helsinki, Finland.

[2] Li, W., Cui, S. W., Wang, Q., Yada, R. Y., Studies of aggregation behaviours of cereal $\beta$-glucans in dilute aqueous solutions by light scattering: Part I. Structure effects. Food Hydrocolloids 2011, 25, 189-195.

[3] Mikkelsen, M. S., Jespersen, B. M., Mehlsen, A., Engelsen, S. B., Frøkiær, H., Cereal $\beta$-glucan immune modulating activity depends on the polymer fine structure. Food Research International 2014, 62, 829-836.

[4] Hunter, K., Gault, R., Berner, M., Preparation of microparticulate $\beta$-glucan from Saccharomyces cerevisiae for use in immune potentiation. Letters in Applied Microbiology 2002, 35, 267-271.

[5] Falch, B. H., Espevik, T., Ryan, L., Stokke, B. T., The cytokine stimulating activity of (1 $\rightarrow 3)$ - $\beta$-d-glucans is dependent on the triple helix conformation. Carbohydrate Research 2000, 329, 587-596.

[6] Kulicke, W.-M., Lettau, A. I., Thielking, H., Correlation between immunological activity, molar mass, and

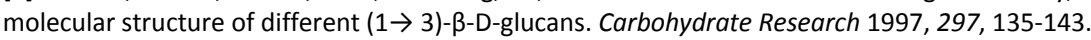

[7] Ferreira, S. S., Passos, C. P., Madureira, P., Vilanova, M., Coimbra, M. A., Structure-function relationships of immunostimulatory polysaccharides: A review. Carbohydrate Polymers 2015, 132, 378-396. 


\section{CHAPTER 3}

[8] Samuelsen, A. B., Rieder, A., Grimmer, S., Michaelsen, T. E., Knutsen, S. H., Immunomodulatory activity of dietary fiber: arabinoxylan and mixed-linked beta-glucan isolated from barley show modest activities in vitro. International Journal of Molecular Sciences 2011, 12, 570-587.

[9] Wismar, R., Brix, S., Lærke, H. N., Frøkiær, H., Comparative analysis of a large panel of non-starch polysaccharides reveals structures with selective regulatory properties in dendritic cells. Molecular Nutrition and Food Research 2011, 55, 443-454.

[10] Goodridge, H. S., Reyes, C. N., Becker, C. A., Katsumoto, T. R., et al., Activation of the innate immune receptor Dectin-1 upon formation of a phagocytic synapse. Nature 2011, 472, 471-475.

[11] Tsoni, S. V., Brown, G. D., B-glucans and Dectin-1. Annals of the New York Academy of Sciences 2008, 1143, 45-60.

[12] Sahasrabudhe, N. M., Tian, L., van den Berg, M., Bruggeman, G., et al., Endo-glucanase digestion of oat $\beta$ glucan enhances Dectin-1 activation in human dendritic cells. Journal of Functional Foods 2016, 21, 104-112.

[13] Brown, G. D., Dectin-1: A signalling non-TLR pattern-recognition receptor. Nature Reviews Immunology 2006, 6, 33-43.

[14] Adams, E. L., Rice, P. J., Graves, B., Ensley, H. E., et al., Differential high-affinity interaction of Dectin-1 with natural or synthetic glucans is dependent upon primary structure and is influenced by polymer chain length and side-chain branching. Journal of Pharmacology and Experimental Therapeutics 2008, 325, 115-123.

[15] Rogers, N. C., Slack, E. C., Edwards, A. D., Nolte, M. A., et al., Syk-dependent cytokine induction by Dectin-1 reveals a novel pattern recognition pathway for $C$ type lectins. Immunity 2005, 22, 507-517.

[16] Beldman, G., Leeuwen, M. F., Rombouts, F. M., Voragen, A. G. J., The cellulase of Trichoderma viride European Journal of Biochemistry 1985, 146, 301-308.

[17] Englyst, H. N., Cummings, J. H., Simplified method for the measurement of total non-starch polysaccharides by gas- liquid chromatography of constituent sugars as alditol acetates. The Analyst 1984, 109, 937-942.

[18] Ahmed, A. E. R., Labavitch, J. M., A simplified method for accurate determination of cell wall uronide content. Journal of Food Biochemistry 1978, 1, 361-365.

[19] Thibault, J., Automatisation du dosage des substances pectiques par la méthode au méta-hydroxydiphenyl. Lebensmittel-Wissenschaft und Technologie. 1979, 12, 247-251.

[20] Håkansson, A., Ulmius, M., Nilsson, L., Asymmetrical flow field-flow fractionation enables the characterization of molecular and supramolecular properties of cereal $\beta$-glucan dispersions. Carbohydrate Polymers 2012, 87, 518-523.

[21] Meijerink, M., Rösch, C., Taverne, N., Venema, K., Gruppen, H., Schols, H. A., Structure related immunomodulation by sugar beet arabinans is induced via Syk tyrosine kinase-dependent pathway. This thesis, chapter 2.

[22] Morgan, E., Varro, R., Sepulveda, H., Ember, J. A., et al., Cytometric bead array: a multiplexed assay platform with applications in various areas of biology. Clinical Immunology 2004, 110, 252-266.

[23] Young, S.-H., Jacobs, R. R., Sodium hydroxide-induced conformational change in schizophyllan detected by the fluorescence dye, aniline blue. Carbohydrate Research 1998, 310, 91-99.

[24] Hromádková, Z., Ebringerová, A., Sasinková, V., Šandula, J., et al., Influence of the drying method on the physical properties and immunomodulatory activity of the particulate $(1 \rightarrow 3)$ - $\beta$-D-glucan from Saccharomyces cerevisiae. Carbohydrate Polymers 2003, 51, 9-15.

[25] Ulmius, M., Önning, G., Nilsson, L., Solution behavior of barley $\beta$-glucan as studied with asymmetrical flow field-flow fractionation. Food Hydrocolloids 2012, 26, 175-180.

[26] Runyon, J. R., Ulmius, M., Nilsson, L., A perspective on the characterization of colloids and macromolecules using asymmetrical flow field-flow fractionation. Colloids and Surfaces A: Physicochemical and Engineering Aspects 2014, 442, 25-33.

[27] Lambo-Fodje, A. M., Leeman, M., Wahlund, K. G., Nyman, M., et al., Molar mass and rheological characterisation of an exopolysaccharide from Pediococcus damnosus 2.6. Carbohydrate Polymers 2007, 68, 577586.

[28] Bermudez-Brito, M., Rösch, C., Schols, H. A., Faas, M. M., Vos, P., Resistant starches differentially stimulate toll-like receptors and attenuate proinflammatory cytokines in dendritic cells by modulation of intestinal epithelial cells. Molecular Nutrition and Food Research 2015, 59, 1814-1826.

[29] Magee, A. S., Langeslay, R. R., Will, P. M., Danielson, M. E., et al., Modification of the degree of branching of a beta-(1,3)-glucan affects aggregation behavior and activity in an oxidative burst assay. Biopolymers 2015, 103, 665-674. 


\section{SUPPLEMENTARY DATA:}
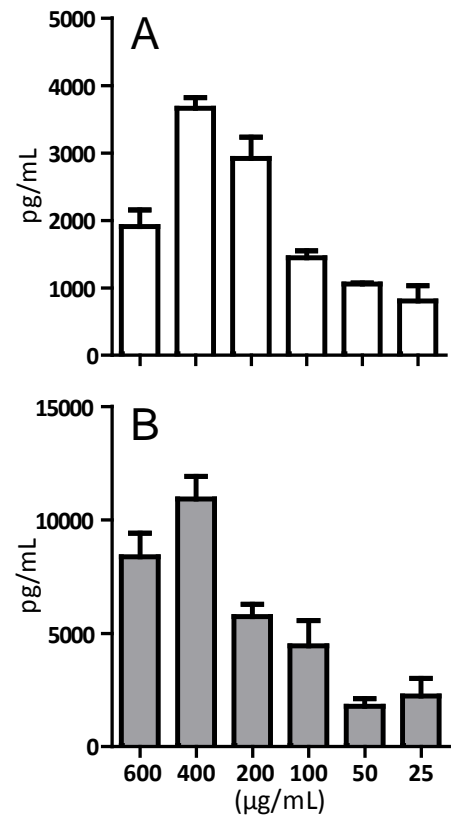

Supplementary Figure 1: TNF response to different concentrations of suspended oat $(A)$ and barley (B) $\beta$-glucans. Values for TNF response for: depleted zymosan $21500 \mathrm{pg} / \mathrm{mL}$; medium, $260 \mathrm{pg} / \mathrm{mL}$. 


\section{CHAPTER 3}

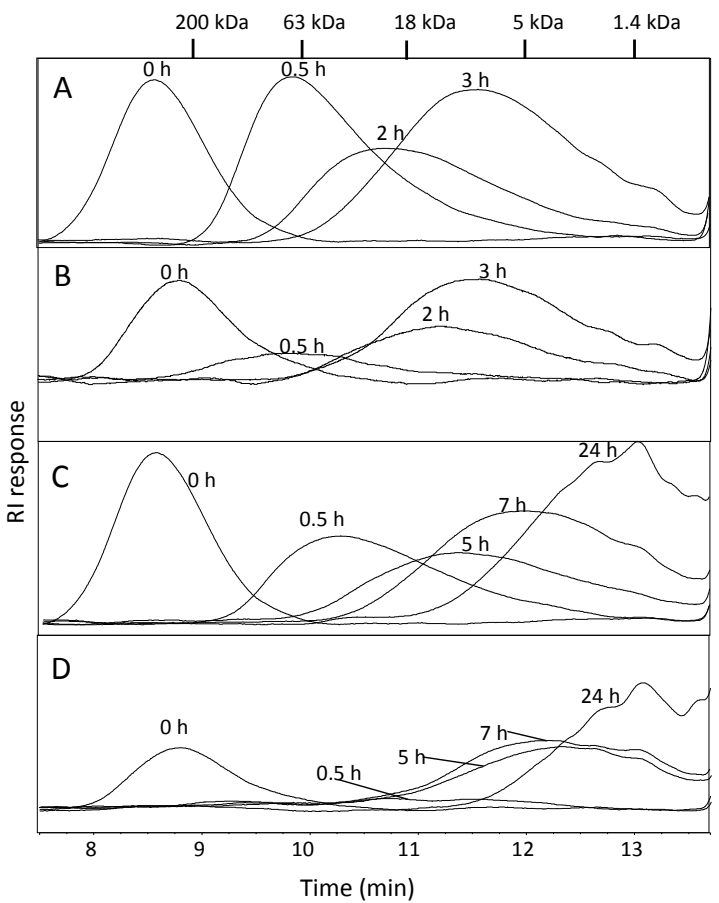

Supplementary Figure 2: HPSEC profile of lichenase ( $A$ and $B$ ) and endoglucanase I ( $C$ and D) treated oat ( $A$ and $C$ ) and barley- (B and D) $\beta$-glucan. Enzyme reactions were stopped by $\mathrm{pH}$ inactivation. Pullulan standards were used for calibration. 
Immunomodulation by $\beta$-glucans
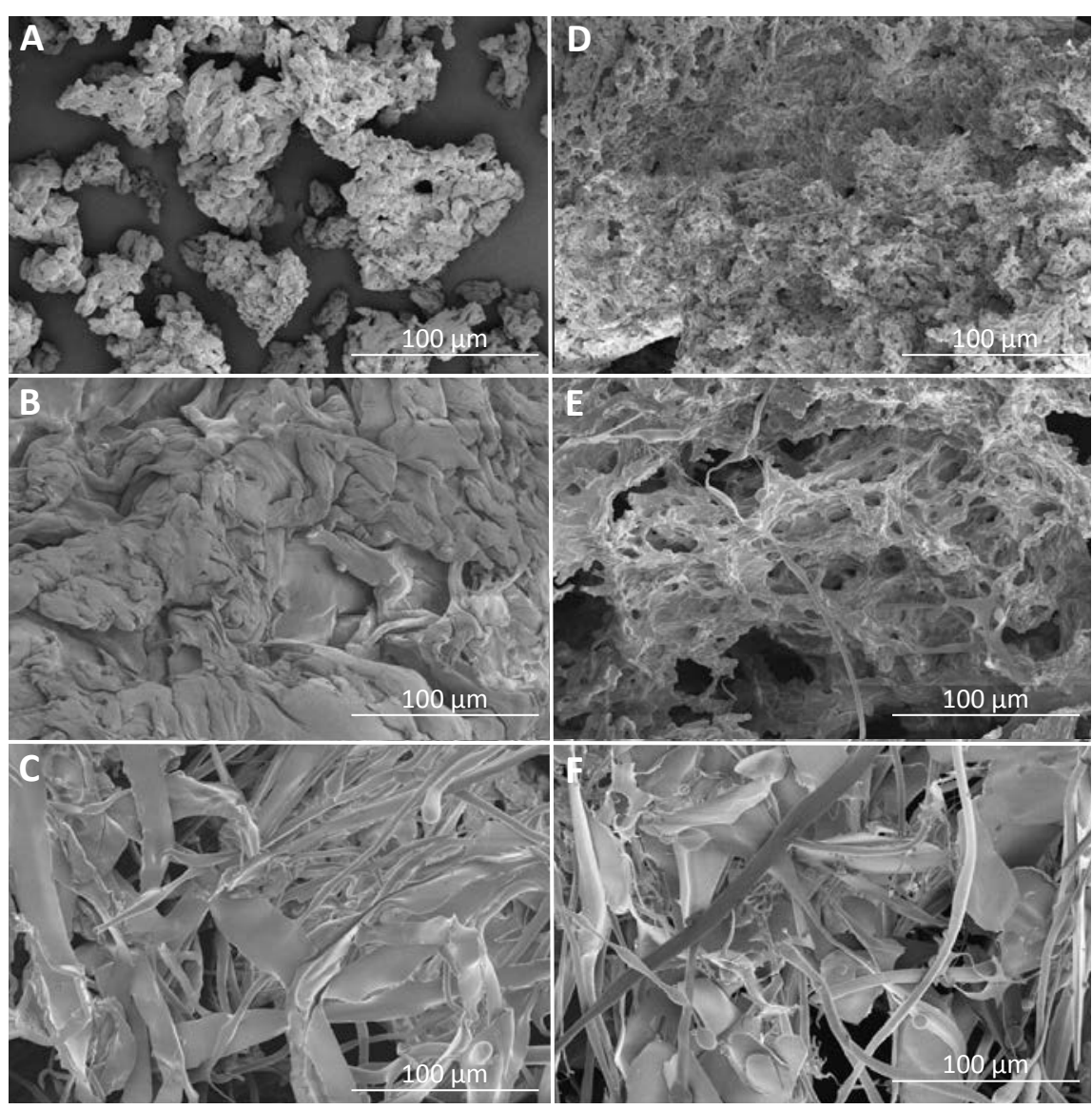

Supplementary Figure 3: Scanning electron micrograph of the oat (A-C) and barley (D-F) $\beta$-glucan dry powder $(A$ and $D)$, particulate $(B$ and $E)$ and soluble ( $C$ and $F)(1000 \times$ magnification). 


\section{ChAPTER 3}




\title{
Chapter 4
}

\section{Effects of in vitro fermentation of barley $\beta$-glucan and sugar beet pectin using human faecal inocula on cytokine expression by dendritic cells}

\begin{abstract}
Dietary fibres are differently fermented by the human gut microbiota and also differently modulate immune responses. This study monitors the degradation products formed during barley $\beta$-glucan and sugar beet pectin (SBP) fermentation using human faecal microbiota and investigates the induced amounts of cytokines in bone marrow derived dendritic cells (BMDCs) from TLR2/4 knock out mice by the fermentation digesta.

The fermentation digesta were incubated with BMDCs from TLR2/4 knock out mice to analyse the induced amounts of cytokines, which could be related to the dietary fibre and not to microbiota and SCFA present in the digest. The fermentation digesta were analysed for their SCFA profiles and glycan metabolites, which induced larger amounts of cytokines than the parental fibre.

The incubation of fermentation digesta with BMDCs from TLR2/4 knock out mice was suitable to test the immunomodulatory properties of the present degradation products. The different fermentation characteristics of dietary fibres led to fibre specific types and amounts of metabolites and immunomodulation.
\end{abstract}

Submitted for publication as:

Rösch, C., Taverne, N., Venema, K., Gruppen, H., Wells J.M \& Schols, H. A. (2016). Effects of in vitro fermentation of barley $\beta$-glucan and sugar beet pectin using human faecal inocula on cytokine expression by dendritic cells 


\section{INTRODUCTION}

Barley $\beta(1,3)(1,4)$ glucan and sugar beet pectin (SBP) are dietary fibres. Thus, they are indigestible in the human small intestine and end up in the large intestine, where they are fermented by the microbiota [1]. Many fermentation studies of dietary fibres have investigated their influence on microbiota composition, possible prebiotic effects and production of short chain fatty acids (SCFA) [2,3]. The microbiota and SCFA are known to influence epithelial functions and immune regulation in the large bowel [4, 5]. Cryptopatches and isolated lymphoid follicles in the colon have been reported to contain $\mathrm{M}$ cells, which may transport particulate antigens from the lumen to dendritic cells, macrophages and lymphocytes in the lymphoid follicles underlying the follicular epithelium [6].

Dietary $\beta(1,3)$ linked glucans found in cell walls of mushrooms and other fungi can elicit immune responses though binding of the $\beta(1,3)$ linked glucans to Dectin- 1 , a member of the C-type lectin receptor (CLR) family [7, 8]. Expression of the CLR Dectin-1 was recently detected in human colonic intestinal epithelial cells (IECs) [9] and was shown to be expressed in primary colonic enterocytes and induce chemokine secretion upon ligand binding to $\beta(1,3)$ linked glucans [10].

Barley $\beta(1,3)(1,4)$ glucan also interacts via Dectin-1 receptors and we recently showed that SBP can induce immune responses via an unknown receptor [11]. The barley derived $\beta$-glucan is a linear polysaccharide (PS) consisting of $\beta(1,3)(1,4)$ linked glucose units. SBP is a much more complex fibre consisting of a homogalacturonan region (HG), which is highly methyl esterified and acetylated. In addition, SBP consists of a rhamnogalacturonan region I (RG I), which is composed of alternating rhamnose and galacturonic acid units and is substituted with short neutral side chains of galactose and arabinose [12, 13].

Several in vitro fermentation models have been used for studies on microbiota and substrates, which all have the general limitation that they are not equipped with a mucus layer, epithelial and other intestinal cells to take up metabolites or study effects on the host [14]. A recent development to overcome this limitation is the Host Microbiota Interaction (HMI) model, that can be connected to the SHIME fermentation model. The HMI model has a mucus layer and semi-permeable layer (double functional layer), which protect the epithelial cells from the bacteria while allowing transport of low molecular weight (LMW) metabolites and oxygen diffusion [15]. When filtered yeast digesta from the SHIME fermentation model were incubated in co-culture with epithelial and immune cells, pro-inflammatory cytokine secretion was decreased [16]. Currently, this is the only study measuring the effect of filtered fermentation digesta on cytokine responses in immune cells. However, the outcome of the HMI/SHIME model might be limited, as insoluble fibre particles, which were recently shown to be highly immunomodulatory [11, 17], are ignored. 
In our in vitro batch fermentation we monitor the degradation products formed during barley $\beta$-glucan and SBP fermentation using human faecal microbiota and investigate the complete digesta for immunomodulatory activity with bone marrow derived dendritic cells (BMDCs) from TLR2/4 knock out mice.

\section{Materials AND Methods}

\section{Substrates}

Barley $\beta$-glucan of low viscosity (Megazyme, Bray, Ireland) and a previously characterised sugar beet pectin (DuPont, Brabrand, Denmark) [12], were used for the fermentation studies.

LPS from Escherichia coli (Sigma-Aldrich, St Louis, MO, USA) was used as a control to show unresponsiveness of the BMDCs from TLR2/4 knockout mice to this common microbe-associated molecular pattern (MAMP). Depleted zymosan, an insoluble $\beta 1,3-$ glucan from Saccharomyces cerevisiae (Invivogen, Toulouse, France) was used as a positive control in the immunoassays.

\section{Culture medium for in vitro fermentation}

The culture medium was based on the standard ileal efflux medium (SIEM) and modified as described elsewhere [18]. All medium components were obtained from Tritium Microbiology (Veldhoven, The Netherlands). The medium included a $1 \mathrm{M}$ MES buffer to maintain $\mathrm{pH} 5.8$, mimicking the $\mathrm{pH}$ conditions in the proximal colon [18].

\section{Human faecal inoculum}

Standardized, pooled faecal inoculum from 8 healthy European adults (25-45 years old) was obtained from TNO (Zeist, The Netherlands), prepared and validated as described elsewhere [19]. The subjects were not treated with antibiotics 2 months before faecal donation. The faecal inoculum was activated in SIEM culture medium for $16 \mathrm{~h}$ and diluted 10 times with medium before use.

\section{In vitro fermentation}

For each time point, two $20 \mathrm{~mL}$ fermentation bottles were filled with $9 \mathrm{~mL}$ culture medium, $100 \mathrm{mg}$ barley $\beta$-glucan and $1 \mathrm{~mL}$ of the activated diluted faecal inoculum. SBP was pre-solubilised in medium solution and equally portioned in the appropriate fermentation bottle and inoculated with $1 \mathrm{~mL}$ of activated diluted inoculum. Hence, at the start of both fermentation experiments the faecal inoculum was diluted 100 times and fibre concentrations were $10 \mathrm{mg} / \mathrm{mL}$. The bottles were immediately closed with rubber stoppers in an anaerobic chamber, sealed with an aluminium cap and incubated at $37{ }^{\circ} \mathrm{C}$ with shaking at $130 \mathrm{rpm}$ for a maximum of 48 hours. Blanks with either no substrate or no inoculum were prepared as controls. Samples were taken for analysis after $0,5,11,24$ and 48 hours for barley $\beta$-glucan and 0, 6, 11, 12, 24 and 48 hours for 
SBP. At each time point $5.5 \mathrm{~mL}$ of the fermentation mixture was heated for $5 \mathrm{~min}$ at $100{ }^{\circ} \mathrm{C}$ to stop bacterial activity.

\section{Chemical analyses}

\section{Constituent monosaccharide composition}

SBP fermentation digesta were separated into soluble and insoluble fractions by centrifugation (10 min, RT (room temperature), $18000 \mathrm{x} \mathrm{g}$ ). The constituent monosaccharide composition of the dried soluble and insoluble SBP fermentation fractions was determined using a pre-hydrolysis step with $72 \%(\mathrm{w} / \mathrm{w})$ sulphuric acid at $30^{\circ} \mathrm{C}$ for 1 hour, followed by hydrolysis with $1 \mathrm{M}$ sulphuric acid at $100{ }^{\circ} \mathrm{C}$ for 3 hours. The monosaccharides released, were derivatized to alditol acetates and analysed by gas chromatography using inositol as an internal standard [20]. The presence of uronic acid (UA) in the samples was quantified by using the colorimetric m-hydroxydiphenyl assay [21] automated on a skalar autoanalyser (Skalar, Breda, The Netherlands) [22].

\section{Molecular weight distribution using HPSEC}

The fermentation samples were centrifuged (10 min, RT, $18000 \mathrm{x} \mathrm{g})$ and the supernatant was analysed for molecular weight distribution of soluble PS present, by high performance size exclusion chromatography (HPSEC) on an Ultimate 3000 HPLC (Dionex, Sunnyvale, CA, USA) equipped with a Shodex RI-101 refractive index detector (Showa Denko, Tokyo, Japan). Three TSK-Gel columns connected in series (4000-3000-2500 SuperAW; 150 x 6 mm) were used for the analysis. These columns were preceded by a TSK Super AW-L guard column ( 35 x 4.6mm) (Tosoh Bioscience, Tokyo, Japan) and covered a molecular mass range from 0-250 kDa. Twenty $\mu \mathrm{L}$ samples were injected and eluted with $0.2 \mathrm{M} \mathrm{NaNO}_{3}$, at $40{ }^{\circ} \mathrm{C}$ with a flow rate of 0.6 $\mathrm{mL} / \mathrm{min}$. Pullulan molecular-mass standards (Polymer Laboratories, Palo Alto, CA, USA) were used for calibration.

\section{Oligosaccharide profiling with HPAEC}

After centrifugation of the fermentation samples (10 min, RT, $18000 \mathrm{x} \mathrm{g})$ the supernatants were analysed for their oligosaccharide profile using high performance anion exchange chromatography (HPAEC) on an ICS5000 system (Dionex), with a CarboPac PA-1 column (2 x $250 \mathrm{~mm}$ ) in combination with a Carbopac PA-1 guard column $(2 \times 50 \mathrm{~mm})$. The elution conditions for barley $\beta$-glucan digesta were the following: the flow rate was $0.3 \mathrm{~mL} / \mathrm{min}$ with an eluent profile starting with $0.02 \mathrm{M}$ $\mathrm{NaOH}$ until $13 \mathrm{~min}$, then increasing to $0.1 \mathrm{M} \mathrm{NaOH}$ in $15 \mathrm{~min}$. The oligosaccharides were eluted from the column using a gradient of 0-500 mM NaOAc in $1 \mathrm{M} \mathrm{NaOH}$ (B) from 15 to $45 \mathrm{~min}$, followed by a gradient to $100 \% \mathrm{~B}$ from 45 to $46 \mathrm{~min}$, which was hold for $7 \mathrm{~min}$. After this, the column was re-equilibrated with $0.1 \mathrm{M} \mathrm{NaOH}$ (A) for 3 min and $0.02 \mathrm{M} \mathrm{NaOH}$ for $20 \mathrm{~min}$. The elution gradient for SBP was different in the following: starting with $0-36 \mathrm{~min}$ from $0 \% \mathrm{~B}$ to $40 \% \mathrm{~B}, 36-40 \mathrm{~min}$ at $100 \% \mathrm{~B}$, and 
Fibre fermentation and immunomodulating properties

40-55 min at $100 \%$ A. An ICS5000 ED (Dionex) pulsed amperometric detector and Chromeleon software version 7 were used for detection and analysis.

\section{Short chain fatty acids (SCFA)}

SCFAs were analysed on a TRACE ${ }^{\mathrm{TM}}$ GC Ultra Gas Chromatograph system coupled with a FID detector (Interscience, Breda, The Netherlands), as described elsewhere [23].

\section{Generation and stimulation of BMDCs}

To obtain BMDCs, 6-10 week old C57bl/6 mice lacking both TLR2 and TLR4 were euthanized and the femurs isolated, washed and gently crushed in $10 \mathrm{ml}$ of RPMI-1640 medium (without HEPES) supplemented with 100 units/ml penicillin G (Invitrogen, Breda, The Netherlands) and $100 \mu \mathrm{g} / \mathrm{ml}$ streptomycin (Invitrogen). Bone marrow cells were filtered using a Steriflip ${ }^{\circledR}$ Filter Unit (Millipore, Billerica, MA, USA) and around 2-4 $\times 10^{4}$-cells per well were seeded in a 96-well flat bottom plate in complete media (RPMI-1640 medium containing 10\% heat-inactivated Fetal Calf Serum (FCS) (SigmaAldrich), 100 units/ml penicillin G, $100 \mu \mathrm{g} / \mathrm{ml}$ streptomycin, $20 \mathrm{ng} / \mathrm{ml}$ of recombinant mouse granulocyte-macrophage colony-stimulating-factor (GM-CSF) (R\&D systems, Minneapolis, MN, USA) and $0.05 \mathrm{mM}$ of $\beta$-mercaptoethanol). Cells were incubated at $37^{\circ} \mathrm{C}$ in $5(\mathrm{v} / \mathrm{v}) \% \mathrm{CO}_{2}$ atmosphere and the medium was changed every three days. On day six BMDCs were stimulated with $400 \mu \mathrm{g} / \mathrm{mL}$ fiber, freeze-dried digesta or digesta blanks containing microbiota and fermentation medium. Other blanks were: SCFA (acetic-, propionic-, butyric acid all in $0.1,0.5$ and $1 \mathrm{mg} / \mathrm{mL}$ concentrations in MES buffer), LPS ( $1 \mu \mathrm{g} / \mathrm{mL})$, depleted zymosan $(20 \mu \mathrm{g} / \mathrm{mL})$ or medium.

\section{Cytokine quantification in culture supernatants}

Supernatants from the BMDC stimulation assays were collected after stimulation for 24 hours. They were analysed for the presence of cytokines (IL-6, IL-10, MCP-I and TNF) using a cytometric bead-based BD mouse inflammation kit that enables multiplex measurements to be made in the same sample (BD Biosciences, Breda, The Netherlands) [24]. The sensitivity-limits of detection, as described by the manufacturer, were as follows: $5.0,17.5,52.7$ and $7.3 \mathrm{pg} / \mathrm{mL}$ for IL-6, IL-10, MCP-I and TNF, respectively. The flow cytometry data were analysed using the BD FCAP software (BD Biosciences).

\section{Statistics}

All statistical tests were performed using Prism 5.0 software (GraphPad, San Diego, CA, USA). Data shown are the means and the standard errors of the means (SEM). Data were tested for normality with the D'Agostino and Pearson normality test. Statistical analyses of normally distributed data were performed with the 2 tailed unpaired $\mathrm{T}$ test. Data that did not show a normal distribution were analysed with the Welch's correction to determine equal variances between the groups. When the 
variances were unequal between the groups, the data were analysed using the unpaired $\mathrm{T}$ test with Welch's correction. Differences were considered statistically significant, highly significant and extremely significant when the $\mathrm{P}$ value were $<0.05,<0.001$ or $<0.0001$, respectively.

\section{RESULTS AND DISCUSSION \\ Physico-chemical and immunological characteristics of barley $\beta$-glucan and SBP}

The monosaccharide composition showed that barley $\beta$-glucan consists of $99 \mathrm{~mol} \%$ glucose. SBP consists for $80 \mathrm{~mol} \%$ of galacturonic acid forming the pectin backbone next to small amounts of rhamnose (2 mol\%), arabinose (6 mol\%) and galactose (12 mol\%). Of all galacturonic acid residues $53 \mathrm{~mol} \%$ are methyl esterified and $17 \mathrm{~mol} \%$ acetylated [12]. The protein content of $\beta$-glucan and SBP was $<1$ and $4.8 \mathrm{w} / \mathrm{w} \%$, respectively. At RT $25(\mathrm{w} / \mathrm{w}) \%$ of $\beta$-glucan and 37 (w/w) \% of SBP was water-soluble (no further data shown).

In previous studies we have shown that the barley $\beta$-glucan and SBP used in this study, induced different amounts of cytokines in BMDCs from TLR2/4 knock out mice [11, 17]. The parental suspensions and particulate fractions were more immunostimulatory than the soluble fractions. Heating the suspended substrates at $80{ }^{\circ} \mathrm{C}$ for $10 \mathrm{~min}$ completely dissolved the substrates, resulting in a reduction in cytokine secretion by stimulated BMDCs. Freeze-drying and re-suspending the solubilized material increased the cytokine production of stimulated BMDCs (Supplementary Figure 1) [11, 17]. This indicates that the immunostimulatory activity of the two substrates was partly affected by freeze-drying and heating, which was used to stop enzymatic reactions.

\section{$\mathrm{pH}$ Monitoring of in vitro batch fermentation of fibres}

The $\mathrm{pH}$ of the barley $\beta$-glucan in vitro batch fermentation started to increase from 5.8 to $\mathrm{pH} 6.2$ within 8 hours of fermentation. This may indicate the microbial utilization of protein in the medium at the beginning of the fermentation, due to a lack in degradability of the barley $\beta$-glucans, resulting in the production of ammonia instead of SCFA [25]. The pH then fluctuated to $5.9(10 \mathrm{~h}), 6.2(11 \mathrm{~h}), 6.3 \mathrm{(24} \mathrm{h})$ and 6.0 (48 h). These minimal $\mathrm{pH}$ changes over time suggest the presence of different glucan populations of different fermentability.

The $\mathrm{pH}$ of the SBP fermentation increased from 5.8 to $\mathrm{pH} 6.0$ within 9 hours of fermentation and can be accounted for the microbial utilization of proteins in the medium as also described above. From 12 hours to $48 \mathrm{~h}$ of fermentation a decrease to a $\mathrm{pH}$ of 5.5 was observed, due to a relatively high increase in acids (SCFA and nonmethylated galacturonic acid residues). 
Fibre fermentation and immunomodulating properties

\section{Short chain fatty acids production}

The microbial production of SCFAs during in vitro fermentation is one of the indicators of fermentability of the fibre and will be discussed for the individual fibres.

\section{Barley $\beta$-glucan fermentation}

After three hours of fermentation the production of SCFA started to increase from 2.5 $\mathrm{mmol} / \mathrm{g}$ barley $\beta$-glucans to a maximum of $6.3 \mathrm{mmol} / \mathrm{g}$ barley $\beta$-glucans at $24 \mathrm{~h}$, of which 1.4 and $1.1 \mathrm{mmol} / \mathrm{g}$ barley $\beta$-glucans were propionic and butyric acid, respectively (Figure $1 \mathrm{~A}$ ). Together they constitute ca. $30 \mathrm{~mol} \%$ of the total SCFA from $3 \mathrm{~h}$ onwards. The remaining part (70 mol\%) was acetic acid, reaching a maximum of $3.9 \mathrm{mmol} / \mathrm{g}$ barley $\beta$-glucans at $24 \mathrm{~h}$ and remaining constant till $48 \mathrm{~h}$. The molar ratio of acetic, propionic and butyric acid at $48 \mathrm{~h}$ was 67:21:12.

\section{Sugar beet pectin fermentation}

The SCFA production of SBP seems to be in exponential increase and within $12 \mathrm{~h}$ fermentation ca. $40 \%$ of the total SCFA present at $48 \mathrm{~h}$ are produced (Figure $1 \mathrm{~B}$ ). The fermentation of SBP led to minor amounts of propionic acid (maximum $5 \mathrm{mmol} \%$ of total SCFA) and butyric acid ( $1 \mathrm{mmol} \%$ of the total SCFA) at $48 \mathrm{~h}$. The molar ratio of acetic, propionic and butyric acid after 48 hours of fermentation was 95:5:1.

Overall, SBP was fermented much slower than $\beta$-glucan (Figure 1). At $12 \mathrm{~h}$ SBP fermentation only $40 \mathrm{mmol} \%$ of total SCFA was produced, while at $11 \mathrm{~h}$ of $\beta$-glucan fermentation more than $90 \mathrm{mmol} \%$ of the total SCFA present at $48 \mathrm{~h}$ was produced, while. The increase in SCFA for the SBP fermentation at $12 \mathrm{~h}$ is in line with the $\mathrm{pH}$ decrease from that time point onwards. This correlation between $\mathrm{pH}$ and SCFA produced is less pronounced due to the small $\mathrm{pH}$ fluctuations during the $\beta$-glucan fermentation. The total amounts of SCFA formed at the end of the fermentation (48 h) were larger for the SBP fermentation ( $8.5 \mathrm{mmol} / \mathrm{g} \mathrm{SBP} ; 6.3 \mathrm{mmol} / \mathrm{g} \beta$-glucan), which is reflected in the end $\mathrm{pH}$ of the $48 \mathrm{~h}$ time points and indicates that the two substrates are fermented by the human microbiota at different rates and probably also to a different extent.

\section{Fermentation digesta in immunoassays on BMDCs}

As we showed previously that the two substrates are immune-modulating substances $[11,17]$, it was of interest to determine whether also the glycosidic fermentation metabolites are immune stimulating. The freeze-dried digesta from selected time points were tested for their capacity to elicit cytokine production in BMDCs. As was previously demonstrated [11], the BMDCs from TLR2/4 KO mice were unresponsive to common bacterial molecular structures such as LPS, that was anticipated to be present in the digesta [26]. Additionally, it was shown that these BMDCs were also unresponsive to flagellin [11], a component of bacterial flagella, which mediates via TLR5 [27]. 


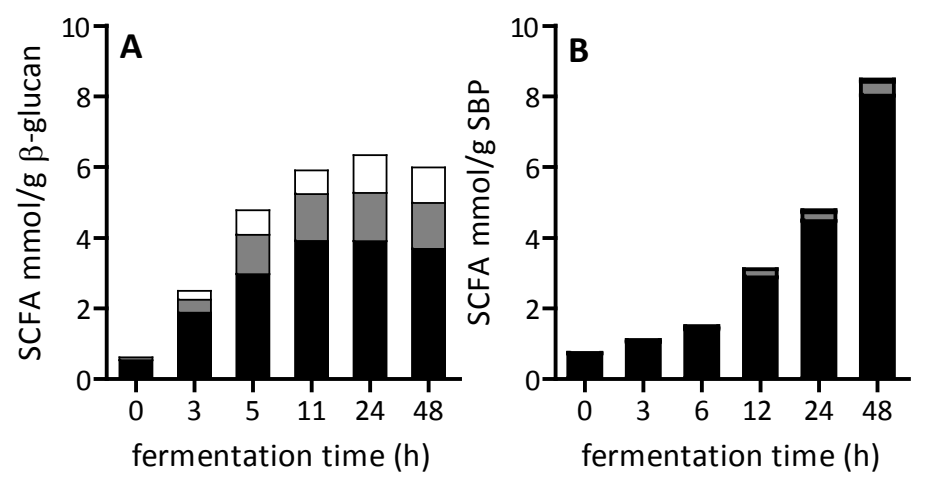

Figure 1: Levels of SCFA produced during the fermentation of barley $\beta$-glucan (A) and SBP (B) using human faecal inocula. acetic acid (black), Propionic acid (grey), butyric acid (white).

The very high concentrations of faecal bacterial cell wall material and the possible presence of SCFA in the digesta could influence the cytokine response in these assays. To test this possibility, fermentation microbiota controls containing only the starting microbiota and fermentation medium (but no substrate) at different fermentation time points (t 0,12, 24, $48 \mathrm{~h}$ ) as well as different concentrations of the three main SCFA were tested for their cytokine induction (Figure 2 and Supplementary Figure 2). Only low amounts of cytokines (e.g. $<900 \mathrm{pg} / \mathrm{mL}$ TNF, $6 \%$ of the positive control) were induced in BMDCs by the controls (SCFA, medium, LPS), while the positive control depleted zymosan, which induces cytokines through Dectin-1 signalling [28], induced high amounts of cytokines (14192 pg/mL TNF) (Supplementary Figure 2). Also the fermentation microbiota blanks induced rather low amounts of cytokines (e.g. 3256 $\mathrm{pg} / \mathrm{mL}$ TNF, $23 \%$ of the positive control), depending on the cytokine (Figure 2). Although the microbiota controls were negative, chances might be still present that microbiota with a completely changed composition may influence the immune activity and needs to be further investigated.

For the digesta containing $\beta$-glucan or SBP, all four cytokines were induced in large amounts (e.g. $18506 \mathrm{pg} / \mathrm{mL}$ TNF for $\beta$-glucan $11 \mathrm{~h}$ ) (Figure 2). This proves that the cytokines were induced due to carbohydrates present and not due to SCFA, LPS and/or flagellin from bacteria. For both substrates a continuous increase of all four cytokines over fermentation time with maxima at $11 \mathrm{~h}$ for $\beta$-glucan and $24 \mathrm{~h}$ for SBP fermentation, was observed. This showed that the fermentation degradation products are more immunomodulatory than the parental fibre at 0 hours. Furthermore, the digesta were not affected by sample preparation steps such as heating or freeze-drying as described above. This is probably due to the high salt concentration of the fermentation digesta. This allowed us to draw conclusions about the immunomodulatory capacity of the fibre components present in the digesta at specific time points and will be discussed in more detail. 

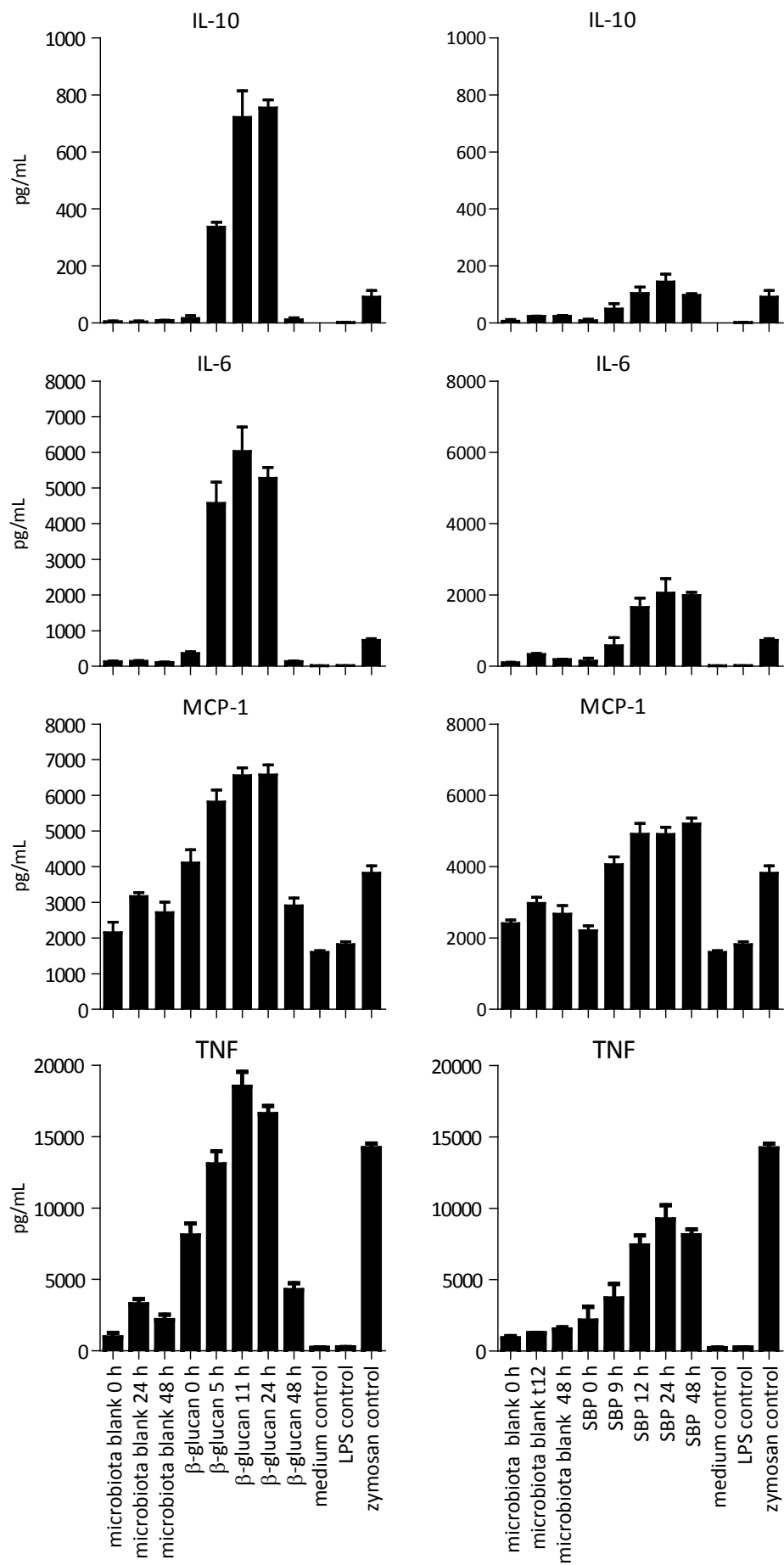

Figure 2: Induced cytokines $(\mathrm{pg} / \mathrm{mL})$ by fermentation digesta of $\beta$-glucan and SBP. Fermentation blanks contain only fermentation medium and microbiota. 


\section{Immunomodulatory effects of soluble and insoluble fibres}

As it was shown that the intact fibres and their degradation products induced cytokines in BMDCs, the fibre products present at each time point was of interest. Previous studies on these two intact fibres showed a positive correlation between dose and amounts of induced cytokines $[11,17]$. The insoluble $\beta$-glucans and SBP induced much higher amounts of cytokines than the soluble $\beta$-glucans and SBP fractions (Supplementary Figure 1) [11, 17]. Hence, the amounts of soluble and insoluble dietary fibres in the digesta in relation to immunomodulation are of interest.

Difficulties existed in precisely separating soluble parts from the insoluble parts of the $\beta$-glucan digesta due to its rather viscous consistency, resulting in untrustworthy amounts of soluble and insoluble $\beta$-glucans, as determined with an enzyme kit (AACC Method 32-23.01, (Megazyme)). Hence, these results are not mentioned and discussed.

\section{Sugar beet pectin}

At time point $0 \mathrm{~h}$ the amounts of all induced cytokines were lowest (Figure 2). At this time the PS was present in its unfermented form. An increase in amounts of induced cytokines was measured over time up to $24 \mathrm{~h}$. The amount of insoluble SBP increased up to $12 \mathrm{~h}$ fermentation (Figure 3), while the total SBP amounts remained rather constant, indicating that precipitation of the pectin occurred. With the increased amounts of insoluble SBP, also the amounts of induced cytokines increased (Figure 2). This suggests that the cytokines were induced by insoluble SBP.

From 12 h of fermentation onwards the total amounts of SBP decreased substantially, especially the amount of soluble SBP. Together with the measurements of $\mathrm{pH}$ and SCFA, which decreased and increased, respectively, from $12 \mathrm{~h}$ onwards, we concluded that this was the start of the main SBP fermentation.

At $48 \mathrm{~h}$ of fermentation mainly soluble SBP was detected $(1.3 \mathrm{mg} / \mathrm{mL}$ digest) and large amounts of cytokines (8112 pg/mL TNF) were induced by the digesta at this time point. This indicates that soluble glycosidic metabolites of SBP fermentation can also induce cytokine production in immune cells.

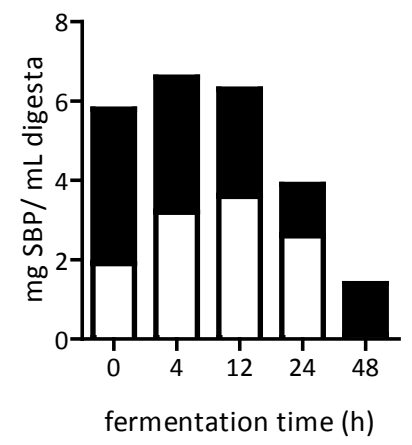

Figure 3: Amounts of soluble (black) and insoluble (white) SBP present in fermentation digesta. 


\section{Polysaccharide degradation of fibres during fermentation}

As not only insoluble fibres, but also soluble fermentation metabolites seem to induce cytokines in BMDCs, the digesta were characterised for the molecular masses of the soluble PS by HPSEC (Figure 4).

\section{Molecular mass distribution during $\beta$-glucan fermentation}

Soluble PSs were detected by HPSEC analysis (Figure $4 \mathrm{~A}$ ). At time point $0 \mathrm{~h}$ the original molecular mass of soluble $\beta$-glucan polymer ranged between $60-370 \mathrm{kDa}$ and remained that size within 5 hours of fermentation, while the amount of these molecules decreased. This was either due to its utilisation by the microbiota and/or due to modification into insoluble molecules.

At 11 hours of fermentation a shift of the higher molecular mass to ca. $60 \mathrm{kDa}$ was observed. Hence, endo-acting enzymes, which degrade the glucan backbone, were present in the digest. At $11 \mathrm{~h}$ the largest amounts of cytokines were induced in the immunoassay. Within the next 13 hours of fermentation the molecular mass of the soluble barley $\beta$-glucans remained the same. The amount of soluble $\beta$-glucans decreased, indicating that the glucans were partly degraded or precipitated. After 48 hours the soluble polymer had almost completely disappeared.

\section{Molecular mass distribution during SBP fermentation}

The degradation profile of SBP revealed that mainly side chain degradation occurred, as no large shift of the molecular mass was observed during the fermentation, as was the case for the barley $\beta$-glucan fermentation.

Soluble PSs at time point $0 \mathrm{~h}$ consisted of a molecular mass range of 18-370 $\mathrm{kDa}$. At $48 \mathrm{~h}$ of SBP fermentation, highest amounts of cytokines were induced and only soluble glycosidic fermentation metabolites were present (Figure 3), having a molecular mass of $60 \mathrm{kDa}$ (Figure $4 \mathrm{~B}$ ). This indicates that soluble SBP might have been responsible for the induced cytokines.

The comparison of the two fermentation substrates showed that each dietary fibre was fermented differently, which led to different metabolites and end products. This difference was expected since the substrates are different in their chemical structure and require different enzymes for degradation. Both substrates seemed to have immunomodulatory active PSs of rather similar molecular mass (60 kDa). 

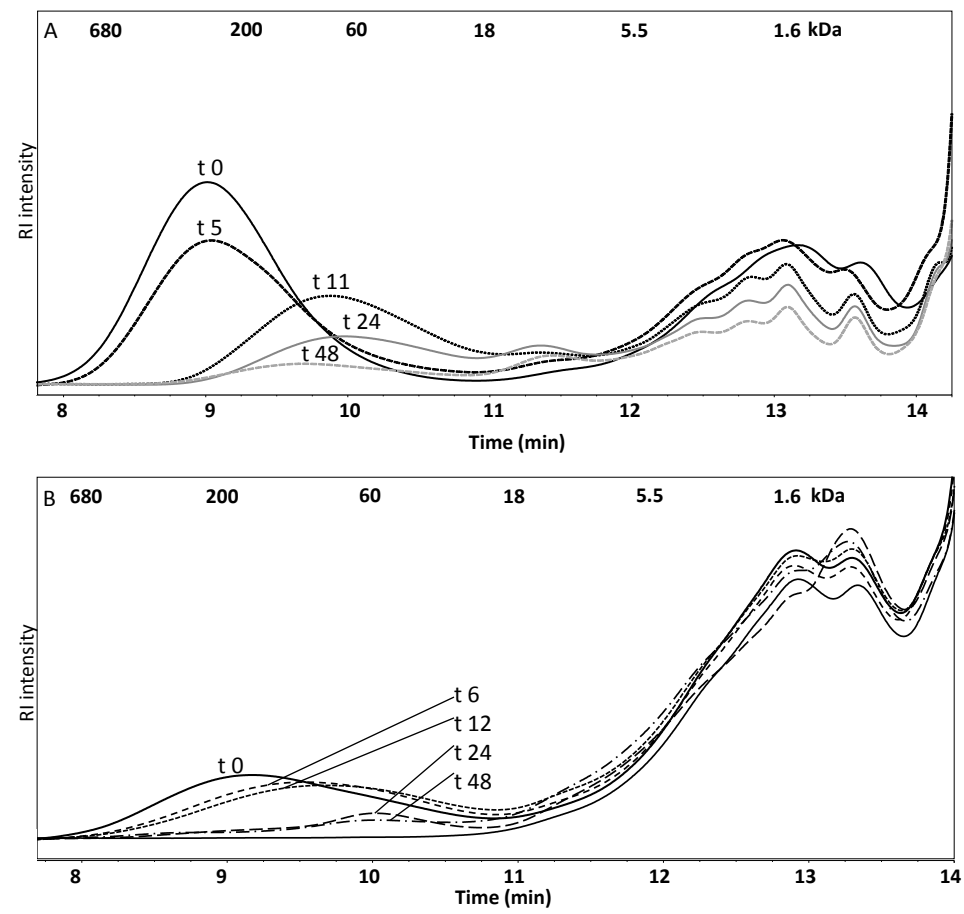

Figure 4: HPSEC polysaccharide profile of barley $\beta$-glucan $(A)(0,5,11,24,48 \mathrm{~h})$ and $\operatorname{SBP}(B)(0,6,12$, $24,48 \mathrm{~h}$ ) fermentation digesta.

\section{Oligosaccharide formation during fermentation}

Since soluble PS were detected with HPSEC, the formation of low molecular mass (LMW) and intermediate molecular mass (IMW) molecules was expected. Furthermore, soluble IMW or LMW present, could be responsible for the immunomodulation of the fermentation digesta as previously suggested [29]. The formation of LMW molecules (< DP 20) and intermediate molecular weight (IMW) molecules ( $>$ DP 20; upper DP limit cannot be predicted from the pattern) during in vitro fermentation of the two substrates was monitored by HPAEC (Figure 5).

\section{$\beta$-Glucan fermentation degradation products}

Soluble glycan degradation products formed during the barley $\beta$-glucan degradation were detected in increasing amounts (Figure $5 \mathrm{~A}$ ). They were present in increasing amounts, because the fermentation of $\beta$-glucan was fast and determined by soluble and insoluble populations, leading to an imbalance in production and utilisation of soluble intermediate products. The degradation products eluted mainly between retention time (Rt) 22 and $50 \mathrm{~min}$, and could not be fully separated. These oligomers and disappear over fermentation time, which can be related to the fermentation of first all soluble, then followed by insoluble $\beta$-glucans at later stages of fermentation. 

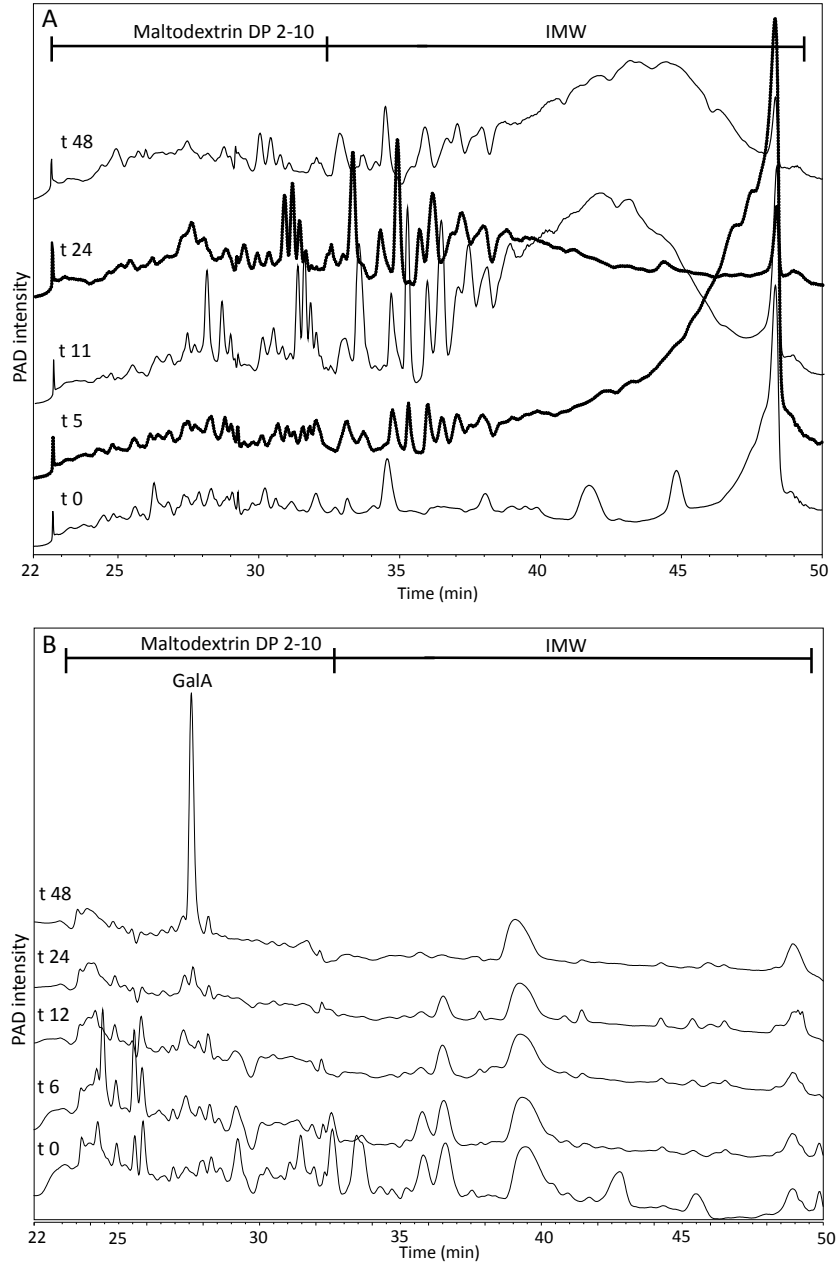

Figure 5: HPAEC elution profiles of barley $\beta$-glucan fermentation digesta $(A)(0,5,11,24,48 \mathrm{~h})$ and SBP fermentation digesta (B) $(0,6,12,24,48 \mathrm{~h})$. IMW, intermediate molecular weight.

The fermentation digesta of 11 and 48 hour consisted of similar soluble degradation products, but only the digesta of $11 \mathrm{~h}$ induced large amounts of cytokines. Also the 24 $\mathrm{h}$ fermentation digesta induced large amounts of cytokines, consisting of mainly soluble IMWs in comparison to the $11 \mathrm{~h}$ digesta. The only common molecules present in the 11 and $24 \mathrm{~h}$ digesta are the LMWs (eluting between 25 and $35 \mathrm{~min}$ ) and were in lower amounts present in the $48 \mathrm{~h}$ digesta and could thus be responsible for the immune stimulation described.

\section{Sugar beet pectin fermentation degradation products}

Contrary to the formation of degradation products during the $\beta$-glucan fermentation, almost no soluble OS were formed during the SBP fermentation (Figure 5B). Only at $48 \mathrm{~h}$ of fermentation galacturonic acid was detected. Since the fermentation of SBP is 
rather slow, it could be the case that easily degradable OS metabolites were immediately utilized by the bacteria and thus not detected. The preferential fermentation of soluble fibre over insoluble fibre has been also observed for pectins present in chicory root pulp [18].

As only large soluble PS (HPSEC) were present at $48 \mathrm{~h}$ fermentation, the stimulation of cytokine secretion in BMDCs was due to large soluble PS molecules (ca. $60 \mathrm{kDa}$ ) (HPSEC) (Figure 4).

Overall, barley $\beta$-glucan and especially SBP, are rather slowly fermentable PSs under the current experimental conditions. For $\beta$-glucan this was probably due to the partial insolubility [18]. For SBP the explanation could be, besides its partly insolubility, that SBP is a rather structurally complex and difficult to degrade PSs. The potential benefit of slow fibre fermentation is that bioactive degradation products could be present in the intestine for a longer time to interact with epithelial and immune cells. In addition, fermentation is also shifted to the more distal colon parts [30].

\section{Fermentation profile of SBP on monosaccharide constitution level}

As it was observed that the molecular structure is also of importance for immunomodulatory activity and SBP consists of many different monosaccharides, it was of interest to analyse which of the glycan moieties present in the oligo- and PSs, were fermented quickly and which were still present in the digesta and not utilized by the microbiota.

Figure 6 and Supplementary Table 1 show the utilisation of soluble and insoluble arabinose, galactose and galacturonic acid, the main monosaccharides in SBP. The amounts of soluble galacturonic acid rich fragments decreased mostly only after $12 \mathrm{~h}$ of fermentation, while soluble polymers rich in galactose and arabinose decreased continuously up to $24 \mathrm{~h}$. For the rest of the fermentation soluble galactose increased, which might originate from the degradation of the insoluble pectin fraction. Insoluble polymers rich in galacturonic acid, galactose and arabinose increased during the first $12 \mathrm{~h}$ of fermentation and were subsequently almost completely utilised at $48 \mathrm{~h}$.

The immune-stimulating SBP digesta of $48 \mathrm{~h}$ consisted of a high amount of soluble galactose rich fragments, which suggests that soluble pectin of equal ratios of galacturonic acid and galactan could be an immune stimulating compound.

Furthermore, the constituent monosaccharide analysis of the SBP digesta showed that no rhamnose was present in the soluble digesta. This indicates that the rhamnogalacturonan I (RG I) backbone is present only in the insoluble fraction, which is confirmed by the high amounts of arabinose and galactose, which are known to be attached to the RG I backbone [13] (Supplementary Table 1). 

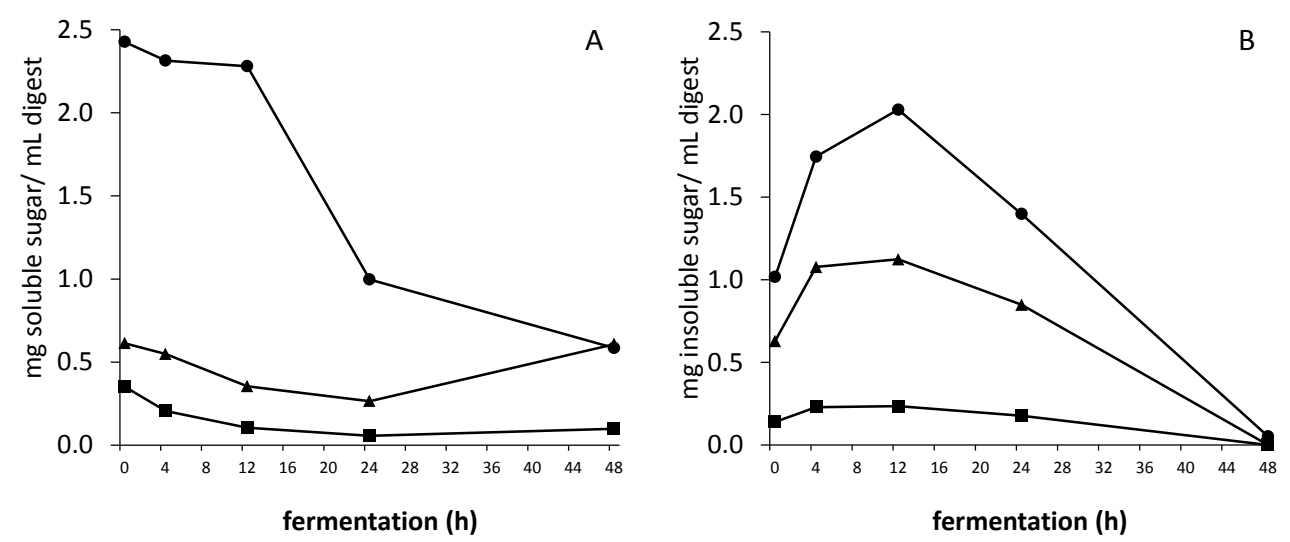

Figure 6: Amounts of soluble (A) and insoluble (B) arabinose $(\boldsymbol{\square})$, galactose $(\mathbf{A})$ and galacturonic acid $(\bullet)$ present as oligo- or polysaccharide in the SBP fermentation digesta.

\section{Possible molecular characteristics of immune-active dietary fibres}

In the highly immunomodulating $\beta$-glucan digesta, two soluble degradation populations were present $(60 \mathrm{kDa}$ and below $\mathrm{DP}$ 20). An increase in immunomodulation was also observed before for enzymatically degraded barley $\beta$ glucans having lower molecular masses [17]. Amounts of insoluble glycans are unknown, but assumed to be present and also to be immunomodulatory.

In the highly immunomodulating SBP digesta, soluble galactan side chains and insoluble galacturonic acid backbones were present. The total amounts of SPB and its degradation products negatively correlated with the amounts of induced cytokines. This indicates that also SBP degradation products are more immune modulating than the parental fibres. Furthermore, for SBP a positive correlation between amounts of cytokines and insoluble fibres was observed.

The induced cytokine amounts are ca. 1.6 to 5.3 fold larger for barley $\beta$-glucan than SBP digesta, depending on the type of cytokine and fermentation time point. This shows that there are differences in immunomodulatory activity between the PS and their glycan degradation products, as well as between the two different fibres. This could be related to molecular differences as suggested in a previous study [11]. In addition to the immunomodulatory effect of the parental fibres, the difference in fibre fermentation may have implications for in vivo effects upon ingestion of these fibres, and could lead to differences in health effects.

\section{CONCLUSIONS}

In vitro fermentation digesta can be directly incubated with BMDCS from mice lacking both TLR2 and TLR4 receptors in order to study the immunostimulatory effect of dietary fibres and their microbiota-generated degradation products. This is one of the first studies investigating complex fermentation digesta for their immune response. Glycosidic soluble and insoluble fermentation metabolites were more 
immunomodulating than the parental fibres. This may have implication for health effects in human individuals when ingesting different dietary fibres. This also highlights the importance and need for innovative fermentation models integrating immune cells. Furthermore, detailed fermentation studies of dietary fibres, including the characterisation of degradation products, in order to make conclusions about beneficial health effects of dietary fibres, are needed.

\section{ABbreviations}

SBP, sugar beet pectin; SCFA, short chain fatty acids; LMW, low molecular weight; IMW, intermediate molecular weight.

\section{ACKNOWLEDGEMENTS}

This work has been funded by TIFN (Top Institute Food and Nutrition) project GH004.2. Uttara Ramasamy is gratefully acknowledged for her help with the in vitro fermentation studies.

\section{REFERENCES}

[1] European-Commission, Commission Directive 2008/100/EC of 28 October 2008 amending Council Directive $90 / 496 / E E C$ on nutrition labelling for foodstuffs as regards recommended daily allowances, energy conversion factors and definitions. Official Journal of the European Union 2008, L 285, 9-12.

[2] Montagne, L., Pluske, J., Hampson, D., A review of interactions between dietary fibre and the intestinal mucosa, and their consequences on digestive health in young non-ruminant animals. Animal Feed Science and Technology 2003, 108, 95-117.

[3] Scott, K., Duncan, S., Flint, H., Dietary fibre and the gut microbiota. Nutrition Bulletin 2008, 33, $201-211$.

[4] Atarashi, K., Tanoue, T., Ando, M., Kamada, N., et al., Th17 cell induction by adhesion of microbes to intestinal epithelial cells. Cell 2015, 163, 367-380.

[5] Atarashi, K., Tanoue, T., Oshima, K., Suda, W., et al., Treg induction by a rationally selected mixture of Clostridia strains from the human microbiota. Nature 2013, 500, 232-236.

[6] Ueki, T., Mizuno, M., Uesu, T., Kiso, T., Tsuji, T., Expression of ICAM-I on M cells covering isolated lymphoid follicles of the human colon. Acta Medica Okayama 1995, 49, 145-151.

[7] Dambuza, I. M., Brown, G. D., C-type lectins in immunity: recent developments. Current Opinion in Immunology 2015, 32, 21-27.

[8] Legentil, L., Paris, F., Ballet, C., Trouvelot, S., et al., Molecular interactions of $\beta$ - $(1 \rightarrow 3)$-glucans with their receptors. Molecules 2015, 20, 9745-9766.

[9] Cohen-Kedar, S., Baram, L., Elad, H., Brazowski, E., et al., Human intestinal epithelial cells respond to $\beta$ glucans via Dectin-1 and Syk. European Journal of Immunology 2014, 44, 3729-3740.

[10] Kimberg, M., Brown, G. D., Dectin-1 and its role in antifungal immunity. Medical Mycology 2008, 46, 631636.

[11] Meijerink, M., Rösch, C., Taverne, N., Venema, K., Gruppen, H., Schols, H. A., Structure related immunomodulation by sugar beet arabinans is induced via Syk tyrosine kinase-dependent pathway. This thesis, chapter 2.

[12] Remoroza, C., Cord-Landwehr, S., Leijdekkers, A. G. M., Moerschbacher, B. M., et al., Combined HILICELSD/ESI-MSn enables the separation, identification and quantification of sugar beet pectin derived oligomers. Carbohydrate Polymers 2012, 90, 41-48.

[13] Schols, H. A., Coenen, G. J., Voragen, A. G. J., in: Schols, H. A., Visser, R. G. F., Voragen, A. (Eds.), Pectins and pectinases, Wageningen Academic Publishers, Wageningen, The Netherlands 2009, pp. 19-31.

[14] Venema, K., van den Abbeele, P., Experimental models of the gut microbiome. Best Practice \& Research Clinical Gastroenterology 2013, 27.

[15] Marzorati, M., Vanhoecke, B., De Ryck, T., Sadaghian Sadabad, M., et al., The HMI ${ }^{\mathrm{TM}}$ module: a new tool to study the Host-Microbiota Interaction in the human gastrointestinal tract in vitro. BMC Microbiology 2014, 14, 114. 
Fibre fermentation and immunomodulating properties

[16] Possemiers, S., Pinheiro, I., Verhelst, A., Van den Abbeele, P., et al., A dried yeast fermentate selectively modulates both the luminal and mucosal gut microbiota and protects against inflammation, as studied in an integrated in vitro approach. Journal of Agricultural and Food Chemistry 2013, 61, 9380-9392.

[17] Rösch, C., Meijerink, M., Delahaije, R. J., Taverne, N., et al., Immunomodulatory effects of oat and barley $\beta$ glucans on bone marrow derived dendritic cells. This thesis, chapter 3.

[18] Ramasamy, U. S., Venema, K., Schols, H. A., Gruppen, H., Effect of soluble and insoluble fibers within the in vitro fermentation of chicory root pulp by human gut bacteria. Journal of Agricultural and Food Chemistry 2014, 62, 6794-6802.

[19] Minekus, M., Smeets-Peeters, M., Bernalier, A., Marol-Bonnin, S., et al., A computer-controlled system to simulate conditions of the large intestine with peristaltic mixing, water absorption and absorption of fermentation products. Applied Microbiology and Biotechnology 1999, 53, 108-114.

[20] Englyst, H. N., Cummings, J. H., Simplified method for the measurement of total non-starch polysaccharides by gas - liquid chromatography of constituent sugars as alditol acetates. The Analyst 1984, 109, 937-942.

[21] Ahmed, A. E. R., Labavitch, J. M., A simplified method for accurate determination of cell wall uronide content. Journal of Food Biochemistry 1978, 1, 361-365.

[22] Thibault, J., Automatisation du dosage des substances pectiques par la méthode au méta-hydroxydiphenyl. Lebensmittel-Wissenschaft und Technologie. 1979, 12.

[23] Ladirat, S. E., Schuren, F. H., Schoterman, M. H., Nauta, A., et al., Impact of galacto-oligosaccharides on the gut microbiota composition and metabolic activity upon antibiotic treatment during in vitro fermentation. FEMS Microbiology Ecology 2014, 87, 41-51.

[24] Morgan, E., Varro, R., Sepulveda, H., Ember, J. A., et al., Cytometric bead array: a multiplexed assay platform with applications in various areas of biology. Clinical Immunology 2004, 110, 252-266.

[25] Cone, J. W., van Gelder, A. H., Influence of protein fermentation on gas production profiles. Animal Feed Science and Technology 1999, 76, 251-264.

[26] Tan, Y., Kagan, Jonathan C., A cross-disciplinary perspective on the innate immune responses to bacterial lipopolysaccharide. Molecular Cell 2014, 54, 212-223.

[27] Hayashi, F., Smith, K. D., Ozinsky, A., Hawn, T. R., et al., The innate immune response to bacterial flagellin is mediated by Toll-like receptor 5 . Nature 2001, 410, 1099-1103.

[28] Brown, G. D., Herre, J., Williams, D. L., Willment, J. A., et al., Dectin-1 mediates the biological effects of $\beta$ glucans. The Journal of Experimental Medicine 2003, 197, 1119-1124.

[29] Sahasrabudhe, N. M., Tian, L., van den Berg, M., Bruggeman, G., et al., Endo-glucanase digestion of oat $\beta$ glucan enhances Dectin-1 activation in human dendritic cells. Journal of Functional Foods 2016, 21, $104-112$.

[30] Jonathan, M. C., Haenen, D., da Silva, C. S., Bosch, G., et al., Influence of a diet rich in resistant starch on the degradation of non-starch polysaccharides in the large intestine of pigs. Carbohydrate Polymers 2013, 93, 232239. 


\section{SUPPLEMENTARY DATA:}
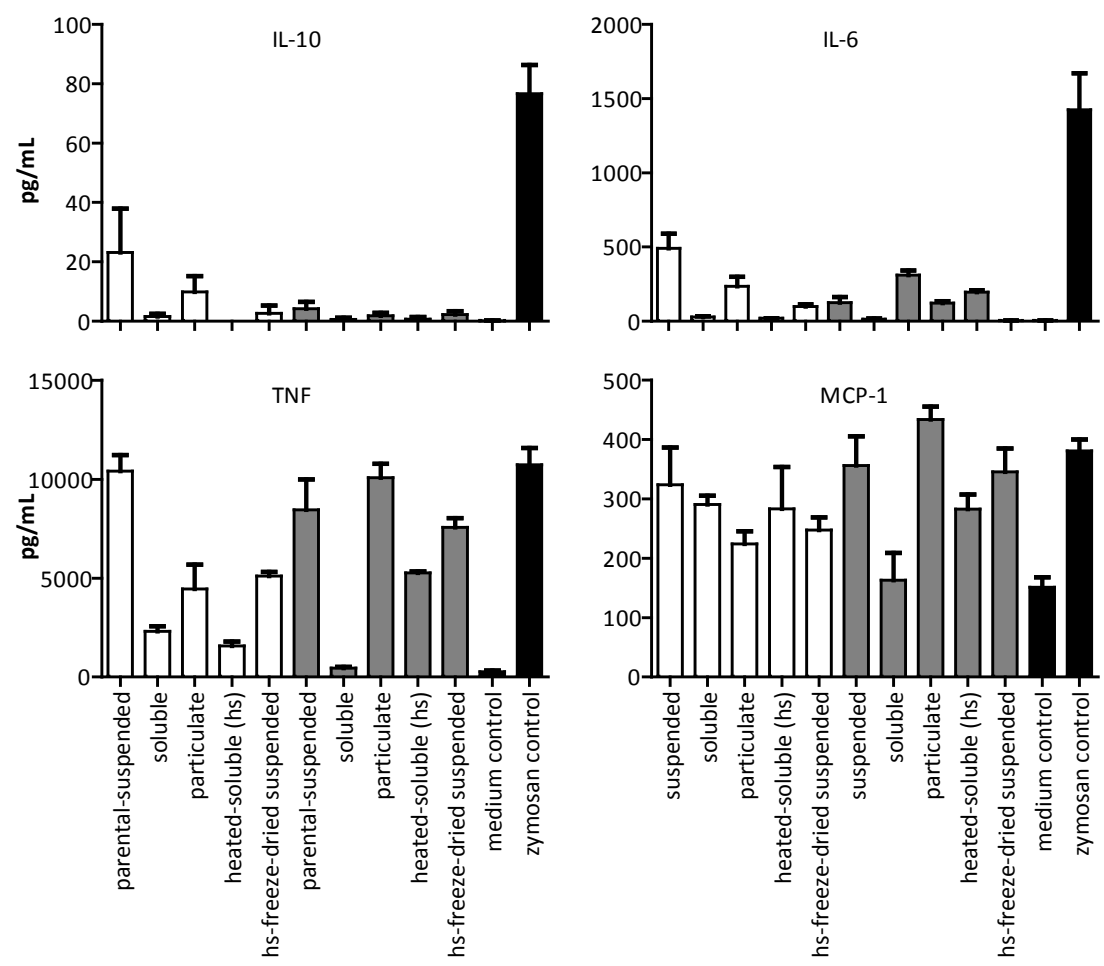

Supplementary Figure 1: Cytokines induced by different fractions of barley $\beta$-glucan (white) and SBP (grey) and blanks or controls (black). hs, heated-soluble. 
Fibre fermentation and immunomodulating properties
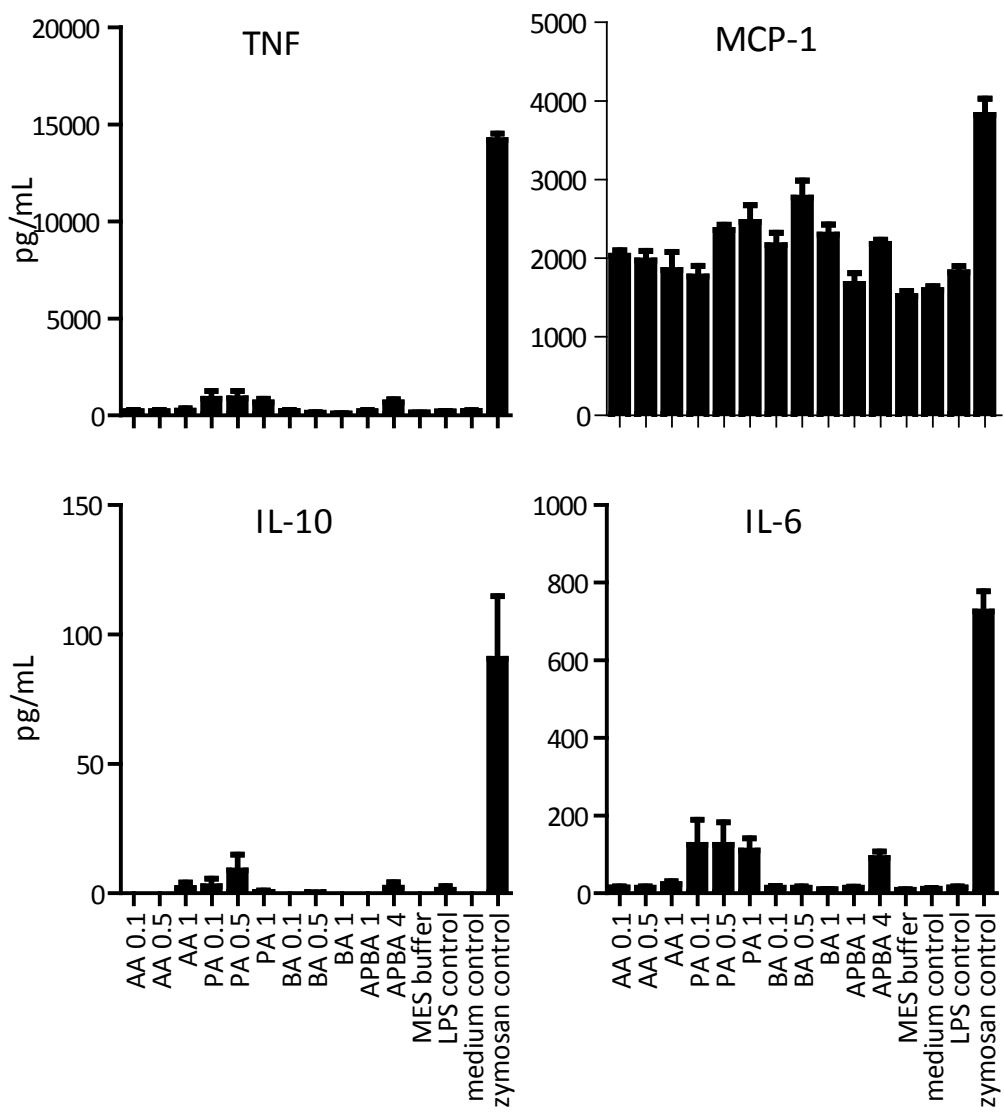

Supplementary Figure 2: Cytokine induction by SCFA $(0.1,0.5,1 \mathrm{mg} / \mathrm{mL})$, MES buffer, medium, LPS and depleted zymosan controls. AA, acetic acid; PA, propionic acid; BA, butyric acid. APBA, acetic-, propionic-, butyric acid. 


\section{CHAPTER 4}

Supplementary Table 1: Monosaccharide composition of SBP fermentation digesta per $1 \mathrm{~mL}$ digesta.

\begin{tabular}{|c|c|c|c|c|c|c|c|c|c|c|c|}
\hline \multicolumn{10}{|c|}{$\mathrm{mg} / \mathrm{mL}$ digest } & \multirow{3}{*}{$\begin{array}{c}\text { total } \\
\text { w/w\% }\end{array}$} & \multirow{3}{*}{$\begin{array}{c}\text { ratio (mol\%) } \\
\text { ara:gal:uronic acid }\end{array}$} \\
\hline & & & & & & & & Uronic & & & \\
\hline & & Rha & Ara & Xyl & Man & Gal & Glc & acid & total & & \\
\hline \multirow{5}{*}{$\frac{\frac{0}{0}}{\frac{0}{2}}$} & t 0 & 0.0 & 0.4 & 0.0 & 0.0 & 0.6 & 0.5 & 2.4 & 3.9 & 8.7 & $1: 2: 7$ \\
\hline & t 4 & 0.0 & 0.2 & 0.0 & 0.0 & 0.5 & 0.4 & 2.3 & 3.4 & 9.2 & $1: 2: 7$ \\
\hline & t 12 & 0.0 & 0.1 & 0.0 & 0.0 & 0.4 & 0.0 & 2.3 & 2.7 & 7.4 & $0: 2: 8$ \\
\hline & t 24 & 0.0 & 0.1 & 0.0 & 0.0 & 0.3 & 0.0 & 1.0 & 1.3 & 4.2 & $0: 2: 8$ \\
\hline & t 48 & 0.0 & 0.1 & 0.0 & 0.0 & 0.6 & 0.0 & 0.6 & 1.3 & 3.9 & $1: 5: 4$ \\
\hline \multirow{5}{*}{$\begin{array}{l}\frac{0}{0} \\
\frac{\partial}{0} \\
. \subseteq\end{array}$} & t 0 & 0.1 & 0.1 & 0.0 & 0.0 & 0.6 & 0.1 & 1.0 & 1.9 & 51.0 & $1: 4: 5$ \\
\hline & t 4 & 0.1 & 0.2 & 0.0 & 0.0 & 1.1 & 0.1 & 1.7 & 3.2 & 47.2 & $1: 4: 5$ \\
\hline & t 12 & 0.2 & 0.2 & 0.0 & 0.0 & 1.1 & 0.0 & 2.0 & 3.6 & 55.6 & $1: 3: 6$ \\
\hline & t 24 & 0.1 & 0.2 & 0.0 & 0.0 & 0.8 & 0.0 & 1.4 & 2.6 & 27.5 & $1: 3: 6$ \\
\hline & $\mathrm{t} 48$ & 0.0 & 0.0 & 0.0 & 0.0 & 0.0 & 0.0 & 0.1 & 0.1 & 1.2 & 0:0:10 \\
\hline
\end{tabular}




\title{
Chapter 5
}

\section{Characterisation and in vitro fermentation of resistant maltodextrins using human faecal inoculum and analysis of bacterial enzymes present}

\begin{abstract}
A commercially available resistant maltodextrin (RMD), which is made out of corn starch by chemically and enzymatically modification, consists of a-typical starch linkages and a low average molecular mass of $2 \mathrm{kDa}$. These characteristics of RMD make it rather complicated to identify with any chromatographic or masspectrometric method at this moment.

A batch fermentation with human inocula over 48 hours under anaerobic conditions showed that the degradation of the indigestible RMD is slow in comparison to dietary fibres like FOS. The RMD is only fermentable for ca. $60 \%$ and no specific oligosaccharide within the RMD population seems to be preferentially utilised by the microbiota present.

Short chain fatty acid (SCFA) production, with acetic acid as the main SCFA, started after ca. 5 hours of fermentation, while the increase of SCFA at 11 hours was concurrent with the major degradation of the oligosaccharides of RMD. The microbiota composition as analysed by HITchip, revealed that RMD slightly stimulated the growth of bifidobacteria in comparison to the blank.

The activity of carbohydrate degrading enzymes, produced by the microbiota during the in vitro fermentation, revealed that potential capacity to degrade typical starch linkages was high, but the RMD was only slowly and partly degradable during the incubation of 20 hours.
\end{abstract}

Published as:

Rösch, C., Venema, K., Gruppen, H., \& Schols, H. A. (2015). Characterisation and in vitro fermentation of resistant maltodextrins using human faecal inoculum and analysis of bacterial enzymes present. Bioactive Carbohydrates and Dietary Fibre, 6(1), 46-53. 


\section{INTRODUCTION}

Resistant starch (RS) belongs to the group of dietary fibre and can be categorised into four types. RS type 1 is physically unavailable starch, RS 2 is raw starch and RS 3 is retrograded starch [1, 2]. Fibersol-2® used in this study belongs to RS 4, chemically modified starches. It is a thermally and enzymatically treated starch, which has resulted in a wide range of resistant maltodextrins (RMDs) [3]. To obtain such a resistant maltodextrin, starch is heated with small amounts of hydrochloric acid under lowmoisture conditions and at the same time hydrolysed by transglucosidases. Afterwards, the solution is further hydrolysed by an amylase and spray dried. This leads to RMDs, which are soluble, heat stable, non-digestible dietary fibre that consist of $\alpha(1,4), \alpha(1,6)$, $(1,2)$ and $(1,3)$ glycosidic linkages [3].

RMDs were demonstrated to have a stool volume increasing- and laxative beneficial health effect [4], attenuate the postprandial blood glucose level and positively affect the fat metabolism [5]. RMD's indigestibility in the upper gastrointestinal tract and partially fermentability has been determined in rat models and it was shown that $38 \%$ of the RMD investigated is excreted unfermented in faeces [6]. However, little is known about the fermentability of RMD with human faecal inoculum and the resulting fermentation metabolites. Since this type of dietary fibre is applied in many food products, its fermentation characteristics are of interest.

It has been demonstrated in an in vivo rat fermentation study, that substrates present specifically induce the expression of enzymes in the bacteria being active on these substrates [7]. The enzymes produced determine the degradation process of the substrate and can be secreted by the bacteria in the lumen or are bound to the bacteria's cell wall. It is known that amylase activity towards starch is primarily provided by cell wall bound bacterial enzymes [8]. Thus, the enzyme activity levels of extracellular and cell wall bound enzymes towards many polysaccharides can be illustrative for the fermentation potential of the microbiota.

The objective of this study is to characterise the structure of a commercially available RMD and investigate its in vitro fermentation behaviour by means of human faecal inoculum. In addition, the microbiota composition was analysed as well as the activities of the microbial enzymes produced during the in vitro fermentation.

\section{Materials AND Methods}

\section{Substrate RMD}

The commercial name of the RMD used is Fibersol-2 ${ }^{\circledR}$ and was obtained from ADM/Matsutani LLC (Hyogo, Japan).

\section{Culture medium for in vitro fermentation}

The culture medium was based on the standard ileal efflux medium (SIEM) and modified as described elsewhere [9]. All medium components were obtained from 
Tritium Microbiology (Veldhoven, The Netherlands). The medium included a $1 \mathrm{M}$ MES buffer pH 5.8 [9].

\section{Human faecal inoculum}

Standardized, pooled inoculum from 8 healthy European adults (25-45 years old) was obtained from TNO (Zeist, The Netherlands), prepared and validated as described elsewhere [10]. The subjects were not treated with antibiotics 2 months before faecal donation. The inoculum was activated in SIEM culture medium for $16 \mathrm{~h}$ and diluted 10 times before use.

\section{In vitro fermentation}

For each time point two times a $20 \mathrm{~mL}$ fermentation bottle was filled with $9 \mathrm{~mL}$ culture medium containing $9 \mathrm{mg} / \mathrm{mL}$ substrate and $1 \mathrm{~mL}$ of the activated inoculum under anaerobic conditions. Hence, the inocula were in total 100 times diluted at the start of the fermentation experiment. The bottles were immediately closed with rubber stoppers, sealed with an aluminium cap and incubated at $37{ }^{\circ} \mathrm{C}$ during shaking at 130 rpm for maximum 48 hours. Blanks with either no substrate or no inoculum were prepared. Time points were $0,5,6,10,11,24$ and 48 hours. After each fermentation time, $5.5 \mathrm{~mL}$ of the solution was heated for $5 \mathrm{~min}$ at $100{ }^{\circ} \mathrm{C}$. The remaining volume was directly frozen in liquid nitrogen, stored at $-80{ }^{\circ} \mathrm{C}$ and used for microbiota composition and enzyme activity analysis.

\section{Chemical and enzymatic analyses}

\section{Determination of starch content}

Total starch and resistant starch contents were analysed according to AOAC method 996.11 and 2002.02 with enzyme kits from Megazyme (Bray, Ireland), respectively, including extensive $\alpha$-amylase and amyloglucosidase digestion.

\section{Constituent monosaccharide composition}

The constituent monosaccharide composition was determined using a pre-hydrolysis step with $72 \%(\mathrm{w} / \mathrm{w})$ sulphuric acid at $30^{\circ} \mathrm{C}$ for 1 hour, followed by hydrolysis with 1 $\mathrm{M}$ sulphuric acid at $100^{\circ} \mathrm{C}$ for 3 hours. The monosaccharides released were derivatized to alditol acetates and analysed by gas chromatography using inositol as an internal standard [11]. The absence of uronic acid (UA) in the samples was substantiated by using the colorimetric m-hydroxydiphenyl assay [12] automated on a skalar autoanalyser (Skalar, Breda, The Netherlands) as described elsewhere [13].

\section{Glycosidic linkage composition}

The monosaccharide linkage composition was determined using the permethylation with methyl iodide as described elsewhere [14] using 4 times higher substrate and end reagent quantities. The hydrolysis, acetylation and analysis with GC-MS was performed as described elsewhere [15]. 


\section{Size exclusion chromatography}

The RMD (2 $\mathrm{mg} / \mathrm{mL}$ ) as such or the RMD fermentation liquids were centrifuged (10 min, RT, $18000 \mathrm{x}$ g) and the supernatant was analysed for molecular weight distribution with high performance size exclusion chromatography (HPSEC) on an Ultimate 3000 HPLC (Dionex, Sunnyvale, CA, USA) equipped with a Shodex RI-101 refractive index detector (Showa Denko, Tokyo, Japan). Three TSK-Gel columns connected in series (4000-3000-2500 SuperAW; 150 x $6 \mathrm{~mm}$ ) were used for the analysis. These columns were preceded by a TSK Super AW-L guard column (35 x $4.6 \mathrm{~mm}$ ). All columns were from Tosoh Bioscience (Tokyo, Japan) and covered a molecular mass range from $0.2-250 \mathrm{kDa}$. Samples $(20 \mu \mathrm{L})$ were injected and eluted with $0.2 \mathrm{M} \mathrm{NaNO}_{3}$, at $40{ }^{\circ} \mathrm{C}$ with a flow rate of $0.6 \mathrm{~mL} / \mathrm{min}$. Pullulan molecular-mass standards (Polymer Laboratories, Palo Alto, CA, USA) were used for calibration.

For semi-preparative size exclusion chromatography (SEC) $100 \mathrm{mg}$ RMD or maltodextrin (AVEBE, Veendam, The Netherlands) was solubilised in $4 \mathrm{~mL}$ water and manually injected on an Äkta purifier (GE Healthcare, Uppsala, Sweden) equipped with three Superdex 30 Hiload 26/60 prep grade columns in series (molecular mass range of approximately $0.1-10 \mathrm{kDa})$. A flow rate of $1.7 \mathrm{~mL} / \mathrm{min}$, water with $0.5 \%(\mathrm{v} / \mathrm{v})$ ethanol as eluent at a column temperature of $35{ }^{\circ} \mathrm{C}$ was used. Fractions $(7 \mathrm{~mL})$ collected were analysed with Maldi-TOF-MS to determine the molecular weight of dextrins present.

\section{Oligosaccharide profiling with HPAEC and HILIC-MS}

After centrifugation of the RMD as such or the fermentation digest (10 min, RT, 18000 $\mathrm{x} g$ ), the supernatant was diluted twice and analysed for its oligosaccharide profile using high performance anion exchange chromatography (HPAEC) on a ICS5000 system (Dionex), with a CarboPac PA-1 column $(2 \times 250 \mathrm{~mm})$ in combination with a Carbopac PA-1 guard column $(2 \times 50 \mathrm{~mm})$. The flow rate was $0.3 \mathrm{~mL} / \mathrm{min}$ with an eluent profile starting with $0.02 \mathrm{M} \mathrm{NaOH}$ until $13 \mathrm{~min}$, then increasing to $0.1 \mathrm{M} \mathrm{NaOH}$ till $15 \mathrm{~min}$, followed by a linear gradient of $0-500 \mathrm{mM} \mathrm{NaOAc}$ in $1 \mathrm{M} \mathrm{NaOH}$ till 45 min, followed by a gradient to $1 \mathrm{M} \mathrm{NaOAc}$ in $0.1 \mathrm{M} \mathrm{NaOH}$ in $1 \mathrm{~min}$ and $7 \mathrm{~min}$ at $1 \mathrm{M}$ $\mathrm{NaOAc}$ in $0.1 \mathrm{M} \mathrm{NaOH}$. After this, the column was equilibrated with $0.1 \mathrm{M} \mathrm{NaOH}$ for 3 min and $0.02 \mathrm{M} \mathrm{NaOH}$ for $20 \mathrm{~min}$. An ICS5000 ED (Dionex) pulsed amperometric detector and Chromeleon software version 7 were used.

Hydrophilic interaction chromatography with mass spectrometry detection (HILICMS) was used to characterise the RMD as such. An Acquity UPLC BEH Amide column (1.7 $\mu \mathrm{m}, 2.1$ x $150 \mathrm{~mm}$; Waters, Milford, MA, USA) in combination with an Acquity UPLC BEH Amide VanGuard precolumn (1.7 $\mu \mathrm{m} 2.1$ x 5 mm; Waters) were used. The mobile phase was used as described previously [16]. MS detection was performed with a Velos Pro ion trap (Thermo Scientific, Waltham, MA, USA) in positive mode, with the ion source voltage set to $3.9 \mathrm{kV}$, a capillary temperature of 350 
${ }^{\circ} \mathrm{C}$, a heated electrospray ionization (ESI) source temperature of $250{ }^{\circ} \mathrm{C}$, a sheath gas flow rate of 40 (arbitrary units), an auxiliary gas flow rate of 12 (arbitrary units), and a sweep gas flow rate of 2 (arbitrary units).

\section{Matrix Assisted Laser-Induced Desorption/Ionisation Time-of-Flight Mass Spectrometry (Maldi-TOF-MS)}

Maldi-TOF-MS was performed using an Ultraflextreme workstation (Bruker Daltonics, Bremen, Germany) equipped with a $\mathrm{N}_{2}$ laser of $337 \mathrm{~nm}$ and operated by FlexControl 3.3 software (Bruker Daltonics). The mass spectrometer was operated in positive linear mode in a mass range of 5 to $20 \mathrm{kDa}$. The delayed extraction time was $120 \mathrm{~ns}$ and the acceleration voltage $25 \mathrm{kV}$. One $\mu \mathrm{L}$ of the matrix solution of $20 \mathrm{mg} 2,5-$ dihydroxybenzoic acid dissolved in $1 \mathrm{~mL}$ acetonitrile:water ( $1: 1 \mathrm{v} / \mathrm{v}$ ) was mixed with 1 $\mu \mathrm{L}$ of the eluent fractions derived from the SEC purification and dried under a hot air stream on a steal plate.

\section{Short chain fatty acids (SCFAs) and organic acids}

SCFAs were analysed on a TRACETM GC Ultra Gas Chromatograph system coupled with a FID detector (Interscience, Breda, The Netherlands). Lactate and succinate were analysed on an Ultimate 3000 HPLC (Dionex) equipped with an Shodex RI-101 refractive index detector (Showa Denko), an ion-exclusion Aminex HPX- 87H column (7.8 x $300 \mathrm{~mm}$ ) and a guard column (Bio-Rad, Hercules, CA, USA). Both methods were used as described elsewhere [17].

\section{Enzyme extraction}

The proteins present in the digesta time points of 11 and 24 hours were isolated as described elsewhere [18]. In short, the samples were centrifuged (10 min, $18000 \mathrm{x} \mathrm{g,} 4$ ${ }^{\circ} \mathrm{C}$ ), then the supernatant was decanted, to obtain the extracellular enzymes (EE). The pellet was subsequently washed with $1.5 \mathrm{~mL} 25 \mathrm{mM}$ MES buffer pH 5.8 containing 1 $\mathrm{mM}$ PMSF and $1 \mathrm{mM}$ DTT and mixed in $2 \mathrm{~mL} 25 \mathrm{mM}$ MES buffer pH 5.8 containing $1 \mathrm{mM}$ PMSF, $1 \mathrm{mM}$ DTT, $1 \mathrm{mM}$ EDTA and $50 \mathrm{mM} \mathrm{NaCl}$. To extract the cell wall bound and intracellular enzymes, the cell walls were disrupted by a digital sonifier (Branson, Danbury, CT, USA). The suspension was cooled on ice while sonifying at 30 $\%$ amplitude for $30 \mathrm{sec}$ with a $40 \mathrm{sec}$ break in between [18]. This was repeated 3 times and the final supernatant was used for enzyme analysis, representing the cellular associated enzymes (CE). The EE and CE extracts (CE 11, EE 11, CE 24, EE 24) were tested for their enzyme activity levels on different carbohydrates.

\section{Analysis of enzyme activities} Glycosidases

To analyse the glycosidase activities of the digesta enzymes, p-nitrophenyl (PNP) glycosides were used. PNP- $\alpha$-D-glucopyranoside, PNP- $\beta$-D-glucopyranoside, PNP- $\beta$ D-xylopyranoside, PNP- $\alpha$-L-arabinofuranoside and as quantification standard p- 
nitrophenol (0-500 $\mu \mathrm{M})$ were obtained from Sigma-Aldrich and dissolved in water (1 $\mathrm{mM})$. To $200 \mu \mathrm{L}$ of the PNP-glycosides $20 \mu \mathrm{L}$ of the enzyme extracts were mixed in a microtiter plate and immediately incubated at $37^{\circ} \mathrm{C}$. Next, the mixture was measured every 3 min over 2 hours at $405 \mathrm{~nm}$ with a microplate reader. The concentration of pnitrophenol was plotted against time and the slope represents the enzyme activity, expressed in $\mathrm{mU}$ (nmol mL-digest ${ }^{-1} \mathrm{~min}^{-1}$ ) [18].

\section{Polysaccharide-degrading enzymes}

For testing polysaccharidase activities present, nine polysaccharides were used: Soluble potato starch, carboxymethylcellulose (CMC) (both Sigma-Aldrich), wheat arabinoxylan (WAX), rye arabinoxylan (RAX), barley $\beta(1,3)(1,4)$ glucan ( $\beta$-GLC) (all Megazyme), soluble soy polysaccharide (SSP) (Soyafibre-S-DA 100; Fuji Oil, Ibaraki, Japan), locust bean gum (LBG) (SKW Biosystems, Rubi, Spain), high methyl esterified- and low methyl esterified pectins (HMP and LMP, respectively) (both Copenhagen Pectin A/S, Lille Skensved, Denmark) and the oligosaccharide RMD. The substrates were solubilised $(2.5 \mathrm{mg} / \mathrm{mL})$ in $25 \mathrm{mM}$ MES buffer, $\mathrm{pH} 5.8$ and if necessary heated for $5 \mathrm{~min}$ at $100{ }^{\circ} \mathrm{C}$ to be completely solubilised. Next, $200 \mu \mathrm{L}$ of the solutions were incubated with $20 \mu \mathrm{L}$ enzyme for $30 \mathrm{~min}$ and 20 hours, at $37^{\circ} \mathrm{C}$ and afterwards heated for $10 \mathrm{~min}$ at $100^{\circ} \mathrm{C}$. To monitor the degradation of the polysaccharide and formation of oligosaccharides, HPSEC and HPAEC were used. Furthermore, this assay was used to measure the amount of released glucose as described below.

\section{Reducing sugar assay}

Ten $\mu \mathrm{L}$ of the 30 min incubated polysaccharide solutions described above were mixed with $200 \mu \mathrm{L}$ of a mix of 5\% (w/v) 4-hydroxybenzoic acid hydrazide (PAHBAH) solution in $0.5 \mathrm{M} \mathrm{HCl}$ and $0.5 \mathrm{M} \mathrm{NaOH}(1: 4)(\mathrm{v} / \mathrm{v})$. Next, the mixture was incubated at $70{ }^{\circ} \mathrm{C}$ for $30 \mathrm{~min}$. Standard curves $(0-250 \mu \mathrm{g} / \mathrm{mL})$ of different monosaccharides that received the same treatment were used for calibration. The absorbance was measured at $405 \mathrm{~nm}$ with a microtiter plate reader and the concentration of reducing ends was expressed in nmol released in 1 min by enzymes from $1 \mathrm{~mL}$ digest $(\mathrm{mU})$.

\section{Microbiota analysis by HITchip}

The 16S rRNA gene was amplified from fermentation samples essentially as described elsewhere. DNA was extracted from $200 \mu \mathrm{L}$ fermentation samples using FastDNA SPIN Kit for Soil (Qbiogene) and a FastPrep disruptor (FP120, Savant Instruments). The primers T7prom-Bact-27-for and Uni-1492-rev were use. RNA production and labelling was as described before [19]. Analysis was performed on a HITchip microarray [20], which is a phylogenetic microarray containing $>1100$ unique probes of microbial phylotypes of sequences found in the human intestinal tract. RNA was hybridized and arrays were analysed as described before [19, 20]. 


\section{RESULTS AND DISCUSSION}

\section{Characterisation of RMD}

The monosaccharide composition of the RMD was analysed to characterise the substrate fermented in this study. The RMD consists of 99 mol\% glucose with a total glucose content of $85 \mathrm{w} / \mathrm{w} \%$, (no further data shown).

Using the AOAC methods $81 \mathrm{w} / \mathrm{w} \%$ of the sample is resistant to $\alpha$-amylase and amyloglucosidase. This resistant starch includes $1 \mathrm{w} / \mathrm{w} \%$ of the sample present as $\alpha-$ amylase- and amyloglucosidase-digestible starch after alkali treatment, which indicates that this is RS type 3. The other $80 \mathrm{w} / \mathrm{w} \%$ of the sample (93\% of all glucose) is RS type 4 , in which molecule configurations and linkages are hindering $\alpha$-amylase and amyloglucosidase to act on it, which makes it undetectable as such with the methods used. Thus, our results confirm the resistance of RMD to human digestion enzymes due to chemical modifications of the starch.

Table 1: Glycosidic linkage types present in RMD in \%.

\begin{tabular}{lc}
\hline $\begin{array}{l}\text { Linked O-position } \\
\text { per glucose unit }\end{array}$ & $\begin{array}{c}\% \\
\text { peak area }\end{array}$ \\
\hline terminal ends & 36.2 \\
1,2 & 4.3 \\
1,3 & 3.7 \\
1,4 & 22.7 \\
1,6 & 18.3 \\
$1,3,4$ & 0.6 \\
$1,2,4$ & 1.5 \\
$1,2,6$ & 1.3 \\
$1,4,6$ & 8.2 \\
$1,3,6$ & 2.4 \\
$1,3,4,6$ & 0.2 \\
$1,2,4,6$ & 0.4 \\
$1,2,3,6$ & 0.1 \\
\hline
\end{tabular}

Linkage analysis of RMD shows that the glycosidic linkages in RMD exhibit a huge diversity (Table 1). The ratio of 1,4 to 1,6 linkages of glucose moieties within RMD is 1.1. This ratio is approximately 20 for starches from various origin: e.g. native waxymaize starch [21]. In RMD $\pm 14 \%$ of the glucose units are 1,2 or 1,3 linked, while 23 $\%$ and $18 \%$ are 1,4 and 1,6 glycosidically linked, respectively. In conclusion, RMD is highly modified starch, containing starch atypical glycosidic linkages.

Table 1 also shows that RMD has $36 \%$ terminally linked glucose moieties. This confirms again that the original starch has been modified from a polymer into small molecules. This corresponds with the molecular mass range of 0.7 to $11 \mathrm{kDa}$ as determined by HPSEC analysis (data not shown). In literature, an average molecular mass of $2 \mathrm{kDa}$ is mentioned [3]. Thus, the dextrins present in RMD are very diverse molecules in terms of type and relative amount of glycosidic linkages. 
The size exclusion elution pattern of the RMD using three semi-preparative Superdex 30 columns in series can be seen in Figure 1. Although a wide peak between 525 and $575 \mathrm{~mL}$ can be seen with a maximum response around DP $22(530 \mathrm{~mL})$, no individual peaks can be recognised for distinct degrees of polymerisation. This is in contrast to regular $\alpha(1,4)$ linked maltodextrins also indicated in the figure.

In Figure 2 the Maldi-TOF-MS data of three consecutive SEC fractions (C10-C12), eluting at 415 to $440 \mathrm{~mL}$, are given. In each fraction molecules of RMD elute together due to their similar hydrodynamic volume, but the MALDI-ToF-MS data show that they differ extensively in their degrees of polymerisation. From these observations it can be concluded that multiple isomers for a dextrin with a given DP exist. This explains our difficulties to separate and identify individual molecules by SEC (Figure 1), HPAEC (Figure 4) and LC-HILIC-MS (data not shown).

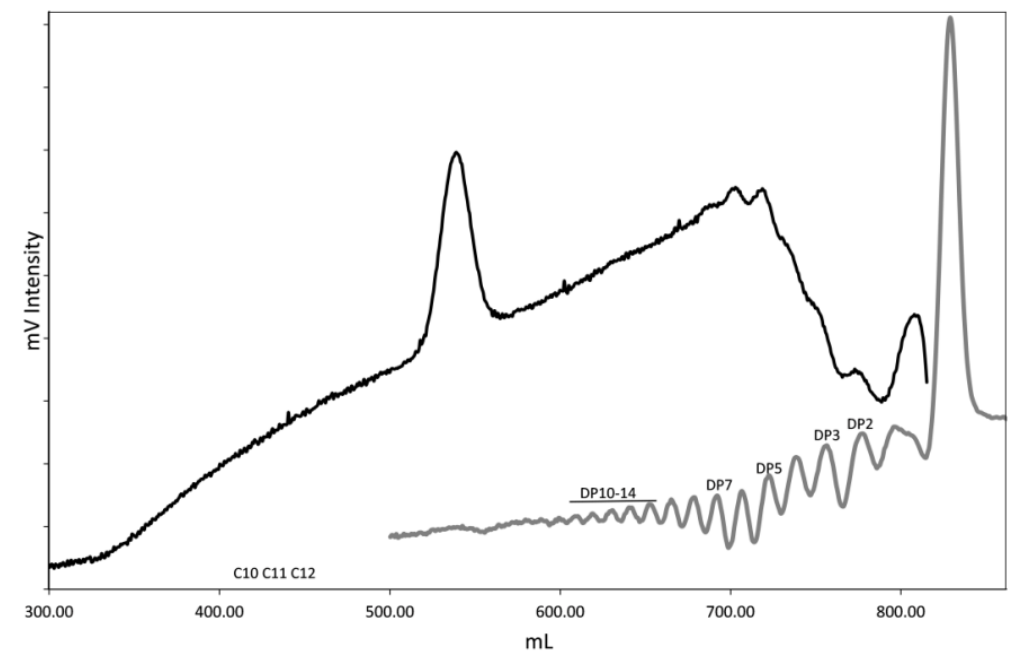

Figure 1: Semi preparative size exclusion chromatography of RMD (black) and maltodextrin (grey).

\section{Fermentation of RMD}

The fermentation in the human proximal colon was simulated with human faecal inocula over 48 hours under anaerobic conditions. To mimic the conditions of the proximal colon the $\mathrm{pH}$ of the fermentation buffer was set to 5.8. The $\mathrm{pH}$ starts to increase at 5 hours to a $\mathrm{pH}$ of 6.2 within 10 hours of fermentation. This indicates a proteolytic fermentation of medium compounds in the beginning of the fermentation due to a lack of degradability of the RMD [22]. From $10 \mathrm{~h}$ of fermentation onwards the $\mathrm{pH}$ decreased to 6.0 at 48 hours of fermentation.

Fermentation of RMD - Short chain fatty acids, lactic acid and succinic acid production

The formation of SCFAs during in vitro fermentation is used as an indicator of the fibre fermentability. The SCFAs production started around 5 hours of fermentation (2.4 $\mathrm{mmol} / \mathrm{g} \mathrm{RMD}$ ) (Figure 3). This indicates that RMD is fermented slowly or that other 


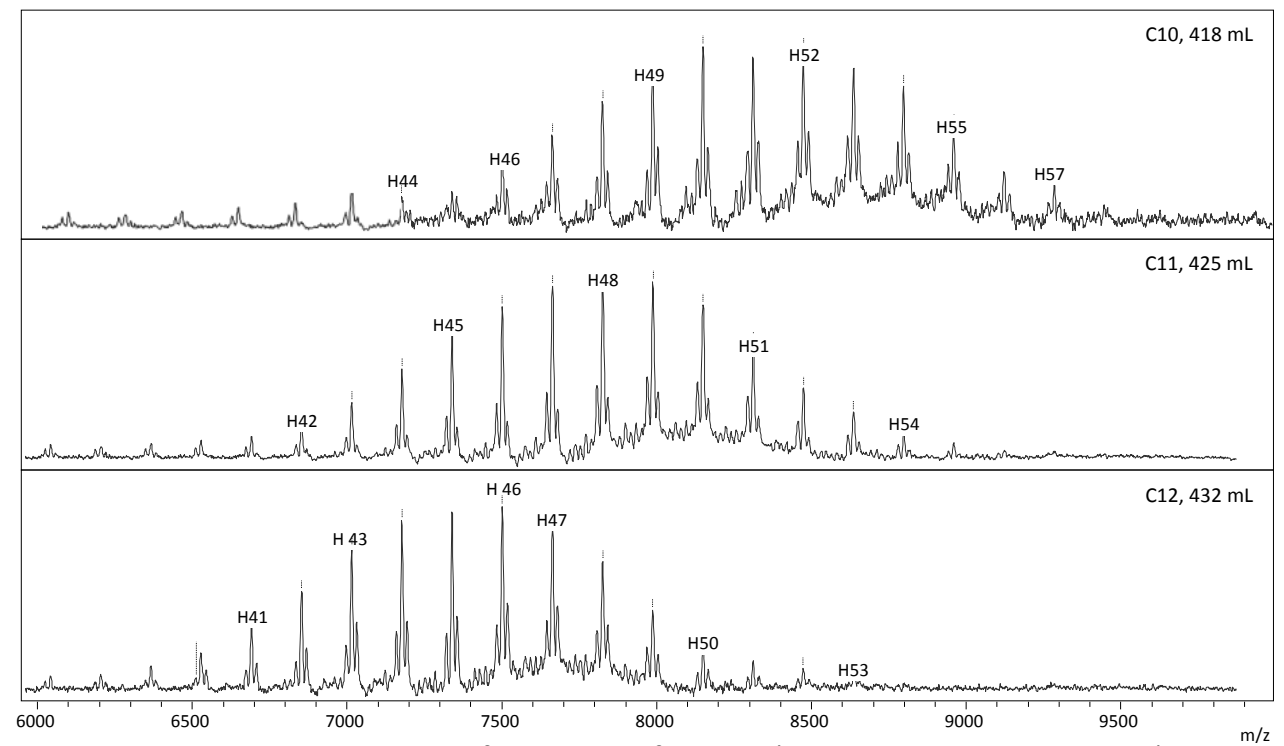

Figure 2: MALDI-TOF mass spectra of three RMD fractions (eluting between $415-440 \mathrm{~mL}$ ) obtained from size exclusion chromatography on three connected Superdex 30 Hiload 26/60 prep grade columns. Hx indicates the presence of oligomer of hexoses with DPx.

medium compounds are fermented. In comparison, fermentation of FOS under the same conditions reached a total SCFA concentration of $5.3 \mathrm{mmol} / \mathrm{g}$ fibre at 6 hours [16]. For RMD, the total SCFA production continued to increase to a maximum of 6.0 $\mathrm{mmol} / \mathrm{g}$ RMD at $48 \mathrm{~h}$ of fermentation, whereof 1.3 and $1.0 \mathrm{mmol} / \mathrm{g}$ RMD are propionic and butyric acid, respectively. The main SCFA is acetic acid with a maximum concentration of $3.8 \mathrm{mmol} / \mathrm{g}$ RMD at time point 24 hours. Between $24 \mathrm{~h}$ and $48 \mathrm{~h}$ only a small increase in total SCFA production is observed, while acetic acid levels slightly decreases. Thus, SCFAs might be utilised by the microbiota due to difficulties in the degradation of RMD. The molar ratio of acetic, propionic and butyric acid ranges from 88:12:0 (3 h) to 60:21:18 (48 h), respectively. Succinic acid was

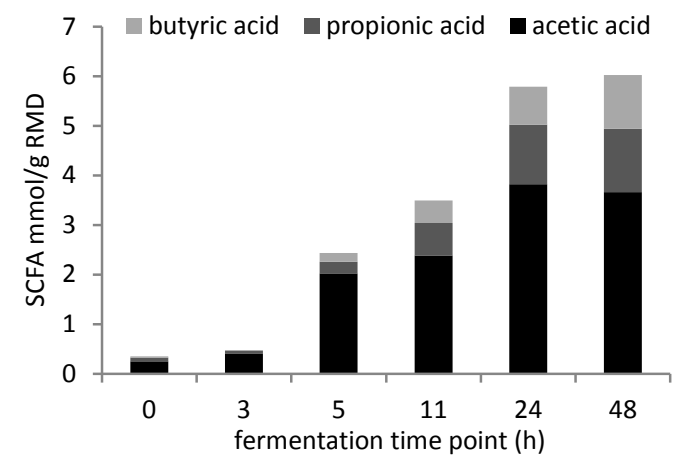

Figure 3: Levels of SCFA produced during the batch fermentation of RMD using human inocula at different fermentation time points. 
present at 6 and 10 hours of fermentation in a concentration of 0.2 and $0.5 \mathrm{mmol} / \mathrm{g}$ RMD, respectively and no lactic acid was found. Both acids are considered as intermediate products, which are formed during an excess of substrate [23] and are usually converted into SCFA during cross-feeding.

\section{Fermentation of RMD - Oligosaccharide profile}

The degradation of RMD during in vitro fermentation in time was monitored by HPAEC (Figure 4). In this figure not all time points analysed were shown to keep the overview. The elution pattern shows that RMD oligosaccharides, mainly eluting between 23 and $43 \mathrm{~min}$, could not be separated effectively. No released glucose could be detected, probably due to its immediate utilisation by the bacteria.

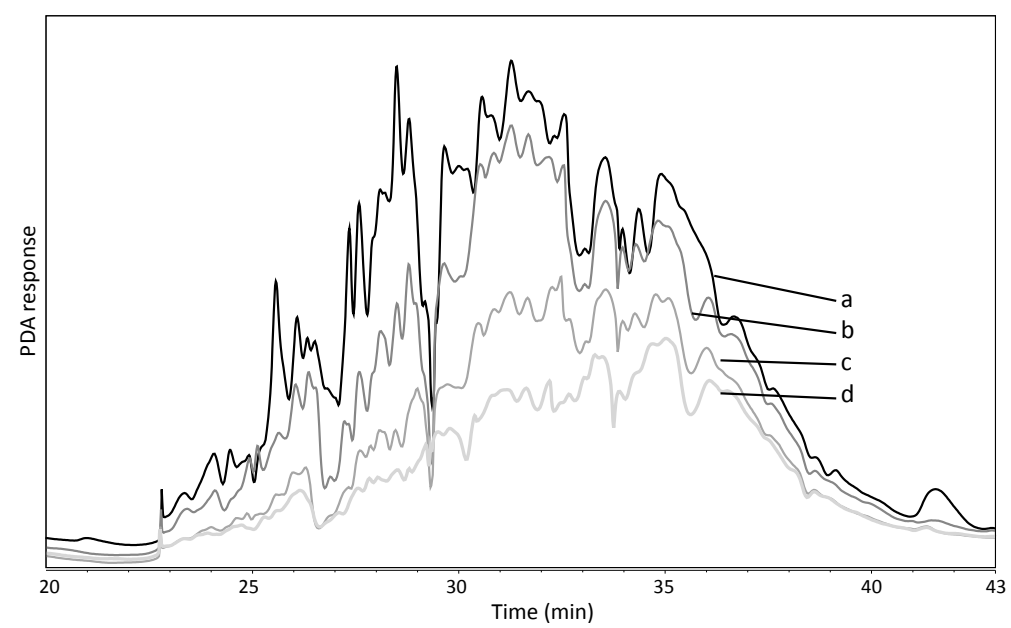

Figure 4: HPAEC elution profiles of RMD fermentation digesta at different fermentation time points, $a=0 h, b=11 h, c=24 h$ and $d=48 h$.

No shift of molecular mass into smaller maltodextrins is observed as analysed with HPSEC upon prolonged fermentation (data not shown). Thus, degradation of RMD by enzymes in an endo fashion into smaller maltodextrins during fermentation does not take place or is not detectable. The degradation of RMD, as indicated by the decreasing total area, seems to be due to cleavage of single glucose units. This indicates that each type of molecule is consumed at a rather similar rate and no specific maltodextrins are preferentially utilised.

By comparing the total areas, it can be concluded that after 11 hours of incubation only $20 \%$ of the starting substrate has been consumed by the bacteria. After 48 hours of fermentation $42 \%$ of the RMD is still present in the digest. Other dietary fibres, like FOS and sugar beet pectic oligosaccharides, fermented under the same in vitro conditions, are completely utilised by the microbiota after only 9 hours [16]. Thus, the fermentation of RMD is slow, which could be due to the complex structure of the chemically modified fibre as mentioned above. This finding is in agreement with 
previous in vivo experiments [6], where it was concluded that $38 \%$ of the RMD was excreted in faeces after rats were orally fed it.

RMD and fermentation digests were also examined by HILIC-UPLC-MS, but also no good resolution and separation of the individual DPs of RMD could be achieved (no further data shown).

\section{Enzyme activities}

Four different enzyme extracts were tested: t $11 \mathrm{EE}$ (extracellular enzymes), t $11 \mathrm{CE}$ (cellular enzymes), t $24 \mathrm{EE}$ and t $24 \mathrm{CE}$. Time points 11 and 24 hours were chosen because they represent the enzyme expression at the beginning $(11 \mathrm{~h})$ and a far enhanced level of about $50 \%$ fermented RMD (24 h) according to HPAEC analysis of the fermentation digest (Figure 4).

\section{Enzyme activity towards PNP-glucosides and glucan polysaccharides}

The main exo activity of the enzyme extracts was towards PNP- $\alpha$-D-glucose and the four enzyme extracts showed exo activity levels of 33-44 (nmol mL-digest ${ }^{-1} \mathrm{~min}^{-1}$ ) (Table 2). The exo enzyme activity levels on PNP- $\alpha$-D-glucoside remained rather constant over the duration of fermentation. Hence, it seems that the microbiota did not further adapt to the substrate by producing different types of glucosidases during the fermentation of 11 and 24 hours. This is despite the fact, that the microbiota was not successful in completely degrading RMD within 24 hours of fermentation under these conditions (see above).

RMD is hardly degraded by the extracted enzymes in the same timeframe, as analysed with HPSEC (Table 3). However, HPAEC analysis indicated that during RMD incubation, glucose is released by EEs and in even higher levels by CEs. Nevertheless, the $\alpha$-amylase present had difficulties to degrade RMD, either due to the specific glycosidic linkages present or due to their inaccessibility. The results of the combined exo- and endo enzyme activity towards RMD in the reducing sugar assay lead to high standard deviations and was not further considered.

Soluble starch was almost completely cleaved to oligosaccharides of $0.5-5.5 \mathrm{kDa}$ by the EEs as analysed with HPSEC (Table 3). The CE cleaved starch slightly less resulting in molecular mass fragments of 2-61 $\mathrm{kDa}$. The results of HPAEC showed that only incubation with CE resulted in high amounts of oligosaccharides of different degrees of polymerisation (data not shown). Hence, a relatively high level of $\alpha$-amylase must be present in the digests.

This is also confirmed by the reducing sugar assay, in which the EE released 165-239 nmol glucose mL-digest ${ }^{-1} \mathrm{~min}^{-1}$ and the CE 61-90 nmol glucose mL-digest ${ }^{-1} \mathrm{~min}^{-1}$.

The exo enzyme activity towards PNP- $\beta$-D-glucose is relatively low for the EEs ( 9 nmol mL-digest ${ }^{-1} \mathrm{~min}^{-1}$ ), but with 27 (t 11) and 35 (t 24) nmol mL-digest ${ }^{-1} \mathrm{~min}^{-1}$ quite high for the CEs and of the same range than towards PNP- $\alpha$-D-glucose. Hence, glycosidases towards $\beta$-linked glucose are also present in high amounts in the CEs. 


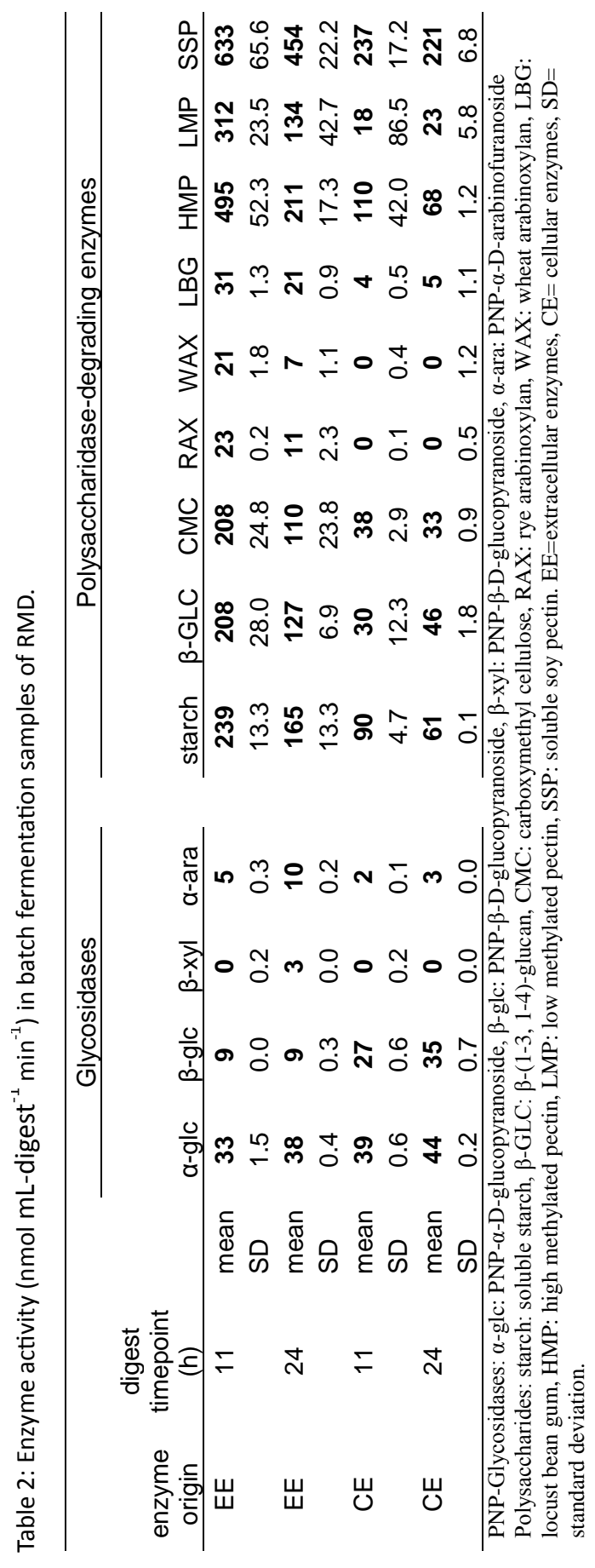


Resistant maltodextrin fermentation

Table 3: Polysaccharide degrading enzyme activities of fermentation digesta analysed by HPSEC ${ }^{\#}$.

\begin{tabular}{ccccccccccc}
\hline $\begin{array}{l}\text { Enzyme } \\
\text { origin }\end{array}$ & RMD & starch & $\beta-G L C$ & CMC & RAX & WAX & LBG & HMP & LMP & SSP \\
\hline EE & - & +++ & ++ & + & ++ & ++ & ++ & - & - & + \\
CE & + & ++ & ++ & + & ++ & ++ & + & - & - & +
\end{tabular}

\#: enzyme extracts obtained after 11 and $24 \mathrm{~h}$ of fermentation behaved similarly; -: no activity, + : minor activity, ++: moderate activity, +++: high activity. Polysaccharides: RMD: resistant maltodextrin, starch: soluble starch, $\beta$-GLC: $\beta$-(1-3, 1-4)-glucan, CMC: carboxymethyl cellulose, RAX: rye arabinoxylan, WAX: wheat arabinoxylan, LBG: locust bean gum, HMP: high methylated pectin, LMP: low methylated pectin, SSP: soluble soy pectin. $\mathrm{EE}=$ extracellular enzymes, $\mathrm{CE}=$ cellular enzymes.

The combined exo and endo enzyme activity (127-208 nmol mL-digest ${ }^{-1} \mathrm{~min}^{-1}$ ) present in the EE towards $\beta$-glucan is much higher than its exo activity level measured towards the PNP- $\beta$-D-glucoside ( $9 \mathrm{nmol} \mathrm{mL-digest}{ }^{-1} \mathrm{~min}^{-1}$ ). In contrast, the CEs show almost no increase in the combined exo- and endo activity (30-46 nmol mL-digest ${ }^{-1} \mathrm{~min}^{-1}$ ) towards $\beta$-glucan in comparison to their exo activity (27-35 nmol mL-digest ${ }^{-1} \mathrm{~min}^{-1}$ ) towards the PNP- $\beta$-D-glucoside. This confirms that endo enzymes are present in the $\mathrm{EE}$ and suggests that the CEs consist of mainly exo acting enzymes. Barley $\beta$-glucan, consisting of a linear glucose backbone with $\beta(1,4)$ and $\beta(1,3)$ glycosidic linkages, is slightly degraded by endo enzymes and cleaved from a molecular mass of 120-190 kDa into fragments of 30-60 kDa. This means that the $\beta$-glucan polymer was only cleaved three to five times per molecule during 20 hours of incubation. Although a change in molecular weight of the $\beta$-glucan was obvious, only a small amount of oligosaccharides was formed and endo-enzyme action was low compared to $\alpha$-amylase action towards starch (Table 3).

In conclusion, exo and endo enzymes are able to degrade glucans present but hardly capable to degrade RMD. The enzymes tested were active towards PNP- $\alpha / \beta$-Dglucosides and glucan polysaccharides, like starch, $\beta(1,3)(1,4)$ glucan and CMC. This was expected because the main fermentation substrate for the microbiota was RMD, a glucan.

\section{Enzyme activity towards non-glucose PNP-glycosides and non-glucan polysaccharides}

It is expected that a basal enzyme activity towards various different substrates is present during microbial growth, even when these are not available during fermentation [24]. Thus, the activities towards non-glucan polysaccharides and nonPNP-glucosides were additionally analysed.

The activity of the four enzyme extracts towards PNP- $\beta$-D-Xylose and PNP- $\alpha-\mathrm{L}-$ Arabinofuranosidase was 0-3 (nmol mL-digest ${ }^{-1} \mathrm{~min}^{-1}$ ) and 2-10 (nmol mL-digest ${ }^{-1}$ $\min ^{-1}$ ), respectively. Hence, exo enzymes able to release arabinose and xylose must be present in the digesta, although at very low levels. 
A low activity was also observed for endo enzymes, which were able to slightly degrade the two arabinoxylans (WAX, RAX), polymers consisting of a $\beta(1,4)$ linked xylose backbone with non- , mono- or di-substitution with $\alpha$-L-arabinofuranosyl residues. By HPSEC it was shown that xylan polymers (120-190 kDa) were degraded to a small extent into smaller molecular mass fragments (30-60 kDa) (Table 3). There was no difference in degradation between the two different xylans observed, even though the RAX is slightly higher in its starting molecular mass. The locust bean gum was also slightly degraded, and only cleaved ca. 3-5 times by endo enzymes, when compared to the xylans (all HPSEC chromatograms not shown). The results of the endo- and exo enzyme incubation on WAX, RAX and LBG showed that there is only a very low activity $\left(0-31 \mathrm{nmol} \mathrm{mL-digest}{ }^{-1} \mathrm{~min}^{-1}\right)$.

The three pectin polysaccharides differ in their chemical structure. Two of them originate from lemon and their galacturonic acid backbones are either highly or lowly methylesterified. The third pectin (SSP) consists in comparison to lemon pectin of less homogalacturonan backbone and more of the rhamnogalacturonan regions with side chains consisting of arabinose and galactose [25]. The backbone of the three pectins were not degraded at all. SSP is degraded to a limited extent by exo enzymes, as analysed with HPSEC (Table 3). Thus, the enzymes present in the fermentation samples were not able to cleave the galacturonic backbone of pectins, but could cleave the arabinan and galactan side chains, which is explained by the high endo-and exoenzyme activities of especially the EE enzymes of time point 11 hours (312-633 nmol mL-digest ${ }^{-1} \min ^{-1}$ ) (Table 2).

Thus, both exo and endo enzymes of the RMD fermentation samples were present, while the combined endo- exo activity was higher towards hetero polysaccharides like pectins, where the endo enzymes were mainly able to degrade glucan based polysaccharides but not pectins. The enzymes present in the digesta were capable to degrade soluble starch, but not RMD.

\section{Microbiota composition during fermentation}

The development of the changes in the microbiota composition upon fermentation of RMD was analysed using the phylogenetic HITChip microarray. The data were compared to the fermentation blank without added carbohydrate, but containing all the other components of the culture medium. Compared to the blank, RMD led to a larger reduction in the proportion of Bacteroides vulgatus et rel., Prevotella tannerae et rel., and Sutterella wadsworthia et rel. (Table A). A major increase is observed for Clostridium symbosium et rel., although this is the same for both the blank and the RMD incubations. Parabacteroides distasonis et rel., which stays about the same in the fermentation blank, is increased by RMD fermentation approximately 6 fold to $6.5 \%$ abundance (based on the HITChip hybridisation signals) (Table A). Also Clostridium sphenoides et rel., which increases 4 fold in the blank incubation, increases 18 fold in the RMD fermentation. Eubacterium rectale et rel. is also increased by RMD ( 16 fold 100 
to $1.12 \%$ abundance). The same accounts for Ruminococcus obeum et rel., which increases $\sim 8$ fold, and Faecalibacterium prausnitzii et rel., which increases 6 fold. The latter three bacteria are important butyrate producers. Phylotypes that increase to a lesser extent compared to the blank and time point zero are Coprococcus eutactus et rel., Dorea formicigenerans et rel., Anaerostipes caccae et rel. and Clostridium nexile et rel. Akkermansia decreases more during the RMD fermentation than in the blank. The same is true for Escherichia coli et rel. Bifidobacteria increase compared to the blank incubation, but decrease in time. The diversity of the microbiota increases a little over time compared to time point zero, but is not different for the blank and the RMD incubations (data not shown).

\section{CONCLUSIONS}

RMD is a soluble, $\alpha$-amylase and amyloglucosidase resistant maltodextrin. Due to its diverse molecules, this RS 4 starch is difficult to characterise using current chromatographic techniques. RMD is slowly fermentable by human faecal bacteria as demonstrated using a batch fermentation model. The molecules are degraded by the microbiota by an aspecific continuous removal of single monosaccharides, which are immediately utilised. The analysis of bacterial enzymes present in the fermentation digesta revealed that besides extra- and intra-cellular glucosidases, a variety of different polysaccharide degrading enzymes at low levels and $\alpha$-amylases at medium levels are present. Changes in the microbiota upon batch fermentation of RMD lead to an increase in butyrate producers and bifidobacteria, and to a decrease in proteobacteria (Escherichia coli et rel., Enterobacter aerogenes et rel.) in comparison to the blank without RMD, both changes are considered to be beneficial for the host's health.

\section{ACKNOWLEDGEMENTS}

This work has been funded by TIFN (Top Institute Food and Nutrition) project GH004. Uttara Ramasamy is gratefully acknowledged for her help with the in vitro fermentation studies and Gerben Hermes for the analysis of the microbiota composition.

\section{REFERENCES}

[1] Cummings, J. H., Edmond, L. M., Magee, E. A., Dietary carbohydrates and health: do we still need the fibre concept? Clinical Nutrition Supplements 2004, 1, 5-17.

[2] Topping, D. L., Fukushima, M., Bird, A. R., Resistant starch as a prebiotic and synbiotic: state of the art. Proceedings of the Nutrition Society 2003, 62, 171-176.

[3] Ohkuma, K., Wakabayashi, S., in: McCleary, B. V., Prosky, L. (Eds.), Advanced Dietary Fibre Technology, Blackwell Science Ltd, Oxford, UK 2001, 509-523.

[4] Flickinger, E. A., Wolf, B. W., Garleb, K. A., Chow, J., et al., Glucose-based oligosaccharides exhibit different in vitro fermentation patterns and affect in vivo apparent nutrient digestibility and microbial populations in dogs. The Journal of Nutrition 2000, 130, 1267-1273.

[5] Okuma, K., Hashizume, C., in: Cho, S. S., Samuel, P. (Eds.), Fiber Ingredients: Food applications and health benefits, CRC Press, Boca Raton, FL, USA 2009, 61-78.

[6] Tsuji, K., Gordon, D. T., Energy Value of a Mixed Glycosidic Linked Dextrin Determined in Rats. Journal of Agricultural and Food Chemistry 1998, 46, 2253-2259. 


\section{CHAPTER 5}

[7] Sonnenburg, J. L., Xu, J., Leip, D. D., Chen, C.-H., et al., Glycan foraging in vivo by an intestine-adapted bacterial symbiont. Science 2005, 307, 1955-1959.

[8] Macfarlane, G. T., Englyst, H., Starch utilization by the human large intestinal microflora. Journal of Applied Bacteriology 1986, 60, 195-201.

[9] Ramasamy, U. S., Venema, K., Schols, H. A., Gruppen, H., Effect of soluble and insoluble fibers within the in vitro fermentation of chicory root pulp by human gut bacteria. Journal of Agricultural and Food Chemistry 2014, 62, 6794-6802.

[10] Minekus, M., Smeets-Peeters, M., Bernalier, A., Marol-Bonnin, S., et al., A computer-controlled system to simulate conditions of the large intestine with peristaltic mixing, water absorption and absorption of fermentation products. Applied Microbiology and Biotechnology 1999, 53, 108-114.

[11] Englyst, H. N., Cummings, J. H., Simplified method for the measurement of total non-starch polysaccharides by gas - liquid chromatography of constituent sugars as alditol acetates. The Analyst 1984, 109, 937-942.

[12] Ahmed, A. E. R., Labavitch, J. M., A simplified method for accurate determination of cell wall uronide content. Journal of Food Biochemistry 1978, 1, 361-365.

[13] Thibault, J., Automatisation du dosage des substances pectiques par la méthode au méta-hydroxydiphenyl. Lebensmittel-Wissenschaft und Technologie. 1979, 1979.

[14] Pettolino, F. A., Walsh, C., Fincher, G. B., Bacic, A., Determining the polysaccharide composition of plant cell walls. Nature Protocols 2012, 7, 1590-1607.

[15] Pustjens, A. M., de Vries, S., Bakuwel, M., Gruppen, H., et al., Unfermented recalcitrant polysaccharide structures from rapeseed (Brassica napus) meal in pigs. Industrial Crops and Products 2014, 58, 271-279.

[16] Leijdekkers, A., Aguirre, M., Venema, K., Bosch, G., et al., In vitro fermentability of sugar beet pulp derived oligosaccharides using human and pig fecal inocula. Journal of Agricultural and Food Chemistry 2014, 62, 10791087.

[17] Ladirat, S. E., Schuren, F. H. J., Schoterman, M. H. C., Nauta, A., et al., Impact of galacto-oligosaccharides on the gut microbiota composition and metabolic activity upon antibiotic treatment during in vitro fermentation FEMS Microbiology Ecology 2014, 87, 41-51.

[18] Jonathan, M. C., Haenen, D., da Silva, C. S., Bosch, G., et al., Influence of a diet rich in resistant starch on the degradation of non-starch polysaccharides in the large intestine of pigs. Carbohydrate Polymers 2013, 93, 232 239.

[19] Rajilić-Stojanović, M., Maathuis, A., Heilig, H. G., Venema, K., et al., Evaluating the microbial diversity of an in vitro model of the human large intestine by phylogenetic microarray analysis. Microbiology 2010, 156, 32703281.

[20] Rajilić-Stojanović, M., Heilig, H. G., Molenaar, D., Kajander, K., et al., Development and application of the human intestinal tract chip, a phylogenetic microarray: analysis of universally conserved phylotypes in the abundant microbiota of young and elderly adults. Environmental Microbiology 2009, 11, 1736-1751.

[21] Gidley, M. J., Quantification of the structural features of starch polysaccharides by n.m.r. spectroscopy. Carbohydrate Research 1985, 139, 85-93.

[22] Cone, J. W., van Gelder, A. H., Influence of protein fermentation on gas production profiles. Animal Feed Science and Technology 1999, 76, 251-264.

[23] Macfarlane, S., Macfarlane, G. T., Regulation of short-chain fatty acid production. Proceedings of the Nutrition Society 2003, 62, 67-72.

[24] Jonathan, M. C., Monitoring the degradation of individual dietary fibres in pig models. Ph.D. Thesis, Wagenignen University, Wageningen, The Netherlands. 2013.

[25] Nakamura, A., Furuta, H., Maeda, H., Nagamatsu, Y., Yoshimoto, A., Analysis of structural components and molecular construction of soybean soluble polysaccharides by stepwise enzymatic degradation. Bioscience, Biotechnology, and Biochemistry 2001, 65, 2249-2258 
Resistant maltodextrin fermentation

\section{SUPPLEMENTARY DATA:}

Supplementary Table 1: Microbiota composition of duplicates of a 48 hour fermentation digest from RMD expressed as \% genus of microbiota present.

\begin{tabular}{|c|c|c|c|c|c|c|c|}
\hline Bacteria genera & $\begin{array}{c}\text { RMD } \\
\text { digest to }\end{array}$ & $\begin{array}{c}\text { blank } \\
\text { digest } \\
\text { t24 }\end{array}$ & $\begin{array}{c}\text { RMD } \\
\text { digest } \\
\text { t48 }\end{array}$ & Bacteria genera & $\begin{array}{c}\text { RMD } \\
\text { digest to }\end{array}$ & $\begin{array}{c}\text { blank } \\
\text { digest } \\
\text { t24 }\end{array}$ & $\begin{array}{c}\text { RMD } \\
\text { digest } \\
\text { t48 }\end{array}$ \\
\hline Actinomycetaceae & $0.01 \%$ & $0.01 \%$ & $0.01 \%$ & Fusobacteria & $0.04 \%$ & $0.05 \%$ & $0.06 \%$ \\
\hline Aerococcus & $0.01 \%$ & $0.01 \%$ & $0.01 \%$ & Gemella & $0.00 \%$ & $0.01 \%$ & $0.01 \%$ \\
\hline Aeromonas & $0.01 \%$ & $0.01 \%$ & $0.01 \%$ & Granulicatella & $0.01 \%$ & $0.01 \%$ & $0.01 \%$ \\
\hline Akkermansia & $6.23 \%$ & $0.98 \%$ & $0.48 \%$ & Haemophilus & $0.01 \%$ & $0.01 \%$ & $0.01 \%$ \\
\hline Alcaligenes faecalis et rel. & $0.09 \%$ & $0.03 \%$ & $0.03 \%$ & Helicobacter & $0.02 \%$ & $0.03 \%$ & $0.03 \%$ \\
\hline Allistipes et rel. & $0.73 \%$ & $0.68 \%$ & $0.75 \%$ & Klebisiella pneumoniae et rel. & $0.51 \%$ & $0.15 \%$ & $0.07 \%$ \\
\hline Anaerobiospirillum & $0.01 \%$ & $0.01 \%$ & $0.01 \%$ & Lachnobacillus bovis et rel. & $0.12 \%$ & $0.25 \%$ & $0.66 \%$ \\
\hline Anaerofustis & $0.01 \%$ & $0.01 \%$ & $0.01 \%$ & $\begin{array}{l}\text { Lachnospira pectinoschiza et } \\
\text { rel. }\end{array}$ & $0.14 \%$ & $0.23 \%$ & $0.59 \%$ \\
\hline Anaerostipes caccae et rel. & $0.14 \%$ & $0.38 \%$ & $1.17 \%$ & $\begin{array}{l}\text { Lactobacillus catenaformis et } \\
\text { rel. }\end{array}$ & $0.01 \%$ & $0.01 \%$ & $0.01 \%$ \\
\hline $\begin{array}{l}\text { Anaerotruncus colihominis et } \\
\text { rel. }\end{array}$ & $0.08 \%$ & $0.08 \%$ & $0.10 \%$ & Lactobacillus gasseri et rel. & $0.06 \%$ & $0.06 \%$ & $0.08 \%$ \\
\hline $\begin{array}{l}\text { Anaerovorax odorimutans et } \\
\text { rel. }\end{array}$ & $0.10 \%$ & $0.18 \%$ & $0.11 \%$ & $\begin{array}{l}\text { Lactobacillus plantarum et } \\
\text { rel. }\end{array}$ & $0.25 \%$ & $0.11 \%$ & $0.11 \%$ \\
\hline Aneurinibacillus & $0.01 \%$ & $0.01 \%$ & $0.01 \%$ & Lactobacillus salivarius et rel. & $0.02 \%$ & $0.02 \%$ & $0.02 \%$ \\
\hline Aquabacterium & $0.06 \%$ & $0.02 \%$ & $0.01 \%$ & Lactococcus & $0.02 \%$ & $0.01 \%$ & $0.02 \%$ \\
\hline Asteroleplasma et rel. & $0.01 \%$ & $0.00 \%$ & $0.01 \%$ & Leminorella & $0.01 \%$ & $0.01 \%$ & $0.01 \%$ \\
\hline Atopobium & $0.01 \%$ & $0.01 \%$ & $0.01 \%$ & $\begin{array}{l}\text { Megamonas hypermegale et } \\
\text { rel. }\end{array}$ & $0.01 \%$ & $0.02 \%$ & $0.02 \%$ \\
\hline Bacillus & $0.02 \%$ & $0.02 \%$ & $0.02 \%$ & Megasphaera elsdenii et rel. & $0.03 \%$ & $0.04 \%$ & $0.04 \%$ \\
\hline Bacteroides fragilis et rel. & $0.99 \%$ & $1.65 \%$ & $1.52 \%$ & Methylobacterium & $0.00 \%$ & $0.00 \%$ & $0.01 \%$ \\
\hline Bacteroides intestinalis et rel. & $0.06 \%$ & $0.05 \%$ & $0.03 \%$ & Micrococcaceae & $0.01 \%$ & $0.01 \%$ & $0.01 \%$ \\
\hline Bacteroides ovatus et rel. & $0.80 \%$ & $0.85 \%$ & $0.93 \%$ & Mitsuokella multiacida et rel. & $0.02 \%$ & $0.02 \%$ & $0.02 \%$ \\
\hline Bacteroides plebeius et rel. & $0.40 \%$ & $0.32 \%$ & $0.20 \%$ & Moraxellaceae & $0.01 \%$ & $0.01 \%$ & $0.01 \%$ \\
\hline $\begin{array}{l}\text { Bacteroides splachnicus et } \\
\text { rel. }\end{array}$ & $0.22 \%$ & $0.26 \%$ & $0.20 \%$ & Novosphingobium & $0.01 \%$ & $0.01 \%$ & $0.01 \%$ \\
\hline Bacteroides stercoris et rel. & $0.30 \%$ & $0.34 \%$ & $0.22 \%$ & Oceanospirillum & $0.02 \%$ & $0.02 \%$ & $0.02 \%$ \\
\hline Bacteroides uniformis et rel. & $0.87 \%$ & $0.69 \%$ & $0.52 \%$ & $\begin{array}{l}\text { Oscillospira guillermondii et } \\
\text { rel. }\end{array}$ & $1.49 \%$ & $1.05 \%$ & $1.14 \%$ \\
\hline Bacteroides vulgatus et rel. & $41.99 \%$ & $34.74 \%$ & $3.85 \%$ & $\begin{array}{l}\text { Outgrouping clostridium } \\
\text { cluster XIVa }\end{array}$ & $0.15 \%$ & $0.31 \%$ & $0.86 \%$ \\
\hline Bifidobacterium & $4.46 \%$ & $1.16 \%$ & $1.92 \%$ & $\begin{array}{l}\text { Oxalobacter formigenes et } \\
\text { rel. }\end{array}$ & $1.55 \%$ & $0.15 \%$ & $0.07 \%$ \\
\hline Bilophila et rel. & $0.02 \%$ & $0.03 \%$ & $0.02 \%$ & $\begin{array}{l}\text { Papillibacter cinnamivorans } \\
\text { et rel. }\end{array}$ & $0.08 \%$ & $0.12 \%$ & $0.19 \%$ \\
\hline Brachyspira & $0.01 \%$ & $0.01 \%$ & $0.01 \%$ & $\begin{array}{l}\text { Parabacteroides distasonis et } \\
\text { rel. }\end{array}$ & $1.00 \%$ & $0.74 \%$ & $6.50 \%$ \\
\hline $\begin{array}{l}\text { Bryantella formatexigens et } \\
\text { rel. }\end{array}$ & $0.31 \%$ & $0.31 \%$ & $0.63 \%$ & Peptococcus niger et rel. & $0.03 \%$ & $0.04 \%$ & $0.04 \%$ \\
\hline Bulleidia moorei et rel. & $0.02 \%$ & $0.02 \%$ & $0.03 \%$ & $\begin{array}{l}\text { Peptostreptococcus } \\
\text { anaerobius et rel. }\end{array}$ & $0.01 \%$ & $0.01 \%$ & $0.01 \%$ \\
\hline Burkholderia & $0.23 \%$ & $0.06 \%$ & $0.04 \%$ & $\begin{array}{l}\text { Peptostreptococcus micros et } \\
\text { rel. }\end{array}$ & $0.02 \%$ & $0.03 \%$ & $0.03 \%$ \\
\hline Butyrivibrio crossotus et rel. & $6.52 \%$ & $2.11 \%$ & $3.21 \%$ & $\begin{array}{l}\text { Phascolarctobacterium } \\
\text { faecium et rel. }\end{array}$ & $0.06 \%$ & $0.38 \%$ & $0.28 \%$ \\
\hline Campylobacter & $0.04 \%$ & $0.04 \%$ & $0.05 \%$ & $\begin{array}{l}\text { Prevotella melaninogenica et } \\
\text { rel. }\end{array}$ & $0.29 \%$ & $0.12 \%$ & $0.31 \%$ \\
\hline $\begin{array}{l}\text { Catenibacterium mitsuokai et } \\
\text { rel. }\end{array}$ & $0.01 \%$ & $0.01 \%$ & $0.07 \%$ & Prevotella oralis et rel. & $0.22 \%$ & $0.14 \%$ & $0.11 \%$ \\
\hline
\end{tabular}




\section{CHAPTER 5}

Supplementary Table 1 (continued): Microbiota composition of duplicates of a 48 hour fermentation digest from RMD expressed as \% genus of microbiota present.

\begin{tabular}{|c|c|c|c|c|c|c|c|}
\hline Bacteria genera & $\begin{array}{c}\text { RMD } \\
\text { digest t0 }\end{array}$ & $\begin{array}{c}\text { blank } \\
\text { digest } \\
\text { t24 }\end{array}$ & $\begin{array}{c}\text { RMD } \\
\text { digest } \\
\text { t48 }\end{array}$ & Bacteria genera & $\begin{array}{c}\text { RMD } \\
\text { digest t0 }\end{array}$ & $\begin{array}{c}\text { blank } \\
\text { digest } \\
\text { t24 }\end{array}$ & $\begin{array}{c}\text { RMD } \\
\text { digest } \\
\text { t48 }\end{array}$ \\
\hline Clostridia & $0.33 \%$ & $0.25 \%$ & $0.25 \%$ & Prevotella ruminicola et rel. & $0.02 \%$ & $0.02 \%$ & $0.02 \%$ \\
\hline Clostridium cellulosi et rel. & $0.29 \%$ & $0.14 \%$ & $0.18 \%$ & \begin{tabular}{|l|} 
Prevotella tannerae et rel. \\
\end{tabular} & $3.31 \%$ & $0.99 \%$ & $0.24 \%$ \\
\hline Clostridium colinum et rel. & $0.05 \%$ & $0.05 \%$ & $0.06 \%$ & Propionibacterium & $0.02 \%$ & $0.02 \%$ & $0.02 \%$ \\
\hline Clostridium difficile et rel. & $0.16 \%$ & $0.10 \%$ & $0.13 \%$ & Proteus et rel. & $0.04 \%$ & $0.04 \%$ & $0.05 \%$ \\
\hline Clostridium felsineum et rel. & $0.01 \%$ & $0.01 \%$ & $0.01 \%$ & Pseudomonas & $0.01 \%$ & $0.01 \%$ & $0.01 \%$ \\
\hline Clostridium leptum et rel. & $0.47 \%$ & $0.11 \%$ & $0.18 \%$ & Roseburia intestinalis et rel. & $0.04 \%$ & $0.07 \%$ & $0.28 \%$ \\
\hline Clostridium nexile et rel. & $0.58 \%$ & $4.20 \%$ & $7.80 \%$ & Ruminococcus bromii et rel. & $0.69 \%$ & $0.04 \%$ & $0.04 \%$ \\
\hline $\begin{array}{l}\text { Clostridium orbiscindens et } \\
\text { rel. }\end{array}$ & $0.30 \%$ & $0.72 \%$ & $0.86 \%$ & Ruminococcus callidus et rel. & $0.08 \%$ & $0.08 \%$ & $0.12 \%$ \\
\hline Clostridium ramosum et rel. & $0.02 \%$ & $0.03 \%$ & $0.04 \%$ & Ruminococcus gnavus et rel. & $0.10 \%$ & $0.12 \%$ & $0.37 \%$ \\
\hline Clostridium sphenoides et rel. & $0.57 \%$ & $2.49 \%$ & $10.46 \%$ & Ruminococcus lactaris et rel. & $0.05 \%$ & $0.05 \%$ & $0.09 \%$ \\
\hline $\begin{array}{l}\text { Clostridium stercorarium et } \\
\text { rel. }\end{array}$ & $0.06 \%$ & $0.03 \%$ & $0.04 \%$ & Ruminococcus obeum et rel. & $0.55 \%$ & $0.43 \%$ & $4.36 \%$ \\
\hline Clostridium symbiosum et rel. & $3.41 \%$ & $30.16 \%$ & $33.80 \%$ & Serratia & $0.02 \%$ & $0.02 \%$ & $0.01 \%$ \\
\hline $\begin{array}{l}\text { Clostridium thermocellum et } \\
\text { rel. }\end{array}$ & $0.00 \%$ & $0.01 \%$ & $0.01 \%$ & Sporobacter termitidis et rel. & $0.56 \%$ & $0.31 \%$ & $0.37 \%$ \\
\hline Collinsella & $0.92 \%$ & $0.45 \%$ & $0.47 \%$ & Staphylococcus & $0.01 \%$ & $0.01 \%$ & $0.01 \%$ \\
\hline $\begin{array}{l}\text { Coprobacillus catenaformis et } \\
\text { rel. }\end{array}$ & $0.03 \%$ & $0.03 \%$ & $0.03 \%$ & Streptococcus bovis et rel. & $0.12 \%$ & $0.08 \%$ & $0.18 \%$ \\
\hline Coprococcus eutactus et rel. & $0.16 \%$ & $0.14 \%$ & $1.58 \%$ & $\begin{array}{l}\text { Streptococcus intermedius et } \\
\text { rel. }\end{array}$ & $0.02 \%$ & $0.02 \%$ & $0.03 \%$ \\
\hline Corynebacterium & $0.02 \%$ & $0.02 \%$ & $0.02 \%$ & Streptococcus mitis et rel. & $0.04 \%$ & $0.04 \%$ & $0.05 \%$ \\
\hline Desulfovibrio et rel. & $0.03 \%$ & $0.03 \%$ & $0.03 \%$ & $\begin{array}{l}\text { Subdoligranulum variable at } \\
\text { rel. }\end{array}$ & $0.43 \%$ & $0.19 \%$ & $0.58 \%$ \\
\hline Dialister & $0.84 \%$ & $3.78 \%$ & $1.17 \%$ & Sutterella wadsworthia et rel. & $9.39 \%$ & $2.30 \%$ & $1.10 \%$ \\
\hline Dorea formicigenerans et rel. & $0.44 \%$ & $0.81 \%$ & $1.58 \%$ & Tannerella et rel. & $0.46 \%$ & $0.40 \%$ & $0.49 \%$ \\
\hline Eggerthella lenta et rel. & $0.08 \%$ & $0.07 \%$ & $0.05 \%$ & Uncultured Bacteroidetes & $0.02 \%$ & $0.01 \%$ & $0.02 \%$ \\
\hline $\begin{array}{l}\text { Enterobacter aerogenes et } \\
\text { rel. }\end{array}$ & $1.56 \%$ & $0.37 \%$ & $0.19 \%$ & Uncultured Chroococcales & $0.01 \%$ & $0.01 \%$ & $0.01 \%$ \\
\hline Enterococcus & $0.09 \%$ & $0.05 \%$ & $0.05 \%$ & Uncultured Clostridiales I & $0.68 \%$ & $0.18 \%$ & $0.20 \%$ \\
\hline Escherichia coli et rel. & $0.22 \%$ & $0.22 \%$ & $0.08 \%$ & Uncultured Clostridiales II & $0.64 \%$ & $0.16 \%$ & $0.19 \%$ \\
\hline Eubacterium biforme et rel. & $0.04 \%$ & $0.03 \%$ & $0.04 \%$ & Uncultured Mollicutes & $0.09 \%$ & $0.08 \%$ & $0.09 \%$ \\
\hline $\begin{array}{l}\text { Eubacterium cylindroides et } \\
\text { rel. }\end{array}$ & $0.02 \%$ & $0.03 \%$ & $0.03 \%$ & $\begin{array}{l}\text { Uncultured } \\
\text { Selenomonadaceae }\end{array}$ & $0.01 \%$ & $0.01 \%$ & $0.01 \%$ \\
\hline Eubacterium hallii et rel. & $0.04 \%$ & $0.09 \%$ & $0.37 \%$ & Veillonella & $0.02 \%$ & $0.02 \%$ & $0.02 \%$ \\
\hline Eubacterium limosum et rel. & $0.02 \%$ & $0.02 \%$ & $0.02 \%$ & Vibrio & $0.09 \%$ & $0.04 \%$ & $0.04 \%$ \\
\hline Eubacterium rectale et rel. & $0.07 \%$ & $0.09 \%$ & $1.12 \%$ & Weissella et rel. & $0.02 \%$ & $0.02 \%$ & $0.03 \%$ \\
\hline Eubacterium siraeum et rel. & $0.02 \%$ & $0.02 \%$ & $0.02 \%$ & Wissella et rel. & $0.01 \%$ & $0.01 \%$ & $0.01 \%$ \\
\hline $\begin{array}{l}\text { Eubacterium ventriosum et } \\
\text { rel. }\end{array}$ & $0.05 \%$ & $0.08 \%$ & $0.15 \%$ & Xanthomonadaceae & $0.17 \%$ & $0.07 \%$ & $0.04 \%$ \\
\hline $\begin{array}{l}\text { Faecalibacterium prausnitzii } \\
\text { et rel. }\end{array}$ & $0.39 \%$ & $0.35 \%$ & $2.52 \%$ & Yersinia et rel. & $0.03 \%$ & $0.02 \%$ & $0.03 \%$ \\
\hline
\end{tabular}


Chapter 6

General Discussion 


\section{RESEARCH AIM AND APPROACH}

The research described in this thesis was part of a project entitled "Molecular interactions of mucosal tissue, bacteria and fibres", which aimed to unravel the complex host-fibremicrobe relationships in the human large intestine. As a subproject, this thesis aimed to analyse the characteristics of selected dietary fibres and their in vitro fermentation characteristics by human faecal microbiota. In addition, a diverse range of dietary fibres and their degradation products were analysed with immune cells for their immunomodulatory properties in relation to their physico-chemical characteristics.

The approach used was a screening of many different fibres for their immunomodulation on bone marrow derived dendritic cells (BMDCs). Based on these results, a number of dietary fibres were selected for further studies concerning their structure and physical related immunological characteristics. Furthermore, dietary fibres were fermented in vitro in a batch fermentation model to study the intermediate degradation products, end products and enzymes produced by the microbiota present. Finally, fermentation digesta of two fibres were incubated on BMDCs to monitor the immunomodulation of degradation products present.

The outcomes of this study connects the research fields of carbohydrate chemistry and immunology and provides the knowledge basis for further research on the identification of chemical structure of dietary fibres in relation to immunomodulation. Additionally, in vitro microbial fermentation activities towards the dietary fibre can be monitored and can support the identification of immunomodulating properties the fibres.

\section{DIETARY FIBRES}

Several dietary fibres, of interest for the project partners and some known, rather pure fibres from our own collection, were analysed for their chemical characteristics (Chapter 2). This analysis revealed that the product name given by the supplier did not always match the content of the sample. For example, samples labelled 'apple pectin' appeared to represent an apple fibre instead. Furthermore, monosaccharide composition analysis revealed that some fibres, e.g. crude fibres, were quite heterogeneous and of complex nature in terms of polysaccharides present. Also, some samples designated as 'resistant starches' still contained digestible starch.

With the aim to analyse structure-function relationships of the fibres, we finally came to a selection of 44 fibres of high diversity. Some fibres were, if possible, matched with another fibre with only minimal physico-chemical differences. For example, linear- (LA) and branched arabinan (BA); two resistant maltodextrins (RMD) from the same supplier, but made of different starch sources; high- and low methyl esterified lemon pectin; chicory inulins with different degrees of polymerisation (DP) and two $\beta$-glucans from different cereal sources. Based on this and the monosaccharide composition analysis, 44 fibres were chosen and categorised into seven groups and investigated for their immunomodulatory properties (Chapter 2) (Table 1). 
Table 1: Categories and variations of dietary fibres used in the project.

\begin{tabular}{|c|c|c|}
\hline Fibre category & Number of fibres & Variations \\
\hline Starchy materials & 9 & $\begin{array}{l}\text { Resistant starch type, solubility, source, } \\
\text { amount of digestible starch }\end{array}$ \\
\hline Cellulosic fibres & 5 & Source, purity \\
\hline Pectic fibres & 10 & $\begin{array}{l}\text { Source, degree of methyl esterification and } \\
\text { acetylation, constituent monosaccharide } \\
\text { composition, molecular mass, branching }\end{array}$ \\
\hline Crude fibres & 8 & Source, purity \\
\hline Hemicelluloses & 5 & $\begin{array}{l}\text { Cereal source, molecular mass, constituent } \\
\text { monosaccharide composition }\end{array}$ \\
\hline Gums & 3 & $\begin{array}{l}\text { Source, constituent monosaccharide } \\
\text { composition }\end{array}$ \\
\hline Prebiotics & 4 & $\begin{array}{l}\text { Molecular mass, fructose:glucose or } \\
\text { galactose:glucose ratio }\end{array}$ \\
\hline
\end{tabular}

Despite the categorisation based on chemical analysis, each fibre in a specific category still had its unique physico-chemical features. Where possible, two or more fibres sharing the same major structural feature and only differing in detail, were selected for further studies.

\section{IMMUNOMODULATION BY DIETARY FIBRES}

Dietary fibres are indigestible carbohydrates, which pass through the small intestine, to be (partly) fermented in the large intestine [1]. During this journey fibres and degradation products might be taken up by M-cells, bind to receptors on dendrites of epithelial associated dendritic cells (DCs), or cells of the epithelium to start a cascade of reactions, resulting in the regulation of innate defence molecules including cytokines [2-4].

\section{Methodological aspects of immunomodulation of dietary fibres}

The immunomodulation of dietary fibres can be tested using a variety of different immune cells. Microbial-associated molecular patterns (MAMPs), such as lipopolysaccharide (LPS) and lipoteichoic acid (LTA), have been frequently reported to bind to TLR4 (Toll-like receptor) and to be contaminants of dietary fibres and hence may influence their immunomodulating properties [5]. We demonstrated that BMDCs from TLR2/4 knockout (KO) mice were not activated by bacterial agonists of TLR2 and TLR4 (Chapter 2). Several of the 44 screened fibres induced cytokines in BMDCs generated from the bone marrow of TLR/4 knockout mice, indicating that other PRRs or mechanisms of immune activation were involved (Chapter 2). Indeed zymosan, a known ligand of Dectin-1, was still able to induce cytokine responses in BMDCs from these mice, showing that signalling through Dectin-1, a CLR was unaffected. Despite the lack in possible fibre signalling via TLRs, the use of BMDCs from TLR2/4 KO mice to analyse the immune stimulation by a broad range of dietary fibres was successfully validated and BMDCs derived from this mouse line were shown to be a valuable approach to investigate immunomodulation by fibres (Chapter 2). 
A further advantage of the BMDCs from TLR2/4 KO mice is that even fermentation digesta with very high amounts of microbes and their MAMPS did not influence the amounts of cytokines induced (Chapter 4). Control samples comprising only faecal microbiota did not induce cytokines in BMDCs from TLR2/4 knockout mice (Chapter 4), even though some intestinal bacteria possess flagella, which can signal through TLR5. This was due to the fact that BMDCs generated from the strain of mice used in these studies also did not respond to purified flagellin (Chapter 2). A blank, containing MES buffer and SCFA in concentrations and ratios as present in the digesta, was also not immunestimulating. Hence, the fermentation digesta containing the glycosidic fermentation metabolites could be incubated with these BMDCs and analysed for their immunomodulatory effects, despite the presence of MAMPs in the samples (Chapter 4). For the fermentation digesta of barley $\beta$-glucan and sugar beet pectin (SBP) a stronger immune-stimulation was observed for glycosidic degradation products formed during fermentation than for the parental fibre at the start of the fermentation. This demonstrates that the glycosidic fermentation metabolites are at least equally important as the parental fibre when evaluating the immune response of fibres. The results of chapter 4 also led to a new approach to link fermentation and immunomodulation by dietary fibres in the large intestine. Currently, only one study [6] discusses the incubation of digesta from the SHIME model on Caco-2/THP1 co-cultured cells. In this study the yeast $\beta$-glucan digesta was sterile-filtered in order to protect the immune cells from the present faecal sample microbiota [6]. However, such a method certainly affects the immune response to fermented fibres, as it is known that the immune response is mainly mediated via the particulate fractions, especially in the case of $\beta$-glucans [7] (Chapter 3). Thus, filtration in order to remove bacteria influences the results of the immune assays and cannot be the recommended method for immunomodulatory studies on insoluble, viscous and even soluble dietary fibre, that might become insoluble during fermentation. This can be avoided by using the experimental set up described in chapter 4 . Although controls of microbiota, even after $24 \mathrm{~h}$ fermentation, did only modestly stimulate cytokine production, in future research it might be investigated whether a totally changed faecal microbiota composition increases induction of cytokines in immune cells via cell stress pathways.

Overall, BMDCs from TLR2/4 KO mice are very suitable to analyse the immunomodulation by dietary fibres and their fermentation digesta.

\section{Carbohydrate binding receptors on immune cells}

The interaction of dietary fibres can occur with different receptors, for example TLRs or CLRs. Only a few receptors on immune cells have been shown to interact with specific carbohydrate structures. The first and most investigated one is Dectin- 1 , which belongs to the C-type lectin receptors and binds $\beta$-glucans. The interaction of a particulate $\beta(1,3)$ glucan with Dectin-1 mediates the clustering of many other receptors as CD45, CD148, ITAM-like motif, Src (proto-oncogene tyrosine-protein kinase) family kinases and recruiting of Syk (spleen tyrosine kinase) [8]. Linear arabinan (LA) and branched arabinan (BA) were shown to induce cytokine production in BMDCs from TLR2/4 KO mice via a Syk-dependent pathway, and likely through a CLR other than Dectin-1 (Chapter 2). This 108 
was validated by the use of piceatannol and an anti-Dectin ligand, which are Syk kinase and Dectin-1 antagonists, respectively. It was shown that LA and BA were able to induce cytokines even though Dectin-1 was blocked by an antibody and when Syk kinase was normally functioning.

In reporter cell lines it was shown that fibres differentially signal via different TLRs (1/2, 2/6, 2 and 4) (Chapter 2) [9], but this was most likely due to contamination with endotoxins, which were detected in some samples. Despite the possible stimulation due to MAMPs in TLR reporter cell lines, the response of TLR reporter cell lines to fibres can give an indication whether to further investigate the specific signalling pathway of a certain fibre via TLRs. The stimulation by carbohydrates in various TLR reporter cell lines should be confirmed by e.g. complete enzymatic degradation of the carbohydrate or by removal of contaminating MAMPs.

Fibres might be able to signal via multiple pattern recognition receptors (PRRs) of different families, as TLR and CLR. This can be concluded when two studies using the same resistant starches (High maize 260 and Novelose 330) are compared. The first study [10] showed that High maize 260 activated NF-кB via TLR2 and Novelose 330 via TLR2 and 5 in reporter cell lines (HEK-Blue). In similar type of reporter cell lines (HEK 293) used in chapter 2, we showed that only Novelose 330 significantly activated NF- $\mathrm{KB}$ via TLR1/2. Nevertheless, in chapter 2 these TLRs were also knocked out and both resistant starches induced significant amounts of cytokines in the BMDCs (Figure 1). These two fibres show that fibre mediate via different types of receptors.

In conclusion, it is difficult to make assumptions whether fibres of the same category interact with the same receptor. Dietary fibres mediate very specific via different receptors including CLRs and TLRs.

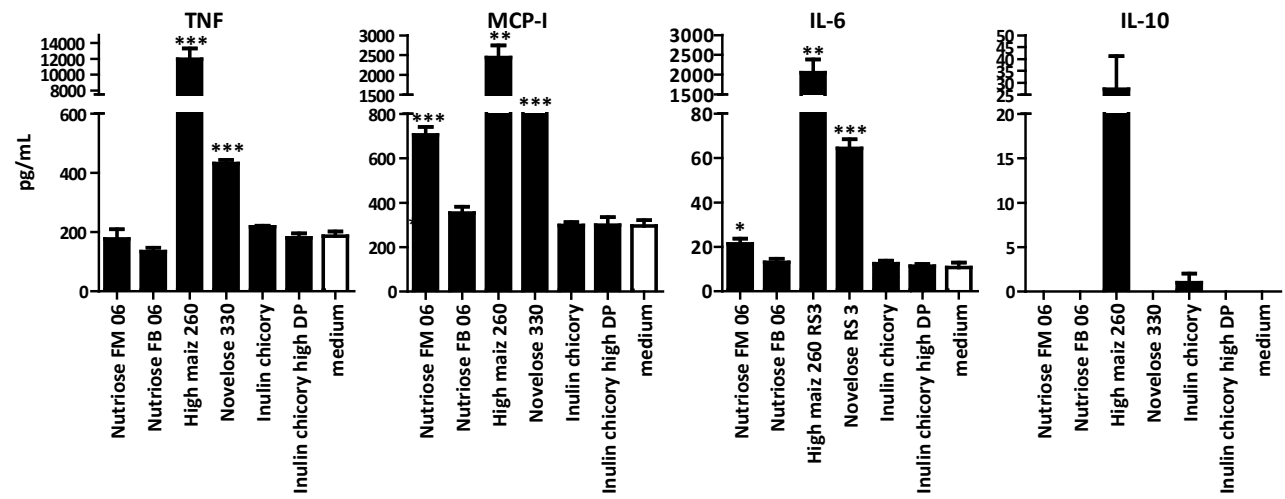

Figure 1: Cytokine profile induced by different resistant starches and fructooligosaccharides (FOS) in BMDCs from TLR2/4 KO mice. Zymosan control: 3792, 10, 8157 and $1722 \mathrm{pg} / \mathrm{mL}$ (IL-6, IL-10, TNF and MCP-1) (Chapter 2).

\section{Dietary fibre fine structure matters}

The 44 selected fibres were screened for their immunomodulation properties on BMDCs from TLR2/4 KO mice (Chapter 2). Only superficial conclusions of immunomodulatory properties of the fibre categories can be made as each fibre has its unique immunologic 
signature, which is related to specific chemical structural features as will be discussed below. Nevertheless, it was observed that the category of 'crude fibres' induced the highest amounts of all five measured cytokines. This might be in relation with their high insolubility as will be discussed below. Furthermore, many fibres of the category 'cellulosic fibres', 'pectic fibres' and some insoluble starches are immunomodulating, which could be due to a higher proportion of insoluble material, but also to other specific characteristics. Hence, it is recommended to compare a broad range of fibres within one category and not to extrapolate conclusions from one fibre to a whole category.

\section{Analysis of structure-function relationships}

$\beta$-Glucans, mannans and pectic polysaccharides are the most studied fibres in terms of immunomodulation [11]. A structure-function relationship has for most polysaccharides not yet been discovered.

In our studies we followed two approaches to analyse immunomodulatory structurefunction relationships. First, we compared two similar substrates within a fibre category, for example LA and BA, and analysed them for immunomodulation depending on the small structural difference of the fibre. These kinds of substrates are either difficult to find or to identify with respect to their minimal physico-chemical difference. Our second approach was to modify fibre characteristics and relate the modification to the immune-activity. The latter is difficult because a targeted modification of a substrate mostly causes a second concomitant modification and mixtures are obtained, which requires further separation. In our study, the linear arabinan (LA), having the same source and rather similar arabinose levels as BA, induced higher amounts of cytokines than BA. Their separated particulate fractions induced similar amounts of cytokines. Thus, the difference in immunomodulation by the suspended LA and BA might be due to different amounts of active particulate material. Furthermore, we demonstrated that a targeted modification, by which BA was enzymatically linearized, and thereby becoming the structure of LA alike, led to an increase in immune activity (Chapter 2). This might be also related to an increase in particulate material, due to linearization and precipitation.

Many of the studies on immunological effects by dietary fibres highlight one structural difference between the fibres as responsible for the immune function, while other physicochemical differences and purities of the compared substrate are ignored. It is, for example, stated that pectins with contents of less than $75 \%$ galacturonic acid can stimulate immunity [12]. Furthermore, low methyl esterified pectin (LMP) was found to be in vivo more antiinflammatory than high methyl esterified pectin (HMP) [13]. Not all important characteristics of these substrates, such as viscosity, solubility and net charge of the molecules are considered in the mentioned studies, although they could have influenced the immune stimulation besides the described characteristic. The fact that pectins cannot have the same viscosity and at the same time different degrees of methyl esterification, complicates the structure-function analysis. Nevertheless, it requires thorough consideration and experimentation before attributing a specific fibre characteristic to its immunomodulating activity. 


\section{Particulate versus soluble fibres}

The particulate oat and barley $\beta(1,3)(1,4)$ glucan fractions induced higher amounts of cytokines than soluble $\beta(1,3)(1,4)$ glucans (Chapter 3$)$. We showed that not only the soluble fraction, but also the complete heat-solubilised $\beta$-glucans induced low amounts of cytokines. Also particulate yeast-derived $\beta$-glucans are more immune-stimulating than soluble $\beta$-glucans [14]. Fungal derived particulate $\beta(1,3)$ glucans are recognised and phagocytosed by Dectin-1 [7, 15]. This receptor was proven to be expressed in the used BMDCs from TLR2/4 KO mice (Chapter 2). In addition, chapter 2 showed that the particulate LA, BA and SBP fractions were highly immunomodulatory. The importance of particulate material is further emphasized by representatives of the category 'crude fibres'. These complex mixtures of several polysaccharides with major parts being insoluble, induced much larger amounts of cytokines in BMDCs, than for example soluble resistant starch fibres (Chapter 2). Also within the class of 'starchy materials', the soluble non-RS 4 type were on average less immune-activating than the partly insoluble RS type 2 and 3 fibres. Hence, other molecular differences between the samples probably exist and may be as well relevant for immunomodulating activity.

Particulate fibres are very important in relation to immune-stimulation. For most neutral and uncharged polysaccharides, interaction with a receptor is probably only possible via binding of soluble molecules to the carbohydrate recognising receptor. The initial contact of particulate ligands is the least understood in the whole phagocytosis process [15]. Figure 2 illustrates the interaction of a fungal particulate $\beta(1,3)$ glucan with Dectin-1. From the insoluble core of the particle many soluble $\beta$-glucan molecules emerge and bind to the Dectin-1 receptors, resulting in clustering of receptors [7, 15]. A single soluble molecule, not connected to particulate material, can also bind to the Dectin-1 receptor, but lacks the high density of $\beta$-glucan molecules emerging from a particle. The high density of soluble emerging $\beta$-glucans might amplify the mediation by clustering many Dectin- 1 receptors [15]. This illustrates the importance of the analysis of the structure-related affinity of soluble, emerging $\beta$-glucans and soluble fibres in general, as they might have a similar binding mechanism and signal lowly only because they do not cluster receptors. Hence, soluble fibres are less immunomodulating on its own, but are partly required for particle interaction and thus of interest for structure-function identification. In contrast, particulate microcrystalline cellulose did not stimulate immune responses (Chapter 2), suggesting that a receptor interaction of particulate material is not just dependent on the presence of any particle, but requires emerging soluble molecules from the particle, which presence might be substrate dependent.

A physical characteristic of particles is their particle size distribution and this has been analysed for oat and barley $\beta$-glucans (chapter 3), LA, BA and SBP (chapter 2) and two resistant starches (High maize 260 and Novelose 330) [10]. In all three studies there was a difference in the particle size distribution between the fibres studied. However, these differences could not fully explain the immunomodulatory difference, as probably other characteristics were important for the immune response as well. Further evidence was obtained by sieving the LA, BA, SBP and the two $\beta$-glucans into two fractions (smaller and 
larger than $106 \mu \mathrm{m})$. These fractions of LA and BA did not differ in immunostimulatory activity (chapter 2). For the two $\beta$-glucans, the small fraction induced larger amounts of cytokines, which was related to a higher homogeneity of the small than that of the large fraction and will be discussed later on.

In contrast, the small oat and barley $\beta$-glucans consisted of a very similar particle size distribution and still induced different amounts of cytokines. This indicates that other characteristics of a fibre than the particle size distribution determines the immunomodulatory properties.

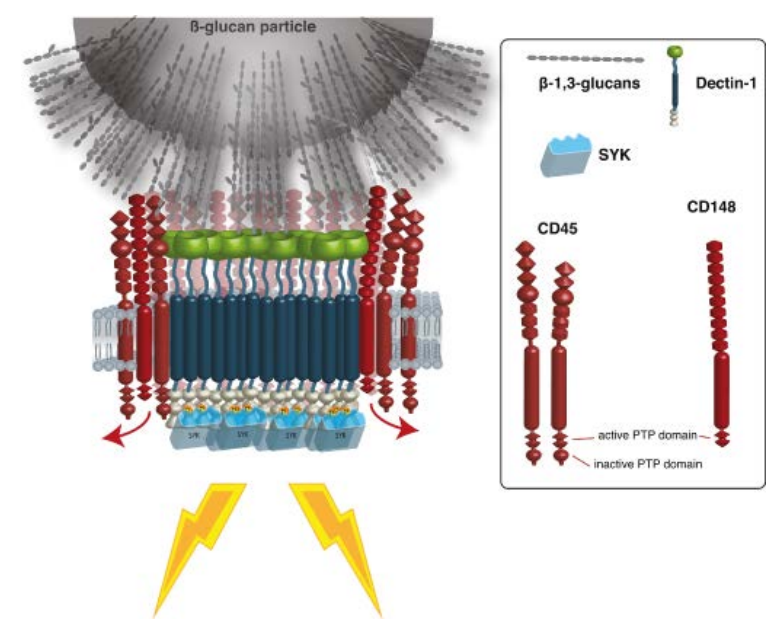

Figure 2: Suggestion of the interaction of a fungal particulate $\beta$-glucan via emerging soluble $\beta$-glucan molecules linked to particulate $\beta$-glucans [15].

Even though the immunostimulatory activity of soluble fibres was in general lower than that of particulate fibres (chapters 2 and 3), there are still differences in amounts of induced cytokines between soluble fibres. In chapter 3 we showed that the soluble fractions of the barley induced larger amounts of cytokines than the soluble oat $\beta$-glucans. Also, Figure 1 shows that different amounts of cytokines were induced by three soluble resistant starches (Chapter 2). Especially intriguing is the difference between the two Nutriose samples, since they are produced in the same way, aiming to yield rather similar structures, but originate from different starch sources. Nutriose FM 06 (from maize) induces significantly higher amounts of IL-6 and MCP-1 than Nutriose FB (from wheat). Chemically they are resistant starch type 4, similar to Fibersol-2. In chapter 5 it is mentioned that Fibersol-2, a resistant maltodextrin (RMD), is difficult to analyse and separate into different fractions. This is also true for the Nutriose samples, which makes the analysis of structure function relationship difficult. However, it emphasizes that all the substrates need to be tested individually in order to make conclusions on their immunomodulatory properties.

In conclusion, we showed that many insoluble fibres or particulate fractions of fibres induce immune responses and not only the well-studied particulate yeast $\beta(1,3)$ glucan. The insolubility seems to be one of the most determining features for immunomodulation, but requires probably soluble connecting molecules. 


\section{Importance of molar mass as immunomodulating feature}

The molar mass is extensively discussed in literature with respect to immunomodulatory properties [11]. Findings of chapter 3 showed that enzymatically degraded barley $\beta$-glucans induced higher amounts of cytokines than parental barley $\beta$-glucans. This is confirmed by findings reported in chapter 4 , in which $\beta$-glucan fragments formed during the fermentation of $\beta$-glucan were increasing immune-stimulation on BMDCs from TLR2/4 KO mice (Chapter 4). This was also observed for SBP and for both substrates it can be speculated that $\beta$-glucan and SBP metabolites of intermediate molecular mass are immune-stimulating. The amounts of insoluble material of all digesta and incubations may be of relevance and should be determined and separately tested in immunoassays.

Another example of a completely soluble fibre are inuline-type fructans. For $\beta(2,1)$ fructan the degree of polymerisation (DP) seems to be important in terms of immunomodulation. A fructan having an average DP of 14 induced larger amounts of anti-inflammatory cytokines in PBMCs than of a DP 26 fructan [16]. In the BMDCs from TLR2/4 KO mice, the same chicory inulin sample of low DP also induced large amounts of IL-10 (Chapter 2). The chicory inulin of higher DP did not induce IL-10 (Figure 1), which is in line with previous findings [16].

Overall, the molar mass seems to determine immunomodulation, dependent on the fibre. For $\beta$-glucans and inulins a lower DP seems to be more immune-stimulating than molecules of higher DP.

\section{Structure related immunomodulation of pectic fibres}

LA induced significantly higher amounts of cytokines than BA in the BMDCs. Furthermore, the enzymatically linearization of BA correlated with an increase in immuneactivity (chapter 2). The fact that the branching characteristic of these fibres was important, was shown for synthetic $\beta$-glucans. The presence of a single glucose side chain increased the affinity for Dectin-1 [17]. This could be similar for arabinans, as it was also shown that they induce cytokines in BMDCs via Syk-dependent signalling through an unknown CLR and not Dectin-1. Further evidence for the importance of branching pattern comes from the comparison of silenan, a pectin from Silene vulgaris [18] and tanecan, from Tanacetum vulgare [19]. Silenan consists of i.a. side chains of linear arabinans and was observed to be more immune activating than tanecan, a pectin with branched arabinans. The study describes the branching of the side chains as the only difference of these two pectins. This seems to be doubtful, but this finding confirms our results on LA and BA.

Typical fine structure characteristics of pectins are their degree of methyl esterification (DM) and degree of acetylation (DA). It was shown that a lemon pectin of high DM (DM 74) increased TLR activation [20]. Our findings in chapter 2 indicate that only low amounts of cytokines were induced in BMDCs and this was independent from the different DM of the two lemon pectins. However, in the BMDCs from TLR2/4 KO mice the lacking TLRs could have been the reason for the different results between these studies, illustrating a limitation of our used cells.

SBP fermentation products induced higher amounts of cytokines than the parental SBP (Chapter 4). This combined fermentation and immunomodulation study revealed that 
soluble pectic galactan side chains and/or insoluble galacturonic acid backbone segments are quite immune-stimulating (Chapter 4). In future studies fermentation digesta should be separated into soluble and particulate fraction in order elucidate the structure of the remaining fibres present in the digesta and its individual immunomodulating properties.

\section{Fibre specific cytokine profiles}

Individual cytokine profiles were obtained for each dietary fibre incubated on BMDCs (Chapters 2, 3 and 4). Different $\beta$-glucans and SBP degradation products induced different amounts of cytokines depending on the substrate and fermentation metabolites (Chapter 4). For each immunomodulating substrate we measured different amounts of cytokines produced (Chapter 2). The different cytokine profiles obtained can be explained by the 44 fibres and fermentation metabolites having either their own specific fine structure or consisting of an individual fibre composition, such as brans. In the BMDCs from TLR2/4 KO mice, chicory inulin of low DP induced high amounts of IL-10 (Figure 1) (Chapter 2), an anti-inflammatory cytokine. In contrast, a second chicory inulin of high DP did not induce IL-10. This was confirmed by another study using the same inulins incubated on PBMCs [16].

These results show that each fibre induces a specific cytokine profile. Knowledge about the cytokine profiles of different fibres may be relevant to their application in intestinal disorders, such as irritable bowel syndrome (IBS), where certain cytokine imbalances are considered to be involved in the pathophysiology of the disease [21, 22].

Consequently, each fibre needs to be characterised and tested in detail and individually in order to make conclusions on immunological and health effects. The challenge in the identification of structure function relationships of fibres is that the fibres are very diverse, even within one category of fibres. Categorising fibres in order to predict their immunologic- or health effects seems to be impossible.

\section{Immunomodulation is affected by sample preparation}

As explained in the previous part of the discussion, the molecular structure of the fibre influences the outcome of the in vitro immune response. Additionally, some properties of fibres are highly influenced by processing methods or sample preparation (Chapter 3). These are, for example, heating, homogenisation and drying. In chapter 3 it is shown that $\beta$ glucans induced significantly less cytokines when they were completely solubilised by heating compared to the unheated, suspended $\beta$-glucans. This observation can be extended and transferred to probably all viscous fibres, since it was also observed for two sugar beet pectin samples from different suppliers and slightly different solubility characteristics. The monosaccharide composition and total amounts of carbohydrates in the two SBP samples were the same. However, they were differently affected by heating and also by freezedrying of the heated solution (Figure 3). SBP 1 induced lower amounts of cytokines after heating and subsequent freeze-drying, while the immune-stimulatory activity of SBP 2 was not affected by any of these processes. In contrast, LA and BA, two non-viscous samples were not affected by heating and freeze-drying (Figure 3). 


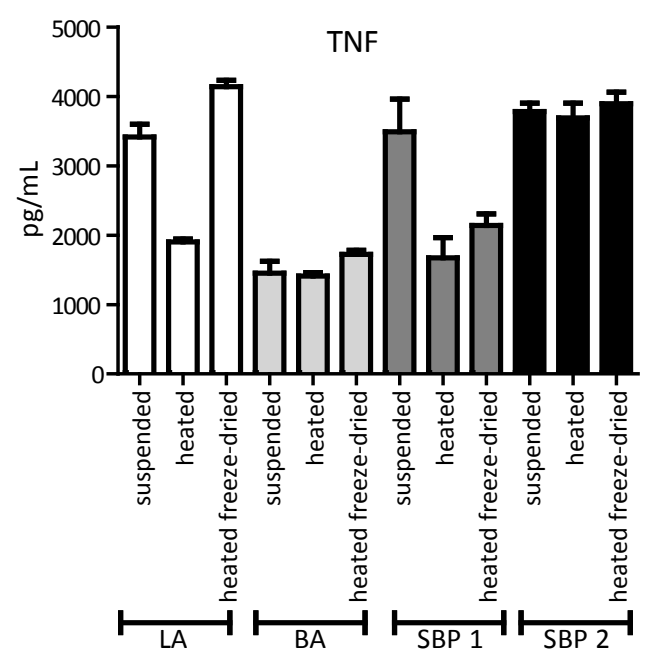

Figure 3: TNF cytokine response of BMDCs from TLR2/4 KO mice to suspended, heated and heated freeze-dried fractions of LA, BA, and SBP 1 and SBP 2 .

Homogenisation of freeze-dried particulate substrates increased the amounts of cytokines induced in BMDCs (Chapter 3). Homogenisation is of high importance if the sample is less well dispersed after the freeze-drying process. Figure 4 shows that homogenisation of suspended barley $\beta$-glucan, as obtained from the supplier, does not increase the amounts of cytokines induced in BMDCs, compared to the non-homogenised $\beta$-glucan. This can be explained because the commercial product was presumably spray-dried by the supplier and thus was more homogeneous when suspended. In contrast, homogenisation of a freezedried particulate $\beta$-glucan fraction induced increased amounts of cytokines in BMDCs than the non-homogenised particulate fraction. Thus homogenisation is necessary to obtain an equitable comparison of their immunomodulatory activity. The need of homogenisation was also observed for SBP, a gelling, partly insoluble fibre.

Overall we can conclude that depending on the fibre, processing and sample preparation methods may modify the fibre in such a way that it affects its immunomodulatory activity. In particular, the immunomodulatory activity of viscous fibres, such as pectins and $\beta$ glucans, are strongly influenced by sample preparation and homogenisation. However, this is not the case for completely insoluble fibres, such as brans. The effects of processing should be considered in relation to health claims of fibres relating to immune effects and their application in food and supplements. 


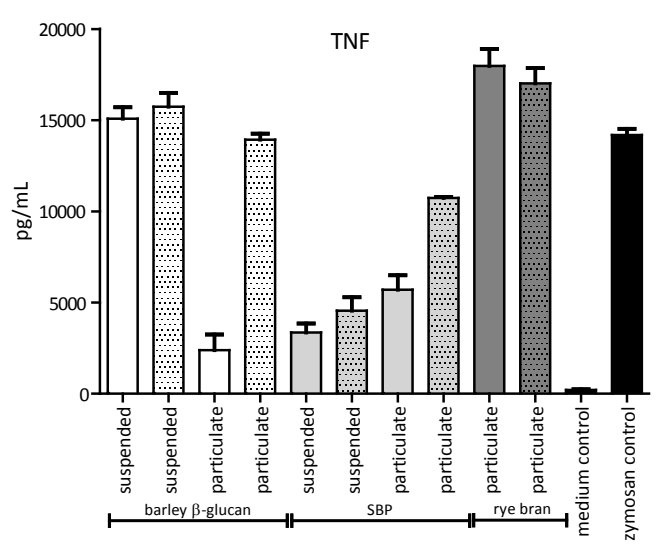

Figure 4: Concentration of TNF induced in BMDCs from TLR2/4 KO mice by suspended and particulate substrates and their homogenised (dotted pattern) fraction on. Barley $\beta$-glucan (white), SBP (light grey), rye bran (dark grey) and controls (black).

\section{FERMENTATION OF DIETARY FIBRES}

\section{Fibre specific in vitro fermentation characteristics}

Many studies on fermentation of dietary fibres focus only on microbiota changes and SCFA produced. Not only the microbiota and SCFA, but also indigestible food components, such as dietary fibres, which reach the large intestine, may influence the health of the host [2325]. Fibre characteristics, as the constituent monosaccharide and sugar linkage compositions, degree of polymerisation, molecular conformation and solubility determine the fermentation characteristics of the fibre [26-28]. All three fibres fermented in this thesis are degraded in different ways and are discussed below.

\section{Fermentation metabolites}

The in vitro fermentation of dietary fibres led to production of diverse glycosidic fermentation metabolites and end products (Chapter 4). For barley $\beta$-glucan soluble lowand intermediate molecular weight molecules are produced, while this is not the case for SBP (Chapter 4). This was not expected, since both fibres are viscous or gelling and were, based on their solubility characteristics, assumed to be degraded in similar rates. The high molecular mass $\beta$-glucan fermentation degradation products vary in DP and also in amounts of soluble and insoluble material. The amount of insoluble fibres can temporarily increase during fermentation, which was observed for the fermentation of SBP (Chapter 4). Microbial enzymes might cleave the substrate in such a way that molecules can align and precipitate, or they cleave off side chains so that the backbone remains and precipitates.

\section{Fermentation rate}

Fermentation characteristics, such as the rate or level of fermentability of fibres, provided in literature, are difficult to compare as different faecal inocula and concentrations of bacteria have been used. The microbiota is a main factor determining the fermentation characteristics of fibres [28]. The three fermentations described in this thesis used the same dilutions of a standardised faecal inocula. Surprisingly, results showed that soluble fibres 
are not always the most rapidly fermented. Fibersol-2, a soluble resistant starch/maltodextrin, was only slowly fermentable by human microbiota (Chapter 5). So far, soluble fibres were described to be more readily fermented than insoluble [27, 28]. Our results demonstrated that solubility does not necessarily correlate with faster fermentation. When the fermentation of Fibersol-2, barley $\beta$-glucan and SBP are compared with regard to their fermentation rate and amounts of SCFA produced, it can be concluded that the $\beta$ glucan reaches fastest and SBP the slowest the maximum amounts of SCFA produced. SBP is, however, most completely fermented. At $48 \mathrm{~h}$ fermentation the amount of total carbohydrates is 14 and $40 \mathrm{w} / \mathrm{w} \%$ for SBP and RMD, respectively.

\section{Microbial degradation characteristics}

SBP and RMDs seems to be rather degraded by exo enzymes and barley $\beta$-glucan by endo enzymes (Chapters 4 and 5). This is indicated by the different molecular mass profiles in which only for the barley $\beta$-glucan a huge shift from 270 to $60 \mathrm{kDa}$ within 6 hours was observed. This could also explain the faster fermentation rate of barley $\beta$-glucan in the beginning, as discussed above. The microbiota preferentially utilised soluble $\beta$-glucans. Hence, only when there is a lack of soluble fibre, the insoluble substrate is degraded (Chapter 4). Fibre molecules, such as RMDs, can be so complex and diverse in glycosidic linkages that they are difficult and only slowly fermentable by the faecal microbiota (Chapter 5). Analysis of enzymes, produced by the microbes during fermentation of RMDs, revealed that a broad enzymatic functionality is present (Chapter 5). The microbial enzymes of that fermentation were able to cleave a broad range of polysaccharides, from starch to complex pectins. However, enzymes present were only moderately active towards RMD.

In conclusion, all three fibre fermentations demonstrated a huge variety of glycosidic metabolites and different ratios of SCFA, as a result of complex and dynamic fibre-microbe interactions. We demonstrated for barley $\beta$-glucan and SBP that these glycosidic metabolites are able to interact with immune cells (Chapter 4). Hence, degradation metabolites need as much attention regarding investigation for immunomodulatory properties as the parental materials.

\section{Advances of in vitro fermentation models}

The batch fermentation model is a powerful in vitro model to monitor the degradation of dietary fibres. The interactions in the large intestine are complex, which requires further development of fermentation models to mimic more of the human digestion characteristics. The most recent developments, such as the HMI model, incorporate a mucus layer and intestinal epithelial cells (IECs) [29]. A membrane in this model prevents the direct interaction of bacteria with intestinal cells. This is necessary as otherwise the bacteria might cause epithelial cell death. The drawback of the membrane in the HMI model is that it hinders the interaction of particulate fibres with the IECs, which was shown in chapters 3 and 4 to be of high importance in terms of immunomodulating effects. Hence, a better alternative is to incubate fermentation digesta on BMDCs from TLR2/4 KO mice, as we performed in chapter 4 . This is the first study using such an experimental set up and proves 
to be a good possibility to combine both analyses of metabolites and determination of immunomodulation.

The batch host-microbe-interaction model could be a very good reference for further developments of sophisticated dynamic fermentation models, combining fermentation and immunomodulation in one system. The abundance of certain glycosidic degradation products to interact with the immune system is of interest when analysing the immunomodulation by a fibre. This highlights the importance and demand of detailed fermentation studies of dietary fibres under identical conditions. This should include the characterisation of metabolites in order to make predictions about the potential beneficial health effects of a dietary fibre.

\section{FUTURE PERSPECTIVES}

The aim of this thesis was to analyse the chemical, fermentation and immunological characteristics of dietary fibres. Overall, the results of this thesis showed that all fibres have individual characteristics in terms of immunomodulation activity and fermentation. The results call attention to the performance of in vitro immunoassays and the complexity of dietary fibres.

Modification and fractionation of dietary fibres by any means are useful and necessary approaches to identify their structure related immune response. The targeted modification of a physico-chemical property mostly causes concomitant modifications of the fibre, which might dominate the immunoassay results. In order to minimize conflicting results in future immunologic structure-function relationship analysis, attention should be given to the sample preparation.

The screening of 44 dietary fibres, which were grouped based on their monosaccharide composition into seven categories, revealed that each fibre has its unique immunologic signature, which is related to a wide range of physico-chemical properties. None of the tested fibres resembled another fibre, even if they are both of the same category and have similar chemical structures. Hence, in the future it is highly recommended to compare a broad range of fibres within one category.

Two fibre categories could be of interest with respect to future research on immunomodulatory properties. First, pectic fibres, because these molecules vary in several structural features, such as degree of methyl esterification and acetylation, side chains, constituent monosaccharide composition, the presence of charged molecules, solubility and viscosity. All these properties provide a great opportunity to investigate structure-function relationships, provided, concurrent modifications are considered. Furthermore, brans are of interest, as they represent complex fibre mixtures and are insoluble. The insoluble fibres might also decelerate fermentation in the gut, which could increase the exposure time of certain metabolites to immune cells and could be highly relevant for gut health. Additionally, particulate fractions of all fibres should be investigated, as they were often more immune-stimulatory than the soluble fractions. Fibre-receptor interactions are believed to take part via soluble molecules, which connect the particulate molecules with the receptor, thus also soluble fibres need to be investigated. 
The determination of cytokine induction after different incubation times on BMDCs could give further information on the effectiveness of certain fibres, fermentation metabolites or modified fibre fractions. This could be important information when dietary fibres are judged for their immunologic health influences in the large intestine.

The BMDCs from TLR2/4 KO mice were shown to be a powerful model to investigate the immunological effects of dietary fibres, while excluding interference of endotoxin contaminants. Additionally, intestinal organoids could be isolated from BMDCs from TLR2/4 KO mice to study the possible effects of fibres directly on the epithelium. Dectin-1 and other CLRs have been shown to be expressed in primary cells from the colon suggesting that fibres could induce responses in epithelial cells [4, 31]. Co-cultures of IECs with other antigen presenting cells, such as dendritic cells (DCs), should also be investigated. This would simulate the in vivo interactions of fibres and immune cells in the gut better than with a mono cell culture, as it was shown that co-cultures of intestinal epithelial cells and DCs affected the cytokine immune response differently [30].

Overall, this thesis showed the potential of dietary fibres to interact and influence the immune system dependent on their individual chemical fine structure. Attention should be paid to sample preparation processes for immune assays and fractionation of modified mixtures is advisable. Furthermore, it was shown that fibre fermentation and immunomodulation analysis should be combined in order to investigate the role of glycosidic degradation products and immunological impact of fibres on gut health.

\section{REFERENCES}

[1] European-Commission, Commission Directive 2008/100/EC of 28 October 2008 amending Council Directive $90 / 496 / E E C$ on nutrition labelling for foodstuffs as regards recommended daily allowances, energy conversion factors and definitions. Official Journal of the European Union 2008, L 285, 9-12.

[2] Ueki, T., Mizuno, M., Uesu, T., Kiso, T., Tsuji, T., Expression of ICAM-I on M cells covering isolated lymphoid follicles of the human colon. Acta Medica Okayama 1995, 49, 145-151.

[3] Rescigno, M., Urbano, M., Valzasina, B., Francolini, M., et al., Dendritic cells express tight junction proteins and penetrate gut epithelial monolayers to sample bacteria. Nature Immunology 2001, 2, 361-367.

[4] Cohen-Kedar, S., Baram, L., Elad, H., Brazowski, E., et al., Human intestinal epithelial cells respond to $\beta$ glucans via Dectin-1 and Syk. European Journal of Immunology 2014, 44, 3729-3740.

[5] Visintin, A., Latz, E., Monks, B. G., Espevik, T., Golenbock, D. T., Lysines 128 and 132 enable lipopolysaccharide binding to $\mathrm{MD}-2$, leading to Toll-like receptor-4 aggregation and signal transduction. Journal of Biological Chemistry 2003, 278, 48313-48320.

[6] Possemiers, S., Pinheiro, I., Verhelst, A., Van den Abbeele, P., et al., A dried yeast fermentate selectively modulates both the luminal and mucosal gut microbiota and protects against inflammation, as studied in an integrated in vitro approach. Journal of Agricultural and Food Chemistry 2013, 61, 9380-9392.

[7] Goodridge, H. S., Reyes, C. N., Becker, C. A., Katsumoto, T. R., et al., Activation of the innate immune receptor Dectin-1 upon formation of a phagocytic synapse. Nature 2011, 472, 471-475.

[8] Huysamen, C., Brown, G. D., The fungal pattern recognition receptor, Dectin-1, and the associated cluster of C-type lectin-like receptors. FEMS Microbiology Letters 2009, 290, 121-128.

[9] Tan, Y., Kagan, Jonathan C., A cross-disciplinary perspective on the innate immune responses to bacterial lipopolysaccharide. Molecular Cell 2014, 54, 212-223.

[10] Bermudez-Brito, M., Rösch, C., Schols, H. A., Faas, M. M., Vos, P., Resistant starches differentially stimulate Toll-like receptors and attenuate proinflammatory cytokines in dendritic cells by modulation of intestinal epithelial cells. Molecular Nutrition and Food Research 2015, 59, 1814-1826.

[11] Ferreira, S. S., Passos, C. P., Madureira, P., Vilanova, M., Coimbra, M. A., Structure-function relationships of immunostimulatory polysaccharides: A review. Carbohydrate Polymers 2015, 132, 378-396. 
[12] Popov, S., Ovodov, Y. S., Polypotency of the immunomodulatory effect of pectins. Biochemistry 2013, 78, 823-835.

[13] Popov, S. V., Markov, P. A., Popova, G. Y., Nikitina, I. R., et al., Anti-inflammatory activity of low and high methoxylated citrus pectins. Biomedicine and Preventive Nutrition 2013, 3, 59-63.

[14] Qi, C., Cai, Y., Gunn, L., Ding, C., et al., Differential pathways regulating innate and adaptive anti-tumor immune responses by particulate and soluble yeast-derived $\beta$-glucans. Blood 2011, 117, 6825-6836.

[15] Goodridge, H. S., Underhill, D. M., Touret, N., Mechanisms of Fc receptor and Dectin-1 activation for phagocytosis. Traffic 2012, 13, 1062-1071.

[16] Vogt, L., Ramasamy, U., Meyer, D., Pullens, G., et al., Immune modulation by different types of $\beta 2 \rightarrow 1-$ fructans is toll-like receptor dependent. PLoS One 2013, 8, e68367.

[17] Adams, E. L., Rice, P. J., Graves, B., Ensley, H. E., et al., Differential high-affinity interaction of Dectin-1 with natural or synthetic glucans is dependent upon primary structure and is influenced by polymer chain length and side-chain branching. Journal of Pharmacology and Experimental Therapeutics 2008, 325, 115-123.

[18] Bushneva, O., Ovodova, R., Shashkov, A., Chizhov, A., Ovodov, Y. S., Structure of silenan, a pectic polysaccharide from campion Silene vulgaris (Moench) Garcke. Biochemistry (Moscow) 2003, 68, 1360-1368.

[19] Polle, A. Y., Ovodova, R., Chizhov, A., Shashkov, A., Ovodov, Y. S., Structure of tanacetan, a pectic polysaccharide from tansy Tanacetum vulgare L. Biochemistry 2002, 67, 1371-1376.

[20] Vogt, L. M., Sahasrabudhe, N. M., Ramasamy, U., Meyer, D., et al., The impact of lemon pectin characteristics on TLR activation and T84 intestinal epithelial cell barrier function. Journal of Functional Foods 2016, 22, 398-407.

[21] Macsharry, J., O'Mahony, L., Fanning, A., Bairead, E., et al., Mucosal cytokine imbalance in irritable bowel syndrome. Scandinavian Journal of Gastroenterology 2008, 43, 1467-1476.

[22] Rogler, G., Andus, T., Cytokines in inflammatory bowel disease. World Journal of Surgery 1998, 22, 382-389.

[23] Flint, H. J., Scott, K. P., Louis, P., Duncan, S. H., The role of the gut microbiota in nutrition and health. Nature Reviews Gastroenterology and Hepatology 2012, 9, 577-589.

[24] O'Keefe, S. J., Nutrition and colonic health: the critical role of the microbiota. Current Opinion in Gastroenterology 2008, 24, 51-58.

[25] Wong, J. M. W., de Souza, R., Kendall, C. W. C., Emam, A., Jenkins, D. J. A., Colonic Health: Fermentation and short chain fatty acids. Journal of Clinical Gastroenterology 2006, 40, 235-243.

[26] Schneeman, B. O., Soluble vs insoluble fiber: different physiological responses. Food Technology 1987, 41, 81-82.

[27] Ramasamy, U. S., The role of soluble and insoluble fibers during fermentation of Chicory root pulp. Ph.D. Thesis, Wageningen University, Wageningen, The Netherlands. 2014.

[28] Jonathan, M. C., van den Borne, J. J., van Wiechen, P., da Silva, C. S., et al., In vitro fermentation of 12 dietary fibres by faecal inoculum from pigs and humans. Food Chemistry 2012, 133, 889-897.

[29] Marzorati, M., Vanhoecke, B., De Ryck, T., Sadabad, M. S., et al., The HMI ${ }^{\mathrm{TM}}$ module: A new tool to study the host-microbiota Interaction in the human gastrointestinal tract in vitro. BMC Microbiology 2014, $14,1$.

[30] Bermudez-Brito, M., Sahasrabudhe, N. M., Rösch, C., Schols, H. A., et al., The impact of dietary fibers on dendritic cell responses in vitro is dependent on the differential effects of the fibers on intestinal epithelial cells. Molecular Nutrition and Food Research 2015, 59, 698-710.

[31] Lech, M., Susanti, H. E., Römmele, C., Gröbmayr, R., et al., Quantitative expression of C-type lectin receptors in humans and mice. International Journal of Molecular Sciences 2012, 13, 10113-10131. 
Summary 


\section{SUMMARY}

Dietary fibres are a heterogeneous group of indigestible substances, being (partially) fermentable in the large intestine, which can have several beneficial health effects. In Chapter 1 it was described how dietary fibre can be categorised according to their size, chemical structures, physical properties and fermentability. For each fibre category, examples were given and their characteristics and health effects, such as lowering blood glucose and cholesterol levels, were illustrated. Fibres end up in the large intestine, where they are fermented by the resident microbiota and are also considered to directly interact with epithelial immune cells. For some carbohydrates, their recognition by receptors on immune cells are known and the interactions with the receptors have been proven. However, structure-function relationships can still not explain the various immunological responses of different fibres. Furthermore, fermentation metabolites produced by the gut microbiota have been hardly investigated. Hence, the aim of this thesis was to monitor in vitro fermentation of various dietary fibres by human faecal microbiota and investigate their immunomodulation properties.

In Chapter 2 forty-four selected dietary fibres were characterised and, based on their monosaccharide composition, divided into 7 categories: 'starchy material', 'cellulosic fibres', 'pectic fibres', 'crude fibres', 'hemicelluloses', 'gums' and 'prebiotics'. These fibres naturally contain compounds, such as lipopolysaccharides (LPS), which influence the immunomodulation by fibres via Toll-like receptors (TLR) 2 and 4 . To be able to recognise fibre initiated signalling, bone marrow derived dendritic cells (BMDCs) from TLR2/4 knockout mice were validated for their unresponsiveness to LPS from bacteria cell walls. Next, the fibres were screened with BMDCs for their immunomodulatory response. Every fibre induced its individual profile of cytokines, even fibres within the same fibre category. We further focused on the immunological difference induced by a linear and a branched arabinan, both derived from sugar beet pulp. The linear arabinan induced larger amounts of cytokines than the branched arabinan and for both fibres the particulate fraction was most immune activating. These results suggested that the poorly soluble linear arabinans play an important role in the affinity to the receptors. Furthermore, for the two arabinans a new syk tyrosine-kinase dependent signalling pathway via C-type lectin receptors other than Dectin-1 was identified.

The investigation of structure function relationships between dietary fibres and their immune response was also followed for oat and barley $\beta$-glucans, which showed different immunological effects in the first screening, even though their structures were considered to be rather similar. In Chapter 3, it was described that the insolubility of the $\beta$-glucans was a key feature influencing their immunomodulation. With respect to the soluble barley $\beta$-glucans, partially enzymatically degraded $\beta$-glucans were more immunostimulating than intact glucans. In addition, sample preparations, such as 
drying, dispersing and heating were shown to affect the solubility and other characteristics of the substrates including their immunomodulatory properties. Next to the importance of particulate fibre material, it was shown that the two soluble $\beta$-glucan fractions induced different amounts of cytokines, indicating that molecular specificity of the fibres mattered for receptor affinity.

In Chapter 4, the in vitro fermentation and immunomodulating characteristics by dietary fibres were studied. Barley $\beta$-glucan and sugar beet pectin were fermented in a batch fermentation model using human faecal inocula. The fermentation digesta were analysed for their glycan degradation profiles and incubated on the BMDCs from TLR2/4 KO mice. The BMDCs were shown to be unresponsive to large amounts of endotoxins present in the cell walls of the faecal microbes. The two fibres led to different glycosidic degradation products and they induced different amounts of cytokines. For both fibres, degradation products of low- and intermediate molecular mass induced higher amounts of cytokines than the fibre polysaccharides. This emphasizes the importance to investigate fermentation of dietary fibres, and to characterize their degradation products as well, when analysing their immunomodulatory properties. With the possibility to combine in vitro batch fermentation with the direct analysis of the digesta's immunomodulation, a new approach for the further development of fermentation models was made.

An in vitro batch fermentation of a soluble resistant maltodextrin was described in Chapter 5. Despite the complete solubility of this fibre, it was fermented rather slowly and incomplete by the human faecal microbiota. The characterisation of the parental substrate and its fermentation metabolites, with current chromatographic techniques, was difficult due to the structurally similar and co-eluting maltodextrins. The activity of carbohydrate degrading enzymes, produced by the microbiota during the in vitro fermentation, reveals that the potential capacity to degrade typical starch linkages was high. However, the enzymes only slowly and partly degraded the resistant maltodextrin during the enzymatic incubation of 20 hours, confirming the presence of complex linkages in this molecule as well as its poor digestibility.

In Chapter 6, the outcomes of all chapters were linked and discussed. First, the dietary fibres characterised and categorized in this thesis were described. The BMDCs used, as well as their advantages, disadvantages and their usefulness to analyse the immunomodulatory properties of fermentation digesta were explained. Furthermore, the importance in terms of immunomodulation by particulate fibres and other fibre fractions was discussed, including the possible mechanism of released soluble molecules, by which they interact with receptors. Also other immunomodulating fibre structural characteristics, as branching pattern, molecular mass and fibre type specific structural features were discussed. Subsequently, the three fibre fermentations were compared in terms of fermentation rate, glycosidic metabolites and short chain fatty acids produced. 
Acknowledgements 
Inspiration to undertake and complete a research work of this magnitude can only be realised due to joint effort. Therefore, I will use this opportunity to express my gratitude regarding the support of many people during the last four years.

First of all, Henk, thank you for guiding me through my $\mathrm{PhD}$, for believing in me, for your honest and personal feedback and for challenging me to bring out the best in me. Thank you for making me think twice how to spell tha/e?nk you -$)^{-}$. Harry, I am grateful that you shared your scientific experience with me and for challenging me with your critical questions, always resulting in a crucial fine-tuning of my thoughts and written words.

Jerry and Marjolein, thank you for your commitment, help with data interpretation and critical comments on my thesis chapters. Nico, I am grateful for all your efforts, cooperation and flexibility with running the immune assays. Roy, thank you for your dedication, plenty and critical comments as co-author, explanations and invested time for discussions.

I also thank all members of the TIFN gut health project 004 and Koen as a project leader for all your input and questions regarding my presentations in project meetings.

To my B.Sc. and M.Sc. thesis students Marlou, Bing, Thao, Edward, Bertus and Liwei, thank you for your interest in my project and all your efforts to find answers to our research questions.

Much of the support for completing this thesis derived from the many remarkable colleagues at the Laboratory of Food Chemistry. To all my fellow PhD students, postdocs, technicians and Jolanda: 'Thank you' for creating an open and supportive atmosphere in the lab, office and during social-, sportive- and creative activities, for many meaningful and inspiring conversations during breaks, trips and walks.

Fangjie and Marisol, thank you for being my paranymph. Aisyah and Lingmin, I am grateful that we shared an office. It was a pleasure and I learned a lot from our conversations! Mama und Papa, auch bei euch möchte ich mich bedanken, dass ihr mich verlässlich und grenzenlos bei all meinen Vorhaben unterstützt habt. Auf diese Basis vertrauen zu können, gibt mir die Freiheit mich vielseitig weiter zu entwickeln.

Thank you all!

Christiane :) 
About the author 


\section{CURRICULUM VITAE}

Christiane Rösch was born on November $25^{\text {th }} 1983$ in Mainz, Germany. After graduating from high school (IGS Kurt Schumacher, Ingelheim, Germany) she completed a dual vocational education and training as a chemical laboratory assistant at Boehringer Ingelheim GmbH in Ingelheim. In 2006 she was admitted at the Justus-Liebig University Gießen, Germany, and studied Nutritional Science and Home Economics. She finalized her B.Sc. studies with a thesis entitled "Possibilities and limitations of the application of Stevia

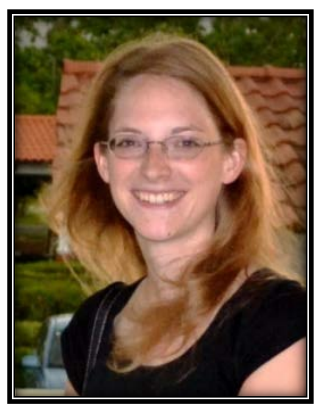
rebaudiana (Bertoni) in food" and she continued her studies with a M.Sc. program in Nutritional Science at the same University. In 2009 she obtained a scholarship within the Hessen-Wisconsin exchange program to study one semester at the University of Wisconsin-Stout, WI, USA. She completed her M.Sc. studies with a thesis at EckesGranini Group GmbH, Nieder-Olm, Germany in 2011. The thesis was entitled "Fortification of fruit juice with dietary fibres as a functional ingredient". Afterwards she started her $\mathrm{PhD}$ research at the Laboratory of Food Chemistry at Wageningen University, The Netherlands, under supervision of Prof. dr. Henk Schols and Prof. dr. ir. Harry Gruppen. The results of her $\mathrm{PhD}$ research are presented in this thesis. Christiane continues to work at the Laboratory of Food Chemistry as a researcher.

Contact: christianeroesch@gmx.de

LinkedIn: www.linkedin.com/in/christianerosch 


\section{LIST OF PUBLICATIONS}

Rösch, C., Venema, K., Gruppen, H., \& Schols, H. A. (2015). Characterisation and in vitro fermentation of resistant maltodextrins using human faecal inoculum and analysis of bacterial enzymes present. Bioactive Carbohydrates and Dietary Fibre, 6(1), 46-53.

Rösch, C., Taverne, N., Venema, K., Gruppen, H., Wells J.M \& Schols, H. A. (2016). Effects of in vitro fermentation of barley $\beta$-glucan and sugar beet pectin using human faecal inocula on cytokine expression by dendritic cells (submitted for publication in Molecular Nutrition \& Food Research).

Rösch, C., Meijerink, M., Delahaije, R.J.B.M., Taverne, N., Gruppen, H., Wells, J.M. \& Schols, H. A. (2016). Immunomodulatory properties of oat and barley $\beta$-glucans on bone marrow derived dendritic cells (submitted for publication).

Meijerink, M., Rösch, C., Taverne, N., Venema, K., Gruppen, H., Schols, H. A. \& Wells J.M. (2016). Structure related immunomodulation by sugar beet arabinans is induced via Syk tyrosine kinase-dependent pathway (to be submitted for publication).

Bermudez-Brito, M., Rösch, C., Schols, H. A., Faas, M. M., \& Vos, P. (2015). Resistant starches differentially stimulate Toll-like receptors and attenuate proinflammatory cytokines in dendritic cells by modulation of intestinal epithelial cells. Molecular Nutrition \& Food Research, 59(9), 1814-1826.

Bermudez-Brito, M., Sahasrabudhe, N. M., Rösch, C., Schols, H. A., Faas, M. M., \& Vos, P. (2015). The impact of dietary fibers on dendritic cell responses in vitro is dependent on the differential effects of the fibers on intestinal epithelial cells. Molecular Nutrition \& Food Research, 59(4), 698-710. 


\title{
OVERVIEW OF COMPLETED TRAINING ACTIVITIES
}

\section{Discipline specific activities}

Summer course Glycosciences*, VLAG, Groningen, The Netherlands, 2012

Advanced Food Analysis*, VLAG, Wageningen, The Netherlands, 2013

Dietary Fibre and Satiety Symposium*, Wageningen, The Netherlands, 2013

Immunology Summer school*, BSI, Edinburgh, Scotland, 2014

3rd International Conference on Food Digestion*, Wageningen, The Netherlands, 2014

EPNOE course "Polysaccharides for health and well-being", EPNOE, Wageningen, The Netherlands, 2015

6th International Dietary Fibre Conference*, Paris, France, 2015

TIFN GI Health theme days, TIFN, The Netherlands, 2012, 2013, 2014

\section{General courses}

PhD Introduction Week (VLAG), Baarlo, The Netherlands, 2012

Information Literacy Introduction, VLAG, Wageningen, The Netherlands, 2012

Presentation Skills, VLAG, Wageningen, The Netherlands, 2012

Basic i $\pi$ for TIFN Researchers, TIFN, Wageningen, The Netherlands 2012

Voice and Presentation Skills Training, Wageningen, The Netherlands 2013

Effective Behaviour in your Professional Surroundings, VLAG, Wageningen, The Netherlands, 2013

VLAG Carousel Workshop, VLAG, Wageningen, The Netherlands, 2014

Techniques for Writing and Presenting Scientific Papers, Wageningen, The Netherlands 2014

Scientific Writing, VLAG, Wageningen, The Netherlands, 2014

Career Orientation, VLAG, Wageningen, The Netherlands, 2015

\section{Optionals}

PhD trip*†, Singapore and Malaysia, 2012

PhD trip*†, Germany, Denmark, Sweden and Finland, 2014

Organisation PhD trip, Germany, Denmark, Sweden and Finland, 2014

B.Sc./ M.Sc. Food Chemistry thesis student presentation and colloquia 2012-2015

PhD Presentations Food Chemistry 2012-2015

\author{
*:poster presentation \\ $\dagger$ : oral presentation \\ VLAG, Graduate School for Nutrition, Food Technology, Agrobiotechnology and Health Science \\ TIFN, Top Institute Food and Nutrition \\ BSI, British Society Immunology
}


The work described in this thesis was performed at the Laboratory of Food Chemistry, Wageningen University, The Netherlands.

The studies presented in this thesis were performed within the framework of TI Food and Nutrition (TIFN), Wageningen, The Netherlands.

Financial support from Wageningen University and the TI Food \& Nutrition for printing this thesis is gratefully acknowledged. 
Cover design: Christiane Rösch and Jelena Balaban (www.jejadesign.com) This thesis was printed by Gildeprint, Enschede, The Netherlands.

Edition: 270 copies

Christiane Rösch, 2016 


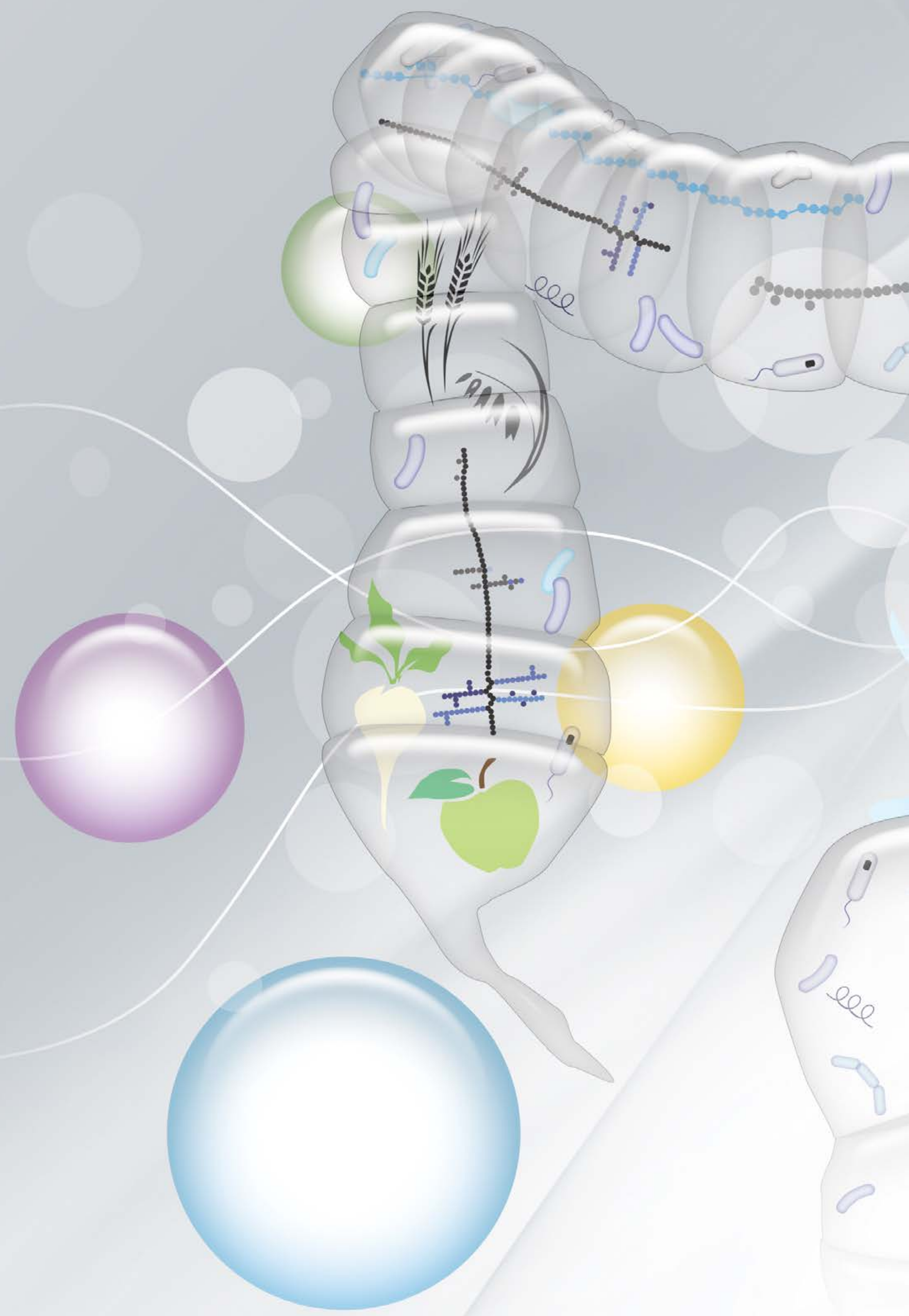

